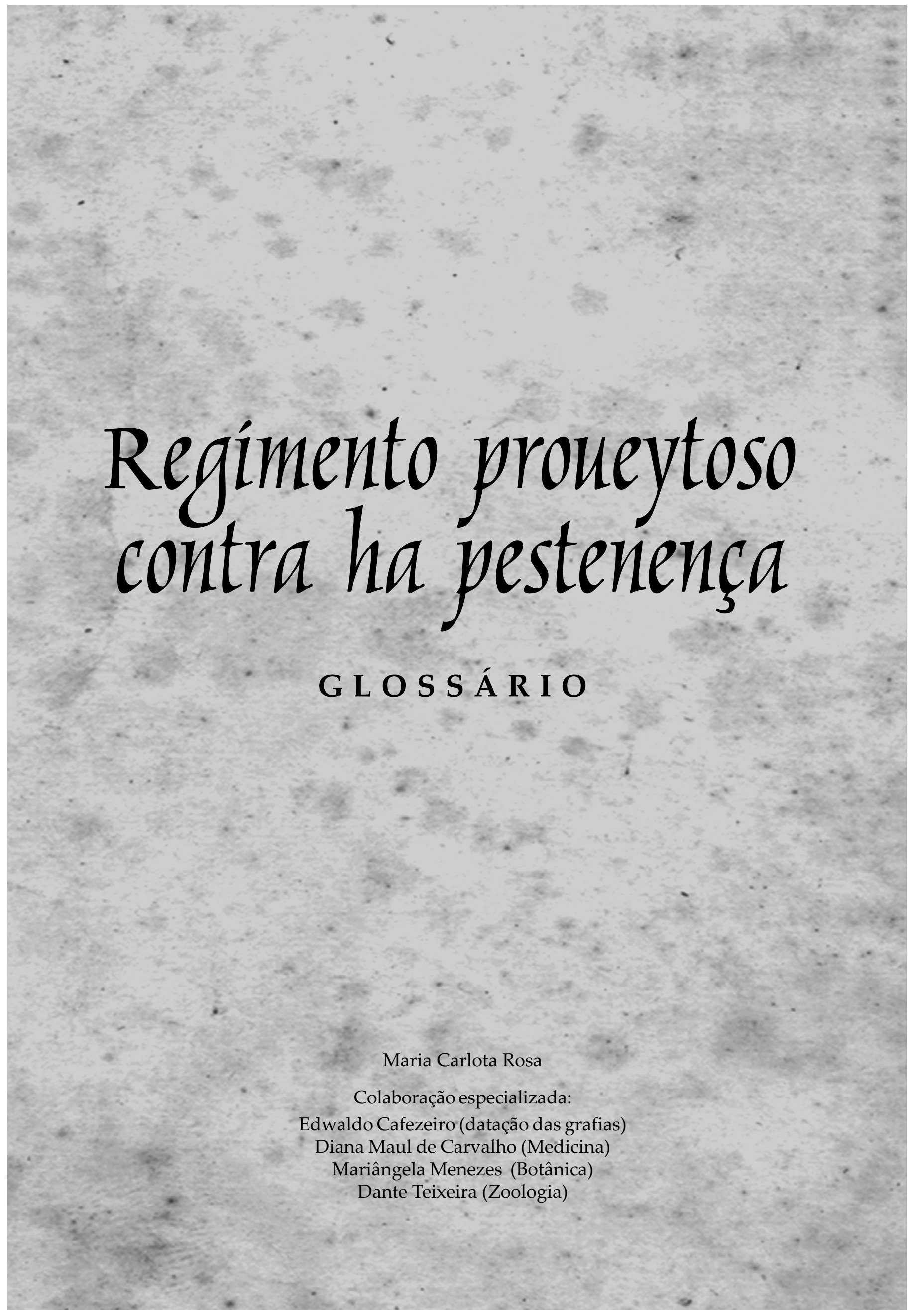




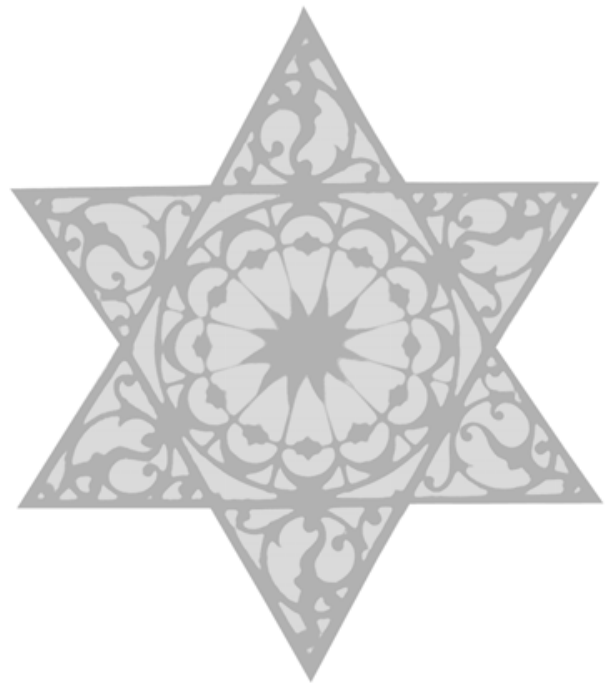




\title{
Regimento proueytoso contra ha pestenença
}

\author{
GL O S S ÁRIO ${ }^{1}$
}

\begin{abstract}
O presente glossário tem por objetivo principal servir de auxiliar na compreensão do Regimento proueytoso contra ha pestenença e, por essa razão, nele estão todos os vocábulos presentes no texto. Como, no entanto, pode ser de interesse para aqueles que trabalham com História da Língua Portuguesa, nele se incluíram também informações sobre a grafia e sobre a forma de origem de todo o vocabulário.

PALAVRAS-CHAVE: Regimento proueytoso contra a pestenença; português quatrocentista léxico; História da Língua Portuguesa; História da Medicina.
\end{abstract}

The main goal of the following glossary is to work as a support to the reading of Regimento proueytoso contra ha pestenença. For this reason it includes every word in the text. However, since it may interest one concerned with the history of Portuguese, the glossary was supplied with additional information on orthography and on the original form of the words.

KEYWORDS: Regimento proueytoso contra a pestenença; Portuguese in the 15th century; History of Portuguese; History of Medicine.

\section{Apresentação do Glossário}

A decisão de se apresentar um glossário que incluísse todas as palavras do Regimento proueytoso - e não apenas nomes, adjetivos, verbos e advérbios de algum modo ligados à área médica - teve como motivação a dificuldade que a leitura e a compreensão de obras antigas apresentam ao leitor atual. Não são apenas os termos ligados às Ciências da Saúde que desapareceram ou ganharam novos significados, como conseqüência de paradigmas teóricos substituídos ao longo dos séculos que separam a época de divulgação do Regimento e o leitor atual: também vocabulário de uso cotidiano - termos como verão ou homem, por exemplo-, só aparentemente é conhecido. Mesmo elementos gramaticais, que garantem a coesão, têm na obra, não raro, valores diversos daqueles com que atualmente são empregados, ou nela se apresentam como elementos completamente desconhecidos para aqueles que não trabalham com História da Língua Portuguesa, ou que não trabalham com textos de fases antigas.

\footnotetext{
${ }^{1}$ Gostaria de agradecer a alguns colegas pelos diferentes tipos de ajuda. A Marinalva Freire Silva (UFPB), por ceder um volume de sua tese sobre o Regimento, defendida na Espanha e de difícil acesso; a Sérgio B. VillasBoas (UFRJ/EPoli), pelo programa de ordenamento de palavras (OrdenaPalavraWin versão 1.0), uma das ferramentas do glossário; a George R. Keiser (Kansas State University), pela cópia da versão inglesa do Regimento, parte do acervo da British Library; a Maria Filomena Gonçalves (Universidade de Évora), pelos esforços envidados na intermediação com a Biblioteca Pública de Évora; a Afrânio Barbosa (UFRJ), Luiz Fagundes Duarte (Universidade Nova de Lisboa) e Ivo Castro (Universidade de Lisboa), pelas sugestões acerca do formato que o glossário tomaria e sobre as edições. Por fim, a Henrique Cairus (UFRJ), pela tradução do aforismo hipocrático e do verso latino referidos no Regimento.
} 
Decidido o conjunto de vocábulos da obra que receberia definição, o formato que estruturaria cada verbete e, ainda, que haveria a inclusão de cada contexto em que cada palavra foi empregada no Regimento, surgiu a questão de se aquilo que se apresenta a seguir é, na verdade um glossário - ou se deveria receber denominação diferente, como índice, vocabulário, concordância... Na medida em que o conjunto que se segue apresenta características de todos esses tipos, mas não é exatamente o que a prática lexicográfica denomina por qualquer desses termos, ${ }^{2}$ optou-se por glossário, tomando por base o sentido medieval com que o termo foi usado, quando denominava as listas de palavras sobre obras específicas que os estudantes de Latim faziam, as quais não tinham maior pretensão que a de serem anotações que auxiliavam os estudantes na compreensão de determinado texto em estudo.

No glossário que se segue, as entradas estão organizadas alfabeticamente com base na grafia atual, em razão das múltiplas grafias que boa parte das palavras apresenta na edição valentiniana. As formas gráficas efetivamente presentes no texto seguem-se a um círculo negro $(\bullet)$ e, quando possível, data-se a grafia. Embora nem sempre possível, a datação permite supor que o testemunho em estudo, talvez de 1496, não fora a primeira versão que o texto teve em português.

A forma originária foi adicionada como um dado a mais para a compreensão da forma gráfica que as palavras apresentam no texto e, raras vezes, do significado. Vocábulos ou expressões relacionados entre si aparecem como subentradas, que são precedidas por uma seta curva $(\rightarrow)$.

De um modo geral, no que toca ao significado, procurou-se apresentar um sinônimo que pudesse substituir, no mesmo contexto, o termo em foco. Isto não foi feito em quatro situações. Primeiramente para vocabulário nuclear como mão ou pé, cujo significado se manteve inalterado, embora nem sempre se possa dizer o mesmo da grafia. Por não se poder contar com a sinonímia nestes casos e por não se querer repetir o mesmo vocábulo, procurou-se apresentar uma breve definição. Em segundo lugar, para alguns dos elementos gramaticais, por não haver palavra que os pudesse substituir sem que se alterasse o significado da frase em que foram empregados, indicamos a função que tinham na frase ou apenas listamos os diferentes contextos. Em terceiro lugar, termos ligados à área da Saúde cuja compreensão é diversa na atualidade, como doença ou digestão, que ganharam um pouco mais de espaço. Por último, também ganharam mais espaço os muitos nomes de especiarias que compõem as receitas apresentadas.

Diferentes significados são assinalados por um pequeno livro aberto (미). Os contextos de ocorrência são apresentados após cada significado, separados, no caso de mais de uma ocorrência no texto, por uma barra vertical ( l ), precedidos de sua localização, página e linha, na edição valentiniana.

\footnotetext{
2 R.R.K. Hartmann \& Gregory James. Dictionary of lexicography. London/New York: Routledge, 1998. p. 63; Henri Béjoint. Modern lexicography: An introduction. Oxford: Oxford University Press, 2000. p.8-32.
} 


\section{REFERÊNCIAS BIBLIOGRÁFICAS}

Fontes primárias

[JACOBI, Johannes ?]

s.d. [1496?] Regimento proueytoso contra ha pestenença .

Johannes Jacobi, trad. de Fr. Luís de Raz .- Lisboa: Valentino de Morávia. BP.Évora, Inc. 210

[JACOBI, Johannes ?] 1534. A moche profitable Treatise against the Pestilence, translated into Eglyshe by T. Paynel Chanon of Martin Abbey. Johannes Jacobi, trad. de Thomas Paynell. In aedibus T. Bertholeti: Londini, 1534. British Library 1167.d.7.

Arnaut, Salvador Dias 1986

[1967]. A arte de comer em Portugal na Idade Média (Introdução a "O Livro de Cozinha" da Infanta D. Maria de Portugal). [Lisboa]: Imprensa Nacional/ Casa da Moeda.

Balmé, François 1978

Bluteau, Raphael. $1712-1721$

Cardoso, Jerônimo 1570

Cunha, Antônio

Geraldo da

Plantas medicinais. Colaboração e adaptação de Sílvia Branco Sarzana. São Paulo: Hemus Livraria Editora Ltd.

Vocabulario Portuguez, e Latino..., Autorizado com exemplos dos melhores escritores Portuguezes, e Latinos. Coimbra: Collegio das Artes da Companhia de Jesus. 9t.

Dicitionarium Latino Lusitanicum $\mathcal{E}$ vice versa. Coimbra: João Barreiro.

1986. Dicionário etimológico Nova Fronteira da Língua Portuguesa. 2a. ed. rev. e acresc. de Suplemento. Rio de Janeiro: Nova Fronteira, 1991.

Cruz, Gilberto Luiz da 1979

Cruzeiro,

Maria Eduarda

1973

Delerue, Alberto 1999

Di Berardino,

Angelo (org.) 2002

Duarte, Rei de Portugal. [séc. xv]

Dicionário das plantas úteis do Brasil.

Rio de Janeiro: Civilização Brasileira.

Processos de intensificação no português dos séculos XIII a XV.

Lisboa: Centro de Estudos Filológicos.

Rumo às estrelas: guia prático para observação do céu.

Rio de Janeiro: Jorge Zahar.

Dicionário patrístico e de antigüidades cristãs.

Trad. de Cristina Andrade. Petrópolis: Vozes.

Leal Conselheiro o qual fez Dom Eduarte Rey de Portugal e do Algarve e Senhor de Cepta. ed. crítica e anotada, org. por Joseph Piel.[Lisboa]:

[Impr. Portugal-Brasil], 1942.

Ferreira, Aurélio

Buarque de Hollanda

Novo Aurélio Século XXI: o dicionário da língua portuguesa.

1999

Ficino, Marsilio

1576

Flandrin, Jean-Louis. 1998

Consiglio di Marsilio Ficino ... contro la pestilentia. Fiorenza: Apresso i Giunti.

Tempero, cozinha e dietética nos séculos xiv, xv e xvi.

In: Flandrin, Jean-Louis \& Montanari, Massimo (org.) Trad. Luciano V. Machado. História da alimentação. São Paulo: Estação Liberdade. p.478-95.

Garcia de Orta

(1499?-1568)

Coloquios dos simples e drogas da India. Fac-símile da edição dirigida e anotada pelo Conde de Ficalho,1891. Lisboa: Imprensa Nacional/ Casa da Moeda. 
Grieve, Maud

1995

Houaiss, Antônio \&

Villar, Mauro.

2001

Lemaître, Nicole;

Quinson, Marie-Thérèse;

Sot, Véronique. 1999

Machado, José Pedro s.d.

Margotta, Roberto. 1998

Maria, Infanta de Portugal [séc . XVI] 1987

Marques, A. H. de Oliveira. 1987

Mattos e Silva, Rosa Virgínia 1989

Neves, Maria

Helena Moura 2000

Piterà, Fernando 1999

Porter, Roy 1996

Roque, Mário da Costa 1979

Silva, Marinalva Freire [s.d.]

The Rainforest Project Foundation, TRP.

Vigarello, Georges. 1988

Viterbo, Joaquim de Santa Rosa de 1983-1984
A Modern Herbal. The Medicinal, Culinary, Cosmetic and Economic Properties, Cultivation and Folk-Lore of Herbs, Grasses, Fungi, Shrubs \& Trees with their Modern Scientific Uses. Electronic version of "A Modern Herbal", editada por Hilda Leyel. Disponível em www.botanical.com/ botanical/mgm

Dicionário Houaiss da Língua Portuguesa.

Rio de Janeiro: Objetiva.

Dicionário cultural do Cristianismo. Trad. de G.S. Ribeiro, M. S.

Gonçalves, Y. M. C. T. da Silva. São Paulo: Loyola, 1999.

Dicionário onomástico e etimológico da língua portuguesa.

Lisboa: Confluência. 3v.

História ilustrada da Medicina. Trad. da versão inglesa por Marcos Leal. São Paulo: Manole. [Original: Medicina nei secoli. 1967.).

Livro de Cozinha da Infanta D. Maria. Cód. port. I. E. 33 da Biblioteca Nacional de Nápoles.1967. Prólogo, leitura, notas, glossário, índices de Giacinto Manuppella. [Lisboa]: Imprensa Nacional/ Casa da Moeda.

A sociedade medieval portuguesa: aspectos da vida cotidiana.

5. ed. Lisboa: Sá da Costa. [1.ed. 1964.]

Estruturas trecentistas: elementos para uma gramática do português arcaico. Lisboa: Imprensa Nacional/Casa do Moeda.

Gramática de usos do português.

São Paulo: Unesp.

Crithmum maritimum L. L'Erba di San Pietro dalla fitoterapia dimenticata. Un novo gemmoderivato. In: Anthropos $\mathcal{E}$ Iati: Rivista Italiana di Studi e Ricerche sulle Medicine Antropologiche e di Storia delle Medicine. 3 (4): disponível em www.medicinealtre.it/1999/fernando4-99.htm (acesso em 18.01.2004)

Cambridge - História ilustrada da medicina. Trad e posfácio G. M. Gomes da Cruz e S. M. Leite Miranda. Rio de Janeiro: Revinter.

As pestes medievais europeias e o "Regimento proueytoso contra ha pestenença", Lisboa, Valentim Fernandes (1495-1496): tentativa de interpretação à luz dos conhecimentos pestológicos actuais. Paris: Fundação Calouste Gulbenkian/ Centro Cultural Português.

Edicion critica del Regimento proueytoso contra ha pestenença (¿1496-1500?). Madrid: Universidad Complutense. Tesis Doctoral. (Mimeo).

Agarwood Project Information and Conference Web site. 2002. The Rainforest Project Foundation. Disponível em www.agarwood.org.vn (acesso em 18.01.2004).

O limpo e o sujo: a higiene do corpo desde a Idade Média. Trad. Isabel St. Aubyn. Lisboa: Fragmentos.

Elucidário das palavras, termos e frases que em Portugal antigamente se usaram e que hoje regularmente se ignoram. ed. crítica por Mário Fiúza. Porto: Civilização. 1798-1799. 2v. 


\section{Abreviaturas e símbolos utilizados}

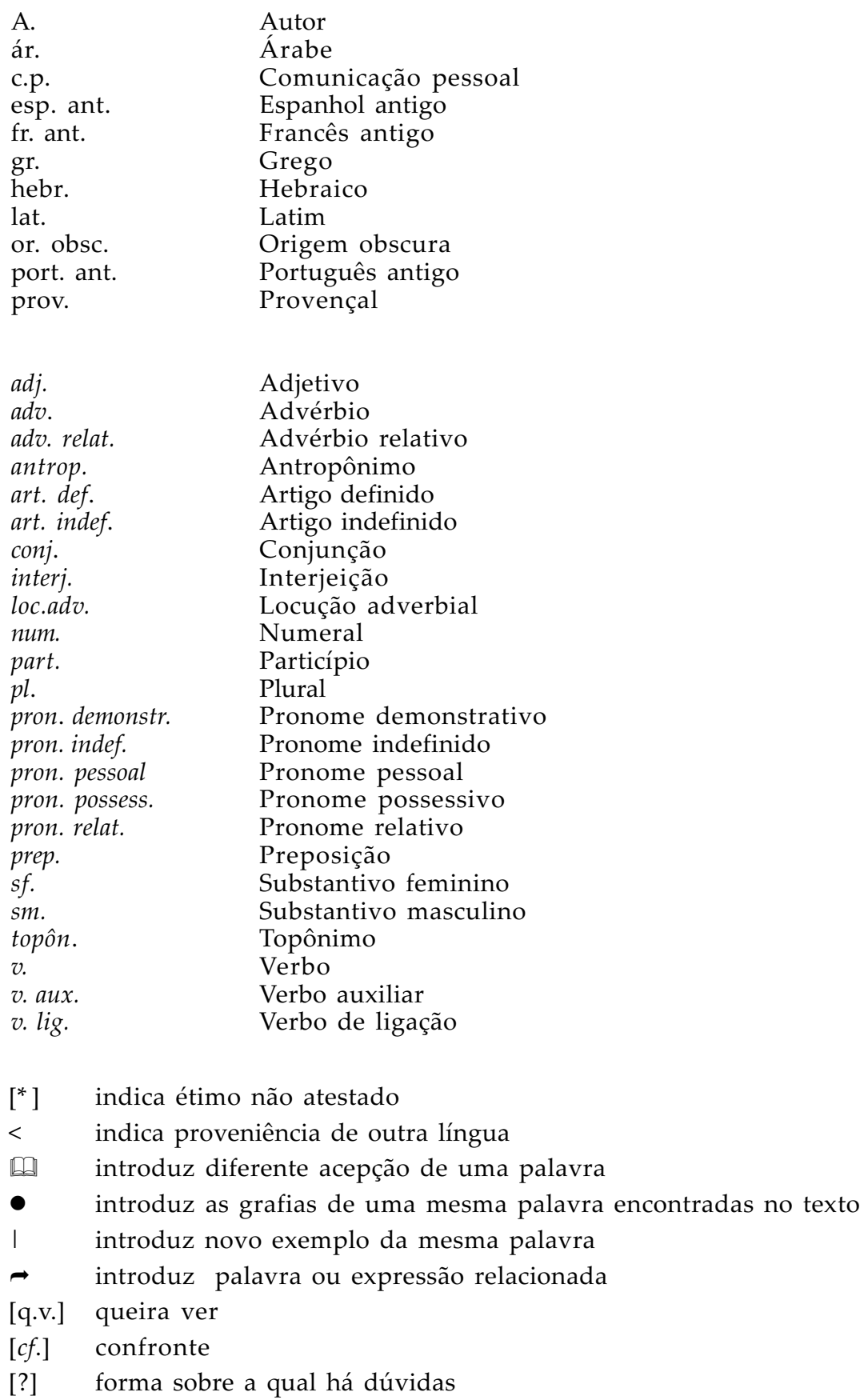




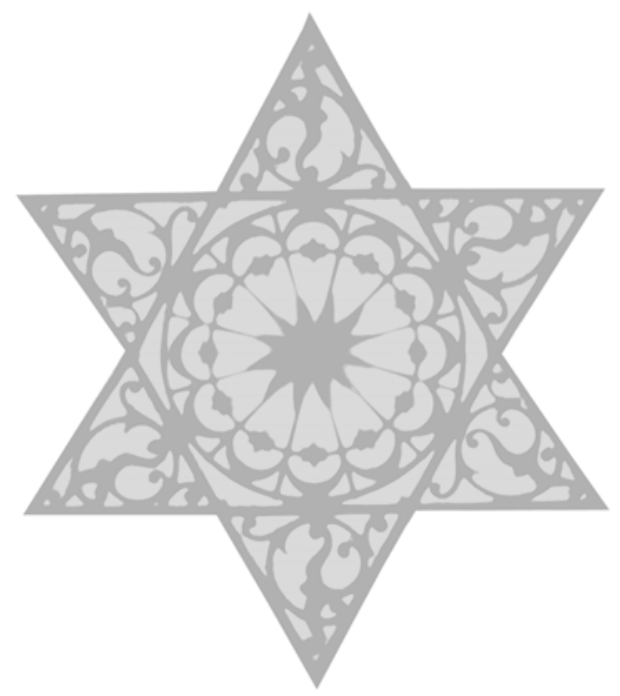




\section{A}

A $^{1}$. [lat. illa, 'aquela'.] art. def. - a, s. XII; as; ha; las: $\left(\mathbf{a 2}{ }^{\mathrm{v}}, \mathbf{1}\right)$ em huũ dia do estio \& do alto veraão se muda a manhaã muytas vezes. $\mid\left(\mathbf{a} 2^{\mathrm{v}}, \mathbf{1 6}\right) \mathbf{A}$ morte se ensanha ha çidade se filha $\mid(\mathbf{a} 3, \mathbf{2 2})$ Da rayz superior veem \& aconteçe a pestilençia per virtude dos corpos de çima dos çeos. I $\left(\mathbf{a} 4^{v},{ }^{15}\right)$ porque o vento do sul teem em si duas causas de de apodrentar A primeyra que faz emfraqueçer os corpos assi dos saãos como dos enfermos. I (a4, 16) A segunda | $(\mathbf{a} 5,9)$ grande remedio he em tempo da pestilençia a sancta penitencia $\mid(\mathbf{a} 5,10)$ \& a confissam $\mid\left(\mathbf{a} 5^{v}, 12\right)$ se deue bem de guardar a casa $\mid\left(\mathbf{a} 5^{v}, 14\right) \&$ faz podridom em a casa $I\left(\mathbf{a 5}^{\mathrm{v}}\right.$, 15$)$ asutileze se a casa $\mid\left(\mathbf{a 5}^{\mathrm{v}}, \mathbf{2 2}\right) \mathrm{E}$ tal fumo entre per a boca $\mid(\mathbf{a 6}, \mathbf{8})$ pouco creçente apeçonhenta toda a massa.| $(\mathbf{a 6}, 21)$ nem he saão andar per a villa | $(\mathbf{a 6}, \mathbf{2 2 )}$ E tambem a casa seja aguada $\mid(\mathbf{b}, \mathbf{1})$ Muyto saã cousa he que se laue a boca $\mid(\mathbf{b}, \mathbf{1 3})$ a triaga te he muyto proueytosa | $(\mathbf{b}, \mathbf{1 8})$ nem se tome mais da triaga que a quantidade de huũ piseo $\mid(\mathbf{b}, 20) \&$ a triaga seja delida $\mid(\mathbf{b}$, 22) porque possa a triaga em o corpo fazer sua operaçam. I $(\mathbf{b}, 25)$ a sobeja abastança $\mid\left(\mathbf{b}^{v}, 5\right)$ \& $\mathbf{a}$ queentura traz podridom. I ( $\left.\mathbf{b}^{\mathrm{v}}, 7\right)$ melhor me pareçe soo a cousa amargosa $\mid\left(\mathbf{b}^{\mathrm{v}}, \mathbf{1 1}\right)$ \& squeenta a cabeça | ( $\mathbf{b}^{v}$, 13) a pestilençia que veem per causa queente ameude se acreçenta. $\mid(\mathbf{b} 2, \mathbf{8}) \mathrm{E}$ tambem a alegria do coraçom he gram remediol $(\mathbf{b} 2,8)$ pera a saude do corpo. I $(\mathbf{b} 2, \mathbf{1 7})$ se nom se a ydade ou outra cousa for em contrayro. I (b2, 21) Faça se ergo a sangria em a vea destra $\mid(\mathbf{b} 2,22)$ despois que a vea for ferida $\mid(\mathbf{b} 2,26)$ em aquelle dia que se sangrar \& abrir a vea $\mid\left(\mathbf{b} 2^{\mathrm{v}}, 5\right)$ caladamente traz a peçonha ao coraçam | (b3, 7) nem andar grande caminho por a grande pigriça do corpo $\mid(\mathbf{b} 3,10)$ porque a peçonha intrinseca pertorua o sprito $\mid(\mathbf{b} 3, \mathbf{2 1})$ \& emtom a peçonha espalha se per os membros | $\left(\mathbf{b} 3^{v}, \mathbf{1}\right)$ pouco minguamento de sangue esperta a peçonha. | $\left(\mathbf{b} 3^{\mathrm{v}}, 2\right)$ emtam leyxe yr a vea aberta | $\left(\mathbf{b} 3^{v}, 5\right)$ mais fortemente esperta a peçonha $\mid\left(\mathbf{b}^{3^{v}}, \mathbf{1 1}\right)$ E se pella ventura naçer a apostema $\mid\left(\mathbf{b} 3^{v}, \mathbf{1 6}^{2}\right) \mathrm{em} \mathbf{a}$

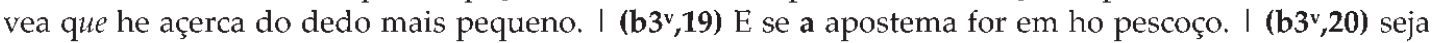
sangrado em a vea de çephalica $\mid\left(\mathbf{b} 3^{\mathrm{v}}, \mathbf{2 1}\right)$ açerca do dedo polegar em a maão $\mid\left(\mathbf{b} 3^{\mathrm{v}}\right.$, 24) faça se a sangria | (b4,6) minguaras a meaã. | (b4, 7) mingua sobre a vea $\mid(\mathbf{b 4}, 8)$ que he chamada a pedica grande. I $(\mathbf{b} 4, \mathbf{1 2})$ ha de menuyr o sangue em a parte crucifixa que he a parte contrayra. I $(\mathbf{b} 4, \mathbf{1 5}) \mathrm{E}$ se apareçer a apostema de bayxo do braço direyto $\mid(\mathbf{b} 4, \mathbf{1 8})$ em os quaaes apareçer a apostema $\mid\left(\mathbf{b} 4^{v}, \mathbf{1}\right) \mathrm{E}$ ysso mesmo por que a apostema mais çedo \& milhor seja madura I (b4v, 7) porque a triaga lança a peçonha fora. I $\left(\mathbf{b} 4^{v}, 9\right)$ que soruesse em si toda a triaga: । $\left(b 4^{v}, 9\right)$ \& assy lança a peçonha. I $\left(\mathbf{b} 4^{v}, 19\right)$ quando a postema primeyro apareçer. I ( $\left.\mathbf{b} 4^{v},{ }^{22}\right)$ E estas cousas abastem pera a pestilença. I $(\mathbf{a} 3,4)$ TRes sam as causas da pestilencia. I (a3v, 19) muytos medicos que em os enfermos soomente esguardam as ourinas $I\left(\mathbf{a}^{\mathrm{v}}, \mathbf{1 1}\right)$ teer as frestas pera ho norte $\mathrm{I}\left(\mathrm{a} 4^{\mathrm{v}}, \mathbf{1 2}\right)$ \& as genelas ou frestas pera ho meo dia ou pera ho sul estem çarradas. I (a5, 1) VIstas as causas da pestilencia. I $(\mathbf{a 5}, \mathbf{1 1})$ sam muyto melhores que todas as mezinhas. I $(\mathbf{a 5}, \mathbf{1 5})$ deuem de euitar \& de sy esquiuar as causas de tal podridom. $(\mathbf{a 5}, \mathbf{1 9 )}$ Fechem se ergo as frestas ou genelas $\mid\left(\mathbf{a} 5^{v}, 1\right)$ em algũas casas estam as agoas çujas $\mid(\mathbf{a} 6, \mathbf{2 5})$ he muyto boõ ameude lauar as maãos | $\left(\mathrm{a}^{\mathrm{v}}{ }^{\mathrm{v}}, 1\right)$ despois cheyrar as maãos. $\mid\left(\mathbf{a} 6^{\mathrm{v}}, 8\right)$ as cousas azedas \& os cheyros taaes opilam \& çarram os poros $\mid\left(\mathbf{a} 6^{v}, 11\right)$ nom consintem entrar as cousas peçonhentas. I (a6v $\left.{ }^{v}, 17\right) A S$ cousas canfortatiuas sam estas $\mid\left(\mathbf{a}^{\mathrm{v}}, \mathbf{1 9}\right) \mathrm{com}$ todas as outras heruas $\mid(\mathbf{b}, \mathbf{2})$ que se laue a boca \& os olhos \& as maãos $\mid\left(\mathbf{b}^{v}, 24\right)$ E as speçias que comuummente conuem a comer.I $(\mathbf{b} 2,18)$ assy como he em as molheres que som prenhes. I (b3, 9) em todas as horas teem grande desejo de dormir. I (a2v, 9) Tercio he quando ha hy muytas moscas em ha terra. I (a2v, 12)Quarto sinal he quando ha cometa

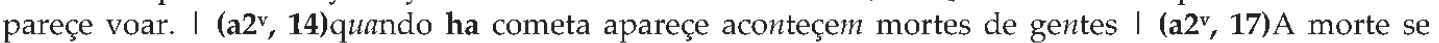
ensanha ha çidade se filha $\mid(\mathbf{a} 3,5)$ as vezes veem \& proçede ha pestilencia da rayz superior. I (a3, 24) dos quaaes se corrompem os spiritos vitaes em ha creatura viuente.l (a3v, 2) por ha empressam dos çeos corrompe ho aar. $\mid\left(\mathbf{a}^{\mathbf{v}}, 3\right)$ \& ha empresam do aar corrompe os spiritos vitaes $\mid\left(\mathbf{a} 3^{\mathrm{v}}, \mathbf{5}\right)$ \& assy se geera ha pestilençia per esta causa. I (a3v , 9) se causa ho morbo ou ha chagua em ho homem $\mid\left(\mathbf{a 3}^{\mathrm{v}}, \mathbf{1 3}\right)$ em tanto que ha natureza he per muytas manejras agrauada I (a $\left.3^{\mathrm{v}}, 14\right)$ mas ajnda tam sobejamente se agraua ha natureza $\mid\left(\mathbf{a}^{\mathrm{v}}{ }^{\mathrm{v}}, \mathbf{2 4 )}\right.$ Aqui se mouem duas questões. Ha primeyra he $\mid(\mathbf{a} 4, \mathbf{1 6})$ dos quaaes se faz ha grande resoluçam $\mid(\mathbf{a} 4,21)$ teem os corpos mais dispostos pera reçeber ha pestilencia. $\mid\left(\mathbf{a} 6^{v}\right.$, 25) nom trouver homem em ha maão I $(\mathbf{b 3}, \mathbf{1 )}$ \& ysso mesmo tem grande door em ha parte dianteira da cabeça. I $\left(\mathbf{b} 3^{v}, \mathbf{1 0}\right)$ em a qual ha doença ou chaga apareçer $\mid\left(\mathbf{b} 3^{v}, 14\right)$ sangre se em ha vea meaã $\mid\left(\mathbf{b}^{v}, 20\right)$ Em tempo da pestilencia valem mais cousas azedas que todalas meezinhas 
$\mathrm{A}^{2}$ [ [ lat. illa, aquela.] pron.demonstr. Aquela. as, S.XII: $(\mathrm{a} 5,21)$ \& abram se as que stam pera o norte

$\mathbf{A}^{3}$. [<lat. illa, aquela.] pron. pessoal. Ela. @as, S. XIII; ha: $\left(\mathbf{a} 5^{\mathrm{v}}, 2\right)$ \& as lançam per canos $\mid(\mathbf{b}, \mathbf{2 1})$ \& a triaga seja delida em ho vaso ou copo em que ha tomares

$\mathrm{A}^{4}$.[<lat. $a d$, 'movimento para'; <lat. $a b$, 'afastamento'.] prep. - a: (a2, 10) EM louuor da santissima trijndade. \& da gloriosa virgem maria \& a proueyto do pouool $\left(\mathbf{a 4}^{\mathbf{v}}, \mathbf{9}\right)$ E por tanto digo que a tal doente de pestilençia he boõ per algữs dias mudar a camera I ( $\left.\mathbf{b}^{v}, 25\right)$ E as speçias que comuummente conuem a comer. I (b2 $\left.{ }^{\mathrm{v}}, \mathbf{1 0}\right)$ A ysto digo breuemente $\mid\left(\mathbf{b} 2^{\mathrm{v}}, \mathbf{2 3}\right)$ A ysto te respondo $\mid\left(\mathbf{b} 4^{\mathrm{v}}, \mathbf{1 7}\right)$ da ho a beber aquelle que teuer apostema. $\rightarrow$ À. prep. a.+ art. def. fem. $\bullet$ aa; a, S. XIII: $(\mathbf{a 4 , 1 1 )}$ Da parte do paciente que aquelle he mays desposto aa morte que aquel outro. I $(\mathbf{a} 4,5)$ A primeyra questam: digo que esto pode aqueçer por duas causas $\mid(\mathbf{a 4}, \mathbf{1 3})$ os corpos mays despostos a jnfirmidade \& a morte sam os corpos queentes $\mid(\mathbf{a 4}, \mathbf{2 2})$ A segunda questam digo que taaes infirmidades pestilençiaaes sam contagiosas. AO. prep. $a+$ art. def. masc. $\bullet$ ao; aos; a os: $(a 2,24)$ quanto ao presente pertençe I (a2v, 11) sobem muytos vapores peçonhentos ao aar. I $\left(\mathbf{a}^{\mathrm{v}} \mathrm{v}, \mathbf{2 0}\right)$ boõ he ao saão $\mid(\mathbf{a}, \mathbf{6})$ inclinar se ao bem. $(\mathbf{b}, \mathbf{1 3})$ Quanto he ao teu mantijmento $\mid\left(\mathbf{b} \mathbf{2}^{\mathrm{v}}, \mathbf{4}\right)$ caladamente traz a peçonha ao coraçam $|\quad|\left(\mathbf{b} 4^{\mathrm{v}}, \mathbf{1 2}\right)$ acharas ao boticairo. I $\left(\mathbf{b} 4^{\mathrm{v}}, \mathbf{1 3}\right)$ vay te ao boticayro I $(\mathbf{a} 2,2)$ muyto proueitoso aos viuentes. I $(\mathrm{a} 3,7)$ senssualmente pareçe aos homens mudança do aar. I (a5v, 19$)$ acharas aos apotecayros. I $(\mathbf{b}, \mathbf{1 5})$ te he muyto proueytosa: assi saãos como aos enfermos.l (b2v ${ }^{2}$, 5) traz a peçonha ao coraçam \& aos outros membros I $(\mathbf{a} 4, \mathbf{1 8 - 1 9 )} \&$ os que vaam ameude a os banhos

ABAIXO. vide BAIXO.

ABASTANÇA. vide ABASTAR.

ABASTAR. [<lat. bastāre, 'ser bastante, suficiente'] v. Bastar, ser o bastante. $\bullet$ abastem, s.XIII: (b4v ,22) E estas cousas abastem pera a pestilença. $\rightarrow$ ABASTANÇA. sf. Abundância, fartura. $\bullet$ abastança, S. XIV: $(\mathbf{b}, \mathbf{2 6})$ porque a sobeja abastança \& grande inchamento tras apodrentamento dos humores

ABERTO. vide ABRIR.

ABREviAR. [<lat. abbreviare, 'resumir'.] v. Encurtar. - abreuiam, S. XIV: (a6,4-5) E por tanto diz auicena em o quarto canone. que aquelles que sempre querem encher seus ventres que abreuiam seus dias \& tempos da sua fim

ABRIR. [<lat. apĕrīre.] v. ๑abrir; abram; abre; aberta, s. XIII. प Cortar, ferir: (b2,26) \& nom conuem dormir em aquelle dia que se sangrar \& abrir a vea. I $\left(\mathbf{b} 3^{\mathrm{v}}, \mathbf{1 1}\right)$ \& sempre naquella meesma parte do corpo: em a qual ha doença ou chaga apareçer se deue de sangrar \& abrir a vea.l $(\mathbf{b} 2,23)$ \& despois que a vea for ferida ou aberta aproueyta muy to tomar muyto prazer. Descerrar: $(\mathbf{a} 5, \mathbf{2 1}) \&$ abram se as que stam pera o norte. $\left(\mathbf{a} 4^{v}, 19\right)$ Ho sul he vento inchado \& agraua o ouuido fere o coraçam. porque abre os poros do homem $\rightarrow$ ABERTo. adj. $\bullet$ aberta, abertas, S.XII: $C$ Cortado: $\left(\mathbf{b 3}^{\mathrm{v}}, \mathbf{3}\right)$ emtam leyxe yr a vea aberta ou ferida atee o retardamento do sangue Descerrado: $\left(\mathbf{a} 4^{\mathrm{v}}, \mathbf{1 2}\right) \&$ muytas vezes teer as frestas pera ho norte ou pera o leuante abertas

AÇAFRÃo. [<ár. az-za'faran.] sm. Crocus satious Linnaeus, família das Iridáceas. Arbusto de origem asiática, cultivado. Seu tubérculo é redondo, as folhas lineares e longas, as flores brancas, violetas ou lilases, com estigmas alaranjados, frutos em forma de cápsulas. Dos estigmas extrai-se o pó de açafrão, utilizado como condimento e no preparo do láudano. Apresenta propriedades emenagogas, sedatioas e antiespasmódicas. $\bullet$ açafram, S. XIV: (bv, 26) E as speçias que comuummente conuem a comer. sam gingiure. canela. cuminhos, froles de heruas cheyrosas. \& açafram. | (b2,5-6) E se nom forem muyto pobres: tomem cuminhos \& açafram \& misturem tudo com vinagre 
ACERCA DE. [<lat. ad circa.] loc, adv, $\bullet$ açerca de, S. XIV. que esta açerca da camera $\mid(\mathbf{b} 3, \mathbf{1 5})$ \& logo sentira apostema de bayxo dos braços. ou açerca das partes vergonçosas. ou açerca das orelhas. I $\left(\mathbf{b} 3^{v}, 16\right)$ sangre se em ha vea meaã daquelle meesmo braço. ou na vea epatica .scilicet. em a vea que he açerca do dedo mais pequeno. I $\left(\mathrm{b}^{\mathrm{v}}{ }^{\mathrm{v}}, 17\right) \mathrm{E}$ se açerca das partes vergonçosas. sangre se em o pee daquelle mesmo lado açerca do calcanhar.l (b3 ${ }^{\mathrm{v}}, \mathbf{2 0 )}$ E se a apostema for em ho pescoço. seja sangrado em a vea de çephalica açerca do dedo polegar em a maão daquelle meesmo lado. I (b3 $\left.{ }^{v}, 23\right)$ ou na maão daquelle meesmo lado açerca do dedo menor. I $\left(\mathbf{b 3}^{\mathrm{v}}{ }^{\mathrm{v}}, \mathbf{2 4}\right)$ E se pela ventura apareçer açerca da orelha: faça se a sangria de çephalica daquelle meesmo lado.l (b4, 2) por que muytas cousas peçonhentas nom destruam o çerebro. ou da vea que he açerca do dedo menor: I $(\mathbf{b} 4,3)$ ou açerca do articulo que he de muytos medicos chamada basilica. I (b4,4) E se polla ventura for açerca das espadoas: minguaras o sangue com ventosas. \& primeiramente minguaras a meaã. respeito de: $(\mathbf{a} 3, \mathbf{1 5})$ \& daly procedem febres pestilençiaes. açerca das quaes muytos medicos sam enganados

ACESO. [<lat. accĕsus, $-a,-u m$.$] adj. Que arde, que tem chama. \bullet$ açeso, S. XIII: (b, 10) Em casa sempre este fogo açeso

ACHAR. [<lat. afflāre, 'soprar'.] v. Encontrar à venda. acharas, S. XIII: (b4v, 12) \& outro que chamam serpillo que acharas ao boticairo. $\mid(\mathbf{b}, 9)$ \& tambem tomaras pirolas pestilençiaaes as quaaes acharas aos apotecayros. $1\left(\mathbf{a 5}^{\mathrm{v}}, \mathbf{1 9}\right)$ baga de louro. junipero. vberiorgano. as quaaes acharas aos apotecayros

ACONTECER. [<lat. *contigescěre.] v. Suceder; sobrevir. aconteçer; aconteçe; aconteçem, s. XIII: (a3, 14) \& esta causa particular \& pode aconteçer cada dia.| $(\mathbf{3} 3,20)$ \& esto aconteçe muytas vezes onde ha lugares podres \& corruptos.। $(\mathbf{a} 3,22)$ Da rayz superior veem \& aconteçe a pestilençia per virtude dos corpos de çima dos çeeos. I (a6 $\left.6^{v}, 21\right)$ onde ligeyramente se aconteçe huũ seer empeçonhentado do outro. I (a2v, 14) quando ha cometa apareçe aconteçe $m$ mortes de gentes em bathalhas \&c

ACRESCENTAR. [<lat. accrescentāre.] v. Ampliar. acreçenta, S. XIV: $\left(\mathbf{b}^{\mathrm{v}}, \mathbf{1 4}\right)$ a pestilençia que veem per causa queente ameude se acreçenta

AFASTADO. vide AFASTAR.

AFASTAR. [or. obsc.] v. Apartar; distanciar. afastar, S. XIV: $(\mathbf{a 5}, 6)$ que primeiro se deue o homem de afastar do mal \& inclinar se ao bem. $\rightarrow$ Afastado. adj. Apartado, distanciado. @afastados: (a4v, 7) os medicos prudentes quando visitam os enfermos deuem de star afastados delles

AFORISMO. [<lat. aphorismus, -i.] sm. Sentença breve que se dá como regra. Neste caso, o termo refere o título de uma das sete obras do Corpus hippocraticum — ou 'Coleção Hipocrática', coletânea assim referida por ser atribuida, no todo ou em parte, a Hipócrates (460 ?-377 ? a.C.), que a teria escrito em torno de 400 a.C. O Livro dos Aforismos, como indica o título, está organizado em aforismos. [Tradução inglesa disponível em http://classics.mit.edu/Hippocrates/aphorisms.1.i.html]. O Regimento faz referência ao quinto aforismo do livro III (aqui traduzido do grego por Henrique Cairus): "5. Os Nótos [i.e., os ventos do Sul - HC] tornam os ouvidos mais pesados [i.e., menos sensíveis - HC], e obscurecem a visão, tornam a cabeça mais pesada, e são languescentes e relaxantes. Quando exercem sua propriedade, sofre-se o que concerne às doenças a eles relativas. Se soprar o Bóreas [i.e., o vento Norte - $\mathbf{H C l}$, ocorrem tosses, doenças da faringe [i.e., do pescoço - $\mathbf{H C}$ ], endurecimento ventral [i.e., constipação - HC], disúrias com arrepios, dores nos flancos e no peito. Quando este vento exerce sua propriedade, é necessário estar-se preparado para o que concerne às doenças a ele relativas". amforismos, S. XV: $\left(a 4^{v}, 17\right)$ A segunda que assi como se escreve em o terçeyro liuro dos amforismos Ho sul he vento inchado \& agraua o ouuido fere o coraçam

AGENTE. [<lat. agēns, -ēntis.] sm. Aquilo que age. agente, S. XV: $(\mathbf{a 4}, 7)$ por parte do agente \& por parte do paçiente $\mid(\mathbf{a} 4,7)$ Da parte do agente quando aquella jnfluençia sobre celestial mays dereytamente fere \& sguarda aquelle ou aquel outro 
AGORA. [<lat. hac hora, 'nesta hora'.] adv. A partir deste ponto ou momento. - agora, S. XIII: ( a5, 1) VIstas as causas da pestilencia. agora ajamos de veer per que modo \& como se deue homem de guardar da pestilencia

AGRAVADO, vide AGRAVAR.

AGRAVAR. [<lat. aggravare.] v. - agrauar; agraua; agrauada, S. XIII. $\square$ Ser afetado (por um mal ou lesão): $\left(\mathbf{b} 2^{\mathrm{v}}, \mathbf{1}\right)$ \& se alguũ se agrauar de apostema $\mid\left(\mathbf{a} 3^{\mathrm{v}}, \mathbf{1 4}\right)$ mas ajnda tam sobejamente se agraua ha natureza que nom sinte sy ser ferida nem enferma. Acometer: $\left(\mathbf{a} 4^{\mathrm{v}}, \mathbf{1 8 )}\right.$ Ho sul he vento inchado \& agraua 0 ouvido fere o coraçam I (a3v, 13-14) em tanto que ha natureza he per muytas manejras agrauada. AGRAVADO. adj. Molestado. - agrauado: $\left(b 2^{\mathrm{v}}, 1\right)$ \& se alguũ se agrauar de apostema ou sentir agrauado: ou se sentir apeçonhentado. em toda maneyra tal como este euite o somno

ÁGUA. [<lat. aqua, -ae. Gonçalves Viana propõe para augoa um antigo *acqua.] sf. $\bullet$ agoa; augoa, S. XIII. [1] Água: $($ a6, 15) de manhaã quando se alguũ aleuantar logo coma da aruda lauada em agoa limpa espargida com sal \& noz nozcada hũa ou duas bem limpas.l \& ysso meesmo he muyto boõ ameude lauar as maãos com augoa \& vinagre.| (b, 19) \& do vinho ou augoa ou çerveja tomaras quantidade de duas colhares. Substância líqüida: $\left(\mathbf{b} \mathbf{4}^{\mathrm{v}}, \mathbf{1 5}\right)$ \& pișa todo muyto bem atee que vejas que quer pareçer que say destas cousas assy pisadas augoa ou çumo. -Pl. agoas; augoas $\mathbb{1}$ Água já utilizada: (a5, 25) \& tambem donde ha hi podridom de agoas \& fedor dellas. $\left(\mathbf{a 5}{ }^{ }, \mathbf{1}\right) \mathrm{em}$ algũas casas estam as agoas çujas per dous \& tres dias \& as lançam per canos \& regos soterranhos: $\left(\mathbf{a 5} \mathbf{5}^{\mathrm{v}}, \mathbf{3}\right)$ em os quaaes taes agoas çujas causam grandes fedores Líquidos secretados pelo corpo humano; humores: $(\mathrm{a} 3 \mathrm{v}, 16)$ \& jsto porque apareçem bõas ourinas \& boõas augoas. $\rightarrow$ ÁGUA RosADA. Solução alcoólica de essência de rosas, muito diluída em água (Viterbo, I). agoa rosada: $(\mathbf{b}, 2-3)$ Muyto saã cousa he que se laue a boca \& os olhos \& as maãos ameude cada dia com agoa rosada mesturada com vinagre. $\rightarrow$ ÁguA-DE-RosAs. sf. Água rosada. - augoa de rosas: (b, 16-17) toma se ergo duas vezes no dia com boõ vinho claro \& auguado. ou com augoa crara de rosas $\rightarrow$ AGUAR. $v$. Molhar. aguada, S.XIII: $(a 6,22)$ E tambem a casa seja aguada: $\&$ em special em o alto veraão com vinagre rosado \& folhas de vinhas. $\rightarrow$ AguAdo. adj. Diluído $\mathrm{em}$ água. O vinho temperado com duas ou três partes de água era recomendado como a bebida ideal (Marques, 1964: 16-17). - auguado: $(b, 16)$ toma se ergo duas vezes no dia com boõ vinho claro \& auguado

ÁGUA-DE-ROSAS. vide ÁGUA.

ÁGUA ROSADA. vide ÁGUA.

AGUADO. vide ÁGUA.

AGUAR. vide ÁGUA.

AINDA. [or. obscura.] adv. Além disso, em complemento. @ajnda, S. XIII: (a3v, 14) mas ajnda tam sobejamente se agraua ha na tureza que nom sinte sy ser ferida nem enferma.l $\left(a 4^{v}, 2\right)$ mais ajnda digo que em o tempo pestilençial nenhuũ nom deue de star em ajuntamento do pouoo. $\rightarrow$ AINDA QuE. Apesar de que. - ajnda que: $\left(b^{v}, 3\right)$ assi como som pigmenta \& alhos. ajnda que pigmenta purga o çerebro da freuma \& os outros membros speciaaes dos humores vis $<\mathrm{c}>\mathrm{Osos}$

AJUNTAMENTO. [<de ajuntar.] sm. Multidão ou reunião de pessoas. @ajuntamento; ajuntamento, s. XIII: (a4v, 3) \& portanto deue homem de fugir dos aares peçonhentos. mais ajnda digo que em o tempo pestilençial nenhữ nom deụe de star em ajuntamento do pouoo. I $(\mathbf{a 6}, 12)$ assi for que companhia \& ajuntamento de pouoo se euite. $\rightarrow$ JUNTAMENTE. adv. Em simultâneo. $\bullet$ juntamente; juntamente: (a3, 910) \& as vezes veem dambos de dous .scilicet. da rayz superior \& da rayz jnferior juntamente. I $\left(\mathbf{a}^{\mathbf{v}}, \mathbf{6}\right)$ Da rayz superior \& jnferior juntamente proçede quando da jmpressam celestrial corrompente ho aar. \& podridam dos corpos mortos. ou lugares çujos se causa ho morbo ou ha chagua em ho homem: I (b3'v, 2) \& se homem nom quiser cortar muytas veas juntamente: emtam leyxe yr a vea aberta ou ferida 
atee o retardamento do sangue.l $(\mathbf{b}, 25)$ E ysso meesmo deues de comer boõ manjar \& bõa yguaria com boõ vinho puro \& ameude. empero nom muyto juntamente

ALEGRIA [de alegre.] sf. Satisfação, contentamento. - alegria, S. XIII: (b2, 8) E tambem a alegria do coraçom he gram remedio pera a saude do corpo.I (b2, 13) porque ymaginaçam faz causa \& perijgo. mas qualquer com muyto prazer \& alegria sempre espere de muyto viuer

ALEVANTAR. [<lat. *levantare.] v. Levantar-se @aleuantar, s. XIII: (a6, 14-15) de manhaã quando se alguũ aleuantar logo coma da aruda lauada em agoa limpa espargida com sal \& noz nozcada $\rightarrow$ LEVANTE. $s m$. Leste, ponto no horizonte de onde o Sol se levanta. - leuante: $\left(\mathbf{a 4}{ }^{\mathrm{v}}, 12\right)$ \& muytas vezes teer as frestas pera ho norte ou pera o leuante abertas

ALGUÉM. [<lat. aliquem.] pron. indef. Indica pessoa não determinada, qualquer pessoa. - alguem: (b3, 17) He ergo gramde remedio sy se alguem sentir apeçonhentado ou em tempo de pestilencia sentir estas cousas que escuse o somno

ALGUM. [<lat. *alicunus < aliquis unus.] pron. indef. $\bullet$ alguũ, s. XIII. $\mathbb{\square}=$ Um dentre número indeterminado, qualquer: $\left(\mathrm{a4}^{\mathrm{v}}{ }^{\mathrm{v}}, 4\right)$ porque podera ser que alguũ delles sera apeçonhentado ou ferido I (a3, 11 e 12) de alguũ fedor particular de alguũ canno çujo se corrompe ho aar em substançia \& qualidade | (b2v, 13) que tal desejo se deue reuogar \& impedir per alguũ andar em jardijs ou em campos. 14) quando se alguũ aleuantar logo coma da aruda lauada em agoa limpa espargida com sal \& noz nozcada $\mid(\mathbf{b} 2, \mathbf{1 9 )}$ assy como he em as molheres que som prenhes. ou em alguũ muyto fraco $\mid(\mathbf{b} 2,20)$ em alguũ que teem corrença ou fluxu do ventre.| (b2, 26) \& se alguũ se agrauar de apostema $\mid$ (b2v 12) se algũ̃ teuer desejo de dormir: que tal desejo se deue reuogar \& impedir $\mid(\mathbf{b} 3,13)$ se alguũ nom quiser creer: spere per huũ meo dia $\mid(\mathbf{b} 4 \mathbf{v}, \mathbf{8})$ quando alguũ teuesse tal apostema que soruesse em si toda a triaga - Pl. alguũs; algũas $\mathbb{U}$. per alguũs dias mudar a camera $\mid\left(\mathbf{b} 4^{\mathbf{v}}, \mathbf{5}\right)$ \& faze emprasto. \& despois poõe tudo na apostema. posto que alguũs çirogiaães querem que lhe ponham triaga I $(\mathbf{a} 2,13)$ Quero algũas cousas da pestenença que nos ameude fere $\mid\left(\mathbf{a} 5^{v}, \mathbf{1}\right)$ em algũas casas estam as agoas çujas per dous \& tres dias

ALHo. [<lat. allium, -ii, 'alho, cebola'.] sm. Allium sativum Linnaeus, família das Liliáceas. Eroa exótica, cultivada, de bulbo oval formado por gomos, folhas estreitas, flores pequenas e esbranquiçadas, reunidas em umbelas. Seus gomos são amplamente empregado em preparações e temperos de vários alimentos. Apresenta propriedades antivermifugas, anti-reumáticas, contra gripes, tosses, insônia e como bactericida intestinal. Segundo a lenda do "vinagre dos quatro ladrões de Marselha", por volta de 1300 preparava-se com o alho um vinagre anti-séptico com o qual se enxaguava a boca e se lavavam as mãos, evitando-se a contaminação de pestes (Balmé, 1978: 42). Na tradição médica hipocrático-galênica o alho foi classificado no quarto grau de calor e, por conseguinte, considerado adequado apenas "para o estômago grosseiro dos camponeses" (Flandrin, 1996:482) $e$, assim como a pimenta, pouco recomendável. - alho; alhos, S. XIII: $\left(\mathrm{b}^{\mathrm{v}}, \mathbf{8}\right)$ ysso mesmo o alho posto: alimpe da freuma \& lança fora os maaos humores. \& prouoca o apetito de comer: \& nom consinta emtrar ho aar seco. empero contorua os olhos \& squeenta a cabeça de cada huũ que ho ameude come. I $\left(\mathbf{b}^{\mathrm{v}}, 3\right) \mathrm{E}$ em os mantijmentos guarte das cousas queentes. assi como som pigmenta \& alhos

ALI. [<lat. ad illic.] adv. $\rightarrow$ DALI. prep $+a d v$. (D)aquele ponto (referido anteriormente). $\bullet$ daly: (a3, 14) \& esta causa particular \& pode aconteçer cada dia. \& daly procede $m$ febres pestilençiaes. vide DE.

ALIMPAR. vide LIMPO.

ALoÉs. [<lat. lōê, -ēs, 'aloés'.] sm. Lenho de aloés, lenho de agar, lenho de águila. Árvore de até $40 m$ (gênero Aquilaria, família das Timeleáceas), com 15 espécies de distribuição indo-malásia. Tem tronco reto de 1,5m a $2,5 \mathrm{~m}$ de diametro, madeira de cor amarela, folhas longas de até $10 \mathrm{~cm}$ de comprimento, flores brancas, fruto em cápsula. O lenho tem propriedades terapêuticas: é anti-reumático, diurético, tônico, estimulante, afrodisiaco. As ároores muito velhas e contaminadas por fungos produzem oleorresina utilizada no preparo de incenso e de agar 
- aloes: $\left(\mathbf{a} 5^{v}, 21\right) \&$ com lenho de aloes que he melhor de tudo

ALOSNA. vide LOSNA.

ALTo. [<lat. altus,-a,-um.] adj. Longe do início, adiantado. $\bullet$ alto, S. XIII: (a2, 25) Primeiro quando em huũ dia do estio \& do alto veraão se muda a manhaã muytas vezes. I $(\mathbf{a} 6, \mathbf{2 3}) \mathrm{E}$ tambem a casa seja aguada: \& em special em o alto veraão com vinagre rosado \& folhas de vinhas

AMARgoso. [de amargo.] adj. De sabor amargo. - amargosa, s. XIII: $\left(\mathbf{b}^{\mathrm{v}}, 7\right)$ melhor me pareçe soo a cousa amargosa que queentura cheyro \& sabor

AмBos. [<lat. ambos] num. Os dois. $\bullet$ ambos de dous: $(\mathbf{a} 3,8-9)$ \& as vezes veem dambos de dous .scilicet. da rayz superior \& da rayz jnferior juntamente

AMÉM. [hebr. 'assim seja'.] interj. Assim seja. Amen, s. XIV: (b4v', 26) \& da benta virgem maria sua madre seja gloria \& louuor pera sempre Amen

AMFORISMO. vide AFORISMO.

AMIÚDE. [<lat. ad minutim.] adv. Com freqüência. $\bullet$ ameude, a meude, S. XIII: (a2, 14) Quero algũas cousas da pestenença que nos ameude fere: dos ditos dos mays autenticos medicos: screver.| $(\mathbf{a 4 , 1 8 )} \&$ os que vaam ameude a os banhos.l $(\mathbf{a 6}, \mathbf{2 4 )} \&$ ysso meesmo he muyto boõ ameude lauar as maãos com augoa \& vinagre. I $(\mathbf{b}, 2)$ Muyto saã cousa he que se laue a boca \& os olhos \& as maãos ameude cada dia com agoa rosada mesturada com vinagre. $\left(\mathbf{b}^{\mathrm{v}}, \mathbf{1 2}\right)$ \& nom consinta emtrar ho aar seco. empero contorua os olhos \& squeenta a cabeça de cada huũ que ho ameude come. I $\left(\mathbf{b}^{\mathbf{v}}, \mathbf{1 4}\right)$ a pestilençia que veem per causa queente ameude se acreçenta.I (b, 24-25) E ysso meesmo deues de comer boõ manjar \& bõa yguaria com boõ vinho puro \& a meude

AMTRE. vide ENTRE.

ANDAR. [or. obsc.] 0.9 andar; andaua; andando, andando, S. XIII. Caminhar, percorrer a pé: (b3, 6) nem andar grande caminho por a grande pigriça do corpo \& muyto grande peso \& carrega corporal. I (b2v, 13) que tal desejo se deue reuogar \& impedir per alguũ andar em jardijs ou em campos. $\mid$ (b4, 23) \& sempre antes do meo dia será em continuo mouimento: ou cavalgando: ou andando temperadamente [1] Deslocar-se; mover-se: $(\mathbf{a} 6,21)$ nem he saão andar per a villa ou çidade. I $(\mathbf{b} 3,5)$ Posto que tal como este no $m$ pode andar e $m$ cauallo ou besta. $\mid\left(\mathbf{b} 2^{\mathrm{v}}, 3\right) \&$ ysto em andando. $\rightarrow$ ANDAR DE CASA EM CASA. Ir pelas portas. andaua de casa em casa: $\left(\mathbf{a}^{\mathrm{v}}, \mathbf{4}\right) \mathrm{Em}$ monpilher nom me pude escusar de companhia de gente. porque andaua de casa em casa curando enfermos por causa da minha pobreza. $\rightarrow$ ANDAR EM MOVIMENTO. Movimentar-se. - andar em mouimento: $\left(\mathbf{b} 2^{\mathrm{v}}, \mathbf{8}\right)$ a qual cousa nom se faria se o homem andar em mouimento. $\rightarrow$ ANDAR FORA. Estar em ambiente aberto, sair. - andar fora: (a6, 21) Mas em tempo de pestilencia milhor he estar em casa que andar fora

ANTE. vide ANTES.

ANTES. [<lat. ante.] adv. - antes, s. XIII. Preferentemente, em lugar de: (b4v, 8) mas eu queria antes que quando alguũ teuesse tal apostema que soruesse em si toda a triaga Pelo contrário: (bv , 13) \& por ysso nom pareçe se neçessario mas antes jnpidoso. $\rightarrow$ ANTES DE. $\bullet$ ante de, ante de; antes de, S. XIII. Anteriormente $\mathbf{a}:(\mathbf{b} 2,22)$ Faça se ergo a sangria em a vea destra ou seestra ante de comer. I (b2v, 17-18) Empero diz auiçena que se homem quiser dormir ha de beber hũa bõa vez de vinho ou çerueja ante de dormir. I $(b 4,22) \&$ sempre antes do meo dia será em continuo mouimento $\rightarrow$ ANTES QUE. Previamente a que. antes que: $(\mathbf{b} 4,9) \mathrm{E}$ todas estas cousas se façam se homem nom dormir antes que conheça que tem apostema

ANTRE, vide ENTRE, 
APARECER. [<lat. apparescere.] v. Surgir. $\bullet$ apareçer; apareçe; apareçem; apareçerem, S. XIII: (b3v $\left.{ }^{2}, \mathbf{1 0}\right)$ em a qual ha doença ou chaga apareçer se deue de sangrar \& abrir a vea.I (b3 $\left.{ }^{v}, 24\right)$ E se pela ventura apareçer açerca da orelha : faça se a sangria de çephalica daquelle meesmo lado.l (b4, 13) porque se apareçer despois em o braço direyto: que se sangre em o braço esquerdo do figado: ou basilica: ou da meaã. I $(\mathbf{b} 4,15)$ E se apareçer a apostema de bayxo do braço direyto: emtom faça se como dito he do braço esquerdo. $\mid(\mathbf{b 4}, \mathbf{1 8})$ \& assi dos outros lugares em os quaaes apareçer a apostema I $\left(\mathbf{b 4} \mathbf{4}^{\mathbf{v}}, \mathbf{1 9 )}\right.$ Item quando apostema primeyro apareçer. tome auelaãs. figos passados \& aruda I (a2v , 14) quando ha cometa apareçe aconteçe $m$ mortes de gentes em bathalhas \&c.I $\left(\mathbf{a}^{\mathrm{v}}{ }^{\mathrm{v}}, 16\right)$ \& jsto porque apareçe $m$ bõas ourinas \& boõas augoas. I $\left(\mathbf{a} 2^{\mathrm{v}}, 25\right)$ Quando ergo estes signaes apareçerem. he pera temer grande pestilencia. $\rightarrow$ APARECIMENTo. sm. Surgimento. - apareçimento, S. XIV: (a2v, 16) \& por isso, diz o verso poetico falando do apareçimento da cometa

APARECIMENTO. vide APARECER.

APEÇONHENTADO. vide PEÇONHA.

APEÇONHENTAR. vide PEÇONHA.

APEGAR. [<lat. app care.] v. Ser transmissível. - apegam, S.XIV: $(\mathbf{a} 4,5)$ Se taaes jnfirmidades pestilençiaes sam contagiosas .scilicet. se se apegam.I $(\mathbf{a 4}, \mathbf{2 3 )}$ taaes infirmidades pestilençiaaes sam contagiosas \& apegam se muy asinha

APETITE. [<lat. appettitus,-us.] sm. Vontade, desejo. - apetito, S. XIV: (bv , 9) ysso mesmo o alho posto: alimpe da freuma \& lança fora os maaos humores. \& prouoca o apetito de comer

APODRENTAMENTO. vide PODRE.

APODRENTAR, vide PODRE

APOStEMA. [<lat. apostema, -atis.] sf. Abscesso. - apostema; postema, s. XV: (a3 $\left.{ }^{v}, 10\right)$ \& tal morbo ou jnfirmidade as vezes he febre. \& as vezes apostema $\mid\left(\mathbf{b} 2^{v}, \mathbf{1}\right)$ \& se alguũ se agrauar de apostema ou sentir agrauado: ou se sentir apeçonhentado.। $(\mathbf{b 3}, \mathbf{1 4})$ \& logo sentirá apostema de bayxo dos braços. I $\left(b^{v}, 19\right)$ E se a apostema for em ho pescoço. seja sangrado na vea de çephalica açerca do dedo polegar em a maão daquelle meesmo lado. I $(\mathbf{b 4}, \mathbf{1 5})$ E se apareçer a apostema de bayxo do braço direyto: emtom faça se como dito he do braço esquerdo. I $(\mathbf{b} 4, \mathbf{1 8})$ \& assi dos outros lugares em os quaaes apareçer a apostema: em maneira que sempre se mingue o sangue per modo contrayro. I (b4v, 1) que a apostema mais çedo \& milhor seja madura $\mid\left(\mathbf{b} 4^{v}, \mathbf{5}\right)$ \& despois poõe tudo na apostema. I (b4v, 8) mas eu queria antes que quando alguũ teuesse tal apostema que soruesse em si toda a triaga: | (b4v, 21$)$ põm lho em çima da apostema. I (b4, 10) E todas estas cousas se façam se homem nom dormir antes que conheça que tem apostema. I $(\mathbf{b} 4,24)$ E se despois creçer apostema:I $(\mathbf{b 4}, \mathbf{2 5})$ nom tema. porque tal apostema lança o mal de fora \& faz o homem ser muyto saão. $\mid\left(\mathbf{b 4} \mathbf{~}^{\mathbf{1}}, \mathbf{1 7}\right)$ toma aquelle çumo \& mistura ho com leyte de mulher \& da ho a beber aquelle que teuer apostema. I $\left(\mathbf{b} 4^{v}, 19\right)$ Item quando a postema primeyro apareçer. tome auelaãs. figos passados \& aruda

APOTECÁRIo. [<lat. appothecarius, -ii, 'escravo encarregado do armazém'.] sm. Aquele que aviava as receitas, equivalente do atual farmacêutico. A profissão começou a ser regulamentada em Portugal no século XV, quando se passou a exigir aprovação em exame para seu exercício, e as boticas tornaram-se sujeitas à fiscalização por $f i$ s $i$ cos [q.v. Físico]. Toda botica passa, então, a ter de estar provida de cinco obras, quatro delas árabes: a Pandecta (Pandecta medicinae, de Matthaeus Sylvaticus, uma compilação traduzida do árabe, século XIV), o Mesue (De Simplicibus, texto árabe do século XI), "o Nicolau (Antidotarium, de Nicolau Myrepso,do século XIII, que tratava da composição e acção dos medicamentos), o Liber Servitoris, outro tratado árabe, e o Quinto Livro do Canon de Avicena" (Marques, 1964:102). Numa botica deveria ainda haver três medidas de onça (para xaropes, 
águas e óleos) e pesos (gräo de trigo, dracma, onça e libra). O boticário comercializava águas, conservas, leituários, emplastros, flores, ervas, drogas, especiarias, marmeladas, mel, óleos, pílulas, pós, xaropes, triagas, ungüentos e outros "medicamentos latinos, hoje dificeis de identificar" (Marques, 1964:103). - apotecayros; boticairo; boticayro, S. $x \mathrm{~V}$ : $\left(\mathbf{a} 5^{\mathrm{v}}, \mathbf{1 9}\right)$ as quaaes acharas aos apotecayros. I (b4v, 12) \& outro que chamam serpillo que acharas ao boticairo. I $\left(\mathbf{b} \mathbf{4}^{\mathrm{v}}\right.$, 13) \& ysso mesmo toma chantagem \& siligem (vay te ao boticayro)

APROVEITAR. vide PROVEITO.

APURAR. vide PURO.

AQUECER. [<lat. accadescere.] v. Acontecer, suceder. - aqueçer, S. XIV: (a4, 6) A primeyra questam: digo que esto pode aqueçer por duas causas .scilicet. por parte do agente \& por parte do paçiente

AQUEENTAR. vide QUENTE.

AQUELE. [<lat. eccum ille.] pron. demonst. - aquel, aquel; aquelle, aquelle, aquella; aquelles. $₫$ Tal: (b2, 26) \& nom conuem dormir em aquelle dia que se sangrar \& abrir a vea. I (b3v, 13) E se pella ventura naçer a apostema de bayxo do braço direyto. sangre se em ho meo daquelle braço da vea meaã. I (b3v', 15) Se de bayxo do braço seestro ou esquerdo. sangre se em ha vea meaã daquelle meesmo braço. I $\left(\mathbf{b} 3^{v}, \mathbf{1 8}\right)$ E se açerca das partes vergonçoșas. sangre se em o pee daquelle mesmo lado açerça do calcanhar.। $\left(\mathbf{b 3}^{\mathrm{v}}\right.$, 21) E se a apostema for em ho pescoço. seja sangrado na vea de çephalica açerca do dedo polegar em a maão daquelle meesmo lado. I (b3 $\left.{ }^{\mathrm{v}}, \mathbf{2 2}\right)$ ou na meaã daquelle meesmo braço. ou na maão daquelle meesmo lado açerca do dedo menor. I $\left(\mathbf{b}^{\mathrm{v}}\right.$, 25) E se pela ventura apareçer açerca da orelha: faça se a sangria de çephalica daquelle meesmo lado. $\left(\mathbf{b} 4^{\mathrm{v}}, \mathbf{1 6}\right)$ emtom toma aquelle çumo \& mistura ho com leyte de mulher $\mid\left(\mathbf{b 4}^{\mathrm{v}}, \mathbf{1 7}\right)$ \& da ho a beber aquelle que teuer apostema. Indica oposição entre dois seres. $\bullet$ aquelle/ aquella ... aquel outro/aquel outra: $(\mathbf{a 4}, 1-2)$ Porque he assy que huũ morre \& ho outro nom. \& daquella villa morrem homens \& daquel outra nom. \& daquella casa morrem \& daquel outra nom. I (a4, 9) Da parte do agente quando aquella jnfluençia sobre celestial mays dereytamente fere \& sguarda aquelle ou aquel outro. que aquelle ou aquel outro lugar ou homem.I $(\mathbf{a} 4, \mathbf{1 1})$ Da parte do paciente que aquelle he mays desposto aa morte que aquel outro. Conjunto determinado: (a6, 3-4) que aquelles que sempre querem encher seus ventres que abreuiam seus dias \& tempos da sua fim $\rightarrow$ AQUELOUTRo. pron. demonst. Indica $3^{a}$ pes. mais afastada que a indicada por $A Q U E L E \bullet$ aquel outro: (a4, 1-2) Porque he assy que huũ morre \& ho outro nom. \& daquella villa morrem homens \& daquel outra nom. \& daquella casa morrem \& daquel outra nom. I $(\mathrm{a} 4,9)$ Da parte do agente quando aquella jnfluençia sobre celestial mays dereytamente fere \& sguarda aquelle ou aquel outro. que aquelle ou aquel outro lugar ou homem.I $(\mathbf{a 4}, \mathbf{1 1})$ Da parte do paciente que aquelle he mays desposto aa morte que aquel outro. $\rightarrow$ EM AQUELE. vide EM. $\rightarrow$ NAQUELE. vide EM.

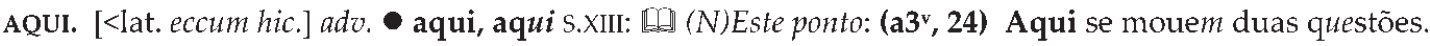
IID Nesta obra: $\left(\mathbf{a 5}^{\mathrm{v}}\right.$, 18) \& faça se tambem com fumo de boõas heruas aqui scriptas, $\left(5^{v}, 4\right) \&$ daqui veem que em tal casa como esta morrem os homens mais azinha

AR. [lat. āèr, äĕris, 'atmosfera'.] sm. Atmosfera. $\bullet$ aar; aares, S. XIV: (a2v, 10) porque emtam pareçe ho aar ser empeçonhentado. I (a2 $\left.{ }^{\mathrm{v}}, \mathbf{1 1}\right)$ \& que sobem muytos vapores peçonhentos ao aar. $\mid(\mathbf{a} 3, \mathbf{8})$ emtanto que senssualmente pareçe aos homens mudança do aar.l $(\mathbf{a 3}, \mathbf{1 3 )}$ ou de alguũ fedor particular de alguũ canno çujo se corrompe ho aar I $\left(\mathbf{a}^{\mathrm{v}} \mathrm{v}, 3\right)$ por ha empressam dos çeos corrompe ho aar. $\mid\left(\mathbf{a} 3^{\mathrm{v}}, 4\right) \&$ ha empresam do aar corrompe os spiritos vitaes em ho homem $\mid\left(\mathbf{a}^{\mathbf{v}}, \mathbf{7}\right)$ Da rayz superior \& jnferior juntamente proçede quando da jmpressam celestrial corrompente ho aar. \& podridam dos corpos mortos. ou lugares çujos se causa ho morbo ou ha chagua em ho homem: I $\left(\mathbf{a}^{\mathrm{v}}\right.$, 11$)$ porque ho aar inspirado as vezes he peçonhento: $\left(\mathbf{a 4}^{v}, \mathbf{1}\right)$ porque dos corpos apeçonhentados procedem humores \& fumos peçonhentos que corrompem ho aar. I (a5 $\left.5^{\mathrm{v}}, \mathbf{1 2}\right)$ porque nom entre em ella ho aar peçonhentado I $\left(5^{v}, 13\right)$ porque ho aar apeçonhentado he humido \& faz podridom em a casa ou em lugar onde 
dormem. I $(\mathbf{a 6}, \mathbf{1 1})$ por que se nom se apeçonhente homem do aar apeçonhentado. I $\left(\mathbf{a} 4^{\mathrm{v}}, \mathbf{1}\right)$ \& por tanto deue homem de fugir dos aares peçonhentos. I (a6 v, 24) Os olhos do aar empeçonhentado logo escureçem se estas cousas nom trouuer home $m$ em ha maão I $(\mathbf{b}, \mathbf{1 1})$ Em casa sempre este fogo açeso. porque clarifica muyto ho aar I (b $\mathbf{b}^{\mathrm{v}}, \mathbf{1 0 )} \&$ nom consinta emtrar ho aar seco

ARISTÓtELEs. [<gr. Aristotélēs.] antrop. Filósofo grego (384?-322 a. C.), discípulo de Platão. Aristóteles seria reintroduzido no Ocidente a partir do século XII, quando várias de suas obras e as de seus comentadores árabes, especialmente Avicena (séc. X) e Averróis (séc. XII), seriam traduzidas do árabe para o latim pelo erudito lombardo Gerardo de Cremona (1114-1187), um dos membros da "Escola de Toledo". Uma das obras de Aristóteles então traduzida é Meteorologia, que é referida no Regimento. [Traduções inglesas disponíveis em http://classics.mit.edu/Aristotle/meteorology.1.i.html e também em http://etext.library.adelaide. edu.au/a/a8met/meteo1.html]. - aristoteles: (a2v, 13) \& segundo diz aristoteles em os metauros. quando ha cometa apareçe aconteçem mortes de gentes em bathalhas \&c

AROMÁtico. [<lat. aromaticus, -a, -um.] adj. Relativo a aromas, isto é, a drogas ou a espécies cheirosas. Segundo Bluteau (I: 514-515), os aromas classificavam-se em simples e compostos. Entre os aromas simples contavam-se o almíscar, o âmbar, a cânfora e a canela; entre os aromas compostos, o aromático rosado. aromatico, S. XVI: $\left(\mathbf{a 5}^{\mathrm{v}}, \mathbf{9 )} \mathrm{E}\right.$ assi como per ho boõ cheyro \& aromatico: se recrea o coraçom \& o sprito do homem

ARRUDA. [<lat. ruta, ae.] sf. Ruta graveolens Linnaeus, família das Rutáceas. Subarbusto ou erva cultivada, de origem européia. Tem folhas fortemente aromáticas, ovais, alternadas, de cor verde-glauco. As flores, pequenas, são amarelas e reunidas em cachos. Os frutos sâo em cápsula. Apresenta diversas propriedades terapêuticas: emenagoga, antivermífuga, antiespasmódica, sudorifera, calmante, contra moléstias da pele. A arruda é utilizada como aromatizante de bebidas e, em algumas religiöes, considera-se que espanta o mau-olhado e traz felicidade (Balmé, 1978; Cruz, 1979). Essas propriedades estão presentes de há muito na literatura. Garcia de Orta (1499?1568), no Coloquio dos simples e drogas da India, apontava os beneficios da arruda: "e mais entonçes usariam da arruda medicinalmente por ser contra a peste e contra o veneno; e tambem alguns praticos receitam salada feita de arruda e de outras cousas, no regimento da peste". Também Bluteau (I, 571): "Toda a casta de arruda he attenuante, incisiva boa contra venenos, \& mordeduras de cães danados, abate os vapores, fortifica o cerebro. Antigamente, mettendo humas folhas de arruda agreste $\&$ duas pernas de noz em hum figo agreste, 0 comiao, para se preservarem da peste. Nas portas se penduraó folhas della, para defensa de feitiços; tambem dizem, que seu fumo he excellente nas casas, \& berço das crianças, para as preservar de quebranto, $\mathcal{E}$ as curar, estando ja abaladas, E enfermas delle". - aruda, S. XIV; arruda, S. XV: $(\mathbf{a 6}, \mathbf{1 5})$ de manhaã quando se alguũ aleuantar logo coma da aruda lauada em agoa limpa espargida com sal \& noz nozcada hũa ou duas bem limpas. I $\left(\mathbf{b} 4^{\mathrm{v}}\right.$, 20) Item quando apostema primeyro apareçer. tome auelaãs. figos passados \& aruda \& tudo bem pisado: pom lho em çima da apostema.। (a5v , 20) \& de alosna \& ysope \& arruda. \& artamija. | (b2, 3) porque se forem pobres contente $m$ se com arruda \& salua

ARTEMísia. [<lat. artemisia, -ae.] sf. Artemisia vulgaris Linnaeus, família das Compostas. Também conhecida como artemija, artemigem, artemísia-verdadeira, artemísia-comum, erva ou flor-de-são-joâo. Planta herbácea de origem européia, com caule avermelhado e folhas verde-claro, pilosas. As flores, amarelas, reúnem-se em curtas espigas. Suas folhas, flores e raízes têm propriedades terapêticas e são utilizadas no combate às afecções uterinas, à epilepsia e à flatulência. Também encontra uso na preparação de licores (Balmé, 1978; Cruz, 1979). artamija, s.Xv: $\left(\mathrm{a}^{\mathrm{v}}\right.$, 20) \& de alosna \& ysope \& arruda. \& artamija

ARTículo. [<lat. articulus, -i.] sm. O dicionário de Jerônimo Cardoso (1570) apresenta duas entradas distintas para o termo: a primeira delas recebe como acepção "Ho nò dos dedos"; a outra, "A juntura dos membros". $O$ termo, no Regimento, parece reportar-se à primeira dessas acepçôes. - articulo: $(\mathbf{b} 4,3)$ ou da vea que he açerca do dedo menor: ou açerca do articulo que he de muytos medicos chamada basilica

ARUDA. vide ARRUDA. 
ARUSIENSE. [de Aarhus, na atual Dinamarca; ou de Arósia, na atual Suécia, mas de 1389 a 1523, parte do reino da Dinamarca ] adj. arusiense: $(\mathbf{2} 2,5)$ Fey to per ho reuerendíssimo Senhor dom Raminto bispo arusiense: do regno de dacia

ASINHA. [<lat. agina, 'orifício onde se move o fiel da balança'] adv. Depressa. • asinha; azinha, S. XIV: $(\mathbf{a 6}, \mathbf{2})$ porque os corpos cheos dos maaos humores sam mais asinha empeçonhentados. I (a4, 23-24) $\mathrm{A}$ segunda questam digo que taaes infirmidades pestilençiaaes sam contagiosas \& apegam se muy asinha | $\left(\mathbf{a 5}^{\mathbf{v}}, \mathbf{5 )}\right.$ em tal casa como esta morre $m$ os homens mais azinha

ASSAR. [< lat. assāre.] v. Cozer um alimento para torná-lo mais seco, corrigindo-lhe a umidade excessiva $e$ tornando-o, desse modo, de melhor $d$ i ges $t \tilde{a} o$ [q.v.]. assados, s. XIII: $\left(\mathbf{b}^{\mathrm{v}}, \mathbf{1 7}\right)$ pela manhaã sejam os manjares cozidos: \& de noyte assados caldos. polmes. \& potagios se euitem: se nom forem azedos

AssAz. [<lat. ad satis, pelo prov. assatz.] adv. Bastante. $\bullet$ assaz, S. XIII: $(\mathbf{b 3}, \mathbf{1 9 )} \&$ assi segundo estas cousas he assaz manifesto: que em o tempo do somno o sprito vital repousa

AssiM. [<lat. ad sic.] adv. - assi; assy, S. XII ou XIII; [?]sy. tal fedor \& doença que muyto empeçe. $\mid\left(\mathbf{a} 3^{\mathrm{v}}, \mathbf{1 2}\right)$ porque ho aar jnspirado as vezes he peçonhento: \& assy corrupto feere ho coraçom. I (b4v $\mathbf{v}, 15)$ atee que vejas que quer pareçer que say de stas cousas assy pisadas augoa ou çumo. Desse modo, do mesmo modo: $(\mathbf{a} 4 \mathrm{v}, 8)$ \& assi ho deuem de fazer os seruidores dos enfermos. I $\left(\mathbf{a}^{\mathrm{v}} \mathrm{v}, \mathbf{2 3}\right) \mathrm{E}$ tal fumo entre per a boca \& per os narizes. porque assi jndiramçe as cousas de dentro | $(\mathbf{a 6}, \mathbf{1 2})$ E quando assi for que companhia \& ajuntamento de pouoo se euite. $\mid\left(\mathbf{a 6} 6^{v}, 11\right)$ \& assi escapey de tal pestilencia.। $(b, 4) \&$ assi guardando estas cousas seguramente entraras em pouoo ou amtre gente.l $(\mathbf{b} 3,23)$ Estantes ergo assi estas cousas quando se homem sente ser tocado da peçonha pestilençial. logo naquelle meesmo dia mingue ho sangue $\mid\left(\mathbf{a}^{\mathrm{v}} \mathrm{v}, 4\right) \mathcal{E}$ assy se geera ha

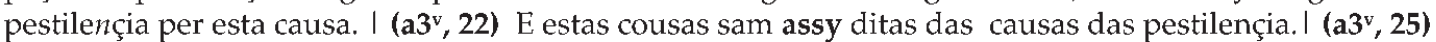
Porque he assy que huũ morre \& ho outro nom. I $\left(\mathbf{b} 4^{\mathrm{v}}, \mathbf{9 )}\right.$ mas eu queria antes que quando alguũ teuesse tal apostema que soruesse em si toda a triaga: \& assy lança a peçonha. I[?] $\left(\mathrm{a3}^{\mathrm{v}}\right.$, 15) mas ajnda tam sobejamente se agraua ha natureza que nom sinte sy ser ferida nem enferma I [sy] $(\mathbf{b} 3,16)$ He ergo gramde remedio sy se algue $m$ sentir apeçonhentado ou e $m$ tempo de pestilencia sentir estas cousas que escuse o somno \& ho euite quanto poder. $(\mathbf{b} 3,19)$ \& assi segundo estas cousas he assaz manifestol $(b 4,17) \&$ assi dos outros lugares em os quaaes apareçer a apostema $\mathbb{\square}$ Do modo como ...da mesma forma. assi ...assi: (a5v, 9-10) E assi como per ho boõ cheyro \& aromatico: se recrea o coraçom \& o sprito do homem. assi emfraquece per o çujo fedor. Tanto ... como. @assi/assy ... como: (a4v, 15) A primeyra que faz emfraqueçer os corpos assi dos saãos como dos enfermos. I (a6v, 2) \& tambem he boõ assi em ho inuerno como no veraão cheirar cousas azedas. I (b, 14) Quanto he ao teu mantijmento digo te que a triaga te he muyto proueytosa: assi saãos como aos enfermos. $\rightarrow$ Assim Como. Do modo como. $\bullet$ assi; assy: $(\mathbf{a} 4,17)$ E por tanto dos quaaes se faz ha grande resoluçam assy como sam os corpos desordenados em luxuria \& coyto | (a4v, 16-17) A segunda que assi como se escreve em o terçeyro liuro dos amforismos $1 \quad\left(\mathbf{b}^{v}, 2\right) \mathrm{E}$ em os mantijmentos guarte das cousas queentes. assi como som pigmenta \& alhos. I $\left(\mathbf{b}^{\mathrm{v}}, \mathbf{2 1}\right)$ Isso mesmo se euite $m$ todos os fructos se nom fore $m$ azedos. assi como sam çirejas. romaãs. I $(\mathbf{b} 2, \mathbf{1 8})$ SAngria huũa vez em huũ mes se pode bem fazer. se nom se a ydade ou outra cousa for em contrayro. assy como he em as molheres que som prenhes.

Assutilezar. [de sutil.] $v$. Impregnar de vapores. asutileze: $\left(\mathbf{a 5}^{\mathrm{v}}\right.$, 15) Apure se ergo \& asutileze se a casa per clara chama ou flama

ATÉ, [or. obscura] prep. Indica um ponto limite no espaço ou no tempo (com verbo no indicativo) - atee, S. XIII: $(\mathbf{a} 4$ v $19-20)$ porque abre os poros do homem \& emtra atee o coraçam. I (a5, 20) Fechem se ergo as frestas ou genelas como dito he que vaam ou estam pera o sul atee hũa hora depois do meo dia $\mid(\mathbf{b}, \mathbf{2 1}) \&$ nom jantaras atee ho meo dia $\mid \mathbf{b} 3,26)$ \& se sangre atee esmoreçer. I (b3v , 3) emtam leyxe yr a vea aberta ou ferida atee o retardamento do sangue. $\mid\left(\mathbf{b 3}^{\mathrm{v}}, \mathbf{8}\right)$ em nenhũa maneyra nom deue de dormir per todo o dia atee mea noyte $\rightarrow$ ATÉ QUE. Afé (com verbo no subjuntivo): $\left(\mathbf{a} 4{ }^{v}, 23\right)$ \& se for neçessario que saya este 
em casa atee que saya o sol I (b4v, $\mathbf{1 4})$ \& pisa todo muyto bem atee que vejas que quer pareçer que say destas cousas assy pisadas augoa ou çumo

AVELÃ. [lat. (nux) abellāna, 'noz de Abella, cidade da Campânia'.] sf. Corylus avellana Linnaeus, família das Betuláceas. Arbusto de até $6 \mathrm{~m}$ de altura. Tem folhas arredondadas, flores amareladas reunidas em amentos, frutos ou aveläs amplamente utilizados na indústria de doces. Das folhas e frutos extrai-se o óleo, aplicado nas inflamações intestinais e, como depurativo e detergente, em chagas, feridas e ulceraçōes (Balmé, 1978). Na dietética medieval, foi um dos frutos considerados quentes. @auelaãs, s.xIV: $\left(\mathbf{b} 4^{v}, 20\right)$ tome auelaãs. figos passados \& aruda

AVICENA. [<ár. Abu Ali al-Husayn ibn Abd Allah ibn Sina, 980-1037] antrop. Filósofo e médico nascido na Pérsia (atual Irã), famoso na medicina por uma imensa obra, O Cânone da Medicina [resumo disponivel em http:/www.traditionalmedicine.net.au/canonavi.htm]. O quarto livro do Cânone, mencionado no Regimento, diz respeito à variabilidade dos humores. Avicena é considerado o representante máximo do aristotelismo árabe platonizado. auicena, auiçena: $(\mathbf{a} 3,25) \&$ de tal diz auicena no quarto liuro que muy ligeyramente se empeçonhentam os corpos da jndisposiçam ou da maa desposiçam dos çeos. I $(\mathrm{a} 6,3)$ E por tanto diz auiçena em o quarto do canone. que aquelles que sempre querem encher seus ventres que abreuiam seus dias \& tempos da sua fim \& minguam sua vida. | (b2v, 16 ) Empero diz auiçena que se homem quiser dormir ha de beber hũa bõa vez de vinho ou çerueja ante de dormir

AUTÊNTICO. [< lat. authent cus, $-a,-u m$.] adj. Que tem autoridade; a que $(m)$ se deve dar crédito. @autenticos, S. XIV: $(\mathbf{2} 2,15)$ Quero algũas cousas da pestenença que nos ameude fere: dos ditos dos mays autenticos medicos: screver

AZEDO. [<lat. acidus, -a, -um.] adj. - azedas; azedos, S. XIII. $\square$ De sabor acre, o sabor mais quente de todos; picante. Segundo Bluteau (I,106-107), é "todo sabor que pica na lingoa; \& no sentido do gosto imprime hum calor, que em certo modo queima, como pimenta": $\left(\mathbf{b}^{\mathrm{v}}, \mathbf{2 0 )}\right.$ Em tempo da pestilencia valem mais cousas azedas que todalas meezinhas $\mid\left(\mathbf{b}^{v}, 19\right)$ \& potagios se euitem: se nom forem azedos $\mid\left(\mathbf{b}^{v}, 21\right)$ Isso mesmo se euite $m$ todos os fructos se nom forem azedos. assi como sam çirejas. romaãs. $\mid\left(a^{v}, 3\right) \&$ tambem he boõ assi em ho inuerno como no veraão cheirar cousas azedas. I $\left(\mathbf{a} 6^{\mathrm{v}}, \mathbf{8}\right)$ porque as cousas azedas \& os cheyros taaes opilam \& çarram os poros \& os meatos \& os caminhos dos humores \& nom consintem entrar as cousas peçonhentas 


\section{B}

BAFO. [or. obsc.] sm. Hálito. baffo, S.XIV: $\left(\mathbf{a} \mathbf{6}^{\mathbf{v}}, \mathbf{2 3}\right)$ E por ysso te digo que em toda maneyra te guardes que nom reçebas do baffo de outrem

BAGA. [<lat. bāca, -ae 'fruto miúdo'.] sf. Fruto carnoso. - baga, S.XV: $\left(\mathbf{a} 5^{\mathbf{v}}, \mathbf{1 8}\right)$ \& faça se tambem com fumo de boõas heruas aqui scriptas scilicet. baga de louro. junipero. vberiorgano

BAIXo. [<lat. bassus, $-a, u m$.] sm. Nível inferior. $\rightarrow$ ABAIXo. Adiante (num texto escrito). a bayxo: $(\mathrm{a} 6,13-14)$ emtam huse homem dos remedios a bayxo scriptas $\rightarrow$ DEBAIXO. Sob. de bayxo: (b2v, 26) \& logo despois de comer tem desejo de dormir. \& sente de bayxo de frio grande quententura. I (b3, 14) se alguũ nom quiser creer: spere per huũ meo dia \& logo sentira apostema de bayxo dos braços. I (b3 $3^{v}$, 12) E se pella ventura naçer a apostema de bayxo do braço direyto. sangre se em ho meo daquelle braço da vea meaã. | $(\mathbf{b} 4, \mathbf{1 6})$ E se apareçer a apostema de bayxo do braço direyto: emtom faça se como dito he do braço esquerdo

BANHO. [< lat. baneum, $-i$ 'sala de banhos, banho'.] sm. - banho, s. XIV. $\mathbb{G} \cong$ Abluçâo: (a6, 7) Item per esta mesma causa se deue evitar ho banho de cada dia. - Pl. banhos, S. XIV. $[$ Estabelecimento para banhos públicos, em geral de vapor, mas a que se poderiam juntar banho de imersão, refeição e cama. Embora relativamente comum na Idade Média — Paris contava com 26 em 1292 (Vigarello, 1985: 25) —, esse tipo de estabelecimento começaria a desaparecer no século XVI. O Regimento já parece associar os banhos a locais de prostituição (vide Vigarello, 1985: 31ss.): $(\mathbf{a 4 , 1 9 )}$ assy como sam os corpos desordenados em luxuria \& coyto. \& os que vaam ameude a os banhos

BARBAJOVIS. [< lat. barba, -ae, 'barba' + Jovis, 'Júpiter'] sf. Sempervivum tectorum Linnaeus, família das Crassuláceas. Planta herbácea, de origem européia, conhecida como olho-de-júpiter, barba-de-júpiter, sempreviva-dos-telhados, barbajovis, barba-jovis (joubarbe des toits em francês e Donnersbart em alemão). Os nomes populares da planta, dedicada a Júpiter, originou-se da organização maciça das numerosas flores da espécie e que foi interpretada como semelhante à barba do referido deus. Por apresentar vitalidade em condiçōes adversas $e$ crescer em telhados, acreditava-se que a planta apresentava proteção contra o fogo, luz e tempestades, crença que ainda prevalece em algumas partes da Europa. As folhas possuem propriedades terapêticas emolientes, diuréticas, refrigerantes, contra inflamações cutâneas, erisipelas (fogo-de-santo-antônio) e queimaduras barbajouis: $\left(\mathbf{b 4}^{\mathrm{v}}, \mathbf{1 1}\right)$ Item outro remedio Tomaras hũa herua que chamam barbajouis. \& outro que chamam serpillo que acharas ao boticairo

BASÍLICA. vide VEIA BASÍLICA.

BATALHA. [<lat. battalia, -ae.] sf. Combate. bathalhas, S.XIV: $\left(\mathbf{a} 2^{\mathrm{v}}, \mathbf{1 5}\right)$ quando ha cometa apareçe aconteçem mortes de gentes em bathalhas \&c

BEBER. [<lat. bibere.] v. Ingerir líqüido. beber: $(\mathbf{b} 2,24)$ \& despois que a vea for ferida ou aberta aproueyta muyto tomar muyto prazer. beber muy boõ vinho ou bõa çerueja. I (b2v, 17) Empero diz auiçena que se homem quiser dormir ha de beber hũa bõa vez de vinho ou çerueja ante de dormir. I $\left(\mathbf{b} 4^{\mathrm{v}}, \mathbf{1 7}\right)$ emtom toma aquelle çumo \& mistura ho com leyte de mulher \& da ho a beber aquelle que teuer a postema 
BEM$^{1}$. [lat, bene.] adv. bem, bem, S, XIV, @ Muito, bastante; (a3v, 22) Ergo he neçessario que todo enfermo se proueja de boõ fisico \& bem esperto. I $(\mathbf{a 6}, \mathbf{1 7})$ quando se alguũ aleuantar logo coma da aruda lauada em agoa limpa espargida com sal \& noz nozcada hũa ou duas bem limpas.l (b4v, 20) Item quando a postema primeyro apareçer. tome auelaãs. figos passados \& aruda \& tudo bem pisado: põm lho em çima da apostema. I (b4v, 14) \& pisa todo muyto bem atee que vejas que quer pareçer que say destas cousas assy pisadas augoa ou çumo. de guardar a casal mas todas estas cousas pode muyto bem euitar \& de sy lançar andando ou espaçando huũ pouco antre ho comer \& o dormir. I $(\mathbf{b} 2, \mathbf{1 7})$ SAngria huũa vez em huũ mes se pode bem fazer

BEM². [lat. bene.] sm. Aquilo que leva a Deus. bem: $(\mathbf{a 5 , 6 )}$ que primeiro se deue o homem de afastar do mal \& inclinar se ao bem

BENTO. [<lat. benedictus, $-a, u m$. ] adj. Abençoado. - benta, s. XV: $\left(\mathbf{b} 4{ }^{\mathrm{v}}, \mathbf{2 5}\right)$ \& da benta virgem maria sua madre seja gloria \& louuor pera sempre

BESTA. [<lat. bestia, -ae.] sf. Termo geral empregado para designar tanto o jumento, Equus asinus Linnaeus, 1758 (Perissodactyla, Equidae), quanto cavalos de carga ou tiro, Equus caballus Linnaeus, 1758 (Perissodactyla, Equidae), bem como os híbridos de ambas as espécies. Domesticados desde tempos imemoriais, estes quadrúpedes eram largamente empregados no transporte dos mais diferentes produtos, embora as mulas também fossem muito apreciadas como montaria pelo passo macio e firme, garantia de uma jornada amiúde bem mais agradável e segura. Esta parece ser a melhor interpretação para o trecho do presente documento. $\bullet$ besta, s. XIII: $(\mathbf{b 3}, \mathbf{6})$ Posto que tal como este nom pode andar em cauallo ou besta

BISPO. [ <lat. episcopus, -i.] sm. Na Igreja Católica, padre que recebeu a plenitude do sacramento da ordem. bispo, s. XIII: $(\mathbf{a} 2,5)$ Feyto per ho reuerendíssimo Senhor dom Raminto bispo arusiense: do regno de dacia

BOCA. [< lat.bŭcca, -ae.] sf. Cavidade na parte inferior do rosto, definida externamente pelos lábios. $\bullet$ boca, $\mathrm{s}$. XIII: $\left(\mathbf{a}^{\mathrm{v}}\right.$, 23) E tal fumo entre per a boca \& per os narizes. I $\left(\mathbf{a}^{\mathrm{v}} \mathrm{v}, 8\right)$ \& emtam leuaua commigo huũa sponja ou paão enssopado em vinagre: \& sempre no punha nos narizes \& na boca. I (b, 1) Muyto saã cousa he que se laue a boca \& os olhos \& as maãos ameude cada dia com agoa rosada mesturada com vinagre

вом. [<lat. bonus, -a, -um.] adj. @bõ̃; bõa; bõas; boõa;boõas. Com qualidade: (a2, 1) Começa se huũ boô regimento muyto neçessario \& muyto proueitoso aos viuentes.I (a3v, 21) Ergo he neçessario que todo enfermo se proueja de boõ fisico \& bem esperto.l $(\mathbf{a 5}, \mathbf{1 2})$ Empero prometo te que muyto boõ remedio he fugir \& mudar o lugar apeçonhentado. I (a5v, 9) E assi como per ho boõ cheyro \& aromatico; se recrea o coraçom \& o sprito do homem.l (b, 16) toma se ergo duas vezes no dia com boõ vinho claro \& auguado. | (b, 23) E ysso meesmo deues de comer boõ manjar $\mid(\mathbf{b}, 24)$ \& bõa yguaria com boñ vinho puro \& ameude. $\mid(\mathbf{b} 2,24)$ beber muy boõ vinho ou bõa çerueja. $\mid(\mathbf{b} 2,4)$ \& todo misturado com vinagre faz muy bõa salsa $\mid\left(\mathrm{a}^{\mathrm{v}}, 17\right) \&$ faça se tambem com fumo de boõas heruas aqui scriptas $\mid(\mathbf{b} 2, \mathbf{1})$ busquem se pera os ricos muyto bõas salsas ou salseamentos. I $(\mathbf{b} 2, \mathbf{7})$ \& tal salsa he muyto boõa \& destruye \& quita ou tira toda podridom. I (b2 ${ }^{\mathrm{v}}, \mathbf{2 0 - 2 1 )} \&$ estes maaos humores se lançam fora per tomar hũa bõa vez de vinho boõ ou bõa çerueja. Bem servido: (b2v, 17) Empero diz auiçena que se homem quiser dormir ha de beber hũa bõa vez de vinho ou çerueja ante de dormir. I $\left(\mathbf{b} 2^{\mathbf{v}}, \mathbf{2 0 )}\right.$ \& estes maaos humores se lançam fora per tomar hũa bõa vez de vinho boõ ou bõa çerueja. 
Desejável: $\left(\mathbf{a 4}^{\mathrm{v}}, \mathbf{1 0}\right)$ E por tanto digo que a tal doente de pestilençia he boõ per alguũs dias mudar a camera $\mid\left(\mathbf{a 4}^{\mathrm{v}}, \mathbf{2 0}\right)$ pola qual cousa boõ he ao saão em tempo da pestilençia quando venta vento sul estar em casa per todo o dia $\mid(\mathbf{a 6}, 24)$ \& ysso meesmo he muyto boõ ameude lauar as maãos com augoa \& vinagre. $\mid\left(\mathrm{a}^{\mathrm{v}}, 2\right)$ \& tambem he boõ assi em ho inuerno como no veraão cheirar cousas azedas. Considerável: $(\mathbf{a} 4 \mathrm{v}, \mathbf{2 3})$ \& se for neçessario que saya este em casa atee que saya o sol \& suba huũ boõ espaço sobre o nosso orizonte. $\square$ De aspecto normal: (a3v, 16-17) \& jsto porque apareçem bõas ourinas \& boõas augoas. \& bõas digestiões

BOTICÁRIO. vide APOTECÁRIO.

BRAÇO. [<lat. brach um, -ii.] sm. Tipo de apêndice que se desenvolve nas laterais da parte superior do corpo humano. $\bullet$ braço, S.XIII: $\left(\mathbf{b 3}^{\mathrm{v}}, \mathbf{1 2}\right)$ E se pella ventura naçer a apostema de bayxo do braço direyto.l (b3 ${ }^{\mathrm{v}}$, 13) sangre se em ho meo daquelle braço da vea meaã. I (b3v, 14) Se de bayxo do braço seestro ou esquerdo.I (b3v, 15) sangre se em ha vea meaã daquelle meesmo braço.। (b3v, 22)E se a apostema for em ho pescoço. seja sangrado em a vea de çephalica açerca do dedo polegar em a maão daquelle meesmo lado. ou na meaã daquelle meesmo braço. I (b4, 13) emto $m$ ha de menuyr o sangue em a parte crucifixa que he a parte contrayra. porque se apareçer despois em o braço direyto:l $(\mathbf{b} 4,14)$ que se sangre em o braço esquerdo do figado: ou basilica: ou da meaã. I $(\mathbf{b 4}, \mathbf{1 6 )}$ E se apareçer a apostema de bayxo do braço direyto: $(\mathbf{b 4}, \mathbf{1 7})$ emtom faça se como dito he do braço esquerdo

BREveMENTE. [de breve.] adv. De modo sucinto [Viterbo (II, 41) assinala a possibilidade de leitura como 'enfim', também possível no contexto em que o termo surge no Regimento]. $\bullet$ breuemente: (b2v , 10) A ysto digo breuemente que em tempo da pestilencia. logo despois de comer. se alguũ teuer desejo de dormir: que tal desejo se deue reuogar \& impedir per alguũ andar em jardijs ou em campos

BUSCAR. [or. obsc.] v. Procurar. - busquem, s.xV: $(\mathbf{b} 2, \mathbf{1})$ estas cousas busquem se pera os ricos muyto bõas salsas ou salseamentos 


\section{C}

CABEÇA. [< lat. cap $t$ um,-i.] sf. Segmento superior do corpo $\bullet$ cabeça, s.XIII: $\left(\mathbf{b}^{\mathrm{v}}, \mathbf{1 1}\right)$ \& nom consinta emtrar ho aar seco. empero contorua os olhos \& squeenta a cabeça de cada huũ que ho ameude come. I $(\mathbf{b} 3,2)$ \& ysso mesmo tem grande door em ha parte dianteira da cabeça

CADA. [<lat. cata.] pron. indef. Indica um elemento qué é parte num conjunto. $\bullet$ cada: $(\mathbf{a} 3,14) \&$ esta causa particular \& pode aconteçer cada dia. I (a6, 7) Item per esta mesma causa se deue euitar ho banho de cada dia. I $(\mathbf{b}, \mathbf{2})$ Muyto saã cousa he que se laue a boca \& os olhos \& as maãos ameude cada dia com agoa rosada mesturada com vinagre $\rightarrow$ CADA UM. Todo homem; de um em um $\bullet$ cada huũ: (bv, 11) \& nom consinta emtrar ho aar seco. empero contorua os olhos \& squeenta a cabeça de cada huũ que ho ameude come

CAído. [de cair.] sm. Enfraquecido, fraco. $\bullet$ caydos, S. XIV: $(\mathbf{a} 2,13)$ a proueyto do pouoo: por conseruaçam dos saãos: \& reformaçam dos caydos

CALAdAMENTE. [de calado.] adv. De forma silenciosa. - caladamente: (b2v, 4) porque em ho somno ha queentura intrinseca. caladamente traz a peçonha ao coraçam \& aos outros membros speciaaes

CALCANHAR. [or. obsc.] $\mathrm{sm}$. Parte posterior do pé. - calcanhar, S. XV: (b3v ${ }^{\mathrm{v}}$ 18-19) E se açerca das partes vergonçosas. sangre se em o pee daquelle mesmo lado açerca do calcanhar

CALDo. [<lat. caldus, a, um.] sm. Prato resultante do cozimento de diversos alimentos em muita água. $\bullet$ caldos: $\left(\mathrm{a}^{\mathrm{v}}, \mathbf{6}\right)$ \& daqui veem que em tal casa como esta morrem os homens mais azinha \& em outra nom como dito he mesmo onde se lançam verças \& caldos podres que sobejam em taaes casas $\mid\left(\mathbf{b}^{v}, \mathbf{1 8}\right)$ pela manhaã sejam os manjares cozidos: \& de noyte assados caldos. polmes. \& potagios se euitem: se nom forem azedos

CÂMARA. [<lat. camara,-ae.] sf. Cômodo em que se dorme. - camera: $(\mathbf{a} 3,11)$ da priuada que esta açerca da camera ou de alguũ fedor particular de alguũ canno çujo se corrompe ho aar em substançia \& qualidade $\mid(\mathbf{a} 4 \mathbf{v}, \mathbf{1 0})$ E por tanto digo que a tal doente de pestilençia he boõ per alguũs dias mudar a camera

CAMINHo. [<lat. camminus, -i.] sm. - caminho, caminho; caminhos, S.XIII. 四 Trajeto, percurso: $(\mathbf{b} 3,6)$ Posto que tal como este nom pode andar e $m$ cauallo ou besta. nem andar grande caminho por a grande pigriça do corpo \& muyto grande peso \& carrega corporal. I $\left(\mathrm{a} 6^{\mathrm{v}}, 10\right)$ as cousas azedas \& os cheyros taaes opilam \& çarram os poros \& os meatos \& os caminhos dos humores $\llbracket$ Direçâa: $\left(\mathbf{a}^{\mathrm{v}}{ }^{\mathrm{v}}\right.$, 17) \& jsto porque apareçem bõas ourinas \& boõas augoas. \& bõas digestiões. empero ho enfermo vay caminho da morte

CAMPo.[<lat. campus, -i.] sm. Espaço aberto, não edificado. - campos, campos: s. XIII: (a5, 23) \& esquiuaras todo ho fedor scilicet. de estrebarias. de campos. de ruas.l (b2v, 14) se alguũ teuer desejo de dormir: que tal desejo se deue reuogar \& impedir per alguũ andar em jardijs ou em campos

CANELA. [<fr. ant. canele.] sf. Cinnamomum zeylanicum Nees, família das Lauráceas. Canela, cinamono. Árvore de até $9 m$ de altura, originária do Ceilão, cultivada, de cascas delicadas e finas, com folhas lanceoladas, flores pequenas, amarelas, reunidas em paniculas. A casca do caule, após a secagem é amplamente usada como condimento e, em conjunto com as folhas apresenta, propriedades terapêuticas como estimulante das funções digestivas e respiratórias. Foi considerada a especiaria mais sutil (Flandrin, 1996: 492), com a propriedade de tornar as carnes mais digeríveis (Flandrin, 1996: 481). canela, S. XIV: (bv, 25) E as speçias que comuummente conuem a comer. sam gingiure. canela. cuminhos. froles de heruas cheyrosas. \& açafram 
CANO. [de cana.] sm. Cloaca. - canos, S. XIV; canno, S. XV: (a5v ${ }^{2}$ ) em algũas casas estam as agoas çujas per dous \& tres dias \& as lançam per canos \& regos soterranhos $\rightarrow$ CANO SUJo. vide CANO. $\bullet$ canno çujo: $(a 3,12)$ da priuada que esta açerca da camera ou de alguũ fedor particular de alguũ canno çujo se corrompe ho aar em substançia \& qualidade

CÂNONE. vide AVICENA.

CÁRrega. [or. obsc.] sf. Carga, peso. - carrega, s. XIII: $(\mathrm{b} 3,8)$ Posto que tal como este nom pode andar em cauallo ou besta. nem andar grande caminho por a grande pigriça do corpo \& muyto grande peso \& carrega corporal

CASA. [<lat. casa, -a.] sf. Lugar onde se mora; residência $\bullet$ casa, casas, S. XIII: $\left(\mathbf{a} 4{ }^{\mathrm{v}}, \mathbf{2 2}\right)$ boõ he ao saão em tempo da pestilençia quando venta vento sul estar em casa per todo o dia: I $\left(\mathbf{a} 4^{\mathrm{v}}, \mathbf{2 3}\right)$ \& se for neçessario que saya este em casa atee que saya o sol \& suba huũ boõ espaço sobre o nosso orizonte.l $\left(\mathbf{a 5}^{\mathrm{v}}, \mathbf{1 2}\right)$ \& por tanto se deue bem de guardar a casa: porque nom entre em ella ho aar peçonhentadol $(\mathbf{a 6}, \mathbf{2 2})$ E tambem a casa seja aguada: \& em special em o alto veraão com vinagre rosado \& folhas de vinhas. I (b, 10) Em casa sempre este fogo açeso. I $(\mathbf{a} 4,2)$ \& daquella casa morrem \& daqueloutra nom. I $\left(\mathbf{a 5}^{\mathrm{v}}, 4\right)$ \& daqui veem que em tal casa como esta morrem os homens mais azinha \& em outra nom como dito he $\mid\left(\mathbf{a} 5^{\mathrm{v}}, \mathbf{1 4}\right)$ porque ho aar apeçonhentado he humido \& faz podridom em a casa $\mid\left(\mathbf{a} 5^{\mathrm{v}}, \mathbf{1 5}\right)$ Apure se ergo \& asutileze se a casa per clara chama ou flama: I $(\mathbf{a} 6,21)$ Mas em tempo de pestilencia milhor he estar em casa que andar fora. nem he saão andar per a villa ou çidade. I (a5v, 1) em algũas casas estam as agoas çujas per dous \& tres dias I $\left(\mathbf{a}^{\mathrm{v}}, \mathbf{7}\right)$ mesmo onde se lançam verças \& caldos podres que sobejam em taaes casas. $\rightarrow$ DE CASA EM CASA. vide ANDAR.

CÁssia-Fístula. [<lat. cassia fistula.] sf. Cassia fistula Linnaeus, familia das Leguminosas. Canafístula. Árvore de até $15 \mathrm{~m}$, "nativa da Ásia e amplamente cultivada, com casca que exsuda resina adstringente, madeira pesada, de longa durabilidade, raiz febrifuga e purgativa, folhas penadas, com folílos ovados, grandes flores em longos racemos, pêndulos de efeito espetacular e béquicas, e vagens cilíndricas e compridas, com a polpa entre as sementes us. em laxantes e em confeitaria" (Houaiss) - cassiafistola: (a6v, 18) AS cousas canfortatiuas sam estas .scilicet. açafram. cassiafistola. chantagem. com todas as outras heruas que endereçam ho spirito interior

CAUSA. [ <lat. causa,-ae.] sf. Razão ou princípio que determina algo. $\bullet$ causa; causas, SÉc. XIII: (a3, 13) \& esta causa particular \& pode aconteçer cada dia.l (a3, 21) \& tambem esta causa he as vezes particular.l (a3v, 5) \& assy se geera ha pestilençia per esta causa. I $(\mathbf{a 5}, \mathbf{2 2 )}$ \& per esta mesma causa euitaras \& esquiuaras todo ho fedor . I $(\mathbf{a 6}, \mathbf{6})$ Item per esta mesma causa se deue euitar ho banho de cada dia. I $\left(\left(\mathbf{b}^{\mathrm{v}}, \mathbf{1 4}\right)\right.$ a pestilençia que veem per causa queente ameude se acreçenta. I (b2, 12) porque ymaginaçam faz causa \& perijgo. I $(\mathbf{a 5} \mathbf{v}, \mathbf{2 4})$ Item per esta meesma $\mathbf{c a}<\mathbf{u}>\mathbf{s a}$ se euite \& esquiue: todo ho inchamento do ventre que veem per muyto comer. I (a3, 3) Das causas da pestilençia. I (a3, 4) TRes sam as causas da pestilencia. I (a4, 6) A primeyra questam: digo que esto pode aqueçer por duas causas I (a3v, 23) E estas cousas sam assy ditas das causas das pestilençia. $\mid\left(\mathbf{a} 4^{v}, \mathbf{1 4}\right)$ o vento do sul teem em si duas causas de de apodrentar $(\mathbf{a} 5, \mathbf{1})$ VIstas as causas da pestilencia. agora ajamos de veer per que modo \& como se deue home $m$ de guardar da pestilencia \& preseruar se della. | $(\mathbf{a} 5, \mathbf{1 6})$ taaes deuem de euitar \& de sy esquiuar as causas de tal podridom. $\rightarrow$ POLA QUAL CAUSA. vide POR. $\rightarrow$ POR CAUSA DE. vide POR. $\rightarrow$ CAusar. $v$. Provocar. causa; causam: $\left(a^{v}, 8\right)$ Da rayz superior \& jnferior juntamente proçede quando da jmpressam celestrial corrompente ho aar. \& podridam dos corpos mortos. ou lugares çujos se causa ho morbo ou ha chagua em ho homem $\mid\left(\mathbf{a}^{\mathrm{v}}, 3\right)$ em algũas casas estam as agoas çujas per dous \& tres dias \& as lançam per canos \& regos soterranhos: em os quaaes taes agoas çujas causam grandes fedores $\mid\left(\mathrm{a}^{\mathrm{v}}, 8\right)$ \& por serem assi podres causam tal fedor \& doença que muyto empeçe

CAUSAR, vide CAUSA. 
CAVALGAR. vide CAVALO.

CAvAlo. [<lat. caballus, $-i$, 'cavalo castrado'.] sm. Equus caballus Linnaeus, 1758 (Perissodactyla, Equidae). Domesticado no Velho Mundo há milhares de anos, este mamifero era um dos principais meios de transporte utilizados pelas classes mais abastadas durante o medievo. - cauallo, s. Xv: $(\mathbf{b 3}, 6)$ Posto que tal como este nom pode andar em cauallo ou besta. $\rightarrow$ CAVAlgar. $v$. Andar em cavalo. caualgando, S.XIII: $(b 4,23)$ \& sempre antes do meo dia sera em continuo mouimento: ou caualgando: ou andando temperadamente

CEDo. [< lat. cito, 'depressa, facilmente'.] adv. Depressa. $\bullet$ çedo, S. XIII: (b4v, 1$)$ E ysso mesmo por que a apostema mais çedo \& milhor seja madura \& seja rompida faça se meezinha em tal maneira

CEFÁLICA. vide VEIA DE CEFÁLICA.

CELESTIAL. [de celeste.] adj. Referente ao(s) céu(s). - celestrial, s. XIV: (a3v, 7) Da rayz superior \& jnferior juntamente proçede quando da jmpressam celestrial corrompente ho aar. \& podridam dos corpos mortos. ou lugares çujos se causa ho morbo ou ha chagua em ho home $m \rightarrow$ sobrecelestial. adj. sobre celestial, s. XII: $(\mathbf{a 4}, \mathbf{8})$ Da parte do agente quando aquella jnfluençia sobre celestial mays dereytamente fere \& sguarda aquelle ou aquel outro. que aquelle ou aqueloutro lugar ou homem

CÉREBRo. [<lat. cerebrum,-i.] sm. Um dos me mbros prin c ip a is [q.v.] do corpo humano. - çerebro: $\left(b^{v}, 3\right)$ E em os mantijmentos guarte das cousas queentes. assi como som pigmenta \& alhos. ajnda que pigmenta purga o çerebro da freuma $\mid(\mathbf{b} 4,2)$ E se pela ventura apareçer açerca da orelha: faça se a sangria de çephalica daquelle meesmo lado. ou da vea que esta antre o dedo demostrador \& ho dedo polegar. por que muytas cousas peçonhentas nom destruam o çerebro

CEREJA. [<lat. ceresia.] sf. Fruto da cerejeira. Considerada uma fruta ácida e fria, deveria ser comida com cuidado, sempre no início das refeições, para que os demais alimentos prevenissem o indivíduo dos perigos que a cereja trazia. O Leal Conselheiro, famosa obra do soberano português D. Duarte (1423-1438), no "Regimento do estômago", também não recomendava as cerejas, por serem "vianda húmida". • çirejas, S. XV: (bv", 22) Isso mesmo se euitem todos os fructos se nom forem azedos. assi como sam çirejas. romaãs

CERRAR. [ <lat. serāre.] v. Obstruir. - çarram, s. XIII: $\left(\mathrm{a}^{\mathrm{v}}, \mathbf{9}\right)$ as cousas azedas \& os cheyros taaes opilam \& çarram os poros \& os meatos \& os caminhos dos humores $\rightarrow$ CERRADo. adj. Obstruído. çarrados; çarradas: $(\mathbf{a 4}, \mathbf{1 5})$ os corpos mays despostos a jnfirmidade \& a morte sam os corpos queentes \& que teem os poros mays largos: \& os corpos peçonhentos que tem os poros opilados: \& çarrados de mujtos humores. I $(\mathbf{a} 4 \mathbf{v}, \mathbf{1 3})$ \& as genelas ou frestas pera ho meo dia ou pera ho sul estem çarradas

CERTAMENTE. [de certo.] adv. Sem dúvida. - çertamente: $\left(\mathbf{a} 6^{v}, 13-14\right)$ Eu çertamente todos estos remédios prouey

CERVEJA. [ <lat. cerevisia, -ae.] sf. Bebida fermentada, obtida principalmente da cevada, da aveia e, desde a baixa Idade Média, aromatizada com lúpulo. - çerueja, S. XV: $(\mathbf{b}, \mathbf{1 7})$ a triaga te he muyto proueytosa: assi saãos como aos enfermos. toma se ergo duas vezes no dia com boõ vinho claro \& auguado. ou com augoa crara de rosas ou com çerueja crara. I $(\mathbf{b}, \mathbf{1 9 )}$ \& do vinho ou augoa ou çerueja tomaras quantidade de duas colhares.l (b2, 24) \& despois que a vea for ferida ou aberta aproueyta muyto tomar muyto prazer. beber muy boõ vinho ou bõa çerueja. I (b2v, 17) Empero diz auiçena que se homem quiser dormir ha de beber hũa bõa vez de vinho ou çerueja ante de dormir. I (b2v, 21) porque o homem estando em o somno traz em si muytos vapores. \& estes maaos humores se lançam fora per tomar hũa bõa vez de vinho boõ ou bõa çerueja

CÉU. [<lat. caelus,-i.] sm. Conjunto formado pelo espaço e pelos corpos celestes, tomado ora como uno, ora como subdivisivel em vários, em oposição ao céu dos bem-aventurados e santos. $\bullet$ çeeo; çeos, S.XIV: $(\mathbf{b}, 12)$ Em casa 
sempre este fogo açeso. porque clarifica muyto ho aar \& poõe grande impedimento aa maa influencia do çeeo. I $(\mathbf{a} 3, \mathbf{2 3})$ Da rayz superior veem \& aconteçe a pestilençia per virtude dos corpos de çima dos çeos. I $\left(\mathbf{a 3}^{\mathrm{v}}, \mathbf{2}\right)$ ligeyramente se empeçonhentam os corpos da jndisposiçam ou da maa desposiçam dos çeos. I $\left(\mathrm{a}^{\mathrm{v}} \mathrm{,}, 3\right)$ por ha empressam dos çeos corrompe ho aar

CHAFARIz. [<ár.sihrig, 'cisterna, tanque'.] sm. Fonte pública. - chafarizes, s. XIV: (a3, 19) As vezes jsso mesmo veem de corpos mortos. ou de corrupçom de pauees \& charcos ou chafarizes çujos podres \& federentos

CHAGA . [<lat. plaga,-ae.] sf. Ferida aberta, úlcera. - chaga, chagas, s. XIII; chagua: (b3v, 10) \& sempre naquella meesma parte do corpo: em a qual ha doença ou chaga apareçer se deue de sangrar \& abrir a vea. I $\left(\mathrm{a}^{\mathrm{v}}{ }^{\mathrm{N}}, \mathbf{1 1}\right) \mathrm{Da}$ rayz superior \& jnferior juntamente proçede quando da jmpressam celestrial corrompente ho aar. \& podridam dos corpos mortos. ou lugares çujos se causa ho morbo ou ha chagua em ho homem $\mid(\mathbf{b} 4, \mathbf{1 1})$ E se pella ventura sentir chagas despois de dormir: emtom ha de menuyr o sangue em a parte crucifixa que he a parte contrayra

CHAMA. [<lat. flamma,-ae.] sf. Fogo. - chama, s.XIII: $\left(\mathbf{a 5}^{\mathrm{v}}\right.$, 16) Apure se ergo \& asutileze se a casa per clara chama ou flama

CHAMAR. [ <lat. clamāre.] v. Denominar. - chamam; chamada, s. XIII: (b4v', 11) Tomaras hũa herua que chamam barbajouis. \& outro que chamam serpillo que acharas ao boticairo. I $(\mathbf{b} 4,4)$ ou da vea que he açerca do dedo menor: ou açerca do articulo que he de muytos medicos chamada basilica. | (b4, 8) E se for em o espinhaço mingua sobre a vea que he chamada a pedica grande

CHANTAGEM. [<lat. plantago, -imis.] sf."Eroa, de que há muitas especies. Nace em lugares frescos, E sombrios; tem virtude adstringente, $\mathcal{E}$ desecativa, $\&$ he soberano remedio para muitos males" (Bluteau: II, 272). chantagem: $\left(\mathrm{a}^{\mathrm{v}}, \mathbf{1 8}\right)$ AS cousas canfortatiuas sam estas .scilicet. açafram. cassiafistola. chantagem. com todas as outras heruas que endereçam ho spirito interior. I (b4v, $\mathbf{1 2 - 1 3 )} \&$ ysso mesmo toma chantagem \& siligem (vay te ao boticayro) \& pisa todo muyto bem atee que vejas que quer pareçer que say destas cousas assy pisadas augoa ou çumo

CHARco. [or. obsc.] sm. Água parada em depressâo pouco profunda. $\bullet$ charcos, s.xIV: (a3, 18) As vezes jsso mesmo veem de corpos mortos. ou de corrupçom de pauees \& charcos ou chafarizes çujos podres \& federentos

CHEIO. [<lat. plenus, a, um.] adj. Repleto. chea; cheo; cheos, S. XIV: (a2v, 2) Primeiro quando em huũ dia do estio \& do alto veraão se muda a manhaã muytas vezes. em modo que de manhaã pareçe chuuosa \& chea neuoa. \& depois ventosa. I $\left(\mathbf{b 2} \mathbf{2}^{\mathrm{v}}\right.$, 24) A ysto te respondo que o homem que em tal dia he apeçonhentado nom come mujto. porque he cheo de maos humores. $\mid(\mathbf{a} 6,1)$ os corpos cheos dos maaos humores sam mais asinha empeçonhentados

CHEIRAR. vide CHEIRO.

CHEIRo. [de cheirar.] sm. Odor, aroma. - cheyro, S.XIII: (a5v, 9) E assi como per ho boõ cheyro \& aromatico: se recrea o coraçom \& o sprito do home $m$. assi emfraqueçe per o çujo fedor.I $\left(\mathbf{b}^{\mathrm{v}}, 7\right)$ melhor me pareçe soo a cousa amargosa que queentura cheyro \& sabor. $\bullet P l$. cheyros, s.XII. Substâncias aromáticas: $(\mathbf{a} 6 \mathrm{v}, 9)$ porque as cousas azedas \& os cheyros taaes opilam \& çarram os poros \& os meatos $\&$ os caminhos dos humores \& nom consintem entrar as cousas peçonhentas. $\rightarrow$ CHEIRoso. adj. De cheiro agradável. - cheyrosas: $\left(\mathbf{b}^{\mathrm{v}}, \mathbf{2 6}\right) \mathrm{E}$ as speçias que comuummente conuem a comer. sam gingiure. canela. cuminhos. froles de heruas cheyrosas. \& açafram. $\rightarrow$ CHEIRAR. v. Aspirar. $\bullet$ cheirar; cheyrar, s.XIII: (a6 ${ }^{v}$, 2) \& tambem he boõ assi em ho inuerno como no veraão cheirar cousas azedas. $\mid\left(\mathbf{a}^{v}\right.$, 1) \& ysso meesmo he muyto boõ ameude lauar as maãos com augoa \& vinagre. \& alimpar o rostro \& despois cheyrar as maãos 
CHEIROSO. vide CHEIRO.

CHuvoso. [de chuva.] adj. Com chuva. chuuosa; chuuoso: (a2v, 2) muda a manhaã muytas vezes. em modo que de manhaã pareçe chuuosa \& chea neuoa. I $(\mathbf{a} 6,19)$ \& ysto seja mayormente em tempo de neuoeiro \& chuuoso. $\rightarrow$ CHOVER. v. Cair água da atmosfera. $\bullet$ chouuer; choue, S.XIII: (a2v, 7) Segundo sinal he quando em tal estio muytas vezes escureçem: ou pareçem escureçer os dias em modo que pareçe que quer chouler e nom choue

CHOVER. vide CHUVOSO.

CIDADE. [<lat. civitas, -atis.] sf. Concelho que tinha por cabeça uma vila acastelada, assento episcopal e alvará do soberano que the concedesse as regalias de cidade (Viterbo, II:100-101) [cf. VILA.] - çidade, S. XIII: (a2v, 17) A morte se ensanha ha çidade se filha \& toma dos jmigos. I $(\mathbf{a 6}, 22)$ Mas em tempo de pestilencia milhor he estar em casa que andar fora. nem he saão andar per a villa ou çidade

CIMA. [<lat. cyma.] sf. Cume, cimo. $\bullet$ çima, s.XIII. $\rightarrow$ DE cIMA. Do alto. $\bullet$ de çima: $(a 3,23)$ Da rayz superior vee $m$ \& aconteçe a pestilençia per virtude dos corpos de çima dos çeos. $\rightarrow$ EM cIMA DE. Sobre. $\bullet$ e $m$ çima: $\left(\mathbf{b} 4^{\mathrm{v}}, \mathbf{2 1}\right)$ Item quando a postema primeyro apareçer. tome auelaãs. figos passados \& aruda \& tudo bem pisado: pom lho em çima da apostema

CIRURGião. [<.lat. "chirurgianus, '(médico) que trabalha com as mãos'.] sm. Médico que "com as operaçoens da mão cura chagas, feridas, \& outras doenças do corpo humano" (Bluteau, II:328) [cf. FísICO, MÉDICO.] - çirogiaães, S.XV: $\left(\mathbf{b}^{\mathrm{v}}, \mathbf{5}\right)$ Toma folhas de sabugo pisadas \& com mostarda pisada \& faze emprasto. \& despois poõe tudo na apostema. posto que alguũs çirogiaães querem que lhe ponham triaga mas eu rogo mujto que se nom ponha

ClARo. [<lat. clarus, -a, -um.] adj. • claro, clara, s. XIV; crara. 1 Com pouca fumaça: $\left(\mathbf{a} 5^{v}, \mathbf{1 6}\right)$ \& faça se fogo claro de lenha. I $\left(\mathbf{a 5}^{\mathrm{v}}, \mathbf{1 6}\right)$ Apure se ergo \& asutileze se a casa per clara chama ou flama $\mathbb{1}$ Diluido em água: $(b, 16)$ toma se ergo duas vezes no dia com boõ vinho claro \& auguado. $(\mathbf{b}, 16)$ ou com augoa crara de rosas I $(b, 17)$ ou com çerueja crara. Que se opóe a escuro: ou com augoa crara de rosas ou com çerueja crara. $\rightarrow$ Clarificar. v. Purificar. Oclarifica: $(\mathbf{b}, 11)$ Em casa sempre este fogo açeso. porque clarifica muyto ho aar \& poõe grande impedimento aa maa influencia do çeeo

CLISTER. [<lat. clyster,-eris.] sm. Introdução de líqüido pelo ânus. - cristel: (b, 8) E tambem he grande remedio vazar o ventre \& se o ventre naturalmente se nom poder vazar. toma huũ cristel

COBRIR. [<lat. cooperire.] v. Ocultar. - cobre, S. XIII: $\left(\mathbf{a} 2^{\mathrm{v}}{ }^{,} \mathbf{1 8}\right)$ A morte se ensanha ha çidade se filha \& toma dos jmigos. ho mar se faz cruel. \& ho sol se cobre .scilicet. de nuueens

coITo. [<lat. coitus,-us.] sm. Cópula. - coyto, s. XIV: $(\mathbf{a 4}, \mathbf{1 8 )}$ E por tanto dos quaaes se faz ha grande resoluçam assy como sam os corpos desordenados em luxuria \& coyto. I (a5, 16-17) \& por ysso quanto for possiuel taaes deuem de euitar \& de sy esquiuar as causas de tal podridom. E per conseguinte todo o coyto \& toda luxuria

COLHER. [<fr. cullière.] sf. Unidade de medida equivalente ao que pode ser contido numa colher. Na Idade Média, as colheres (ao contrário dos garfos, que seriam incomuns ainda no século XVI) já eram conhecidas, embora pouco utilizadas (Marques, 1964: 19; Arnaut, [1967]: 69-70). $\bullet$ colhares, S XIV: (b, 20) \& do vinho ou augoa ou çerueja tomaras quantidade de duas colhares

coM. [lat. cŭm.] prep. - com; com: $(\mathbf{a} 4,19)$ \& os homens que se muyto esqueentam com grande trabalho ou grande yra. I $\left(\mathrm{a}^{\mathrm{v}}, \mathbf{1 7}\right) \&$ faça se tambem com fumo de boõas heruas aqui scriptas $\mid\left(\mathbf{a} 5^{\mathrm{v}}, 20\right) \& \mathrm{com}$ lenho de aloes que he melhor de tudo I $(\mathbf{6} 6,16)$ quando se alguũ aleuantar logo coma da aruda lauada 
em agoa limpa espargida com sal \& noz nozcada I (a6, 23) E tambem a casa seja aguada: \& em special em o alto veraão com vinagre rosado \& folhas de vinhas.l $(a 6,25)$ \& ysso meesmo he muyto boõ ameude lauar as maãos com augoa \& vinagre. I $\left(\mathbf{a}^{\mathrm{v}}\right.$, 18) AS cousas canfortatiuas sam estas .scilicet. açafram. cassiafistola. chantagem. com todas as outras heruas que endereçam ho spirito interior. I (b, 2) Muyto saã cousa he que se laue a boca \& os olhos \& as maãos ameude cada dia com agoa rosada $\mid$ (b, 3) mesturada com vinagre. | (b, 4) \& se estas cousas nom poder auer faça se com vinagre. $\mid(\mathbf{b}, \mathbf{1 5})$ toma se ergo duas vezes no dia com boõ vinho claro \& auguado. $(\mathbf{b}, \mathbf{1 6})$ ou com augoa crara de rosas | $(\mathbf{b}, 17)$ ou com çerueja crara. | (b, 24) E ysso meesmo deues de comer boõ manjar \& bõa yguaria com boõ vinho puro \& ameude. $\left(\mathbf{b}^{v}, 26\right) \&$ com estas cousas busque $m$ se pera os ricos muyto bõas salsas ou salseamentos. I (b2, 3) porque se forem pobres contentem se com arruda \& salua. I (b2, 4) noz nozcadas. pere $<x>$ il \& todo misturado com vinagre faz muy bõa salsa $\mid(\mathbf{b} 2,6)$ E se nom forem muyto pobres: tomem cuminhos \& açafram \& misturem tudo com vinagre. | $(\mathbf{b} 2, \mathbf{1 3})$ mas qualquer com muyto prazer \& alegria sempre espere de muyto viuer.l $(\mathbf{b 4}, \mathbf{5 )}$ E se polla ventura for açerca das espadoas: minguaras o sangue com ventosas. $\left(\mathbf{b} 4^{\mathrm{v}}\right.$, 3) Toma folhas de sabugo pisadas \& com mostarda pisada \& faze emprasto. $\mid\left(\mathbf{b} 4^{\mathrm{v}}, \mathbf{1 6}\right)$ emtom toma aquelle çumo \& mistura ho com leyte de mulher $\mid\left(\mathbf{b} \mathbf{4}^{\mathrm{v}}\right.$, 17) \& da ho a beber aquelle que teuer a postema. \& ysto com o estamago gejuũ. I (b4v ${ }^{\text {, }} \mathbf{2 3 )}$ \& qualquer que se per este modo reger escapara muytos perijgos da pestilencia com virtude \& meezinha de nosso senhor jesu christo

COMEÇAR. [<lat. * cominitiare.] v. Iniciar. - começa, S. XIII: $(\mathbf{a} 2,1)$ Começa se huũ boõ regimento muyto neçessario \& muyto proueitoso aos viuentes

COMER. [lat. comedere.] 0 v. Ingerir alimentos sólidos. $\bullet$ comer; come; coma: (b, 23) E ysso meesmo deues de comer boõ manjar \& bõa yguaria com boõ vinho puro \& ameude.l $\left(\mathbf{b}^{\mathrm{v}}\right.$, 10) ysso mesmo o alho posto: alimpe da freuma \& lança fora os maaos humores. \& prouoca o apetito de comer $\mid\left(\mathbf{b}^{v}, 25\right)$ $\mathrm{E}$ as speçias que comuummente conuem a comer. sam gingiure. canela. cuminhos. froles de heruas cheyrosas. \& açafram. I (b2, 22) Faça se ergo a sangria em a vea destra ou seestra ante de comer. I (b2 ${ }^{\mathrm{v}}$, 15) tal desejo se deue reuogar \& impedir per alguũ andar em jardijs ou em campos. em modo que o somno natural se possa tomar per hũa hora despois de comer. I $(\mathbf{a} 6, \mathbf{1})$ Item per esta meesma ca<u>sa se euite \& esquiue: todo ho inchamento do ventre que veem per muyto comer. I $\left(\mathbf{b} 2^{\mathrm{v}}, \mathbf{2 5}\right)$ \& logo despois de comer tem desejo de dormir. I

$\left(b^{v}, 12\right) \&$ nom consinta emtrar ho aar seco. empero contorua os olhos \& squeenta a cabeça de cada huũ que ho ameude come. I $\left(\mathbf{b} 2^{\mathrm{v}}, \mathbf{2 4 )}\right.$ A ysto te respondo que o homem que em tal dia he apeçonhentado nom come mujto $\mid(\mathbf{a 6}, \mathbf{1 5})$ quando se alguũ aleuantar logo coma da aruda lauada em agoa limpa espargida com sal \& noz nozcada I $(\mathbf{a 6}, 17)$ E ysto nom poder auer, emtam coma paão ou hũa sopa molhada em vinagre. I [II] sm. Ingestão de alimento. - comer; $(\mathbf{b} 3,4)$ mas todas estas cousas pode muyto bem euitar \& de sy lançar andando ou espaçando huũ pouco antre ho comer \& o dormir

COMETA. [<lat. cometa,-ae.] sf. "Astro formado de uma mistura de gelo, rochas e pó, envolto por uma camada gasosa, que orbita ao redor so Sol" (Delerue, 1999: 76) - cometa, S. XIV: (a2v, 12) Quarto sinal he quando ha cometa pareçe voar. I (a2v, 14) quando ha cometa apareçe aconteçem mortes de gentes em bathalhas \&c. I $\left(\mathrm{a} 2^{\mathrm{v}}, \mathbf{1 6}\right)$ \& por isso diz ho verso poetico falando do apareçimento da cometa

Comigo. [<lat. cum mecum.] pron. pess. Em minha companhia, em meu poder. commigo: $\left(\mathbf{a} \mathbf{6}^{\mathrm{v}}, \mathbf{6}\right.$ ) \& emtam leuaua commigo huũa sponja ou paão enssopado em vinagre

CominHo. [<lat. cuminum,-i.] sm. Cuminum cyminum Linnaeus, família das Umbelíferas. Planta herbácea originária do Egito, cultivada. Tem folhas estreitas, flores pequenas, brancas ou róseas, formando umbelas. Seus frutos são oblongos e aromáticos, e as sementes são de uso tradicional na culinária como tempero. Essa especiaria já aparece em documentos de 1269, à venda numa das feiras medievais, em Coimbra. O cominho foi classificado como tempero de segundo grau de calor [vide DIGESTÃO]. - cuminhos: $\left(\mathbf{b}^{\mathrm{v}}, \mathbf{2 5 - 2 6 )} \mathrm{E}\right.$ as speçias que comuummente conuem a comer. sam gingiure. canela. cuminhos. froles de heruas cheyrosas. \& 
açafram.l $(\mathbf{b} 2,5)$ E se nom forem muyto pobres: tomem cuminhos \& açafram \& misturem tudo com vinagre

como $^{1}$ [<lat. quomo de quomodo.] adv. De que maneira. - como, s. xIII: (a5, 2) VIstas as causas da pestilencia. agora ajamos de veer per que modo \& como se deue homem de guardar da pestilencia \& preseruar se della. I $\left(\mathbf{b} 2^{v}, 21\right)$ Mas diras tu. como sintira homem que está apeçonhentado \& ferido da pestilençia

$\mathrm{COMO}^{2}$ [<lat. quomo de quomodo.] conj. Da mesma forma que. - como, s. XIII: (a5v, 4) \& daqui veem que em tal casa como esta morrem os homens mais azinha \& em outra nom como dito he $1(\mathrm{a} 5,19)$ Fechem se ergo as frestas ou genelas como dito he $I(\mathbf{b} 4,16)$ E se apareçer a apostema de bayxo do braço direyto: emtom faça se como dito he do braço esquerdo. $\rightarrow$ ASSIM COMO. vide ASSIM. $\rightarrow$ TAL COMO. vide TAL.

COMPANHEIRO. vide COMPANHIA.

COMPANHIA [<lat. * compania.] sf. Reunião de pessoas. - companhia, S. XV: (a6, 12) E quando assi for que companhia \& ajuntamento de pouoo se euite. I (a6v, 4) Em monpilher nom me pude escusar de companhia de gente. $\rightarrow$ companHEIro. sm. Aquele que participa de dada atividade com outra pessoa. companheiros, S.XIV: $\left(\mathrm{a}^{\mathrm{w}} \mathrm{v}, 12\right)$ \& assi escapey de tal pestilencia. que os meos companheiros nom podiam creer que eu podesse viuer \& escapar

COMPRAR. [<lat. comperare.] v. Adquirir. comprar, s.XIII: $\left(\mathbf{a 5}^{\mathrm{v}}, \mathbf{2 2 )} \&\right.$ com lenho de aloes que he melhor de tudo posto que se nom pode comprar por pequeno preço

COMUMENTE. [de comum.] adv. De ordinário; quase sempre. - comuummente: $\left(b^{v}, 24\right)$ E as speçias que comuummente conuem a comer. sam gingiure. canela. cuminhos. froles de heruas cheyrosas. \& açafram

COMUNIDADE. [<lat. comunitas, -atis.] sf. Ação ou evento em grupo. comunidade: $(\mathbf{a 6}, \mathbf{9})$ onde finalmente digo que toda multidom de pouoo \& comunidade em tal tempo se deue de euitar em quanto for possíuel

CONFESSAR. [<lat. confessare.] v. Revelar os próprios pecados em confissão. - confessar, s. XIII: (a5, 7) primeiro se deue o homem de afastar do mal \& inclinar se ao bem .scilicet. que homem primeiramente ha de confessar seus pecados humildosamente. $\rightarrow$ confissão. sf. Ato de confessar. - confissam, S. XIII: $(\mathbf{a}, \mathbf{1 0})$ grande remedio he em tempo da pestilençia a sancta penitencia \& a confissam

CONFISSÃO. vide CONFESSAR.

CONFORMIDADE. [de conforme.]. sf. Remédio fortificante. - conformidades: (a2, 19) Quarto das conformidades do coraçam: \& dos prinçipaes membros. I $\left(\mathbf{a}^{\mathrm{v}}{ }, 15\right)$ Das conformidades do coraçam \& dos outros membros

CONFORTATIVo. [<lat. confortativus, $-a,-u m$.] adj. Revigorante, fortificante. $\bullet$ canfortatiuas: $\left(\mathbf{a} 6^{\mathrm{v}}\right.$, 17) AS cousas canfortatiuas sam estas scilicet. açafram. cassiafistola. chantagem. com todas as outras heruas que endereça $m$ ho spirito interior

CONHECER. [<lat. cognoscere.] v. Saber; identificar. - conheçem; conheça: (a3, 16) muytos medicos sam emganados. porque nom conheçem taes febres serem pestilençiaes. I (b4, 9) E todas estas cousas se façam se homem nom dormir antes que conheça que tem a postema

CONSEGUINTE. vide POR CONSEGUINTE. 
CONSENTIR. [<lat. consentire.] v. Permitir. - consintem; consinta, S. XIII: (a6 $\left.{ }^{\mathrm{v}}, \mathbf{1 0}\right)$ as cousas azedas \& os cheyros taaes opilam \& çarram os poros \& os meatos \& os caminhos dos humores \& nom consintem entrar as cousas peçonhentas. $\mid\left(b^{v}, 10\right) \&$ nom consinta emtrar ho aar seco. empero contorua os olhos \& squeenta a cabeça de cada huũ que ho ameude come

CONSERVAÇão. [<lat. conservatio,-onis.] sf. Preservação; manutenção. $\bullet$ conseruaçam: $(\mathbf{a} 2,2)$ Começa se huũ boõ regimento muyto neçessario \& muyto proueitoso aos viuentes. \& per conseruaçam de suas saudes \& segurança das pestinençias. I (a2, 9) EM louuor da santissima trijndade. \& da gloriosa virgem maria \& a proueyto do pouoo: por conseruaçam dos saãos: \& reformaçam dos caydos

Contagioso. [<lat. contagiosus,-a, um.] adj. Transmissível. - contagiosas, s. XV: (a4, 23) A segunda questam digo que taaes infirmidades pestilençiaaes sam contagiosas \& apegam se muy asinha. | (a4, 4) Se taaes jnfirmidades pestilençiaes sam contagiosas .scilicet. se se apegam

CONTENTAR. [<lat. contentare.] v. Satisfazer. - contentem, s. XV: $(\mathbf{b} 2,2-3)$ porque se forem pobres contentem se com arruda \& salua

Contínuo. [ <lat. continuus, $-a,-u m$.] adj. Continuado, ininterrupto. - continuo, s. XV: (b4, 22-23) E despois do sangue menuido se for muyto fraco emtom podera dormir despois do meo dia. \& sempre antes do meo dia sera em continuo mouimento

CONTORVAR. vide CONTURBAR.

CONTRÁRIO. [<lat. contrarius, $-a$, um.] adj. Contralateral. $\bullet$ contrayra, s. XIII: $(\mathbf{b} 4, \mathbf{1 2})$ E se pella ventura sentir chagas despois de dormir: emtom ha de menuyr o sangue em a parte crucifixa que he a parte contrayra. $\rightarrow$ EM CONTRÁrio. Contradizente. em contrayro, S. XIII: $(\mathbf{b} 2,18)$ SAngria huũa vez em huũ mes se pode bem fazer. se nom se a ydade ou outra cousa for em contrayro

CONTURbar. [lat. conturbare.] v. Perturbar $\bullet$ contorua, S. XIII: $\left(b^{v}, 11\right) \&$ nom consinta emtrar ho aar seco. empero contorua os olhos \& squeenta a cabeça de cada huũ que ho ameude come.

Convir. [<lat. convenire.] v. Ser adequado, conveniente. $\bullet$ conuem, S.XIII: $\left(b^{v}, 25\right)$ E as speçias que comuummente conuem a comer. sam gingiure. canela. cuminhos. froles de heruas cheyrosas. \& açafram. I (b2, 25) \& nom conuem dormir em aquelle dia que se sangrar \& abrir a vea

copo. [<de copa.] sm. Recipiente em que se bebe [cf. VASO]. $\bullet$ copo: $(\mathbf{b}, \mathbf{2 1})$ \& a triaga seja delida em ho vaso ou copo em que ha tomares

CORAÇÃo. [or. obsc.] sm. Órgão do aparelho circulatório. - coraçam; coraçam; coraçom: (a2, 19) Quarto das conformidades do coraçam: \& dos prinçipaes membros. I $\left(\mathbf{a}^{\mathbf{v}}\right.$, 15) Das conformidades do coraçam \& dos outros membros.l $\left(\mathrm{a} 4^{\mathrm{v}}, \mathbf{1 9}\right)$ Ho sul he vento inchado \& agraua o ouuido fere o coraçam. I (a4 ${ }^{\mathrm{v}}$, 20) porque abre os poros do homem \& emtra atee o coraçam. I (b2v, 5) porque em ho somno ha queentura intrinseca. caladamente traz a peçonha ao coraçam \& aos outros membros speciaaes.l (a3 ${ }^{\mathrm{v}}$, 12) porque ho aar jnspirado as vezes he peçonhento: \& assy corrupto feere ho coraçom.I (b2, 8) $\mathrm{E}$ tambem a alegria do coraçom he gram remedio pera a saude do corpo.I $\left(\mathbf{a 5}^{\mathrm{v}} \mathbf{\mathrm { v }} \mathbf{1 0}\right)$ E assi como per ho boõ cheyro \& aromatico: se recrea o coraçom \& o sprito do homem

CORPo. [<lat. corpus,-oris.] sm. corpo; corpos. 1 Organismo: $(\mathbf{b}, 22) \&$ nom jantaras atee ho meo dia porque possa a triaga em o corpo fazer sua operaçam.l $(\mathbf{b} 2, \mathbf{9 )}$ E tambem a alegria do coraçom he gram remedio pera a saude do corpo.I $(\mathbf{b} 3,7)$ Posto que tal como este nom pode andar em cauallo ou besta. nem andar grande caminho por a grande pigriça do corpo \& muyto grande peso \& carrega corporal । $\left(a 3^{v}, 1\right)$ ligeyramente se empeçonhentam os corpos da jndisposiçam ou da maa desposiçam dos çeos. I $(\mathbf{a} 4,12) \&$ por tanto deues de notar que os corpos mays despostos a jnfirmidade \& a morte $\mid(\mathbf{a} 4, \mathbf{1 3})$ 
sam os corpos queentes \& que teem os poros mays largos: $(\mathbf{a 4 , 1 4 )} \&$ os corpos peçonhentos que tem os poros opilados: \& çarrados de mujtos humores. I (a4, 17) E portanto dos quaaes se faz ha grande resoluçam assy como sam os corpos desordenados em luxuria \& coyto. I (a4, 20) \& os homens que se muyto esqueenta $m$ com grande trabalho ou grande yra. teem os corpos mais dispostos pera reçeber ha pestilencia. I (a4, 24) A segunda questam digo que taaes infirmidades pestilençiaaes sam contagiosas \& apegam se muy asinha. porque dos corpos apeçonhentados procedem humores \& fumos peçonhentos I $\left(a 4^{v}, 15\right)$ A primeyra que faz emfraqueçer os corpos assi dos saãos como dos enfermos.l (a6, 1) os corpos cheos dos maaos humores sam mais asinha empeçonhentados. I $(\mathbf{a} 3,18)$ As vezes jsso mesmo veem de corpos mortos. I ( $\mathrm{a}^{\mathrm{v}}, \mathbf{7-8)}$ Da rayz superior \& jnferior juntamente proçede quando da jmpressam celestrial corrompente ho aar. \& podridam dos corpos mortos. ou lugares çujos se causa ho morbo ou ha chagua em ho homem $\mid(\mathbf{a} 5,24)$ \& per esta mesma causa euitaras \& esquiuaras todo ho fedor scilicet. de estrebarias. de campos. de ruas. \& em special donde ha hi corpos mortos \& podres. [1] Matéria celeste: $(\mathbf{a} 3,23)$ Da rayz superior veem \& aconteçe a pestilençia per virtude dos corpos de çima dos çeos. $\rightarrow$ corporal. adj. Relativo a corpo. - corporal: $(b 3,8)$ Posto que tal como este nom pode andar em cauallo ou besta. nem andar grande caminho por a grande pigriça do corpo \& muyto grande peso \& carrega corporal

CORPORAL. vide CORPO.

CORRENÇA.[de correr.] sf. Diarréia. • corrença, S. xV: (b2, 20) SAngria huũa vez em huũ mes se pode bem fazer. se nom se a ydade ou outra cousa for em contrayro. assy como he em as molheres que som prenhes. ou em alguũ muyto fraco. scilicet. em alguũ que teem corrença ou fluxu do ventre

CORROMPENTE. vide CORROMPER.

CORROMPER. [<lat. corrumpere.] v. Apodrecer, deteriorar. - corrompe; corrompem, s. XIV: (a3, 12) Da rayz jnferior proçede segundo nos veemos que da priuada que esta açerca da camera ou de alguũ fedor particular de alguũ canno çujo se corrompe ho aar em substançia \& qualidade. I $\left(a^{3}{ }^{v}, 3\right)$ ha empressam dos çeos corrompe ho aar. I $\left(\mathbf{a}^{\mathrm{v}}, 4\right)$ \& ha empresam do aar corrompe os spiritos vitaes em ho homem | $(\mathbf{a} 3,24)$ Da rayz superior veem \& aconteçe a pestilençia per virtude dos corpos de çima dos çeos. dos quaaes se corrompem os spiritos vitaes em ha creatura viuente.l (a4, 25) porque dos corpos apeçonhentados procedem humores \& fumos peçonhentos que corrompe $m$ ho aar. $\rightarrow$ CORROMPENTE. part. pres. Que corrompe. corrompente: $(\mathrm{a} 3 \mathrm{v}, 7)$ Da rayz superior \& jnferior juntamente proçede quando da jmpressam celestrial corrompente ho aar. $\rightarrow$ Corrupto. adj. Podre. - corrupto; corruptos: (a3v, 12) porque ho aar jnspirado as vezes he peçonhento: \& assy corrupto feere ho coraçom. I (a3, 21) \& esto aconteçe muytas vezes onde ha lugares podres \& corruptos. $\rightarrow$ CORRUPÇão. sf. Putrefação. $\bullet$ corrupçom: $(\mathbf{a} 3,18)$ As vezes jsso mesmo veem de corpos mortos. ou de corrupçom de pauees \& charcos ou chafarizes çujos podres \& federentos

CORRUPÇÃO. vide CORROMPER.

CORRUPTO. vide CORROMPER.

CORTAR. [<lat. curtare.] v. Seccionar. - cortar: $\left(\mathbf{b} 3^{v}, 2\right)$ \& se homem nom quiser cortar muytas veas juntamente: emtam leyxe yr a vea aberta ou ferida atee o retardamento do sangue

cousA. [<lat. causa,-ae.] sf. - cousa; cousas. Razão, causa: $(\mathbf{a} 2,13)$ Quero algũas cousas da pestenença que nos ameude fere: dos ditos dos mays autenticos medicos: screuer.। $(\mathbf{a 2}, \mathbf{1 7})$ Dos signaes pronosticos da pestilençia. Segundo das cousas della. Matéria indeterminada: (bv $\left.{ }^{v}, 7\right)$ melhor me pareçe soo a cousa amargosa que queentura cheyro \& sabor. I (Muyto saã cousa he que se laue a boca \& os olhos \& as maãos ameude cada dia com agoa rosada mesturada com vinagre. I E estas cousas sam assy ditas das causas das pestilençia. I $(\mathbf{b} 3, \mathbf{1 8})$ sy se alguem sentir apeçonhentado ou em tempo de pestilencia sentir estas cousas que escuse o somno $\mid(\mathbf{b} 3, \mathbf{1 9})$ \& assi segundo estas cousas he assaz manifesto: que 
em o tempo do somno o sprito vital repousa $\mid(\mathbf{b} 3,22)$ Estas cousas per my mesmo prouey. | (b3, 23) Estantes ergo assi estas cousas quando se homem sente ser tocado da peçonha pestilençial. logo naquelle meesmo dia mingue ho sangue $\mid(\mathbf{b} 4, \mathbf{1})$ por que muytas cousas peçonhentas nom destruam o çerebro. I $\left(\mathbf{b} 4^{v},{ }^{15}\right)$ \& pisa todo muy to bem atee que vejas que quer pareçer que say destas cousas assy pisadas augoa ou çumo. I (b4v $\mathbf{v}, \mathbf{2 1 )}$ E estas cousas abastem pera a pestilença. I $\left(\mathbf{a} 5^{\mathbf{v}}, \mathbf{2 3}\right)$ E tal fumo entre per a boca \& per os narizes. porque assi jndiramçe as cousas de dentro $\mid\left(\mathbf{a}^{v}, 3\right)$ \& tambem he boõ assi em ho inuerno como no veraão cheirar cousas azedas. I $\left(\mathbf{a} 6^{v}, 8\right)$ as cousas azedas \& os cheyros taaes opilam \& çarram os poros \& os meatos \& os caminhos dos humores $\mid\left(\mathbf{a}^{\mathrm{v}}, \mathbf{1 1}\right)$ \& nom consintem entrar as cousas peçonhentas. I $\left(\mathrm{a}^{\mathrm{v}}{ }^{\mathrm{r}}, \mathbf{1 7 )}\right.$ AS cousas canfortatiuas sam estas scilicet. açafram. cassiafistola. chantagem. com todas as outras heruas que endereçam ho spirito interior. I $\left(\mathbf{a} \mathbf{6}^{\mathrm{v}}, \mathbf{2 0}\right)$ \& estas cousas prestam pera antre pouoo $\mid\left(\mathbf{a 6}^{\mathrm{v}}, \mathbf{2 5}\right)$ Os olhos do aar empeçonhentado logo escureçem se estas cousas nom trouuer home $m$ em ha maão $\mid(\mathbf{b}, \mathbf{4})$ \& se estas cousas nom poder auer faça se com vinagre. $\mid(\mathbf{b}, \mathbf{5})$ \& assi guardando estas cousas seguramente entraras em pouoo ou amtre gente.l $\left(\mathbf{b}^{\mathrm{v}}, \mathbf{2}\right) \mathrm{E}$ em os mantijmentos guarte das cousas queentes. I $\left(\mathbf{b}^{\mathrm{v}}, \mathbf{1 9 )} \mathrm{Em}\right.$ tempo da pestilencia valem mais cousas azedas que todalas meezinhas $\mid(\mathbf{b} 2, \mathbf{1})$ estas cousas busquem se pera os ricos $\rightarrow$ A QUAL CoUSA. vide QUAL. POLA QUAL COUSA. vide POR.

CozIDo. [de cozer.] adj. Cozinhado em líquiido. - cozidos, S. Xv: $\left(\mathbf{b}^{\mathrm{v}}, \mathbf{1 7}\right)$ pela manhaã sejam os manjares cozidos

CRER. [<lat. credere.] $v$. Acreditar. $\bullet$ creer; creem: $\left(\mathbf{a 6} \mathbf{w}^{\mathrm{v}}, \mathbf{1 3 )}\right.$ assi escapey de tal pestilencia. que os meos companheiros nom podiam creer que eu podesse viuer \& escapar. I $(\mathbf{b} 3, \mathbf{1 3})$ mas se alguũ nom quiser creer: spere per huũ meo dia \& logo sentira apostema de bayxo dos braços. ou açerca das partes vergonçosas. ou açerca das orelhas. I $(\mathbf{a} 3, \mathbf{1 7})$ muytos medicos sam emganados. porque nom conheçem taes febres serem pestilençiaes. nem ho creem

CRESCENTE. vide CRESCER.

CRESCER. [<lat. crescere.] v. Desenvolver-se. $\bullet$ creçer, S. XIII: $(\mathbf{b 4}, \mathbf{2 4 )}$ E se despois creçer apostema: nom tema. $\rightarrow$ CRESCENTE. sm. Fermento (?). - creçente, S. XIII: $(\mathbf{a 6}, 7)$ Item per esta mesma causa se deue euitar ho banho de cada dia. porque pouco creçente apeçonhenta toda a massa

CRIATURA. [<lat. creatura, -ae.] sf. Ser que resulta da Criação. - creatura, S. XIII: (a3, 24) Da rayz superior veem \& aconteçe a pestilençia per virtude dos corpos de çima dos çeos. dos quaaes se corrompem os spiritos vitaes em ha creatura viuente

CRISTEL. vide CLISTER.

CRISTO. vide JESUS.

CRUCIFIxo. [<lat. crucifixus, $-\boldsymbol{a}, u m$.$] adj. Contralateral. -$ crucifixa: $(\mathbf{b} 4, \mathbf{1 2})$ E se pella ventura sentir chagas despois de dormir: emtom ha de menuyr o sangue em a parte crucifixa que he a parte contrayra

CRUEL. [< lat. crudelis,-e.] adj. Atroz. $\bullet$ cruel: $\left(\mathbf{a}^{2}\right.$, 18$)$ A morte se ensanha ha çidade se filha \& toma dos jmigos. ho mar se faz cruel

CURAR. [<lat. curare.] v. Cuidar, com vistas a restabelecer a saúde. $\bullet$ curando: $\left(\mathbf{a}^{\mathbf{v}}\right.$, 5) Em monpilher nom me pude escusar de companhia de gente. porque andaua de casa em casa curando enfermos por causa da minha pobreza 
DACIA. [<lat. Dacia.] topôn. A Dinamarca, ou Dânia (Costa Roque, 1979: 296). - dacia: (a2, 5) Feyto per ho reuerendissimo Senhor dom Raminto bispo arusiense: do regno de dacia

DALI. vide ALI.

DAQUELE. vide AQUELE.

DAQUI. vide AQUI.

DAVI. [<gr. Dauid, do hebr. dawid, 'querido, amado', pelo lat. David.] antrop. O Regimento parece seguir a tradição patrística que vê em Davi o Cristo e o grande médico (Di Berardino, 1983: 379-381). Não se trataria, por conseguinte, de algum médico famoso na Idade Média, embora tenha havido dois grandes médicos medievais com esse nome, ambos judeus e tendo vivido ambos no Cairo por volta do século XIII (um deles entre 1212 e 1300 , e o outro, entre 1161 e 1241), como mostra Costa Roque (1979:323n31). Testemunhos do Regimento em latime em francês apresentam Jeremias em lugar de Davi (Costa Roque, 1979:323n31). A versão inglesa de 1534 também difere da portuguesa, e também refere Jeremias ("wherfore ye shall note after the mynde of the natural phisition, spekyng by the mouth of theremie, that if a man will be surely cured, and haue a sure medecine, he must leaue his synnes, and confesse hym selfwith humilitie and great repentaunce" - A moche profitable treatise against the pestilence, 1534: fo. A5). Para Costa Rogue, Davi surge como uma alusão à conhecida passagem biblica da peste que cai por três dias sobre Israel, resultante de pecado cometido por Davi, e que é suspensa por Deus quando Davi Lhe constrói um altar e Lhe oferece holocaustos e sacrificios de comunhão (Samuel, I, 24 e Crônicas — que refere como Paralipômenos - I, 21), o que leva Costa Rogue a concluir que o "grande médico" seria Deus, que falaria pela boca de Davi ou do profeta Jeremias. @ dauid: $(\mathbf{a} 5,5)$ pollo qual deues de notar que segundo diz o grande medico scilicet. dauid. que primeiro se deue o homem de afastar do mal \& inclinar se ao bem

DE. [<lat. de.] prep. - de; de: $(\mathbf{a} 2,3)$ \& per conseruaçam de suas saudes| $(\mathbf{a} 3,18)$ ou de corrupçom de pauees $\mid(\mathbf{a} 4 \mathbf{v}, \mathbf{1 4})$ duas causas de de apodrentar $\mid(\mathbf{a} 6,12) \&$ ajuntamento de pouoo se euite. $\mid(\mathbf{b}, \mathbf{1 7})$ com augoa crara de rosas $\mid\left(\mathbf{b}^{\mathrm{v}}, \mathbf{2 6}\right)$ froles de heruas cheyrosas $\left.\mid \mathbf{( b 4} \mathbf{4}^{\mathrm{v}}, 3\right)$ folhas de sabugo $\mid\left(\mathbf{b} 4^{\mathrm{v}}, \mathbf{1 6}\right)$ leyte de mulher $\mid\left(\mathbf{b} 4^{\mathrm{v}}, \mathbf{2 4 )}\right.$ com virtude \& meezinha de nosso senhor jesu christo $\mid(\mathbf{a} 4 \mathbf{v}, \mathbf{9})$ a tal doente de pestilençia he boõ per alguũs dias mudar a camera: $\mid(\mathbf{a 5}, 22)$ \& esquiuaras todo ho fedor .scilicet. de estrebarias. $\mid(\mathbf{a} 5,23)$ de campos. de ruas. $\mid(\mathbf{a 5}, \mathbf{2 5}) \&$ tambem donde ha hi podridom de agoas $\mid\left(\mathbf{b} 3^{\mathrm{v}}, \mathbf{5}\right)$ pequena sayda de sangue. I $\left(a 5^{v}, 16\right)$ \& faça se fogo claro de lenha. $\left(\mathbf{a} 5^{v}, 18\right)$ baga de louro. I $\left(\mathbf{a}^{\mathrm{v}}\right.$, $19)$ \& de alosna $\mid\left(\mathrm{a}^{\mathrm{v}}, \mathbf{2 1}\right)$ \& com lenho de aloes $\mid\left(\mathrm{a} 5^{\mathrm{v}}, 24\right)$ as cousas de dentro. $\mid(\mathrm{a} 6,7)$ ho banho de cada dia. $\mid(\mathbf{a} 6,9)$ toda multidom de pouoo $\mid(\mathbf{a 6}, \mathbf{2 3})$ \& folhas de vinhas. $\mid(\mathbf{a} 2,5)$ do regno de dacia. $\mid$ $(\mathbf{a} 2,7)$ padre frey Luys de ras: I $\left(b 4^{\mathrm{v}}, \mathbf{2 7}\right)$ Valentino de morauia. I $(\mathbf{a} 2, \mathbf{8})$ ordem de sam francisco. | $\left(\mathbf{a 2}{ }^{\mathrm{v}}\right.$, 4) he ho vento meridional. ou da parte de estrela do Sul. I (a2v, 14) quando ha cometa apareçe aconteçem mortes de gentes $\mid(\mathbf{a} 3,11)$ da priuada que esta açerca da camera ou de alguũ fedor particular $\mid(\mathbf{a} 3,12)$ de alguũ canno çujo se corrompe ho aar $\mid(\mathbf{a} 3,23)$ per virtude dos corpos de çima dos çeos. I (b2 $\mathbf{2}^{\mathrm{v}}, \mathbf{1 )}$ se agrauar de apostema $\mid(\mathbf{b} 3, \mathbf{3})$ pode muyto bem euitar \& de sy lançar $\mid\left(\mathbf{a} \mathbf{6}^{\mathrm{v}}, \mathbf{4}\right)$ nom me pude escusar de companhia de gente. $(\mathbf{a} 2,5)$ E tralladado de latim em lingoagem $\mid\left(\mathbf{a} 2^{\mathrm{v}}, 8\right)$ he pera temer de vijr grande pestilençia. I $(\mathrm{a} 2 \mathrm{v}, \mathbf{1 8})$ ho sol se cobre scilicet. de nuueens. I $(\mathbf{a} 3, \mathbf{1 7})$ As vezes jsso mesmo veem $\mathrm{d} e$ corpos mortos. I $(\mathrm{a} 3,25) \& \mathrm{~d} e$ tal diz auicena I $\left(\mathrm{a} 3^{\mathrm{v}}, 21\right)$ que todo enfermo se proueja de boõ fisicol $(\mathbf{a 4}, \mathbf{1 2})$ \& por tanto deues de notar $\mid\left(\mathbf{a}^{\mathrm{v}}{ }^{\mathrm{v}}, \mathbf{1}\right) \&$ por tanto deue homem de fugir dos aares peçonhentos. I $\left(\mathrm{a} 4^{\mathrm{v}}, 3\right)$ nenhuũ nom deue de star em ajuntamento do pouoo. I $\left(\mathrm{a} 4^{\mathrm{v}},{ }^{\mathrm{r}}\right.$ ) quando visitam os enfermos deuem de star afastados delles $(\mathbf{a} 4 \mathbf{v}, \mathbf{8 )} \&$ assi ho deuem de fazer os seruidores dos enfermos.l (a5, 4) deues de notar que segundo diz o grande medicol $\left(\mathbf{b 3} 3^{\mathrm{v}}, \mathbf{1 0}\right)$ se deue de sangrar \& abrir a vea.I $(\mathbf{a} 5, \mathbf{6})$ primeiro se deue o homem de afastar do mal $\mid(\mathbf{a} 5, \mathbf{1 5})$ \& por ysso quanto for possiuel taaes deuem de euitar\& de sy esquiuar $\mid(\mathbf{a} 5,16)$ as causas de tal podridom. $\mid(\mathbf{a} 5 \mathrm{v}, 11)$ \& por tanto se deue bem de guardar a casa: $\mid(\mathbf{b}, 23)$ E ysso meesmo deues de comer boõ manjar I $(\mathbf{a 6}, \mathbf{1 0})$ 
toda multidom de pouoo \& comunidade em tal tempo se deue de euitar em quanto for possíuel. I (b2, 10) polla qual cousa deue se homem de guardar $\mid\left(\mathbf{b} \mathbf{2}^{\mathrm{v}}, \mathbf{9 )}\right.$ se o homem deue de euitar ho somno | ( (b3v, 8) em nenhũa maneyra nom deue de dormir per todo o dia atee mea noyte $\mid(\mathbf{a} 5,7)$ primeiramente ha de confessar seus pecados $\mid(\mathbf{b 4}, \mathbf{1 1})$ ha de menuyr o sangue $\mid\left(\mathbf{b} 2^{\mathrm{v}}, \mathbf{1 7}\right)$ ha de beber hũa bõa vez de vinho $\mid(\mathbf{a} 5,2)$ ajamos de veer $\mid(\mathbf{a} 5,3)$ per que modo \& como se deue homem de guardar da pestilencia | $(\mathbf{a 6}, \mathbf{1 0})$ em tal tempo se deue de euitar $\mid(\mathbf{a 4}, \mathbf{1 5})$ que tem os poros opilados: \& çarrados de mujtos humores.। $\left(\mathbf{a} \mathbf{6}^{\mathrm{v}}, \mathbf{1 2}\right)$ \& assi escapey de tal pestilencia. I $(\mathbf{a} 3,9)$ \& as vezes veem dambos de dous $\mid$ $\left(\mathbf{a} 6^{v}, 4\right)$ porque andaua de casa em casa $\mid\left(\mathrm{a}^{\mathrm{v}}, \mathbf{1}\right)$ em modo que de manhaã pareçe chuuosa \& chea neuoa. | $(\mathbf{a 6}, \mathbf{1 4})$ de manhaã | $\left(b^{v}, 17\right)$ de noyte $\mid(a 6,19)$ em tempo de neuoeiro | $(\mathbf{a 6}, 20)$ Mas em tempo de pestilencia milhor he estar em casa que andar fora.l $(\mathbf{b} 3,17)$ em tempo de pestilencia I $\left(a 6^{y}\right.$, 23) nom reçebas do baffo de outrem. $\mid(\mathbf{b}, 18)$ a quantidade de huũ piseo $\mid(b, 19)$ tomaras quantidade de duas colhares. I $\left(\mathbf{b}^{v}, 9\right)$ \& prouoca o apetito de comer $\mid\left(\mathbf{b}^{v}, 11\right)$ \& squeenta a cabeça de cada huũ que ho ameude come. I ( $\left.\mathbf{b}^{\mathbf{v}}, \mathbf{1 5}\right)$ todos os mantijmentos quanto som de mais leue digestam tanto som milhores. $\mid\left(\mathbf{b}^{v}, \mathbf{2 2}\right)$ ou huũ pequeno de pero ou maçaã $\mid\left(\mathbf{b}^{\mathrm{v}}, \mathbf{2 3}\right)$ em lugar de meezinha. $\left.\mid \mathbf{( b 2}, \mathbf{1 4}\right)$ sempre espere de muyto viuer. I (b2, 22) ante de comer. $\mid\left(\mathbf{b} 2^{\mathrm{v}}, \mathbf{1 8}\right)$ ante de dormir $\mid\left(\mathbf{b} 2^{\mathrm{v}}, \mathbf{1 1}\right) \log 0$ despois de comer. $\mid\left(\mathbf{b} 2^{\mathrm{v}}, \mathbf{2 5}^{2}\right)$ logo despois de comer. | (b2 $\left.{ }^{\mathrm{v}}, \mathbf{1 5}\right)$ per hũa hora despois de comer. $\mid$ (b4, 11) despois de dormir: I (b2v, 12) se alguũ teuer desejo de dormir:| $\left(\mathbf{b} 2^{v}, 26\right)$ tem desejo de dormir. | $(\mathbf{b} 3,9)$ em todas as horas teem grande desejo de dormir. I ( b2v, 17) ha de beber hũa bõa vez de vinho I $\left(\mathbf{b} 2^{\mathrm{v}}, \mathbf{2 0}\right)$ hũa bõa vez de vinho $\mid\left(\mathbf{b} 2^{\mathrm{v}}, \mathbf{2 4}\right)$ he cheo de maos humores $\mid(\mathbf{b} 3,21)$ peçonha espalha se per os membros de toda parte. $\mid\left(\mathbf{b}^{\mathrm{v}}, \mathbf{1}\right)$ pouco minguamento de sangue esperta a peçonha. $\mid\left(\mathbf{b 3}^{\mathrm{v}}{ }^{\mathrm{v}}, \mathbf{2 0}\right)$ a vea de çephalica | $(\mathbf{b} 3 v, 25)$ faça se a sangria de çephaliç $\mid(\mathbf{b} 4,3)$ he de muytos medicos chamada basiliçal $\left(\mathbf{b} 4^{\mathrm{v}}, \mathbf{2 4}\right) \mathrm{com}$ virtude \& meezinha de nosso senhor jesu christo. $\rightarrow$ Do. prep. + art. - da; das; do; dos, dos: $(\mathbf{a} 3,4)$ TRes sam as causas da pestilencia $\mid(\mathbf{a} 3,3)$ Das causas da pestilençia $\mid\left(\mathbf{a 2} \mathbf{v}^{\mathbf{v}}\right.$, 21) se veem da parte do meo dia $\mid(\mathbf{a} 3,5)$ as vezes vee $m$ \& proçede ha pestilencia da rayz superior. $\mid(\mathbf{a} 3,9) \&$ as vezes veem dambos de dous scilicet. da rayz superior \& da rayz jnferior juntamente. I (a2, 21) Quinto \& derradeyro da sangria. | (a2, 23) SIgnaes pronosticos da pestilencia | (a2, 7) mestre em sancta theologia da orde $m$ de sam francisco. I $\left(\mathbf{a 2}{ }^{\mathrm{v}}, 4\right)$ da parte de estrela do Sul. I (a2, 9) EM louuor da santissima trijndade. $\mid(\mathbf{a} 2,10)$ \& da gloriosa virgem maria $\mid(\mathbf{a} 2,13)$ Quero algũas cousas da pestenença que nos ameude fere: dos ditos dos mays autenticos medicos: screuer. I (a2, 16) Dos signaes pronosticos da pestilençia | (a2v $\left.{ }^{\mathrm{v}}, \mathbf{1 6}\right)$ apareçimento da cometa. $\mid(\mathbf{a} 3,6)$ \& as vezes proçede da rayz jnferior. I (a3, 10) Da rayz jnferior proçede segundo nos veemos $\mid(\mathbf{a}, \mathbf{1 1})$ que da priuada que esta açerca da camera $\mid$ $\left(\mathbf{b} 3^{v}, 24\right)$ açerca da orelha $\mid(a 3,22)$ Da rayz superior veem \& aconteçe a pestilençia per virtude dos corpos de çima dos çeos $\mid\left(\mathbf{a} 3^{\mathrm{v}}, \mathbf{1}\right)$ ligeyramente se empeçonhentam os corpos da jndisposiçam $\mid(\mathbf{a} 3 \mathbf{v}, 2)$ ou da maa desposiçam dos çeos $\mid\left(\mathbf{a} 3^{\mathbf{v}}, \mathbf{5}\right)$ Da rayz superior \& jnferior juntamente proçede $\mid\left(\mathbf{a 3}^{\mathbf{v}}, \mathbf{6}\right)$ quando da jmpressam celestrial corrompente ho aar. I (a3 $\left.{ }^{\mathrm{v}}, \mathbf{1 7}\right)$ ho enfermo vay caminho da morte I (b2, 15) Da sangria. | (a4, 7) Da parte do agente | (a4, 10) Da parte do paciente | (a5, 9) em tempo da pestilençia | (a4v , 25) Dos remedios da pestilençia | (a5, 1) VIstas as causas da pestilencia. I (a5, 3) como se deue homem de guardar da pestilencia $\mid(\mathbf{a 5}, 9)$ em tempo da pestilençia $\mid(\mathbf{a 6 , 5 )} \&$ tempos da sua fim $\mid(\mathbf{a 6}, \mathbf{1 5})$ logo coma da aruda lauada $\mid\left(\mathbf{a} 6^{v}, 5\right)$ por causa da minha pobreza. $\mid(\mathbf{b}, \mathbf{1 8})$ nem se tome mais da triaga que a quantidade de huũ piseo $\mid\left(\mathbf{b}^{\mathbf{v}, 3)}\right.$ pigmenta purga o çerebro da freuma $\mid(\mathbf{b}, \mathbf{8})$ ysso mesmo o alho posto: alimpe da freuma $\mid\left(\mathbf{b} 2^{\mathrm{v}}, \mathbf{2 2}\right)$ home $m$ que esta apeçonhentado \& ferido da pestilençia | (b3,2) parte dianteira da cabeça $\mid(\mathbf{b} 3,24)$ se homem sente ser tocado da peçonha $\mid\left(\mathbf{b} 3^{v}\right.$, 13) sangre se em ho meo daquelle braço da vea meaã.l $\left(b^{v}\right.$, 25$)$ ou da vea que esta antre o dedo demostrador \& ho dedo polegar I $(\mathbf{b} 4,2)$ ou da vea que he açerca do dedo menor $\mid(\mathbf{b} 4, \mathbf{1 5})$ ou basilica: ou da meaã. I $\left(\mathrm{b}^{\mathrm{v}}{ }^{2}, 21\right)$ põm lho em çima da apostema I (b4v, 23) perijgos da pestilencia | $\left(\mathbf{b} 4^{\mathrm{v}}, 25\right)$ \& da benta virgem maria $\mid(\mathbf{a} 2,3)$ \& segurança das pestinençias | $(\mathbf{a 2}, 17)$ Segundo das cousas della | (a2, 19) Quarto das conformidades do coraçam $\mid(\mathbf{a} 3, \mathbf{1 5})$ açerca das quaes muytos medicos sam emganados $\mid$ $\left(\mathbf{a} 3^{\mathrm{v}}, 22\right)$ sam assy ditas das causas das pestilençia. I $\left(\mathbf{a} \mathbf{6}^{\mathrm{v}}, \mathbf{1 5}\right)$ Das conformidades do coraçam $\mid\left(\mathbf{b}^{\mathrm{v}}, \mathbf{2}\right)$ guarte das cousas queentes I $(\mathbf{b} 3,15)$ ou açerca das partes vergonçosas. I $(b 3,16)$ ou açerca das orelhas | $(\mathbf{b} 3 \mathrm{v}, \mathbf{1 7})$ açerça das partes vergonçosas. | $(\mathbf{b} 4,5)$ açerça das espadoas | $(\mathrm{b} 4,2)$ do dedo menor | $(\mathbf{b} 4$, 14) que se sangre em o braço esquerdo do figado: I $(\mathbf{a} 2,5)$ do regno de dacia. I $(\mathbf{a} 2,11)$ a prouey to do pouoo | $(\mathbf{a} 2,19)$ Quarto das conformidades do coraçam:। $(\mathbf{a} 2,25)$ em huũ dia do estio \& do alto veraão | $\left(\mathrm{a} 2^{\mathrm{v}}, 4\right)$ estrela do Sul. | (a2v $\left.{ }^{\mathrm{v}}, 16\right)$ falando do apareçimento da cometa $\mid\left(\mathrm{a} 2^{\mathrm{v}}, \mathbf{2}^{2}\right)$ se veem da parte do 
meo dia scilicet. do sul. I $\left(\mathrm{a} 2^{\mathrm{v}}\right.$, 23) ventos do meo dia.| $(\mathrm{a} 3,8)$ mudança do aar $\mid\left(a 3^{\mathrm{v}}, 4\right)$ \& ha empresam do aar corrompe os spiritos vitaes ||$(\mathbf{a} 4,6)$ por parte do agente $\mid(\mathbf{a 4}, 7) \&$ por parte do paçientel $(\mathrm{a} 4,7)$ Da parte do agente $\mid(\mathrm{a} 4,10)$ Da parte do pacientel $(\mathrm{a} 4 \mathrm{v}, 3)$ ajuntamento do pouoo. I $\left(\mathbf{a} 4^{\mathrm{v}}, 5\right)$ por razam do qual I $\left(\mathrm{a}^{\mathrm{v}}\right.$, 14) o vento do sul $\mid\left(\mathbf{a} 4^{\mathrm{v}}, \mathbf{1 9}\right)$ poros do homem $\mid(\mathbf{a} 5, \mathbf{6})$ afastar do mal | $(\mathbf{a} 5, \mathbf{2 0})$ depois do meo dia $\mid\left(\mathbf{a} 5^{\mathrm{v}}, \mathbf{1 0}\right)$ sprito do homem $\mid\left(\mathbf{a 5} \mathbf{v}^{\mathrm{v}}, \mathbf{2 5}\right)$ inchamento do ventre $\mid(\mathbf{a 6}, 3)$ em o quarto do canone $\mid(\mathbf{a 6}, \mathbf{1 1})$ por que se nom apeçonhente homem do aar apeçonhentado $\mid\left(\mathbf{a} 6^{v}, 24\right)$ Os olhos do aar empeçonhentado logo escureçem $\mid\left(\mathbf{a 6}^{\mathrm{v}}, \mathbf{1 5}\right)$ Das conformidades do coraçam $\mid\left(\mathbf{a} 6^{\mathrm{v}}, \mathbf{2 2}\right)$ aconteçe huũ seer empeçonhentado do outro I $\left(\mathbf{a}^{\mathrm{v}}, \mathbf{2 3}\right)$ nom reçebas do baffo de outrem $\mid(\mathbf{b}, 12)$ influencia do çeeo I $(b, \mathbf{1 8})$ do vinho ou augoa ou çerueja tomaras quantidade de duas colhares. I (b2, 8) a alegria do coraçom $\mid(\mathbf{b} 2,9)$ a saude do corpo $\mid(\mathbf{b 2}, 20)$ fluxu do ventre $\mid(b 3,7)$ pigriça do corpo $\mid(\mathbf{b} 3,20)$ em o tempo do somno o sprito vital repousa $\mid\left(\mathbf{b} 3^{\mathrm{v}}, 3\right)$ retardamento do sangue $\mid\left(\mathbf{b} 3^{\mathrm{v}}, \mathbf{9}^{\mathbf{9}}\right)$ parte do corpo $\mid\left(\mathbf{b 3}^{\mathrm{v}}, \mathbf{1 6}\right)$ açerca do dedo $\mid\left(\mathbf{b 3}^{\mathrm{v}}, \mathbf{1 8}\right)$ açerca do calcanhar. | (b4, 4) açerca do articulo | $(b 4,14)$ se sangre em o braço esquerdo do figado | $(\mathbf{b 4}, \mathbf{1 7 )}$ emtom faça se como dito he do braço esquerdo. I $(\mathbf{a} 2, \mathbf{1 2})$ por conseruaçam dos saãos:\& reformaçam dos caydos. I (a2, 14) dos ditos dos mays autenticos medicos | (a, 16) Dos signaes pronosticos da pestilençia. I (a2, 18) Terçeyro. dos remedios della. I (a2, 19) \& dos prinçipaes membros. I (a2, 22) Dos signaaes. I (a2v $\left.{ }^{v}, 17\right)$ ha çidade se filha \& toma dos jmigos $\mid(\mathbf{a} 3,23)$ per virtude dos corpos de çima dos çeos $\mid(\mathbf{a} 3,23)$ dos quaaes se corrompem os spiritos vitaes $\mid\left(\mathbf{a 3}^{\mathrm{v}}, \mathbf{2}\right)$ desposiçam dos çeos $\mid\left(\mathbf{a} 3^{\mathrm{v}}, \mathbf{3}^{3}\right)$ por ha empressam dos çeos corrompe ho aar. I $\left(\mathrm{a}^{\mathrm{v}}, \mathrm{7}\right)$ podridam dos corpos $1(\mathbf{a 4}, 16)$ E por tanto dos quaaes se faz ha grande resoluçam $\mid(\mathbf{a} 4, \mathbf{2 4})$ dos corpos apeçonhentados procedem humores \& fumos peçonthentos $\mid\left(\mathbf{a} 4^{\mathrm{v}}, \mathbf{1}\right)$ deue home $m$ de fugir dos aares peçonhentos. I $\left(\mathrm{a}^{\mathrm{v}} \mathrm{v}, 8\right)$ os seruidores dos enfermos $\mid\left(\mathbf{a} 4^{v}, \mathbf{1 5}^{2}\right)$ os corpos assi dos saãos I (a4v, 16) como dos enfermos. I (a4v, 17) liuro dos amforismos I (a4v, 25) Dos remedios da pestilençia $\mid(\mathbf{a} 6, \mathbf{1})$ corpos cheos dos maaos humores | $(\mathbf{a 6}, \mathbf{1 3})$ huse homem dos remédios | $\left(\mathbf{a} 6^{v}, 10\right)$ os caminhos dos humores | $\left(\mathbf{a 6}^{\mathrm{v}}, \mathbf{1 5}\right)$ Das conformidades do coraçam \& dos outros membros.l ( $\left(\mathbf{b}^{\mathrm{v}}, \mathbf{1}\right)$ apodrentamento dos humores $\mid\left(\mathbf{b}^{\mathrm{v}}, 4\right)$ purga o çerebro da freuma \& os outros membros speciaaes dos humores vis $<c>\operatorname{osos} \mid(\mathbf{b} 3, \mathbf{1 4})$ de bayxo dos braços $\mid(\mathbf{b} 4, \mathbf{1 7})$ \& assi dos outros lugares em os quaaes apareçer a apostema $\mid \rightarrow$ ANTES DE. vide ANTES. $\rightarrow$ DEPOIS DE. vide DEPOIS.

DEBAIXO. vide BAIXO.

DEDo. [<lat. digitus,-i.] sm. Cada um dos prolongamentos que terminam a mão ou o pé. $\rightarrow$ DEDo DEMONSTRADOR. Dedo indicador. - dedo demostrador: $\left(\mathbf{b 3}^{\mathrm{v}}, \mathbf{2 2}\right)$ ou da vea que esta antre o dedo demostrador \& ho dedo polegar. $\rightarrow$ DEDO MAIS PEQUENO. Dedo menor $\bullet$ dedo mais pequeno: $\left(\mathbf{b 3}^{\mathrm{v}}, \mathbf{1 6}\right)$ a vea que he açerca do dedo mais pequeno. $\rightarrow$ DEDO MENor. Dedo mínimo. $\bullet$ dedo menor; $\left(b^{2}{ }^{v}, 23\right)$ ou na maão daquelle meesmo lado açerca do dedo menor. I $(b 4,2)$ ou da vea que he açerca do dedo menor

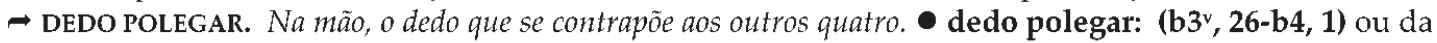
vea que esta antre o dedo demostrador \& ho dedo polegar. I (b3 $\left.{ }^{v}, 20-21\right)$ a vea de çephalica açerca do dedo polegar em a maão daquelle meesmo lado

DELE. vide ELE.

DELIR. [<lat. delere.] v. Diluir. - delida: $(\mathbf{b}, \mathbf{2 0})$ a triaga seja delida em ho vaso ou copo em que ha tomares

DEMAIS. [de de+ mais.] pron. A única ocorrência de demais no Regimento está num trecho que não é claro. Costa Roque (1979:320) propõe como leitura que "demais" está por "na maioria dos casos". - demais: (a3v, 11) se causa ho morbo ou ha chagua em ho homem: \& tal morbo ou jnfirmidade as vezes he febre. \& as vezes apostema \& jsto em os demais

DEMONSTRADOR. vide DEDO. 
DENTRO.[<lat. de intro.] adv. Na parte interna. dentro: porque assi jndiramçe as cousas de dentro

DEPoIs. [or. obsc.] adv. Em seguida. • depois; despois: (a2v, 2) em modo que de manhaã pareçe chuuosa \& chea neuoa. \& depois ventosa. I $\left(\mathbf{a}^{\mathbf{v}}, \mathbf{1}\right)$ he muyto boõ ameude lauar as maãos com augoa \& vinagre. \& alimpar o rostro \& despois cheyrar as maãos. I (b4, 24) E se despois creçer apostema: faze emprasto. I $\left(\mathbf{b} 4^{v}, 4\right)$ \& despois poõe tudo na apostema. | $(\mathbf{b 4}, 13)$ se apareçer despois em o braço direyto $\rightarrow$ DEPOIS DE. Após. - depois de; despois de: $(\mathbf{a} 5,20)$ atee hũa hora depois do meo dia $\mid\left(\mathbf{b 2}{ }^{v}\right.$, 11) logo despois de comer. se alguũ teuer desejo de dormir: que tal desejo se deue reuogar $\mid\left(\mathbf{b} 2^{v}, 15\right)$ per hũa hora despois de comer $\mid\left(\mathbf{b} 2^{v}, 25\right)$ \& logo despois de comer tem desejo de dormir. $\mid(\mathbf{b} 4,11)$ E se pella ventura sentir chagas despois de dormir $\mid(b 4,20)$ E despois do sangue menuido se for muyto fraco I $(\mathbf{b 4}, \mathbf{2 1 )}$ emtom podera dormir despois do meo dia. $\rightarrow$ DEPOIS QUE. Após o tempo em que. despois que: $(\mathbf{b} 2,22)$ \& despois que a vea for ferida ou aberta aproueyta muyto tomar muyto prazer

DERRADEIRo. [<lat. * de retrarius.] adj. Último. - derradeyro, s.XIV: (a2, 21) Quinto \& derradeyro da sangria

DESEJAR. vide DESEJO.

DESEJO. [<lat. *desediu-.] sm. Vontade. - desejo: $\left(\mathbf{b 2} \mathbf{2}^{\mathrm{v}}, \mathbf{1 2 )}\right.$ em tempo da pestilencia. logo despois de comer. se alguũ teuer desejo de dormir: que tal desejo se deue reuogar \& impedir $\mid\left(\mathbf{b} \mathbf{2}^{\mathbf{v}}, \mathbf{2 2}\right)$ \& $\log 0$ despois de comer tem desejo de dormir. I (b3,9) o homem ja apeçonhentado em todas as horas teem grande desejo de dormir. $\rightarrow$ DESEJAR. $v$. Querer. $\bullet$ deseja: $(\mathbf{b 3}, \mathbf{1 1})$ a peçonha intrinseca pertorua o sprito vital. em modo que sempre deseja folgança

Desordenado. [de desordenar.] adj. Perturbado. desordenados: $(a 4,17)$ E por tanto dos quaaes se faz ha grande resoluçam assy como sam os corpos desordenados em luxuria \& coyto

DESTE. vide ESTE.

DESTRA. vide VEIA DESTRA.

DESTRUIR. [<lat. destruere.] v. Eliminar. - destruye, S. XIV; destruam: (b2, 7) \& tal salsa he muyto boõa \& destruye \& quita ou tira toda podridom.I $(\mathbf{b 4 , 2 )}$ por que muytas cousas peçonhentas nom destruam o çerebro

DEVER. [<lat. debere.] v. Ter de, precisar. - deues; deue; deuem, deuem, S.XIII: $(\mathbf{a 4}, \mathbf{1 2})$ por tanto deues de notar que os corpos mays despostos a jnfirmidade \& a morte sam os corpos queentes $\mid(b, 23)$ E ysso meesmo deues de comer boõ manjar | $(\mathbf{a 5}, 4)$ pollo qual deues de notar que segundo diz o grande medico .scilicet. dauid.। $(\mathbf{a} 5,5-6)$ que primeiro se deue o homem de afastar do mal I (a5 ${ }^{\mathrm{v}}$, 11) \& por tanto se deue bem de guardar a casa $(\mathbf{( a 6 , 6 )}$ Item per esta mesma causa se deue euitar ho banho de cada dia. I $(\mathrm{a} 6, \mathbf{1 0})$ toda multidom de pouoo \& comunidade em tal tempo se deue de euitar em quanto for possíuel.। $(\mathbf{b} 2, \mathbf{1 0})$ polla qual cousa deue se homem de guardar | $\left(\mathbf{b} 2^{\mathrm{v}}, \mathbf{9}\right)$ se o homem deue de euitar ho somno que fara homem se teuer o somno natural. I (b2v, 13) se alguũ teuer desejo de dormir: que tal desejo se deue reuogar $\left(\mathbf{( b 3}{ }^{v}, 8\right)$ em nenhũa maneyra nom deue de dormir per todo o dia atee mea noyte I (b3 $\left.{ }^{v}, \mathbf{1 0}\right)$ \& sempre naquella meesma parte do corpo: em a qual ha doença ou chaga apareçer se deue de sangrar \& abrir a vea.l $\left(a 4^{v}, 1\right)$ \& por tanto deue homem de fugir dos aares peçonhentos $\mid\left(\mathbf{a} 4^{\mathrm{v}}, \mathbf{3}\right)$ em o tempo pestilençial nenhuũ nom deue de star em ajuntamento do pouoo I $\left(\mathbf{a} 4^{v}, 6\right)$ os medicos prudentes quando visitam os enfermos deuem de star afastados delles $\mid\left(a 4^{v}, 8\right)$ \& assi ho deuem de fazer os seruidores dos enfermos. $(\mathbf{a 5}, \mathbf{1 5})$ \& por ysso quanto for possiuel taaes deuem de euitar \& de sy esquiuar as causas de tal podridom

DIA. [<lat. *dia.] sm. Período de 24 horas. dia; dias: $(\mathbf{a} 2,25)$ Primeiro quando em huũ dia do estio \& do alto veraão $\mid\left(\mathbf{b 3}^{\mathbf{v}}, 8\right)$ deue de dormir per todo o dia atee mea noyte $\mid\left(\mathbf{a} 4^{\mathrm{v}}, 22\right)$ boõ he ao saão em 
tempo da pestilençia quando venta vento sul estar em casa per todo o dia $1 \quad(\mathbf{b} 2, \mathbf{2 6})$ \& nom conuem dormir em aquelle dia que se sangrar \& abrir a vea.l (b3, 25) logo naquelle meesmo dia mingue ho sangue | $(a 3,14)$ \& esta causa particular \& pode aconteçer cada dia. I $(b, 2)$ Muyto saã cousa he que se laue a boca \& os olhos \& as maãos ameude cada dia $\mid(\mathbf{a} 6,7)$ Item per esta mesma causa se deue euitar ho banho de cada dia. I (b2v ${ }^{2}$, 23) A ysto te respondo que o homem que em tal dia he apeçonhentado nom come mujto. $(\mathbf{b}, \mathbf{1 5})$ toma se ergo duas vezes no dia com boõ vinho claro \& auguado. | $(\mathbf{a} 2 \mathrm{v}, 5)$ em tal estio muytas vezes escureçem: ou pareçem escureçer os dias $\mid\left(a 4^{v}, 10\right)$ he boõ per alguũs dias mudar a camera $\mid(\mathbf{( a 5}$, 2) em algũas casas estam as agoas çujas per dous \& tres dias $\mid(\mathbf{a 6}, \mathbf{5})$ aquelles que sempre querem encher seus ventres que abreuiam seus dias $\rightarrow$ MEIO-DIA. vide MEIO. $\rightarrow$ MEIO DIA. vide MEIO.

DIANTEIRo. [de diante.] adj. Que está na parte da frente. $\bullet$ dianteira: $(\mathbf{b} 3,2) \&$ ysso mesmo tem grande door em ha parte dianteira da cabeça

DIGESTÃo. [<lat. digestio, -onis.] sf. Absorção pelo aparelho digestizo. A digestão foi entendida "como um processo de cozimento. O agente especial era o calor animal, que cozia lentamente o alimento no estômago, uma espécie de panela natural" (Flandrin, 1996: 481). Ainda segundo Flandrin, as e s p e c $i$ a $r$ i a s [q.v. ESPÉCIA] "usadas para temperar os alimentos contrabalançavam a eventual frieza destes, ajudando assim em sua cocção, uma vez que todas eram consideradas quentes e, em sua maioria, secas" (Flandrin, 1996: 481-482). A ajuda que os condimentos traziam à digestão era avaliada em graus de calor ou frieza, considerados perigosos aqueles classificados a partir do quarto grau, como os cogumelos venenosos (quarto grau de frieza), ou o alho (quarto grau de calor). - digestam, S. XV; digestiões, S. XV: $\left(b^{v}, 16\right)$ \& por tanto todos os mantijmentos quanto som de mais leue digestam tanto som milhores. I (a3v, 17) nom sinte sy ser ferida nem emferma. \& jsto porque apareçem bõas ourinas \& boõas augoas. \& bõas digestiões

DIREITAMENTE. vide DIREITO.

DIREITO. [<lat. directus, $-\mathfrak{a},-4 m$.$] adj. Destro. - direyto, s.XIII: \left(\mathbf{b 3}^{\mathrm{v}}{ }^{\mathrm{v}}, \mathbf{1 2}\right)$ E se pella ventura naçer a apostema de bayxo do braço direyto.। $(\mathbf{b 4}, \mathbf{1 3 )}$ porque se apareçer despois em o braço direyto: que se sangre em o braço esquerdo do figado $\mid(\mathbf{b} 4, \mathbf{1 6})$ E se apareçer a apostema de bayxo do braço direyto: emtom faça se como dito he do braço esquerdo. $\rightarrow$ DIREITAMENTE. adv. Diretamente. - dereytamente, $s$. XIII: (a4, 8-9) Da parte do agente quando aquella jnfluençia sobre celestial mays dereytamente fere \& sguarda aquelle ou aquel outro

DISPOSIÇÃo. [<lat. dispositio, -onis.] sf. Ordenação. - desposiçam, s.xIV: (a3ve, 2) ligeyramente se empeçonhentam os corpos da jndisposiçam ou da maa desposiçam dos çeos. $\rightarrow$ Disposto. adj. Propenso. - desposto, despostos, S. XIV;dispostos, S. XV: $(\mathbf{a 4 , 1 1 )}$ aquelle he mays desposto aa morte que aquel outro. I $(\mathbf{a 4 , 1 2 )} \&$ por tanto deues de notar que os corpos mays despostos a jnfirmidade \& a morte sam os corpos queentes \& que teem os poros mays largos $\mid(\mathbf{a} 4, \mathbf{2 1})$ \& os homens que se muyto esqueentam com grande trabalho ou grande yra. teem os corpos mais dispostos pera reçeber ha pestilencia

DISPOSTO. vide DISPOSIÇÃO.

DIZER. [<lat. dicere.] $v$ - digo; diz;dira; diras; dito; dicto; ditas. 1 Declarar; afirmar: (a4, 5) A primeyra questam: digo que esto pode aqueçer por duas causas $\mid(\mathbf{a} 4, \mathbf{2 2})$ A segunda questam digo que taaes nfirmidades pestilençiaaes sam contagiosas I $\left(\mathrm{a} 4^{\mathrm{v}}, 2\right)$ mais ajnda digo que em o tempo pestilençial nenhuũ nom deue de star em ajuntamento do pouoo. I $\left(\mathbf{a}^{\mathrm{v}}\right.$, 9) E por tanto digo que a tal doente de pestilençia he boõ per alguũs dias mudar a camera $\mid(\mathbf{a 6}, 8)$ onde finalmente digo que toda multidom de pouoo \& comunidade em tal tempo se deue de euitar $\mid\left(\mathbf{a} 6^{v}, 22\right)$ E por ysso te digo que em toda maneyra te guardes I (b, 13) Quanto he ao teu mantijmento digo te que a triaga te he muyto proueytosa I ( $\left(\mathbf{b}^{\mathrm{v}}{ }^{2}, \mathbf{1 0}\right)$ A ysto digo breuemente que em tempo da pestilencia. logo despois de comer. se alguũ teuer desejo de dormir: que tal desejo se deue reuogar $\mid\left(\mathbf{a} 2^{\mathrm{v}}, \mathbf{1 3}\right)$ \& segundo diz aristoteles em os 
metauros. quando ha cometa apareçe aconteçem mortes de gentes em bathalhas \&c. I (a2v, 15) \& por isso diz ho verso poetico falando do apareçimento da cometa. $\mid(\mathbf{a} 3,25)$ \& de tal diz auicena no quarto liuro | $(\mathbf{a 5}, 5)$ pollo qual deues de notar que segundo diz o grande medico .scilicet. dauid. | $(\mathbf{a} 6,3)$ E por tanto diz auiçena em o quarto do canone. $\mid\left(\mathbf{b} 2^{\mathrm{v}}, \mathbf{1 6}\right)$ Empero diz auiçena que se homem quiser dormir ha de beber hũa bõa vez de vinhol $(\mathbf{a} 5,19)$ Fechem se ergo as frestas ou genelas como dito he que vaam ou estam pera o sul $\mid\left(\mathbf{a} \mathbf{5}^{\mathbf{v}}, \mathbf{6}\right)$ em tal casa como esta morrem os homens mais azinha \& em outra nom como dito he $\mid\left(\mathrm{b}^{\mathrm{v}}, \mathbf{6}\right)$ pequena sayda de sangue. mais fortemente esperta a peçonha se gundo dicto he. I (a3 $\left.{ }^{v}, 22\right)$ E estas cousas sam assy ditas das causas das pestilençia. $\llbracket$ Falar: $\left(\mathbf{b} 2^{v}, \mathbf{8}^{2}\right)$ Mas dira alguũ. se o homem deue de euitar ho somno que fara homem se teuer o somno natural $\mid(\mathbf{b} 2 \mathrm{v}$, 21) Mas diras tu. como sintira homem que está apeçonhentado \& ferido da pestilençia. $\rightarrow$ DITo. sm. Aquilo que se disse. - ditos: $(\mathbf{a} 2,14)$ Quero algũas cousas da pestenença que nos ameude fere: dos ditos dos mays autenticos medicos: screuer

DOENÇA. [<lat. dolentia, -ae.] sf. No paradigma hipocrático-galênico, reflexo, no corpo humano, de deseguilibrio causado quer pelos fluidos ou humores, quer pelas forças do universo, quer por outras forças, como o calor e o frio, $o$ doce e o azedo. - doença: $\left(\mathbf{a} 5^{\mathrm{v}}, \mathbf{8}\right)$ \& por serem assi podres causam tal fedor \& doença । (b3v, 10) sempre naquella meesma parte do corpo: em a qual ha doença ou chaga apareçer se deue de sangrar \& abrir a vea. $\rightarrow$ DOENTE. sm. Aquele que sofre uma doença ou enfermidade $\bullet$ doente: $(\mathbf{a} 4 \mathbf{v}, 9)$ E por tanto digo que a tal doente de pestilençia he boõ per alguũs dias mudar a camera

DOIS. [<lat. duo, $-a e,-o$.$] num. - dous; duas: \left(\mathbf{a 5}^{\mathbf{v}}, \mathbf{1}\right)$ em algũas casas estam as agoas çujas per dous \& tres dias I (a3 $\left.{ }^{v}, 24\right)$ Aqui se mouem duas questões. I (a4, 6) A primeyra questam: digo que esto pode aqueçer por duas causas. I $(\mathbf{a} 4 \mathrm{v}, \mathbf{1 4})$ o vento do sul teem em si duas causas de de apodrentar $\mid(\mathbf{a 6}, 16)$ coma da aruda lauada em agoa limpa espargida com sal \& noz nozcada hũa ou duas bem limpas. $(\mathbf{( b , 1 5 )}$ toma se ergo duas vezes no dia com boõ vinho claro \& auguado. | (b, 19-20) \& do vinho ou augoa ou çerueja tomaras quantidade de duas colhares. $\rightarrow$ AMBOs DE DOUs. vide AMBOs.

DOR. [<lat. dolor, -is.] sf. Forte incômodo físico. - door, s.XIII: $(\mathbf{b 3}, \mathbf{1 )}$ \& ysso mesmo tem grande door em ha parte dianteira da cabeça

DORMIR. [<lat. dormire.] v. Entregar-se ao sono. Esse é um dos verbos de maior freqüuencia no texto, associado sempre a maleficios ao estado do doente, especialmente se o dormir se fizesse durante o dia. Tais males são consensuais, $e$ outros autores do período, como Marsilio Ficino (1433-1499), confirmam tal idéia: "Quanto al sonno, E alla vigiliatone, dico che il dormire di dì è cattiuo massimamête a quelli, $i$ quali sono ripieni d'humori, $\mathcal{E}$ hanno humida la testa" (Ficino, 1576: 91). - dormir; dormem: (b3, 9-10) o homem ja apeçonhentado em todas as horas tee $m$ grande desejo de dormir $\mid(\mathbf{b} 2,25)$ \& nom conuem dormir em aquelle dia que se sangrar \& abrir a vea. | (b2v $\left.{ }^{12}\right)$ se alguũ teuer desejo de dormir: que tal desejo se deue reuogar $\mid$ (b2v, 16) se homem quiser dormir | (b2v, 18$)$ ha de beber hũa bõa vez de vinho ou çerueja ante de dormir. | $(\mathbf{b} 2 \mathbf{v}, \mathbf{2 6})$ \& logo despois de comer tem desejo de dormir $(\mathbf{b 3}, \mathbf{5})$ todas estas cousas pode muyto bem euitar \& de sy lançar andando ou espaçando huũ pouco antre ho comer \& o dormir. I (b3v, 8) Item o home $m$ que se sangra ou tenha pestenença ou nom. em nenhũa maneyra nom deue de dormir per todo o dia atee mea noyte $\mid(\mathbf{b} 4,9)$ E todas estas cousas se façam se homem nom dormir antes que conheça que tem apostema. I $(\mathbf{b 4}, \mathbf{1 1})$ E se pella ventura sentir chagas despois de dormir: emtom ha de menuyr o sangue em a parte crucifixa $\mid(\mathbf{b} 4,21)$ E despois do sangue menuido se for muyto fraco emtom podera dormir despois do meo dia. I $\left(\mathrm{a}^{\mathrm{v}} \mathrm{v}, \mathbf{1 4}\right)$ porque ho aar apeçonhentado he humido \& faz podridom em a casa ou em lugar onde dormem

DURAR. [<lat. durare.] v. Persistir. $\bullet$ durar: $\left(\mathbf{a} 2^{\mathrm{v}}, \mathbf{8}\right)$ se isto mujto durar he pera temer de vijr grande pestilençia 
E. [<lat. et]. conj. [No texto há duas representações gráficas para a conjunção aditiva e: o sinal tironiano, semelhante ao algarismo $\langle 2\rangle$, mas invertido, aqui representado por $\langle\mathcal{E}\rangle$, e a maiuscula $\langle E\rangle$, que são as representações comuns em impressos para essa conjunção até meados do século XVI. ] $\bullet \mathcal{E}:(\mathbf{a} 2,2)$ Começa se huũ boõ regimento muyto neçessario \& muyto proueitoso aos viuentes. \& per conseruaçam de suas saudes $\mid(\mathbf{a} 2,3)$ \& segurança das pestinençias.| (a2, 10) EM louuor da santissima trijndade. \& da gloriosa virgem maria \& a proueyto do pouoo: $(\mathbf{a 2}, \mathbf{1 2})$ por conseruaçam dos saãos: \& reformaçam dos caydos. I (a2, 19) Quarto das conformidades do coraçam: \& dos prinçipaes membros. I (a2, 21) Quinto \& derradeyro da sangria. I $(\mathbf{a} 2,25)$ Primeiro quando em huũ dia do estio \& do alto veraão se muda a manhaã muytas vezes. I (a2v, 2) em modo que de manhaã pareçe chuuosa \& chea neuoa. \& depois ventosa.I $\left(\mathrm{a} 2^{\mathrm{v}}, 3\right)$ \& prinçipalmente quando he ho vento meridional. ou da parte de estrela do Sul.I (a2v, 7) ou pareçem escureçer os dias em modo que pareçe que quer chouuer \& nom choue.l (a2v , 7) \& emtam se isto mujto durar he pera temer de vijr grande pestilençia. I $\left(\mathbf{a} 2^{v}, 10\right)$ porque emtam pareçe ho aar ser empeçonhentado. \& que sobem muytos vapores peçonhentos ao aar.l (a2v, 13) \& segundo diz aristoteles em os metauros. I (a2v, 15) \& por isso diz ho verso poetico falando do apareçimento da cometa. I (a2v $\left.{ }^{v}, \mathbf{1 7}\right)$ A morte se ensanha ha çidade se filha \& toma dos jmigos. I $\left(\mathbf{a} 2^{\mathrm{v}}, \mathbf{1 8}\right)$ ho mar se faz cruel. \& ho sol se cobre .I (a2v, 19) ho pouoo padeçe fame \& pestilencia. I (a2v, 21) Quinto sinal. he quando se fazem mujtas relampados \& trouoadas. \& mayormente se veem da parte do meo dia I (a2v, 24) porque taes ventosidades sam muyto çujas \& muito velhacas $\mid(\mathbf{a} 3, \mathbf{2})$ se ho senhor deus todo poderoso ho nom quitar \& estoruar. I $(\mathbf{a} 3, \mathbf{5})$ porque as vezes veem \& proçede ha pestilencia da rayz superior. $\mid(\mathbf{a} 3,6) \&$ as vezes proçede da rayz jnferior. | $(\mathbf{a} 3,8)$ \& as vezes veem dambos de dous | (a3, 9). scilicet. da rayz superior \& da rayz jnferior juntamente. $\mid(a 3,13)$ se corrompe ho aar em substançia \& qualidade. \& esta causa particular | $(\mathbf{3} 3, \mathbf{1 4})$ \& pode aconteçer cada dia. \& daly procedem febres pestilençiaes. I $(\mathbf{a} 3,18)$ ou de corrupçom de pauees \& charcos I $(\mathrm{a} 3,19)$ ou chafarizes çujos podres \& federentos. \& esto aconteçe muytas vezes $\mid(\mathbf{a} 3, \mathbf{2 1})$ onde ha lugares podres \& corruptos. \& tambem esta causa he as vezes particular. I (a3, 22)Da rayz superior veem \& aconteçe a pestilençia per virtude dos corpos de çima dos çeos. I $(\mathrm{a} 3,25) \&$ de tal diz auicena no quarto liuro $\mid\left(\mathrm{a}^{\mathrm{v}} \mathrm{v}, 3\right)$ por ha empressam dos çeos corrompe ho aar. \& ha empresam do aar corrompe os spiritos vitaes em ho homem $\mid\left(\mathbf{a 3}^{\mathrm{v}}, 4\right)$ \& assy se geera ha pestilençia per esta causa. I $\left(a 3^{\mathrm{v}}, 6\right)$ Da rayz superior \& jnferior juntamente proçedel $\left(a 3^{\mathrm{v}}\right.$, 7) quando da jmpressam celestrial corrompente ho aar. \& podridam dos corpos mortos. ou lugares çujos se causa ho morbo $\mid\left(\mathbf{a 3}^{\mathbf{v}}, \mathbf{9}\right)$ \& tal morbo ou jnfirmidade as vezes he febre. $\mid\left(\mathbf{a} \mathbf{3}^{\mathrm{v}}, \mathbf{1 0}\right)$ \& as vezes apostema \& jsto em os demais. I $\left(\mathbf{a}^{\mathrm{v}} \mathrm{v}, \mathbf{1 2}\right)$ \& assy corrupto feere ho coraçom. $\mid\left(\mathbf{a} 3^{\mathrm{v}}, 16\right)$ \& jsto porque apareçem bõas ourinas \& boõas augoas. \& bõas digestiões. I (a3v, 20) superficialmente falam. \& lygeyramente sam emganados.l $\left(\mathrm{a}^{\mathrm{v}}, \mathbf{2 2}\right)$ todo enfermo se proueja de boõ fisico \& bem esperto. I (a3 ${ }^{\mathrm{v}}$, 25) Porque he assy que huũ morre \& ho outro nom. \& daquella villa morrem homens | (a4, 1) \& daqueloutra nom. \& daquella casa morre $m \mid(\mathbf{a 4}, \mathbf{2}) \&$ daqueloutra nom. $\mid(\mathbf{a 4}, 7)$ por parte do agente \& por parte do paçiente $\mid(\mathbf{a 4}, \mathbf{9 )}$ aquella jnfluençia sobre celestial mays dereytamente fere \& sguarda aquelle ou aquel outro. I $(\mathbf{a 4 , 1 2 )} \&$ por tanto deues de notar $\mid(\mathbf{a 4}, \mathbf{1 3})$ que os corpos mays despostos a jnfirmidade \& a mortel $(\mathbf{a} 4, \mathbf{1 4})$ sam os corpos queentes \& que teem os poros mays largos: \& os corpos peçonhentos | $(\mathbf{a} 4, \mathbf{1 5})$ que tem os poros opilados: \& çarrados de mujtos humores. $\mid(\mathbf{a} 4, \mathbf{1 8})$ assy como sam os corpos desordenados em luxuria \& coyto. \& os que vaam ameude a os banhos.l (a4, 19) \& os homens que se muyto esqueentam com grande trabalho ou grande yra. I (a4, 23) taaes infirmidades pestilençiaaes sam contagiosas \& apegam se muy asinha. I (a4, 25) dos corpos apeçonhentados procedem humores \& fumos peçonhentos $\mid\left(\mathbf{a} 4^{\mathrm{v}}, \mathbf{1}\right)$ \& por tanto deue homem de fugir dos aares peçonhentos. I $\left(\mathrm{a}^{\mathrm{v}}, \mathbf{8}\right)$ teendo o rostro pera genela ou fresta: \& assi ho deuem de fazer os seruidores dos enfermos. $\mid\left(\mathbf{a} 4^{\mathrm{v}}, \mathbf{1 0}\right)$ he boõ per alguũs dias mudar a camera: \& muytas vezes teer as frestas pera ho norte ou pera o leuante abertas. $\mid\left(\mathrm{a}^{\mathrm{v}}, \mathbf{1 2}\right)$ \& as genelas ou frestas pera ho meo dia ou pera ho sul estem çarradas. I (a4v $\mathbf{1 8})$ Ho sul he vento inchado \& agraua o ouuido fere o coraçam. I $\left(\mathbf{a} 4^{\mathrm{v}}, \mathbf{1 9}\right)$ abre os poros do home $m$ \& emtra atee o coraçam. $\mid\left(\mathrm{a}^{\mathrm{v}}, \mathbf{2 2}\right) \&$ se for neçessario que saya este em casa atee que saya o sol \& suba huũ boõ espaço sobre o nosso orizonte. I $(\mathbf{a} 5,2)$ agora ajamos de veer per que modo \& como se deue homem de guardar da pestilencia | (a5, 3) \& preseruar se della. I (a5, 6) primeiro se deue o home $m$ de afastar do mal \& inclinar se ao bem. | (a5, 10) grande remedio he em 
tempo da pestilençia a sancta penitencia \& a confissam as quaaes preçedem \& sam muyto melhores que todas as mezinhas. I $(\mathbf{a} 5, \mathbf{1 2})$ muyto boõ remedio he fugir \& mudar o lugar apeçonhentado. | (a5, 14) \& por ysso quanto for possiuel $\mid(\mathbf{a} 5, \mathbf{1 5})$ taaes deuem de euitar \& de sy esquiuar as causas de tal podridom. I $(\mathbf{a} 5,17)$ E per conseguinte todo o coyto \& toda luxuria. \& tambem o vento meridional ou sul: | (a5, 21)\& abram se as que stam pera o norte. \& per esta mesma causa | $(\mathbf{a} 5, \mathbf{2 2})$ euitaras \& esquituaras todo ho fedor $\mid(\mathbf{a 5}, 23)$.scilicet. de estrebarias. de campos. de ruas. \& em special | (a5, 24)donde ha hi corpos mortos \& podres. \& tambem donde ha hi podridom de agoas $\mid(\mathbf{a} 5,25)$ \& fedor dellas. | $\left(\mathbf{a} 5^{\mathrm{v}}, 2\right)$ em algũas casas estam as agoas çujas per dous \& tres dias \& as Iançam per canos \& regos soterranhos: $\left(\mathbf{a 5}^{\mathrm{v}}, 4\right)$ taes agoas çujas causam grandes fedores: \& daqui veem que em tal casa como esta morrem os homens mais azinhal $\left(\mathbf{a 5} 5^{\mathrm{v}}, \mathbf{5}\right)$ \& em outra nom como dito he $\mid\left(\mathbf{a} 5^{\mathrm{v}}, \mathbf{6}\right)$ mesmo onde se lançam verças \& caldos podres $\mid\left(\mathbf{a 5}^{\mathrm{v}}, \mathbf{7}\right)$ \& por serem assi podres $\mid\left(\mathbf{a} 5^{\mathrm{v}}, 8\right)$ causam tal fedor \& doença que muyto empeçe. I $\left(\mathbf{a 5}^{\mathrm{v}}, 9\right) \mathrm{E}$ assi como per ho boõ cheyro \& aromatico: $\mid\left(\mathbf{a}^{\mathrm{v}}, \mathbf{1 0}^{\mathrm{C}}\right)$ se recrea o coraçom \& o sprito do homem. $\mid\left(\mathbf{a}^{\mathrm{v}}, \mathbf{1 1}\right)$ assi emfraqueçe per o çujo fedor. \& por tanto se deue bem de guardar a casa: I $\left(\mathbf{a 5}^{\mathrm{v}}, \mathbf{1 3}\right)$ ho aar apeçonhentado he humido \& faz podridom em a casa ou em lugar onde dormem. I (a5 $\left.5^{\mathrm{v}}, \mathbf{1 4}\right) \&$ ysso naturalmente. $\mid\left(\mathbf{a} 5^{\mathrm{v}}, \mathbf{1 5}\right)$ Apure se ergo \& asutileze se a casa per clara chama ou flama:I (a5v, 16) \& faça se fogo claro de lenha.l (a5v, 17) \& faça se tambem com fumo de boõas heruas aqui scriptas $\mid\left(\mathbf{a} 5^{\mathrm{v}}, 19\right)$ \& de alosna $\mid\left(\mathrm{a5}^{\mathrm{v}}, 20\right) \&$ ysope \& arruda. \& artamija. \& com lenho de aloes I (a5v 23$)$ E tal fumo entre per a boca \& per os narizes. I $\left(\mathbf{a} 5^{v}, 24\right)$ Item per esta meesma $c a<u>s a$ se euite \& esquiue: todo ho inchamento do ventre $(\mathbf{a 6}, 5)$ aquelles que sempre querem encher seus ventres que abreuiam seus dias \& tempos da sua fim \& minguam sua vida. $\mid(\mathbf{a} 6, \mathbf{9})$ toda multidom de pouoo \& comunidade em tal tempo se deue de euitar I $(\mathbf{a 6}, 12)$ que companhia \& ajuntamento de pouoo se euite. I $(\mathbf{a} 6, \mathbf{1 6})$ coma da aruda lauada em agoa limpa espargida com sal \& noz nozcada $\mid(\mathbf{a} 6,18)$ \& ysto seja mayormente $\mid(\mathbf{a} 6,19)$ em tempo de neuoeiro \& chuuoso $\mid(\mathbf{a} 6$, 22)E tambem a casa seja aguada: \& em special em o alto veraão I (a6, 23) com vinagre rosado \& folhas de vinhas. $\mid(\mathbf{a 6}, \mathbf{2 4 )}$ \& ysso meesmo he muyto boõ $\mid(\mathbf{a 6}, \mathbf{2 5})$ ameude lauar as maãos com augoa \& vinagre. \& alimpar o rostro $\mid\left(\mathbf{a}^{v}, \mathbf{1}\right)$ \& despois cheyrar as maãos. \& tambem he boõ assi em ho inuerno como no veraão cheirar cousas azedas. $\mid\left(\mathbf{a}^{\mathbf{v}}, \mathbf{6}\right)$ \& emtam leuaua commigo huũa sponja ou paão enssopado em vinagre: $\left(\mathbf{a} 6^{v}, 7\right) \&$ sempre no punha nos narizes $\mid\left(\mathbf{a}^{\mathrm{v}}, \mathbf{8}\right)$ \& na boca. porque as cousas azedas \& os cheyros taaes $\mid\left(\mathbf{a}^{\mathrm{v}}, \mathbf{9}\right)$ opilam \& çarram os poros \& os meatos $\mid\left(\mathbf{a} 6^{\mathrm{v}}, \mathbf{1 0}\right) \&$ os caminhos dos humores \& nom consintem entrar as cousas peçonhentas. I $\left(\mathbf{a}^{\mathrm{v}}\right.$, 11) \& assi escapey de

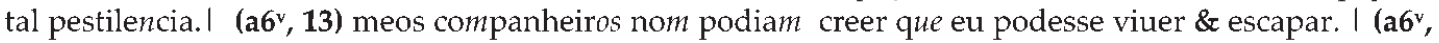
15)Das conformidades do coraçam \& dos outros membros. I $\left(a^{\mathrm{v}}, 20\right)$ \& estas cousas prestam pera antre pouoo | (b, 1) Muyto saã cousa he que se laue a boca \& os olhos $\mid(\mathbf{b}, 2)$ \& as maãos $\mid(\mathbf{b}, 3)$ \& se estas cousas nom poder auer faça se com vinagre.| $(\mathbf{b}, \mathbf{4})$ \& assi guardando estas cousas seguramente entraras em pouoo $\mid(\mathbf{b}, 7)$ \& se o ventre naturalmente se nom poder vazar. toma huũ cristel. $\mid(\mathbf{b}, \mathbf{8})$ \& tambem tomaras pirolas pestilençiaaes $\mid(\mathbf{b}, \mathbf{1 1})$ clarifica muyto ho aar \& poõe grande impedimento aa maa influencia do çeeo. I $(b, 16)$ toma se ergo duas vezes no dia com boõ vinho claro \& auguado. I $(b$, 18) \& do vinho ou augoa ou çerueja tomaras quantidade de duas colhares $\mid(\mathbf{b}, \mathbf{2 0})$ \& a triaga seja delida em ho vaso ou copo em que ha tomares. I $(\mathbf{b}, 21)$ \& nom jantaras atee ho meo dia $\mid(\mathbf{b}, 24)$ deues de comer boõ manjar \& bõa yguaria com boõ vinho puro \& a meude.l $(\mathbf{b}, \mathbf{2 6})$ a sobeja abastança \& grande inchamento tras apodrentamento dos humores. I $\left(b^{v}, 3\right)$ guarte das cousas queentes. assi como som pigmenta \& alhos. $\left(\mathbf{b}^{v}, 4\right)$ ajnda que pigmenta purga o çerebro da freuma \& os outros membros speciaaes dos humores vis $<\mathrm{c}>0$ osos $\mid\left(b^{v}, 5\right)$ mas porque muyto aqueenta. \& a queentura traz podridom. I ( $\left(\mathbf{b}^{\mathrm{v}}, \mathbf{7}\right)$ queentura cheyro \& sabor. I ( $\left.\mathbf{b}^{\mathrm{v}}, 8\right)$ ysso mesmo o alho posto: alimpe da freuma \& lança fora os maaos humores. $\mid\left(\mathbf{b}^{\mathbf{v}}, \mathbf{9}\right)$ \& prouoca o apetito de comer: $\mid\left(\mathbf{b}^{\mathbf{v}}, \mathbf{1 0}\right) \&$ nom consinta emtrar ho aar seco. I (bv , 11) empero contorua os olhos \& squeenta a cabeça de cada huũ que ho ameude come. I (bv', 12)\& por ysso nom pareçe se neçessario mas antes jnpidoso. $\mid\left(\mathbf{b}^{\mathrm{v}}, \mathbf{1 4}\right) \&$ por tanto todos os mantijmentos quanto som de mais leue digestam tanto som milhores. I ( $\left.\mathbf{b}^{v}, 17\right)$ pela manhã sejam os manjares cozidos: \& de noyte assados $\mid\left(\mathbf{b}^{v}, \mathbf{1 8}\right)$ caldos. polmes. \& potagios se euitem: $\mid\left(\mathbf{b}^{v}, 26\right)$ froles de heruas cheyrosas. \& açafram. \& com estas cousas busquem se pera os ricos $\mid(\mathbf{b} 2,3)$ porque se forem pobres contentem se com arruda \& salua. $\mid(\mathbf{b} 2,4)$ noz nozcadas. pere $<x>$ il \& todo misturado com vinagre faz muy bõa salsa $\mid(\mathbf{b} 2,5)$ tomem cuminhos \& açafram $\mid(\mathbf{b} 2, \mathbf{6})$ \& misturem tudo com vinagre. \& tal salsa he muyto boõal $(\mathbf{b} 2,7) \&$ destruye \& quita ou tira toda podridom. I $(\mathbf{b} 2,12)$ 
ymaginaçam faz causa \& perijgo.l $(\mathbf{b} 2, \mathbf{1 3})$ mas qualquer com muyto prazer \& alegria sempre espere de muyto viuer.I $(\mathbf{b} 2,22) \&$ despois que a vea for ferida ou aberta aproueyta muyto tomar muyto prazer. | (b2, 25) \& nom conuem dormir | $(\mathbf{b} 2,26)$ em aquelle dia que se sangrar \& abrir a vea. \& se alguũ se agrauar de apostema $\mid\left(\mathbf{b} 2^{\mathrm{v}}, 3\right)$ em toda maneyra tal como este euite o somno \& ysto em andando. I (b2v , 5) caladamente traz a peçonha ao coraçam \& aos outros membros speciaaes. I (b2v 13)tal desejo se deue reuogar \& impedir $\mid\left(\mathbf{b} 2^{v}, 19\right) \&$ estes maaos humores se lançam fora per tomar hũa bõa vez de vinho boõ $\mid\left(\mathbf{b} 2^{v}\right.$, 22) como sintira homem que esta apeçonhentado \& ferido da pestilençia. I (b2v $\left.{ }^{2}, 25\right) \&$ logo despois de comer tem desejo de dormir. I $\left(\mathbf{b 2}{ }^{\mathrm{v}}, \mathbf{2 6}\right)$ \& sente de bayxo de frio grande quententura. I (b3,1) \& ysso mesmo tem grande door em ha parte dianteira da cabeça.I $(\mathbf{b} 3, \mathbf{3})$ mas todas estas cousas pode muyto bem euitar \& de sy lançar $\mid(\mathbf{b} 3,4)$ andando ou espaçando huũ pouco antre ho comer \& o dormir. $\mid(b 3,7)$ nem andar grande caminho por a grande pigriça do corpo \& muyto grande peso $\mid(b 3,8)$ \& carrega corporal. | (b3, 14) spere per huũ meo dia \& logo sentira apostema $\mid(\mathbf{b} 3, \mathbf{1 8})$ escuse o somno \& ho euite quanto poder. $(\mathbf{b 3}, \mathbf{1 9 )} \&$ assi segundo estas cousas he assaz manifesto I $(\mathbf{b} 3, \mathbf{2 1}) \mathrm{em}$ o tempo do somno o sprito vital repousa: \& emtom a peçonha espalha se per os membros de toda parte. I $(\mathbf{b} 3,25) \log$ naquelle meesmo dia mingue ho sangue: \& se sangre atee esmoreçer. | $\left(\mathbf{b 3}^{\mathrm{v}}, \mathbf{1}\right)$ \& se homem nom quiser cortar muytas veas juntamente: |(b3 $\left.{ }^{\mathrm{v}}, \mathbf{8}\right)$ \& sempre naquella meesma parte do corpo: em a qual ha doença ou chaga apareçer $\mid\left(\mathbf{b}^{\mathbf{v}}{ }^{\mathrm{v}}\right.$, 11$)$ se deue de sangrar \& abrir a vea. I (b3v , 26) ou da vea que esta antre o dedo demostrador \& ho dedo polegar. I $(\mathbf{b} 4,6) \&$ primeiramente minguaras a meaã. । $(\mathbf{b} 4, \mathbf{1 7})$ faça se como dito he do braço esquerdo. \& assi dos outros lugares em os quaaes apareçer a apostema: I (b4,22) \& sempre antes do meo dia sera em continuo mouimento: I (b4,26) tal apostema lança o mal de fora \& faz o homem ser muyto saão. I (b4v $\left.{ }^{\text {, }} \mathbf{1}\right)$ que a apostema mais çedo \& milhor seja madural $\left(\mathbf{b} 4^{\mathrm{v}}, \mathbf{2}\right)$ \& seja rompida I (b4 $\left.{ }^{\mathrm{v}}, 3\right)$ Toma folhas de sabugo pisadas \& com mostarda pisada $\mid\left(\mathbf{b} 4^{\mathrm{v}}, \mathbf{4}\right)$ \& faze emprasto. \& despois poõe tudo na apostema. I (b4v, 9$)$ \& assy lança a peçonha. I (b4viv $\mathbf{1 1}$ )Tomaras hũa herua que chamam barbajouis. \& outro que chamam serpillo $\mid\left(\mathbf{b} 4^{v}, 12\right)$ \& ysso mesmo toma chantagem $\mid\left(\mathbf{b} 4^{v}, 13\right)$ \& siligem (vay te ao boticayro) \& pisa todo muyto bem. | $\left(\mathbf{b} 4^{\mathrm{v}}, \mathbf{1 6}\right)$ emtom toma aquelle çumo \& mistura ho com leyte de mulher $\mid\left(\mathbf{b} 4{ }^{\mathrm{v}}, \mathbf{1 7}\right) \&$ da ho a beber aquelle que teuer a postema. \& ysto com o estamago gejuũ. I $\left(\mathbf{b} 4^{\mathrm{v}}, \mathbf{2 0}\right)$ tome auelaãs. figos passados \& aruda \& tudo bem pisado: pom lho em çima da apostema. I (b4v, 22) \& qualquer que se per este modo reger $\mid\left(\mathbf{b} 4^{v}, \mathbf{2 4}\right)$ escapara muytos perijgos da pestilencia com virtude \& meezinha de nosso senhor jesu christo. sem o qual nom ha hy saude.| (b4v, 25) \& da benta virgem maria sua madre $\mid\left(\mathbf{b} 4 \mathbf{v}^{\mathrm{v}}\right.$, 26) seja gloria \& louuor pera sempre - E: $(\mathbf{a} 2,5) \mathbf{E}$ tralladado de latim em lingoagem $\mid(\mathbf{a 2}, \mathbf{1 5}) \mathrm{E}$ primeyramente. I (a3v, 18) E por tanto muytos medicos que em os enfermos soomente esguardam as ourinas superficialmente falam. I (a3v, 22) E estas cousas sam assy ditas das causas das pestilençia. | $(\mathbf{a} 4, \mathbf{1 6})$ E por tanto dos quaaes se faz ha grande resoluçam $\mid\left(\mathbf{a} 4^{\mathrm{v}}, 9\right)$ E por tanto digo que a tal doente de pestilençia he boõ per alguũs dias mudar a camera: | $(\mathbf{a} 5,16)$ E per conseguinte todo o coyto \& toda Iuxuria. I $\left(\mathbf{a}^{\mathrm{v}}\right.$, 9) E assi como per ho boõ cheyro \& aromatico: se recrea o coraçom \& o sprito do homem. I $(\mathbf{a} 5 \mathrm{v}, 22) \mathbf{E}$ tal fumo entre per a boca \& per os narizes. I $(\mathbf{a} 6,3) \mathrm{E}$ por tanto diz auiçena em o quarto do canone. I $(\mathbf{a 6}, \mathbf{1 2}) \mathbf{E}$ quando assi for que companhia \& ajuntamento de pouoo se euite. I (a6, 17) E ysto nom poder auer. emtam coma paão | $(\mathbf{a 6}, 22) \mathbf{E}$ tambem a casa seja aguada: | (a6, 22$) \mathrm{E}$ por ysso te digo que em toda maneyra te guardes $\mid(\mathbf{b}, \mathbf{6}) \mathbf{E}$ tambem he grande remedio vazar o ventre $\mid(\mathbf{b}$, 23) E ysso meesmo deues de comer boõ manjar $\mid\left(\mathbf{b}^{\mathrm{v}}, \mathbf{1}\right) \mathbf{E}$ em os mantijmentos guarte das cousas queentes. I ( $\mathbf{b}^{\mathrm{v}}, \mathbf{2 4 )} \mathbf{\mathrm { E }}$ as speçias que comuummente conuem a comer. I $(\mathbf{b} 2,5) \mathbf{E}$ se nom forem muyto pobres: tomem cuminhos $\mid(\mathbf{b} 2, \mathbf{8}) \mathbf{E}$ tambem a alegria do coraçom he gram remedio pera a saude do corpo. I (b3 $\left.{ }^{v}, 11\right)$ E se pella ventura naçer a apostema de bayxo do braço direyto. I $\left(\mathbf{b}^{\mathrm{v}}{ }^{\mathrm{v}}, \mathbf{1 7}\right) \mathbf{E}$ se açerca das partes vergonçosas. I ( $\mathbf{b 3}^{\mathrm{v}}, \mathbf{1 9 )} \mathbf{E}$ se a apostema for em ho pescoço. I $\left(\mathbf{b} 3^{\mathrm{v}}, 23\right) \mathbf{E}$ se pela ventura apareçer açerca da orelha: |(b4, 4) E se polla ventura for açerca das espadoas: | $(\mathbf{b} 4,7)$ E se for em o espinhaço $\mid(\mathbf{b} \mathbf{4}, \mathbf{8}) \mathbf{E}$ todas estas cousas se façam se homem nom dormir antes que conheça que tem a postema. I (b4, 10)E se pella ventura sentir chagas despois de dormir: I $(\mathbf{b} 4, \mathbf{1 5}) \mathbf{E}$ se apareçer a apostema de bayxo do braço direyto: I (b4, 20)E despois do sangue menuido I (b4, 24) E se despois creçer a postema: | (b4, 26)E ysso mesmo por que a apostema mais çedo \& milhor seja madura | (b4v', 21) E estas cousas abastem pera a pestilença. $\rightarrow$ ETC. [<lat. et caetera,'e as demais coisas'.] Abreviatura de et caetera. $-\mathcal{E}$ c: $\left(\mathbf{a}^{2}\right.$, 15) Quarto sinal he quando ha cometa pareçe voar. \& segundo diz aristoteles em os metauros. quando ha cometa apareçe aconteçem mortes de gentes em bathalhas \&c 
ELE. [lat. illus, $-a$, - ud 'aquele'.] pron. pess. Indica aquele/aquilo de que se fala. $\bullet$ ella: $\left(\mathbf{a} 5^{v}, 12\right)$ \& por tanto se deue bem de guardar a casa: porque nom entre em ella ho aar peçonhentado [vide EM.] $\rightarrow$ DELE. prep. + pron. delle; delles; della: $\left(\mathbf{a}^{\mathrm{v}} \mathbf{}, 4\right)$ em o tempo pestilençial nenhuũ nom deue de star em ajuntamento do pouoo. porque podera ser que alguũ delles sera apeçonhentado ou ferido I $(\mathrm{a} 4 \mathrm{v}, 7)$ por razam do qual os medicos prudentes quando visitam os enfermos deuem de star afastados delles I (a2, 17) Segundo das cousas della. I (a2, 18) Terçeyro. dos remedios della. I (a5, 4) como se deue homem de guardar da pestilencia \& preseruar se della. $\mid(\mathbf{a} 5,25) \&$ tambem donde ha hi podridom de agoas \& fedor dellas. $\rightarrow$ NELE. prep. + pron. vide EM.

EM. [<lat. in.] prep. $-\mathbf{e m}$; em: $(\mathbf{a} 2,6)$ E tralladado de latim em lingoagem | (a2, 7) mestre em sancta theologia I (a2, 9) EM louuor da santissima trijndade | (b2, 19) ou em alguũ muyto fraco | (a2, 20) scilicet. em alguũ que teem corrença ou fluxu do ventre. I (a2v, 14) quando ha cometa apareçe aconteçem mortes de gentes em bathalhas \&c. I $(\mathbf{a 3}, 13)$ de alguũ canno çujo se corrompe ho aar em substançia \& qualidade. I $(\mathbf{a} 4, \mathbf{1 8})$ assy como sam os corpos desordenados em luxuria \& coyto. I $(\mathbf{a 6}, \mathbf{1 5})$ coma da aruda lauada em agoa limpa espargida com sal $\mid(\mathbf{a 6}, \mathbf{1 8 )}$ emtam coma paão ou hũa sopa molhada em vinagre. $\mid\left(\mathrm{a}^{v}, 7\right)$ \& emtam leuaua commigo huũa sponja ou paão enssopado em vinagre | $\left(\mathbf{a} 4^{v}, 3\right)$ nenhuũ nom deue de star em ajuntamento do pouoo | $\left(\mathbf{a} 6^{v}, 3\right)$ Em monpilher nom me pude escusar de companhia de gente.| $\left(\mathbf{a}^{\mathbf{v}}\right.$, 27) Feyto em Lixboa $\mid(\mathbf{b}, \mathbf{5})$ \& assi guardando estas cousas seguramente entraras em pouoo ou amtre gente. $\left(\mathbf{( b 2} 2^{\mathrm{v}}, 3\right)$ \& ysto em andando. I (b2v, 8) a qual cousa nom se faria se o homem andar em mouimento. I $(\mathbf{b} 3,5)$ Posto que tal como este nom pode andar em cauallo ou besta. | $(\mathbf{b} 4,22)$ \& sempre antes do meo dia sera em continuo mouimento | (b2v, 13) per alguũ andar em jardijs $\mid\left(\mathbf{b} 2^{v}, 14\right)$ ou em campos. I $\left(a 4^{v}, 14\right)$ o vento do sul teem em si duas causas de de apodrentar | (b4v , 9) quando alguũ teuesse tal apostema que soruesse em si toda a triaga: | (a4v, 22) quando venta vento sul estar em casa per todo o dia I (a4 $\mathbf{a}^{\mathbf{v}}, \mathbf{2 3 )}$ ) este em casa atee que saya o sol I (a6, 21) milhor he estar em casa que andar fora. I (b, 10) Em casa sempre este fogo açeso. I (a5 $\left.{ }^{v}, 4\right)$ em tal casa como esta morrem os homens mais azinha $\mid\left(a 5^{v}, 5\right)$ \& em outra nom $\mid\left(a 5^{v}, 7\right)$ mesmo onde se lançam verças \& caldos podres que sobejam em taaes casas.l (b2v, 23) o homem que em tal dia he apeçonhentado nom come mujto. I (a2v, 5) Segundo sinal he quando em tal estio muytas vezes escureçem: ou pareçem escureçer os dias $\mid\left(\mathbf{b} 4^{\mathbf{v}}, \mathbf{2}\right)$ \& seja rompida faça se meezinha em tal maneira. $\mid$ $(\mathbf{a} 6,9)$ toda multidom de pouoo \& comunidade em tal tempo se deue de euitar $\mid(\mathbf{a 6}, \mathbf{1 0})$ em quanto for possiuel. $\mid\left(\mathbf{a} 4^{v}, 20\right)$ boõ he ao saão em tempo da pestilençia $\mid(\mathbf{a} 5,9)$ grande remedio he em tempo da pestilençia a sancta penitencia \& a confissam I ( $\mathbf{b}^{\mathrm{v}}, \mathbf{1 9 )}$ Em tempo da pestilencia valem mais cousas azedas $\mid(\mathbf{b} \mathbf{2}, \mathbf{1 0})$ deue se home $m$ de guardar em tempo da pestilencia que nenguem nom tema morte. $\mid$ $(\mathbf{b} 2 \mathbf{v}, \mathbf{1 3})$ em tempo da pestilencia. logo despois de comer.que tal desejo se deue reuogar \& impedir I $(\mathbf{b} 3, \mathbf{1 7})$ se alguem sentir apeçonhentado ou e $m$ tempo de pestilencia sentir estas cousas que escuse o

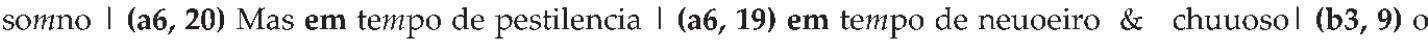
home $m$ ja apeçonhentado em todas as horas teem grande desejo de dormir. I (a5v , 1) em algũas casas estam as agoas çujas per dous \& tres dias. $(\mathbf{( b 2}, \mathbf{1 6})$ SAngria huũa vez em huũ mes se pode bem fazer. $\rightarrow$ No. prep. + art. - em o; em ho; em os; em a; em ha; em as: $(b 3,20)$ em o tempo do somno o sprito vital repousa: | $\left(\mathbf{a 4}^{v}, \mathbf{2}\right)$ mais ajnda digo que em o tempo pestilençial nenhuũ nom deue de star em ajuntamento do pouoo. ( $(\mathrm{b} 4,7)$ E se for em o espinhaço mingua sobre a vea que he chamada a pedica grande. I $(\mathbf{b} 4,13)$ porque se apareçer despois em o braço direyto:I $(\mathbf{b} 4,14)$ que se sangre em o braço esquerdo do figado | $\left(\mathbf{b 4}^{\mathrm{v}}{ }^{\mathrm{w}}, \mathbf{1 8}\right)$ emtom obra milhor em o homem. I $\left(\mathbf{a} 4^{\mathrm{v}}, \mathbf{1 7}\right)$ A segunda que assi como se escreue em o terçeyro liuro dos amforismos $\mid(\mathbf{a} 6,3)$ E por tanto diz auiçena em o quarto do canone. I $(\mathbf{a} 6,23)$ \& em special em o alto veraão | $(\mathbf{b}, 22)$ possa a triaga em o corpo fazer sua operaçam. I (b2v, 18) porque o homem estando em o somno traz em si muytos vapores. I (b3 $\left.{ }^{v}, 18\right)$ sangre se em o pee daquelle mesmo lado $\mid\left(\mathbf{a}^{\mathbf{v}}, 4\right)$ \& ha empresam do aar corrompe os spiritos vitaes $\mathbf{e} m$ ho homem $\mid$ (b, 20) \& a triaga seja delida em ho vaso ou copo em que ha tomares. I (b2v, 3-4) porque em ho somno ha queentura intrinseca. I $\left(\mathbf{a} 3^{v}, 9\right)$ se causa ho morbo ou ha chagua em ho homem: I assi em ho inuerno

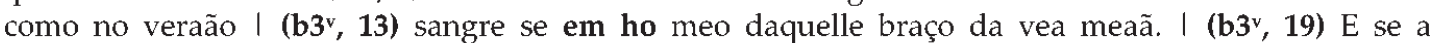
apostema for em ho pescoço. $\mid\left(\mathbf{a} 2^{v}, 13\right)$ \& segundo diz aristoteles em os metauros. I $(\mathbf{b} 4,17)$ \& assi dos 
outros lugares em os quaaes apareçer a apostema I ( $\left(\mathbf{b}^{\mathbf{v}}, \mathbf{2}\right) \mathrm{E}$ em os mantijmentos guarte das cousas queentes. I (a3 $\left.{ }^{v}, \mathbf{1 1}\right) \&$ as vezes apostema \& jsto em os demais. I (a3 $\left.{ }^{\mathrm{v}}, \mathbf{1 8}\right)$ muytos medicos que em os enfermos soomente esguardam as ourinas $\mid\left(\mathbf{a 5}^{\mathrm{v}}, 3\right)$ \& as lançam per canos \& regos soterranhos: em os quaaes taes agoas çujas causam grandes fedores $\mid(\mathbf{b} 4, \mathbf{1 2})$ emtom ha de menuyr o sangue em a parte crucifixa | (b2, 21) Faça se ergo a sangria em a vea destra ou seestra ante de comer. | (b3 $\left.{ }^{v}, 20\right)$ seja sangrado em a vea de çephalica açerca do dedo polegarl $\left(\mathbf{b} 3^{\mathrm{v}}, 21\right)$ em a maão daquelle meesmo lado l $\left(\mathbf{a} 5^{\mathrm{v}}, 14\right)$ \& faz podridom em a casa ou em lugar onde dormem. I $\left(\mathbf{b 3}^{\mathrm{v}}\right.$, 16$)$ em a vea que he açerca do dedo mais pequeno. $\mid\left(\mathbf{b}^{\mathrm{v}} \mathbf{v}, \mathbf{1 0}\right)$ \& sempre naquella meesma parte do corpo: em a qual ha doença ou chaga apareçer $\mid\left(\mathbf{a} 2^{v}, 9\right)$ Tercio he quando ha hy muytas moscas em ha terra. I Da rayz superior veem $\&$ aconteçe a pestilençia per virtude dos corpos de çima dos çeos. dos quaaes se corrompem os spiritos vitaes em ha creatura viuente. I \& ysso mesmo tem grande door em ha parte dianteira da cabeça. I $\left(\mathbf{a} 6^{\mathrm{v}}, \mathbf{2 5}\right)$ se estas cousas nom trouuer homem em ha maão I $\left(\mathbf{b} 3^{\mathrm{v}}, \mathbf{1 4}\right)$ sangre se em ha vea meaã daquelle meesmo braço. I (b2, 19) assy como he em as molheres que som prenhes. $\bullet$ no;nos; na: $(\mathrm{a} 6 \mathrm{v}, 2)$ \& tambem he boõ assi em ho inuerno como no veraão cheirar cousas azedas, I $(\mathbf{3} 3,25)$ \& de tal diz auicena no quarto liuro I he boõ assi em ho inuerno como no veraão I toma se ergo duas vezes no dia com boõ vinho claro \& auguado $\mid\left(\mathbf{a}^{\mathrm{v}}, \mathbf{8}\right)$ \& sempre no punha nos narizes \& na boca. $\mid(\mathbf{b 3}, 21)$ ou na meaã daquelle meesmo braço. I $(\mathbf{b} 3,22)$ ou na maão daquelle meesmo lado $\mid\left(\mathbf{b} 4^{v}, 5\right)$ \& despois poõe tudo na apostema. I (b3v, $\mathbf{1 5})$ ou na vea epatica $\rightarrow$ NAQUELE. prep. + pron. $\bullet$ em aquelle; naquelle; naquella: (b2, 26) \& nom conuem dormir em aquelle dia que se sangrar \& abrir a vea. I (b3, 25) Estantes ergo assi estas cousas quando se homem sente ser tocado da peçonha pestilençial. logo naquelle meesmo dia mingue ho sangue I $\left(\mathbf{b}^{\mathrm{v}}, \mathbf{9}\right)$ \& sempre naquella meesma parte do corpo: em a qual ha doença ou chaga apareçer se deue de sangrar \& abrir a vea. $\rightarrow$ NELE. prep. + pron. $\bullet$ em ella: $(\mathbf{a} 5$ v, 12$) \&$ por tanto se deue bem de guardar a casa: porque nom entre em ella ho aar peçonhentado $\rightarrow$ EM CIMA. vide CIMA. $\rightarrow$ EM CONTRÁRIO. vide CONTRÁRIO. $\rightarrow$ EM ESPECIAL. vide ESPECIAL. $\rightarrow$ EM LUGAR DE. vide LUGAR. $\rightarrow$ EM MODO QUE. vide MODO. $\rightarrow$ EM QUANTO. vide QUANTO. $\rightarrow$ EM MANEIRA QUE. vide MANEIRA. $\rightarrow$ EM NENHUMA MANEIRA. vide MANEIRA. $\rightarrow$ EM TANTO QUE. vide TANTO. $\rightarrow$ EM TODA MANEIRA. vide MANEIRA.

EMPECER. [<lat. impediscere. ]. ซ. Prejudicar, causar estoroo ou dano. empeçe, S. XV: (a5v, 8) \& por serem assi podres causam tal fedor \& doença que muyto empeçe

EMPEÇONHENTAR. vide PEÇONHA.

EMPEÇONHENTADO. vide PEÇONHA.

EMPERó. [ de en(de) 'dali, dele' + pero (<lat. per hoc 'por isso').] conj. empero: @ Por isso: (a5, 11) Empero prometo te que muyto boõ remedio he fugir \& mudar o lugar apeçonhentado. I (b2v, 16) Empero diz auiçena que se homem quiser dormir ha de beber hũa bõa vez de vinho ou çerueja ante de dormir. Contudo, apesar disso: $\left(\mathrm{a}^{\mathrm{v}}, \mathbf{1 7}\right)$ \& jsto porque apareçem bõas ourinas \& boõas augoas. \& bõas digestiões. empero ho enfermo vay caminho da morte. I $(\mathbf{b}, 25)$ E ysso meesmo deues de comer boõ manjar \& bõa yguaria com boõ vinho puro \& ameude. empero nom muyto juntamente. Posto que, ainda que (com verbo no subjuntivo): $(\mathbf{b} 2,24)$ \& despois que a vea for ferida ou aberta aproueyta muyto tomar muyto prazer. beber muy boõ vinho ou bõa çerueja. empero sempre se tome temperadamente

EMPLASTRO. [< lat. emplastrum, -i.] sm. "Medicamento exterior de substancia solida, E glutinosa, cõposto de varios simples, ou drogas, amassadas num corpo. Há emplastos de muytas materias, \& muytos delles com nomes exquisitos" (Bluteau: III, 64). - emprasto, S. XIV: $\left(\mathrm{b4} 4^{\mathrm{v}}, 4\right)$ Toma folhas de sabugo pisadas \& com mostarda pisada \& faze emprasto

ENCHER (O VENTRE). [<lat. implere.] $v$. Fartar-se, comer muito. $\bullet$ encher: $(\mathbf{a} 6,4)$ aquelles que sempre querem encher seus ventres que abreuiam seus dias \& tempos da sua fim

ENDEREÇAR. [<de adereçar, do lat. *ad-directiare, de directus, part. de dirigere, 'dirigir, alinhar, endireitar'] 
v. Endireitar. - endereçam, S. XIV: (a6v, 19) AS cousas canfortatiuas sam estas .scilicet. açafram. cassiafistola. chantagem. com todas as outras heruas que endereçam ho spirito interior [ $c f$. INDIRAMçE].

ENFERMO. [<lat. infirmus, - $a$, um.] • enfermo; enfermos; enfermos; emferma. [adj. Que não tem saúde, fraco, doente: $\left(\mathbf{a} 3{ }^{\mathrm{v}}, \mathbf{1 5}\right)$ mas ajnda tam sobejamente se agraua ha natureza que nom sinte sy ser ferida nem emferma. ourinas \& boõas augoas. \& bõas digestiões. empero ho enfermo vay caminho da morte.l (a3v, 21) Ergo he neçessario que todo enfermo se proueja de boõ fisico \& bem esperto. I (a3 $\left.{ }^{\mathrm{v}}, 19\right)$ E por tanto muytos medicos que em os enfermos soomente esguardam as ourinas superficialmente falam. \& lygeyramente sam enganados $\mid\left(\mathbf{a} 4^{\mathbf{v}}, \mathbf{6}\right)$ os medicos prudentes quando visitam os enfermos deuem de star afastados delles: I $\left(\mathbf{a} 4^{v}, 9\right)$ \& assi ho deuem de fazer os seruidores dos enfermos. I $\left(\mathbf{a} 4^{\mathrm{v}}, \mathbf{1 6}\right)$ A primeyra que faz emfraqueçer os corpos asşi dos saãos como dos enfermos. I $\left(\mathbf{a 6} \mathbf{6}^{\mathrm{v}}, \mathbf{5}\right)$ porque andaua de casa em casa curando enfermos por causa da minha pobreza. I $(b, 15)$ Quanto he ao teu mantijmento digo te que a triaga te he muyto proueytosa: assi saãos como aos enfermos. $\rightarrow$ ENFERMIDADE. sm. Doença. - jnfirmidade; infirmidade; infirmidades: $\left(\mathrm{a}^{\mathrm{v}}, 9\right)$ \& tal morbo ou jnfirmidade as vezes he febre. I (a4, 4) Se taaes jnfirmidades pestilençiaes sam contagiosas I $(\mathbf{a 4}, \mathbf{1 3})$ \& por tanto deues de notar que os corpos mays despostos a jnfirmidade \& a morte sam os corpos queentes $\mid \mathbf{( b 2}, \mathbf{1 1})$ que nenguem nom tema morte. sem teer infirmidade pestilencial.I $(a 4,22)$ taaes infirmidades pestilençiaaes sam contagiosas

ENFRAQUECER. vide FRACO.

ENGANAR. [< lat. ingannare.] v. Iludir, induzir a erro. - emganados; emganados: (a3, 16) \& daly procedem febres pestilençiaes. açerca das quaes muytos medicos sam emganados. $\left(\mathbf{a} 3^{\mathrm{v}}, 20\right)$ E por tanto muytos medicos que em os enfermos soomente esguardam as ourinas superficialmente falam. \& lygeyramente sam emganados

ENTÃo. [<lat. in tunc.] adv. - emtam; emtam; emtom, emtom, s. XIII. 凹 Naquele tempo: (a6v, 6) Em monpilher nom me pude escusar de companhia de gente. porque andaua de casa em casa curando enfermos por causa da minha pobreza. \& emtam leuaua commigo huũa sponja ou paão enssopado em vinagre: Nesse caso: $\left(\mathrm{a}^{\mathrm{v}},7\right)$Segundosinalhequandoemtalestiomuytasvezesescureçem:ou pareçem escureçer os dias em modo que pareçe que quer chouuer e nom choue. \& emtam se isto mujto durar he pera temer de vijr grande pestilençia. I (a2v, 10) Tercio he quando ha hy muytas moscas em ha terra. porque emtam pareçe ho aar ser empeçonhentado. I $(\mathbf{a 6}, 13)$ E quando assi for que companhia \& ajuntamento de pouoo se euite. emtam huse homem dos remedios abayxo scriptas . I (b3v ${ }^{2}$ ) \& se homem nom quiser cortar muytas veas juntamente: emtam leyxe yr a vea aberta ou ferida atee o retardamento do sangue. I $(\mathbf{a} 6, \mathbf{1 8})$ E ysto nom poder auer. emtam coma paão ou hũa sopa molhada em vinagre. I $(\mathbf{b} 3,21)$ em o tempo do somno o sprito vital repousa: \& emtom a peçonha espalha se per os membros de toda parte. I $\left(\mathbf{b} 4^{v}, \mathbf{1 8}\right)$ \& ysto com o estamago gejuũ. porque emtom obra milhor em o homem. I $(\mathbf{b} 4,11)$ E se pella ventura sentir chagas despois de dormir: emto $m$ ha de menuyr o sangue em a parte crucifixa $\mid(\mathbf{b 4}, \mathbf{1 6})$ E se apareçer a apostema de bayxo do braço direyto: emtom faça se como dito he do braço esquerdo. I $(\mathbf{b} 4,21)$ E despois do sangue menuido se for muyto fraco emtom podera dormir despois do meo dia. I $\left(\mathbf{b} 4^{v}, 15\right)$ \& pisa todo muyto bem atee que vejas que quer pareçer que say destas cousas assy pisadas augoa ou çumo. emtom toma aquelle çumo \& mistura ho com leyte $\mathrm{d} e$ mulher

ENSANHAR. [<lat. insaniare.] $v$. Enfurecer. - ensanha, S. XIV: $($ a2v , 16) A morte se ensanha ha çidade se filha \& toma dos jmigos

ENSOPAR, vide SOPA.

ENTRAR . [<lat. intrare.] v. Penetrar. $\bullet$ emtra; emtrar; entrar; entraras; entre; entre: $\left(\mathbf{a 4}{ }^{\mathrm{v}}\right.$, 19) Ho sul he vento inchado \& agraua o ouvido fere o coraçam. porque abre os poros do homem \& emtra atee o 
coraçam. $\mid\left(\mathbf{b}^{\mathrm{v}}, \mathbf{1 0}\right)$ \& nom consinta emtrar ho aar seco.l $\left(\mathbf{a} \mathbf{6}^{\mathrm{v}}, \mathbf{1 1}\right)$ \& os cheyros taaes opilam \& çarram os poros \& os meatos \& os caminhos dos humores \& nom consintem entrar as cousas peçonhentas. $\mid(\mathbf{b}, \mathbf{5})$ \& assi guardando estas cousas seguramente entraras em pouoo ou amtre gente. I (a5 $\left.{ }^{\mathrm{v}}, \mathbf{1 2}\right)$ \& por tanto se deue bem de guardar a casa: porque nom entre em ella ho aar peçonhentado I $\left(a 5^{\mathrm{v}}, 22\right)$ E tal fumo entre per a boca \& per os narizes. I (a5v, 12) \& por tanto se deue bem de guardar a casa: porque nom entre em ella ho aar peçonhentado

ENTRE. [<lat. inter.] prep. Entre; no meio. - amtre; antre, S. XIII: (b, 6) \& assi guardando estas cousas seguramente entraras em pouoo ou amtre gente. I $\left(\mathbf{a} 6^{v}, 20\right)$ \& estas cousas prestam pera antre pouoo I $(\mathbf{b} 3,4)$ mas todas estas cousas pode muyto bem euitar \& de sy lançar andando ou espaçando huũ pouco antre ho comer \& o dormir.। (b3v, 22) faça se a sangria de çephalica daquelle meesmo lado. ou da vea que esta antre o dedo demostrador \& ho dedo polegar

ERGo. [<lat. ergo.] conj. Por isso; logo; portanto. $\bullet$ ergo: (a2v $\left.{ }^{2}, 25\right)$ Quando ergo estes signaes apareçerem. he pera temer grande pestilencia. I $\left(\mathbf{a}^{\mathrm{v}}, \mathbf{2 0}\right) \mathrm{E}$ por tanto muytos medicos que em os enfermos soomente esguarda $m$ as ourinas superficialmente falam. \& lygeyramente sam emganados. Ergo he neçessario que todo enfermo se proueja de boõ fisico \& bem esperto. I (a5v, 15$)$ Apure se ergo \& asutileze se a casa per clara chama ou flama $\mid(\mathbf{b}, \mathbf{1 5})$ digo te que a triaga te he muyto proueytosa: assi saãos como aos enfermos. toma se ergo duas vezes no dia com boõ vinho claro \& auguado. I (b2, 21) Faça se ergo a sangria em a vea destra ou seestra ante de comer. I (b3, 11) Ergo per estes signaaes se sente homem apeçonhentado. I $(\mathbf{b} 3, \mathbf{1 6})$ He ergo gramde remedio sy se alguem sentir apeçonhentado ou em tempo de pestilencia sentir estas cousas que escuse o somno I $(\mathbf{b 3}, 23)$ Estantes ergo assi estas cousas quando se homem sente ser tocado da peçonha pestilençial. logo naquelle meesmo dia mingue ho sangue

ERVA. [<lat. herba, ae.] sf. Planta geralmente de pequeno porte, de caule tenro, não lenhoso. - herua; heruas: $(\mathbf{b} 4 \mathrm{v}, \mathbf{1 0})$ Tomaras hũa herua que chamam barbajouis.। $\left(\mathbf{b 2} \mathbf{2}^{\mathrm{v}}, \mathbf{6 - 7}\right)$ em modo que escassamente pode nenhũa herua tal peçonha reuogar. a qual cousa nom se faria se o homem andar em mouimento. I (a5 ${ }^{\mathrm{v}}$, 17) \& faça se fogo claro de lenha. \& faça se tambem com fumo de boôas heruas aqui scriptasl $\left(a 6^{v}, 19\right)$ AS cousas canfortatiuas sam estas .scilicet. açafram. cassiafistola. chantagem. com todas as outras heruas que endereçam ho spirito interior I ( $\left.\mathbf{b}^{v}, 26\right)$ E as speçias que comuummente conuem a comer. sam gingiure. canela. cuminhos. froles de heruas cheyrosas. \& açafram

ESCAPAR. [<lat. *excappare.] v. Livrar-se (de perigo). - escapey; escapar; escapara: (a6v, 11) \& assi escapey de tal pestilencia. I $\left(\mathrm{a}^{\mathrm{v}}, \mathbf{1 3}\right)$ que os meos companheiros nom podiam creer que eu podesse viuer \& escapar. I $\left(\mathrm{b} 4^{v}, 23\right)$ \& qualquer que se per este modo reger escapara muytos perijgos da pestilencia

escassamente. [de escasso.] adv. Dificilmente. escassamente: $\left(\mathbf{b} 2^{\mathrm{v}}, \mathbf{6}\right)$ em ho somno ha queentura intrinseca. caladamente traz a peçonha ao coraçam \& aos outros membros speciaaes. em modo que escassamente pode nenhũa herua tal peçonha reuogar

ESCREVER. [<lat. scribere.] v. Dizer por meio da escrita. - screuer; escreue; scriptas: $(\mathbf{a} 2,15)$ Quero algũas cousas da pestenença que nos ameude fere: dos ditos dos mays autenticos medicos: screuerl $\left(\mathrm{a}^{\mathrm{v}}\right.$, 17) A segunda que assi como se escreue em o terçeyro liuro dos amforismos.l $\left(\mathbf{a} 5^{v}, 18\right)$ \& faça se fogo claro de lenha. \& faça se tambem com fumo de boõas heruas aqui scriptas

ESCURECER. [de escuro.] v. • escureçer; escureçem. [La] Tornar-se menos luminoso: (a2v, 5-6) Segundo sinal he quando em tal estio muytas vezes escureçem: $\mid\left(\mathbf{a} 2^{v}, \mathbf{6}^{\prime}\right)$ ou pareçem escureçer os dias em modo que pareçe que quer chouuer e nom choue. 1 Turvar-se: $\left(\mathbf{a 6}^{\mathrm{v}}, \mathbf{2 4 )}\right.$ Os olhos do aar empeçonhentado logo escureçem

ESCUSAR. [<lat. excusare.] $v$. escusar; escuse. Dispensar: $(\mathbf{b} 3,18)$ He ergo gramde remedio sy se alguem sentir apeçonhentado ou em tempo de pestilencia sentir estas cousas que escuse o somno [D] Furtar-se: $\left(\mathbf{a}^{v}\right.$, 4) Em monpilher nom me pude escusar de companhia de gente 


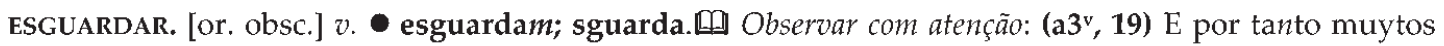
medicos que em os enfermos soomente esguardam as ourinas superficialmente falam. \& Iygeyramente sam emganados. Vigiar: $(\mathbf{a} 4, \mathbf{9 )}$ Da parte do agente quando aquella jnfluençia sobre celestial mays dereytamente fere \& sguarda aquelle ou aquel outro. que aquelle ou aqueloutro lugar ou homem

ESMORECER. [or. obsc.] v. Perder as forças. esmoreçer: $(\mathbf{b 3}, \mathbf{2 6 )}$ logo naquelle meesmo dia mingue ho sangue: \& se sangre atee esmoreçer

ESPAÇO. [<lat. spatium,-ii.] sm. Distância. - espaço: $(\mathbf{a} 4 \mathbf{v}, \mathbf{2 3 - 2 4 )}$ \& se for neçessario que saya este em casa atee que saya o sol \& suba huũ boõ espaço sobre o nosso orizonte. $\rightarrow$ EsPaçAR. $v$. Distanciar dois momentos. espaçando: $(\mathbf{b} 3,4)$ mas todas estas cousas pode muyto bem euitar \& de sy lançar andando ou espaçando huũ pouco antre ho comer \& o dormir

ESPÁDUA. [<lat. spatula, -ae.] sf. Ombro. - espadoas: (b4, 5)E se polla ventura for açerca das espadoas: minguaras o sangue com ventosas.

ESPALhAR. [de palha.] $v$. Alastrar. espalha:(b3, 21) em o tempo do somno o sprito vital repousa: \& emtom a peçonha espalha se per os membros de toda parte

ESPARGIR.[<lat. sparegere.] v. Borrifar. espargida: $(\mathbf{a 6}, \mathbf{1 6})$ de manhaã quando se alguũ aleuantar logo coma da aruda lauada em agoa limpa espargida com sal

ESPÉCIA. [de espécie.] sf. Especiaria. Inicialmente, produto exótico, importado de terras distantes. Foram atribuidas funçōes medicinais a muitos desses produtos, incluidos alguns que não tiveram uso como condimentos na culinária. Classificadas como quentes e, em geral, secas, as especiarias, mais do que os condimentos de produção local, foram consideradas auxiliares efetivas na $d i \mathrm{~g}$ e $\mathrm{s} t \tilde{a}$ o [q.v.]. O calor que produziam foi classificado em graus, sendo perigosas aquelas classificadas a partir do quarto grau, como a pimenta. - speçias: $\left(\mathbf{b}^{\mathrm{v}}\right.$, 24) E as speçias que comuummente conuem a comer. sam gingiure. canela. cuminhos. froles de heruas cheyrosas. \& açafram

espeCial. [<lat. specialis, -e.] adj. Particular. $\rightarrow$ EM especial. Particularmente $\bullet$ em special: $(\mathbf{a} 5,23) \&$ per esta mesma causa euitaras \& esquiuaras todo ho fedor .scilicet. de estrebarias. de campos. de ruas. \& em special donde ha hi corpos mortos \& podres. I $(\mathbf{a 6}, 22)$ E tambem a casa seja aguada: \& em special em o alto veraão com vinagre rosado $\&$ folhas de vinhas. $\rightarrow$ MEMBRos ESPECIAIS. vide MEMBRO.

ESPERAR.[<lat. sperare.] 0.0 spere; espere. 1 Aguardar: $(\mathbf{b 3}, 13)$ mas se alguũ nom quiser creer: spere per huũ meo dia \& logo sentira apostema de bayxo dos braços. [ᄄ] Ter esperança; confiar: $(\mathbf{b} 2, \mathbf{1 4})$ mas qualquer com muyto prazer \& alegria sempre espere de muyto viuer

ESPERTO. [<lat. expertus, $-a,-u m$.] adj. Atento; perito. - esperto: $(\mathbf{a} 3 v, 22)$ Ergo he neçessario que todo enfermo se proueja de boõ fisico \& bem esperto. $\rightarrow$ ESPERTAR. $v$. Estimular, acordar. $\bullet$ esperta: (b3v, 1) porque pouco minguamento de sangue esperta a peçonha.l $\left(\mathbf{b} 3^{v}, 5\right)$ porque pequena sangria: ou pequena sayda de sangue. mais fortemente esperta a peçonha segundo dicto he

ESPINHAÇO. [de espinha.] sm. Coluna vertebral. • espinhaço: $(\mathbf{b 4}, 7)$ E se for em o espinhaço mingua sobre a vea que he chamada a pedica grande

ESPÍRITO. [<lat. spiritus, -us.] sm. Ânimo. - sprito; spirito: (a5v, 10) E assi como per ho boõ cheyro \& aromatico: se recrea o coraçom \& o sprito do homem. assi emfraqueçe per o çujo fedor.l (a6v, 19) AS cousas canfortatiuas sam estas .scilicet. açafram. cassiafistola. chantagem. com todas as outras heruas que endereçam ho spirito interior. $\rightarrow$ ESPírITo viTAL. Segundo Bluteau (II, 281) são partes sutilíssimas do 
sangue arterial, geradas no cérebro. sprito vital; spiritos vitaes: (b3, 10) porque o homem ja apeçonhentado em todas as horas tee $m$ grande desejo de dormir. porque a peçonha intrinseca pertorua o sprito vital. em modo que sempre deseja folgança. I (b3, 20) \& assi segundo estas cousas he assaz manifesto: que em o tempo do somno o sprito vital repousa:\& emtom a peçonha espalha se per os membros de toda parte. I $($ a3, 24) Da rayz superior vee $m \&$ aconteçe a pestilençia per virtude dos corpos de çima dos çeos. dos quaaes se corrompem os spiritos vitaes em ha creatura $\mid\left(\mathbf{a} 3^{\mathrm{v}}, 4\right)$ ha empressam dos çeos corrompe ho aar. \& ha empresam do aar corrompe os spiritos vitaes em ho homem

ESPONJA. [<lat. spongia, -ae.] sf. Termo geral empregado para designar a parte fibrosa do corpo de determinados espongiários marinhos (Porifera), particularmente aqueles pertencentes ao gênero Spongia (Dictyocerata, Spongiidae). Entre as espécies mais vulgares, Spongia communis (Lamarck, 1814) fornece uma esponja grosseira, usada nas lavagens domésticas e em várias indústrias, enquanto Spongia officinalis Linnaeus, 1759 dá origem a um material de melhor qualidade, próprio para o banho e diversos outros fins. Explorado desde tempos muito remotos em várias áreas do Mediterrâneo, este último artigo chegou a ter amplo emprego na medicina, sendo utilizado não apenas como absorvente, mas também como detergente, fundente, resolutivo, redutor, etc. Na proximidade de vitimas da peste, os medievais procuravam respirar através de pedaços de pão, pano, esponja ou outros materiais absorventes encharcados de substâncias fortemente aromáticas, como o vinagre e o vinho, pois era crença geral que a doença se propagava graças aos "eflúvios malignos" de uma atmosfera contaminada. • sponja, S. XV: $\left(\mathbf{a}^{\mathbf{v}}, \mathbf{6}\right)$ porque andaua de casa em casa curando enfermos por causa da minha pobreza. \& emtam leuaua commigo huũa sponja ou paão enssopado em vinagre: \& sempre no punha nos narizes \& na boca

ESQUENTAR. vide QUENTE.

ESQUERDO. [or, obsc.] adj. O lado que corresponde àquele do coração do ser humano. - esquerdo: (b3 ${ }^{14}$ ) Se de bayxo do braço seestro ou esquerdo. sangre se em ha vea meaã daquelle meesmo braço. I (b4, 14) se apareçer despois em o braço direyto: que se sangre em o braço esquerdo do figado $\mid(\mathbf{b} 4,17) \mathrm{E}$ se apareçer a apostema de bayxo do braço direyto: emto $m$ faça se como dito he do braço esquerdo

esquivar. [or. obsc.] v. Afastar. esquiuar; esquiuaras; esquiue: (a5, 15) \& por ysso quanto for possiuel taaes deuem de euitar \& de sy esquiuar as causas de tal podridom. I (a5, 22) \& per esta mesma causa euitaras \& esquiuaras todo ho fedor . I (a5v , 25) Item per esta meesma ca<u>sa se euite \& esquiue: todo ho inchamento do ventre que veem per muyto comer

ESTAR. [<lat. stare.] - estar; star; esta; estam; estando; estantes; estem; este. v. $\square$ Localizar-se: (a6, 20) Mas em tempo de pestilencia milhor he estar em casa que andar fora. I $(\mathbf{a} 4 \mathbf{v}, 21)$ pola qual cousa boõ he ao saão em tempo da pestilençia quando venta vento sul estar em casa per todo o dia I $\left(a 4^{v}\right.$, 3) mais ajnda digo que em o tempo pestilençial nenhuũ nom deue de star em ajuntamento do pouoo. I $(\mathbf{a} 3,11)$ nos veemos que da priuada que esta açerca da camera ou de alguũ fedor particular de alguũ canno çujo se corrompe ho aar em substançia \& qualidadel $\left(\mathbf{b 3}^{v}\right.$, 26) faça se a sangria de çephalica daquelle meesmo lado. ou da vea que esta antre o dedo demostrador \& ho dedo polegar.l $(\mathrm{a} 5,20)$ Fechem se ergo as frestas ou genelas como dito he que vaam ou estam pera o sul atee hũa hora depois do meo dia $\mid(\mathbf{a} 5,21)$ \& abram se as que stam pera o norte. $\mid\left(\mathbf{a 5}^{v}, 1\right)$ em algũas casas estam as agoas çujas per dous \& tres dias $\mid\left(\mathrm{a}^{\mathrm{v}}\right.$, 23) \& se for neçessario que saya este em casa atee que saya o sol \& suba huũ boõ espaço sobre o nosso orizonte. I (b, 10) Em casa sempre este fogo açeso. I (b2v, 3) em toda maneyra tal como este euite o somno $\mid(\mathbf{b} 3,5)$ Posto que tal como este nom pode andar em cauallo ou besta. I (b2v, 18) porque o home $m$ estando em o somno traz em si muytos vapores. I $(\mathbf{b 3}, \mathbf{2 3 )}$ Estantes ergo assi estas cousas quando se homem sente ser tocado da peçonha pestilençial. logo naquelle meesmo dia mingue ho sangue: [icar: $\left(\mathbf{a 4}^{\mathbf{v}}, \mathbf{7}\right)$ os medicos prudentes quando visitam os enfermos deuem de star afastados delles: teendo o rostro pera genela ou fresta | (b2v ${ }^{v}$,2) Mas diras tu. como sintira homem que esta apeçonhentado \& ferido da pestilençia $\mid\left(\mathbf{a} 4^{v}, 13\right) \&$ as genelas ou frestas pera ho meo dia ou pera ho sul este $m$ çarradas 
ESTE. [<lat.iste, ista. ] pron. demonstr. - este; estes; estos; esta; estas. @ $\square$ Refere algo que se acabou de mencionar: $(\mathbf{b} 4 \mathbf{v}, 22)$ \& qualquer que se per este modo reger escapara muytos perijgos da pestilencia I $\left(\mathbf{a} 2^{\mathrm{v}}, \mathbf{2 5}\right)$ Quando ergo estes signaes apareçerem. he pera temer grande pestilencia. I $\left(\mathbf{b} 2^{\mathrm{v}}, \mathbf{1 9}\right) \&$ estes maaos humores se lançam fora per tomar hũa bõa vez de vinho boõ $\mid(\mathbf{b} 3,12)$ Ergo per estes signaaes se sente homem apeçonhentado. $\left(\mathbf{a} 6^{v}, 14\right)$ Eu çertamente todos estos remedios prouey. I $\left(\mathbf{a 5}^{v}, 4\right) \&$ daqui veem que em tal casa como esta morrem os homens mais azinha \& em outra nom $\mid$ (a3, 13) \& esta causa particular \& pode aconteçer cada dia.l (a3, 21) \& tambem esta causa he as vezes particular. I $\left(\mathbf{a}^{\mathrm{v}}, \mathbf{5}\right)$ \& assy se geera ha pestilençia per esta causa. I $\left(\mathbf{a}^{\mathrm{v}} \mathrm{v}, \mathbf{5}\right)$ \& assy se geera ha pestilençia per esta causa. | $(\mathbf{a} 5,21)$ \& per esta mesma causa euitaras \& esquiuaras todo ho fedor . I $\left(\mathbf{a 5}{ }^{\mathrm{v}}, \mathbf{2 4 )}\right.$ Item per esta meesma ca<u>sa se euite \& esquiue: todo ho inchamento do ventre $\mid(\mathbf{a 6}, \mathbf{6})$ Item per esta mesma causa se deue euitar ho banho de cada dia. I $\left(\mathrm{a3}^{\mathrm{v}}, \mathbf{2 3}\right)$ E estas cousas sam assy ditas das causas das pestilençia. I $\left(\mathrm{a}^{\mathrm{v}}, \mathbf{2 0}\right)$ \& estas cousas prestam pera antre pouoo $\mid\left(\mathbf{a} 6^{\mathrm{v}}, \mathbf{2 5}\right)$ Os olhos do aar empeçonhentado logo escureçe $m$ se estas cousas nom trouuer homem em ha maão $\mid \mathbf{( b , 3 )} \&$ se estas cousas nom poder auer faça se com vinagre. I (b, 5) \& assi guardando estas cousas seguramente entraras em pouoo ou amtre gente. $\mid(\mathbf{b} 2, \mathbf{1})$ estas cousas busquem se pera os ricos $\mid(\mathbf{b} 3,2)$ mas todas estas cousas pode muyto bem euitar $\mid(\mathbf{b} 3, \mathbf{1 8})$ sy se alguem sentir apeçonhentado ou em tempo de pestilencia sentir estas cousas que escuse o somno $\mid(\mathbf{b} 3,19)$ \& assi segundo estas cousas he assaz manifesto | $(\mathbf{b 3}, \mathbf{2 2 )}$ Estas cousas per my mesmo prouey. I (b3, 23) Estantes ergo assi estas cousas quando se homem sente ser tocado da peçonha pestilençial. logo naquelle meesmo dia mingue ho sangue:। (b4, 8) E todas estas cousas se façam se homem nom dormir antes que conheça que tem a postema. I $(\mathbf{b} 4 \mathbf{v}, 21)$ E estas cousas abastem pera a pestilença. I \& emtam se isto mujto durar he pera temer de vijr grande pestilençia. Indica o que será mencionado em seguida. - esta; estas: (a4, 3) Segunda questam he esta. I $\left(\mathrm{a}^{\mathrm{v}}, \mathbf{1 7}\right)$ AS cousas canfortatiuas sam estas $\rightarrow$ DESTE. prep. + pron. $\bullet$ destas: $(\mathbf{b} 4 \mathbf{v}, \mathbf{1 4 - 1 5})$ pisa todo muyto bem atee que vejas que quer pareçer que say destas cousas assy pisadas augoa ou çumo. $\rightarrow$ ISTO. [<lat. istud.]. pron. demonstr. Resume o que acabou de ser dito. $\bullet$ isto; jsto; ysto; esto: $(\mathbf{a} 2 \mathbf{v}, 7)$ \& emtam se isto mujto durar he pera temer de vijr grande pestilençia. $\mid\left(\mathbf{a}{ }^{v}\right.$, 10) \& tal morbo ou jnfirmidade as vezes he febre. \& as vezes apostema \& jsto em os demais. I (a3v, 15) \& jsto porque apareçem bõas ourinas \& boõas augoas. I $(\mathbf{a} 6,17)$ E ysto nom poder auer. emtam coma paão ou hũa sopa molhada em vinagre. $\mid(\mathbf{a 6}, \mathbf{1 8})$ \& ysto seja mayormente em tempo de neuoeiro \& chuuoso | (b2v $\left.{ }^{\mathrm{v}}, 3\right)$ em toda maneyra tal como este euite o somno \& ysto em andando. I (b2v, 10) A ysto digo breuemente que em tempo da pestilencia. logo despois de comer. se alguũ teuer desejo de dormir: que tal desejo se deue reuogar \& impedir per alguũ andar em jardijs ou em campos. I (b2v, 23) A ysto te respondo que o homem que em tal dia he apeçonhentado nom come mujto. I $\left(\mathbf{b} 4^{\mathrm{v}}, \mathbf{1 7}\right)$ \& da ho a beber aquelle que teuer a postema. \& ysto com o estamago gejuum. I $(\mathbf{a} 3,20)$ \& esto aconteçe muytas vezes onde ha Iugares podres \& corruptos. I $(\mathbf{a 4 , 6 )}$ digo que esto pode aqueçer por duas causas

ESTIO. [<lat. aestivus, -a, um.] sm. A parte mais quente do ano, em seguida ao ve rão [q.v.]. estio: (a2,25) quando em huũ dia do estio \& do alto veraão se muda a manhaã muytas vezes. $\mid\left(a 2^{v}, 5\right)$ Segundo sinal he quando em tal estio muytas vezes escureçem: ou pareçem escureçer os dias

eStôMAgo. [< lat. stomachus,-i.] sm. Um dos órgãos do aparelho digestivo. •estamago, S. XIV: (b4v, 18) \& mistura ho com leyte de mulher \& da ho a beber aquelle que teuer a postema. \& ysto com o estamago gejuũ

ESTORVAR. [<lat. exturbare.] v. Impedir. - estoruar, S. XIII: $(\mathbf{a} 3, \mathbf{2})$ Quando ergo estes signaes apareçerem. he pera temer grande pestilencia. se ho senhor deus todo poderoso ho nom quitar \& estoruar

ESTREBARIA. [de estrabo < lat. stabulum, -i.] sf. Local onde se recolhem as bestas e os arreios.. - estrebarias: $(a 5,23)$ \& per esta mesma causa euitaras \& esquiuaras todo ho fedor scilicet. de estrebarias. de campos. de ruas

ESTRELA. [<lat. stella, -ae.] sf. Corpo celeste com luz própria. • estrela: $\left(\mathbf{a} 2^{v}, 4\right)$ \& prinçipalmente quando he ho vento meridional. ou da parte de estrela do Sul 
EU. [<lat. *eo< ego.] pron. pessoal. Indica aquele que fala. - eu: $\left(\mathbf{a}^{\mathbf{v}}\right.$, 13) que os meos companheiros nom podiam creer que eu podesse viuer \& escapar. Eu çertamente todos estos remedios prouey. I $\left(\mathbf{b} 4^{\mathrm{v}}, 6\right)$ alguũs çirogiaães querem que lhe ponham triaga mas eu rogo mujto que se nom ponha, I $\left(\mathbf{b} 4^{v}, 7\right)$ eu queria antes que quando alguũ teuesse tal apostema que soruesse em si toda a triaga

EVITAR. [<lat. evitare.] v. Fugir a. $\bullet$ euitar; euitaras;euite; euitem: $(\mathbf{a} 5, \mathbf{1 5})$ \& por ysso quanto for possiuel taaes deue $m$ de euitar \& de sy esquiuar as causas de tal podridom. $(\mathbf{a 6}, \mathbf{6})$ Item per esta mesma causa se deue euitar ho banho de cada dia. I $(\mathbf{a 6}, \mathbf{1 0})$ toda multidom de pouoo \& comunidade em tal tempo se deue de euitar em quanto for possiuel $\mid\left(\mathbf{b} 2^{v}, \mathbf{9}\right)$ Mas dira algũ̃. se o homem deue de euitar ho somno que fara homem se teuer o somno natural.। $(\mathbf{b} 3,3)$ mas todas estas cousas pode muyto bem euitar \& de sy lançar andando ou espaçando huũ pouco antre ho comer \& o dormir.| (a5, 15) \& por ysso quanto for possiuel taaes deuem de euitar \& de sy esquiuar as causas de tal podridom.l (a5, 22)\& per esta mesma causa euitaras \& esquiuaras todo ho fedor.I $\left(\mathbf{a}^{\mathrm{v}}\right.$, 24) Item per esta meesma ca<u>sa se euite \& esquiue: todo ho inchamento do ventre I $(\mathbf{a 6}, 13)$ E quando assi for que companhia \& ajuntamento de pouoo se euite. | (b2v, 3$)$ em toda maneyra tal como este euite o somno $\mid(\mathbf{b} 3, \mathbf{1 8})$ que escuse o somno \& ho euite quanto poder. I $\left(\mathbf{b}^{\mathrm{v}}, \mathbf{1 8 )} \&\right.$ potagios se euitem 


\section{F}

FALAR. [ <lat. fabulare.] v. falam; falando. Declarar seu pensamento oralmente: $(\mathbf{a} 3 \mathrm{v}, 20)$ E por tanto muytos medicos que em os enfermos soomente esguardam as ourinas superficialmente falam. \& lygeyramente sam emganados. Comentar: $\left(\mathbf{a} 2^{v}, \mathbf{1 5 - 1 6}\right)$ \& por isso diz ho verso poetico falando do apareçimento da cometa

FAME. vide FOME.

FAZER. [<lat. facere. ] v. fazer; faz; fazem; fara; faria; faze;faça; façam; feyto. 凹 Realizar, executar: (a4v, 8) \& assi ho deuem de fazer os seruidores dos enfermos. I (b, 22) \& nom jantaras atee ho meo dia porque possa a triaga em o corpo fazer sua operaçam. I ((b2, 17) SAngria huũa vez em huũ mes se pode bem fazer. | (a4, 16)E por tanto dos quaaes se faz ha grande resoluçam $\mid\left(\mathbf{a} 2^{\mathrm{v}}, \mathbf{2 0}\right)$ he quando se fazem mujtas relampados \& trouoadas. I (b2v, 9) Mas dira alguũ. se o homem deue de euitar ho somno que fara homem se teuer o somno natural. $\mid\left(\mathbf{b} 2^{\mathbf{v}}, 7\right)$ escassamente pode nenhũa herua tal peçonha reuogar. a qual cousa nom se faria se o homem andar em mouimento. I $\left(\mathbf{b} \mathbf{4}^{\mathbf{v}}, 4\right)$ Toma folhas de sabugo pisadas \& com mostarda pisada \& faze emprasto. I $\left(\mathrm{a}^{\mathrm{v}}, \mathbf{1 6}\right)$ \& faça se fogo claro de lenha. I $\left(\mathrm{a}^{\mathrm{v}}\right.$, 17) \& faça se tambem com fumo de boõas heruas aqui scriptas $\mid(\mathbf{b}, \mathbf{4})$ \& se estas cousas nom poder auer faça se com vinagre. $\mid(\mathbf{b} 2,21)$ Faça se ergo a sangria em a vea destra ou seestra ante de comer $\mid\left(\mathbf{b} 3^{v}, 24\right)$ faça se a sangria de çephalica daquelle meesmo lado.l $(\mathbf{b 4}, \mathbf{1 6})$ E se apareçer a apostema de bayxo do braço direyto: emtom faça se como dito he do braço esquerdo.। $\left(\mathbf{b} 4^{v}, 2\right)$ faça se meezinha em tal maneira. I $(\mathbf{b 4}, \mathbf{9 )}$ E todas estas cousas se façam se homem nom dormir antes que conheça que tem a postema.I (a2, 3-4) Feyto per ho reuerendíssimo Senhor dom Raminto I (b4v , 27)Feyto em Lixboa per Valentino de morauia. $\mathbb{0}$ Resultar em; criar: $(\mathbf{b} 2,4)$ noz nozcadas. pere $<x>$ il \& todo misturado com vinagre faz muy bõa salsa $\square$ Tomar-se: $(\mathbf{a} 2 \mathbf{v}, \mathbf{1 8})$ ho mar se faz cruel. I $(\mathbf{b 4}, \mathbf{2 6})$ porque tal apostema lança o mal de fora \& faz o homem ser muyto saão. $\square$ Causar: $\left(a 4^{v}, 15\right)$ A primeyra que faz emfraqueçer os corpos assi dos saãos como dos enfermos. I $\left(\mathbf{5}^{\mathrm{v}}, \mathbf{1 3}\right)$ ho aar apeçonhentado he humido \& faz podridom em a casa.I $(b 2,12)$ porque ymaginaçam faz causa \& perijgo

FEBRE. [<lat. febris, -is.] sf. Sindrome que se caracteriza por diversos sinais e sintomas, dentre eles, a aceleração do pulso e o aumento de temperatura $\bullet$ febre; febres, S. XIV: $(\mathrm{a3v}, \mathbf{1 0}) \&$ tal morbo ou jnfirmidade as vezes he febre. \& as vezes apostema $\mid(\mathbf{a} 3, \mathbf{1 4})$ \& daly procedem febres pestilençiaes. açerca das quaes muytos medicos sam emganados. I $(\mathbf{a} 3, \mathbf{1 6})$ porque nom conheçem taes febres serem pestilençiaes

FECHAR. [de fecho.] v. Cerrar. - fechem: $(\mathbf{a} 5,18)$ Fechem se ergo as frestas ou genelas como dito he que vaam ou estam pera o sul

FEDOR. [<lat. foetor, -oris, 'mau cheiro, infecção'.] sm. Mau cheiro. - fedor:(a3, 12) da priuada que esta açerca da camera ou de alguũ fedor particular de alguũ canno çujo se corrompe ho aar em substançia \& qualidade. $\mid(\mathbf{a} 5,22)$ \& per esta mesma causa euitaras \& esquiuaras todo ho fedor .| $(\mathrm{a} 5,25) \&$ tambem donde ha hi podridom de agoas \& fedor dellas. I (a5v , 11) assi emfraqueçe per o çujo fedor. I (a5v, 8$)$ \& por serem assi podres causam tal fedor \& doença que muyto empeçe. $\mid\left(\mathbf{a}^{\mathrm{v}} \mathbf{}, \mathbf{4}\right)$ taes agoas çujas causam grandes fedores: $\rightarrow$ FEDorento. adj. Fétido. - federentos: As vezes jsso mesmo veem decorpos mortos. ou de corrupçom de pauees \& charcos ou chafarizes çujos podres \& federentos

FERIR. [<lat. ferire.] $v$. $\bullet$ feere; fere; ferido; ferida. Causar dano: $\left(\mathbf{a 3}^{\mathbf{v}}, \mathbf{1 2}\right)$ ho aar jnspirado as vezes he peçonhento: \& assy corrupto feere ho coraçom. I $(\mathbf{a} 2, \mathbf{1 4 )}$ Quero algũas cousas da pestenença que nos ameude fere: dos ditos dos mays autenticos medicos: screuer.। $(\mathbf{a} 4, \mathbf{9 )}$ aquella jnfluençia sobre celestial mays dereytamente fere \& sguarda aquelle ou aquel outro. que aquelle ou aqueloutro lugar ou homem.l $\left(\mathbf{a} 4^{v}, 5\right)$ alguũ delles sera apeçonhentado ou ferido । | Cortar: $(\mathbf{b} 2,22)$ \& despois que a vea for ferida ou aberta aproueyta muyto tomar muyto prazer. $(\mathbf{b} 3 \mathbf{v}, 3)$ emtam leyxe yr a vea aberta ou ferida atee o retardamento do sangue. $\rightarrow$ FERIDo. adj. Tocado; atingido. - ferido: $\left(\mathbf{a}^{\mathrm{v}}, \mathbf{1 5}\right)$ mas ajnda tam 
sobejamente se agraua ha natureza que nom sinte sy ser ferida nem emferma I (b2v, 22) Mas diras tu. como sintira homem que esta apeçonhentado \& ferido da pestilençia

FígADo. [< lat. ficatum, de jecur ficatum, 'fígado (jecur) de ave engordado com figos'.] sm. Órgão do corpo que secreta a bílis. - figado: $(\mathbf{b} 4, \mathbf{1 4})$ porque se apareçer despois em o braço direyto:que se sangre em o braço esquerdo do figado

FIGo. [<lat. ficus, i.] sm. Fruto da figueira ( Ficus Linnaeus, família das Moráceas). $\bullet$ figos: (b4v' 20) Item quando a postema primeyro apareçer. tome auelaãs. figos passados \& aruda \& tudo bem pisado: pom lho em çima da apostema

FILHAR. [or. obsc.] v. Tomar, pilhar. filha: $(\mathbf{a} 2 \mathrm{v}, 17)$ A morte se ensanha ha çidade se filha \& toma dos jmigos

FIM. [<lat. finis, -is.] sf. [Segundo Bluteau (IV, 1220), no português antigo a forma era feminina apenas no singular.] Término da vida. • fim: $(\mathrm{a} 6,5) \mathrm{E}$ por tanto diz auiçena em o quarto do canone. que aquelles que sempre quere $m$ encher seus ventres que abreuiam seus dias \& tempos da sua fim $\rightarrow$ FINALMENTE. adv. Em conclusão. - finalmente: $(\mathbf{a} 6,8)$ onde finalmente digo que toda multidom de pouoo \& comunidade em tal tempo se deue de euitar em quanto for possiuel

Fisico. [<lat. physicus, -i.] sm. "Medico em quanto theoricamente considera a compleyção, temperamento, \& propriedades das cousas naturaes" (Bluteau: VI, 489). [cf. CIRURGIÃO; MÉDICO.] - fisico: (a3v, 21) Ergo he neçessario que todo enfermo se proueja de boõ fisico \& bem esperto

FlAmA. [<lat. flamma, ae. ] sf. Chama, fogo. @ flama: $(\mathbf{a} 5 \mathrm{v}, \mathbf{1 6})$ Apure se ergo \& asutileze se a casa per clara chama ou flama:

FLEUMA. [<lat. phlegma, -atis.] sf. Fluido, ou $h u$ mor [q.v.] responsázel por vários males, como, por exemplo, a epilepsia. $\bullet$ freuma, S. XV: $\left(\mathbf{b}^{\mathrm{v}}, 4\right)$ ajnda que pigmenta purga o çerebro da freuma $\mid\left(\mathbf{b}^{\mathrm{v}}, 8\right)$ ysso mesmo o alho posto: alimpe da freuma \& lança fora os maaos humores. \& prouoca o apetito de comer

FLOR. [<lat. flos,-oris.] sf. Aparelho reprodutor das gimnospermas e angiospermas, representado por ramos especializados de crescimento geralmente limitado, cujas folhas especializadas formam os órgãos sexuais masculino (androceu) e feminino (gineceu). A flor apresenta constituintes e morfologia extremamente variados entre os diversos grupos de plantas. $\bullet$ froles: $\left(\mathbf{b}^{\mathrm{v}}, \mathbf{2 6}\right) \mathrm{E}$ as speçias que comuummente conuem a comer. sam gingiure. canela. cuminhos. froles de heruas cheyrosas. \& açafram

FLuxo do ventre. [<lat. fluxus, -us.] sm. Diarréia. - fluxu, s. XV: (b2, 20) assy como he em as molheres que som prenhes. ou em alguũ muyto fraco scilicet. em alguũ que teem corrença ou fluxu do ventre

FOGo. [<lat. focus, i.] sm. Chama. fogo: $\left(\mathbf{a 5}^{v}, \mathbf{1 6}\right)$ faça se fogo claro de lenha. I $(\mathbf{b}, \mathbf{1 0})$ Em casa sempre este fogo açeso

FOLGançA. [de folgar.] sf. Descanso. - folgança, S. XV: $(\mathbf{b 3}, \mathbf{1 1 )}$ porque a peçonha intrinseca pertorua o sprito vital. em modo que sempre deseja folgança

FOLHA. [<lat. *folia.] sf. Expansão laminar do caule, geralmente de crescimento limitado, formada em geral por lâmina foliar alargada, denominada limbo, e por um pedúnculo ou peciolo inserido na base do limbo, que prende a folha ao caule. A folha mostra grande variação na morfologia e no tamanho entre as diversas famílias das plantas. - folhas, S. XIV: $(a 6,23)$ E tambem a casa seja aguada: \& em special em o alto veraão com vinagre rosado \& folhas de vinhas. I (b4v , 3) Toma folhas de sabugo pisadas \& com mostarda pisada \& faze emprasto 
FOME. [<lat. fames,-is.] sf. Falta de mantimentos. - fame, s. XIII: (a2v, 19) ho mar se faz cruel. \& ho sol se cobre .scilicet. de nuueens. ho regno se muda. ho pouoo padeçe fame \& pestilencia

FORA. [<lat. foras.] adv. Na parte exterior. fora: $(\mathbf{b} 4 \mathbf{v}, 7)$ a triaga lança a peçonha fora. $\rightarrow$ ANDAR FORA. vide ANDAR, $\rightarrow$ DE FORA. À vista. $\bullet$ de fora: $(\mathbf{b 4}, \mathbf{2 5})$ E se despois creçer a postema: nom tema. porque tal apostema lança o mal de fora \& faz o home $m$ ser muyto saão. $\rightarrow$ LANÇAR FoRA. vide LANÇAR

FORTEMENTE. [de forte.] adv. Com força. - fortemente: $\left(\mathbf{b 3}^{\mathrm{v}}{ }^{\mathrm{w}}, \mathbf{5}\right)$ pequena sangria: ou pequena sayda de sangue. mais fortemente esperta a peçonha segundo dicto he

FRACO. [<lat. flaccus, $-a,-u m$.] adj. Sem forças. - fraco: $(\mathbf{b} 2, \mathbf{2 0})$ assy como he em as molheres que som prenhes. ou em alguũ muyto fraco I $(\mathbf{b 4}, \mathbf{2 4 )}$ despois do sangue menuido se for muyto fraco emtom podera dormir despois do meo dia. $\rightarrow$ ENFRAQUECER. $v$. Tornar fraco. - emfraqueçer; emfraqueçe: $\left(a 4^{v}\right.$, 15)A primeyra que faz emfraqueçer os corpos assi dos saãos como dos enfermos. I (a5v, 10$) \mathrm{E}$ assi como per ho boõ cheyro \& aromatico: se recrea o coraçom \& o sprito do homem. assi emfraqueçe per o çujo fedor

FRESTA. [<lat. fenestra,-ae.] sf. Janela pequena. Na Idade Média, especialmente no sul de Portugal, as aberturas para o exterior estavam "reduzidas ao mínimo, limitando-se por vezes à simples porta de entrada" (Marques, 1987: 84). fresta; frestas, S. XIV: $\left(\mathbf{a} 4^{\mathrm{v}}, \mathbf{8}\right)$ os medicos prudentes quando visitam os enfermos deuem de star afastados delles: teendo o rostro pera genela ou fresta $\mid\left(\mathbf{a} 4^{\mathrm{v}}, \mathbf{1 1}\right)$ \& muytas vezes teer as frestas pera ho norte ou pera o leuante abertas. I $\left(a 4^{v}, 12\right) \&$ as genelas ou frestas pera ho meo dia ou pera ho sul estem çarradas. I $(\mathbf{a 5}, \mathbf{1 9 )}$ Fechem se ergo as frestas ou genelas como dito he

FREUMA. vide FLEUMA.

FRIO. [<lat. frigidus, $-a_{-}-u m$. ] sm. Baixa temperatura. $\bullet$ frio: $\left(\mathbf{b} 2^{\mathrm{v}}, \mathbf{2 6 )} \&\right.$ logo despois de comer tem desejo de dormir. \& sente de bayxo de frio grande quententura

FROL. vide FLOR.

FRUTO. [<lat. fructus,-us. ] sm. Ovário desenvolvido após a fecundação da flor e formado, geralmente, pelo pericarpo e a semente. Algumas plantas desenvolvem frutos sem sementes ou por partenocarpia, isto é, sem que tenha ocorrido a fecundação. Exibem grande variação de forma, de tamanho e cores entre as diferentes famílias das plantas. A tradição médica galênica desaconselhava a ingestāo de qualquer fruto. Para consumir frutas, o individuo deveria precaver-se, dando preferência aos que fossem quentes, caracterizados pelo sabor acre, evitando os frutos verdes, mas também cerejas, pêssegos, figos, melöes, classificados como frios e, por conseguinte, causadores de putrefaçẫo [vide DIGESTÃO; SABOR.] - fructo; fructos, S. XIII: $\left(\mathbf{b}^{v}, 24\right)$ porque todo ho fructo traz podridom. I $\left(\mathbf{b}^{\mathbf{v}}, \mathbf{2 1}\right)$ Isso mesmo se euite $m$ todos os fructos se nom fore $m$ azedos

FUGiR. [<lat. fugire.] v. Afastar-se a toda pressa. - fugir: $\left(\mathbf{a 4}^{\mathrm{v}}, \mathbf{1}\right) \&$ por tanto deue homem de fugir dos aares peçonhentos. I $(\mathbf{a} 5, \mathbf{1 2})$ Empero prometo te que muyto boõ remedio he fugir \& mudar o lugar apeçonhentado

FuMO. [<lat. fumus, i.] sm. fumo; fumos. $\square$ Fumaça: $\left(\mathrm{a}^{\mathrm{v}}\right.$, 22$)$ E tal fumo entre per a boca \& per os narizes. I (a5v, 17) faça se fogo claro de lenha. \& faça se tambem com fumo de boõas heruas Emanação: $(\mathbf{a} 4,25)$ dos corpos apeçonhentados procedem humores \& fumos peçonhentos que corrompem ho aar 
GEJUUM, vide JEJUM.

GENELA. vide JANELA.

GENGIBRE. [<lat. zingiber, -eris.] sm. Zingiber officinalis Roscoe, da família das Zingiberáceas. Erva aromática e de sabor picante, originária da India, cultivada, de rizoma carnoso, folhas verde-claras e lanceoladas, com flores reunidas em espigas. Seu rizoma apresenta propriedades excitantes, carminativas, descongestionantes, como condimento estimulante da digestão, contra gripes, tosses, bronquites, resfriados, afecçôes reumáticas, doenças das vias respiratórias. O gengibre foi a especiaria [q.v. ESPÉCIA] mais utilizada, por ser considerado quente mas com certa umidade, o que permitia não lhe ser necessário ser empregado em combinação com outros sabores. - gingiure, s. XV: $\left(b^{v}, 25\right)$ E as speçias que comuũmente conuem a comer. sam gingiure. canela. cuminhos. froles de heruas cheyrosas. \& açafram

GERAR. [<lat. generare.] v. Produzir; formar. - geera, s. XIII: $\left(\mathbf{a}^{\mathrm{v}}\right.$, 5) \& ha empresam do aar corrompe os spiritos vitaes e $m$ ho home $m \&$ assy se geera ha pestilençia per esta causa

GLÓRIA. [<lat. gloria, -ae.] sf. Honra, renome. - gloria: (b4v, 26) seja gloria \& louuor pera sempre $\rightarrow$ GLORIOso. adj. Que participa da beatitude celeste. gloriosa: $(\mathbf{a 2}, 10)$ EM loutor da santissima trijndade. \& da gloriosa virgem maria

GRANDE. [<lat. grandis, e.] adj $\bullet$ gramde; grande; grande. [DID De qualidade excelente: $(\mathbf{b} 3,16)$ He ergo gramde remedio I $(\mathbf{a} 5,5)$ segundo diz o grande medico scilicet. dauid. I $(\mathbf{a 5}, \mathbf{8})$ grande remedio he em tempo da pestilençia a sancta penitencia \& a confissam $\mid(\mathbf{b}, \mathbf{6})$ E tambem he grande remedio vazar o ventre Excessivo; forte; intenso; $(\mathrm{a} 2 \mathrm{v}, 8)$ he pera temer de vijr grande pestilençia. I $(\mathrm{a} 3,1)$ he pera temer grande pestilencia. I $(\mathbf{a} 4, \mathbf{2 0})$ \& os homens que se muyto esqueentam com grande trabalho ou grande yra.l $(b, 11)$ Em casa sempre este fogo açeso. porque clarifica muyto ho aar \& poõe grande impedimento aa maa influencia do çeeo.l $(\mathbf{b}, 26)$ a sobeja abastança \& grande inchamento tras apodrentamento dos humores. I (b2v, 26) \& sente de bayxo de frio grande quententura. I (b3, 1) \& ysso mesmo tem grande door em ha parte dianteira da cabeça. I $(\mathbf{b 3}, 9)$ o homem ja apeçonhentado em todas as horas tee $m$ grande desejo de dormir. I (a5, 13) muytos sem grande perda nom podem mudar o lugar I (b3, 6) nem andar grande caminho por a grande pigriça do corpol $(\mathbf{b 3}, \mathbf{7})$ \& muyto grande peso \& carrega corporal.I $(\mathbf{a} 4,17)$ E por tanto dos quaaes se faz ha grande resoluçam $\rightarrow$ PÉDICA GRANDE. vide VEIA. $\rightarrow$ GRÃo. [de grande.] adj. Grande. - gram, S.XIII: (b2, 8) E tambem a alegria do coraçom he gram remedio pera a saude do corpo.

GUARDAR.[<lat. guardare.] $v$. - guardar; guardes; guardando; guarte. $\square$ Observar: (b, 4) \& assi guardando estas cousas seguramente entraras em pouoo ou amtre gente.l (b2, 10) deue se homem de guardar em tempo da pestilencia $\mathbb{Q}$ Vigiar: $(\mathbf{a} 5 \mathrm{v}, 11)$ \& por tanto se deue bem de guardar a casa $\mathbb{1}$ Precaver-se, proteger-se: $(\mathbf{a} 5,3)$ como se deue homem de guardar da pestilencia \& preseruar se della. I $\left(\mathbf{a} 6^{v}, 23\right)$ em toda maneyra te guardes que nom reçebas do baffo de outrem. Evitar: $\left(\mathbf{b}^{v}, 2\right)$ E em os mantijmentos guarte das cousas queentes 


\section{$\mathrm{H}$}

HA. vide $\mathrm{A}^{\mathrm{I}} ; \mathrm{A}^{3}$; HAVER.

HAVER. [<lat. habere.] $v$. auer; ha. Ter, adquirir: $(\mathrm{a} 6,17)$ E ysto nom poder auer. emtam coma paão ou hũa sopa molhada em vinagrel $(b, 4) \&$ se estas cousas nom poder auer faça se com vinagre. Existir: $(\mathrm{a} 3,20)$ \& esto aconteçe muytas vezes onde ha lugares podres \& corruptos. I (b2v, 4) porque em ho somno ha queentura intrinseca. $\rightarrow$ HAVER DE. Ter de; dever. ha de, ajamos de: (se homem quiser dormir ha de beber hũa bõa vez de vinho ou çerueja ante de dormir. I (a5, 7) que homem primeiramente ha de confessar seus pecados humildosamente. I (b4,11) E se pella ventura sentir chagas despois de dormir: emtom ha de menuyr o sangue em a parte crucifixa I (a5, 1-2) VIstas as causas da pestilencia. agora ajamos de veer per que modo \& como se deue homem de guardar da pestilencia \& preseruar se della. $\rightarrow$ HI HAVER. vide HI.

HEPÁTICA. vide VEIA HEPÁTICA.

HI. [<lat. hi(c),'aqui'] adv. Nesse lugar, nesse ponto (já referido no texto). No Regimento, hi aparece apenas na expressão hi haver, equivalente do francês y avoir. $\rightarrow$ HI HAVER. Existir. $\bullet$ ha hi; ha hy, s.XII: (a5, 24) \& em special donde ha hi corpos mortos \& podres. $1(25,25)$ \& tambem donde ha hi podridom de agoas \& fedor dellas. I (a2v, 9) Tercio he quando ha hy muytas moscas em ha terra. I (b4v , 25) com virtude \& meezinha de nosso senhor jesu christo. sem o qual nom ha hy saude

HISSOPO. [<lat. hyssopus, -i.] sm. Hissopus officinallis Linnaeus, da famillia das Labiadas. Sub-arbusto, originário da Europa, com cerca de $45 \mathrm{~cm}$ de altura. Possui caule lenhoso, folhas lanceoladas, estreitas, flores tubulosas, azuis ou róseas, reunidas em espiga. O hissopo era considerado sagrado entre os hebreus, pois acreditaram que a planta trazia energia e vida. Foi empregada na medicina e na fabricação de alguns licores e perfumes. Apresenta propriedade sudorifera, adstringente, depurativa, estimulante e aromática. - ysope:(a5v, 20) as quaaes acharas aos apotecayros. \& de alosna \& ysope \& arruda

HOMEM. [<lat. homo,-inis. ]. - homem; homens. sm. Individuo: $\left(\mathrm{a} 3^{\mathrm{v}}, 4\right)$ \& ha empresam do aar corrompe os spiritos vitaes em ho homem $\mid\left(\mathrm{a}^{\mathrm{v}}, 9\right)$ \& podridam dos corpos mortos. ou lugares çujos se causa ho morbo ou ha chagua em ho home $m$ I $(a 4,10)$ aquella jnfluençia sobre celestial mays dereytamente fere \& sguarda aquelle ou aquel outro. que aquelle ou aqueloutro Iugar ou homem. I (a4v, 19) porque abre os poros do homem \& emtra atee o coraçam. I $(a 5,6)$ primeiro se deue o homem de afastar do mal \& inclinar se ao bem.l $\left(\mathrm{a}^{\mathrm{v}}\right.$, 10) E assi como per ho boõ cheyro \& aromatico: se recrea o coraçom \& o sprito do homem. assi emfraqueçe per o çujo fedor.l (b2v, 8) a qual cousa nom se faria se o homem andar em mouimento.l (b2v, 9) se o homem deue de euitar ho somno que fara homem se teuer o somno natural.। $(\mathrm{b} 2 \mathrm{v}, 18)$ porque o homem estando em o sommo traz em si muytos vapores. I (b2v, 23) o homem que em tal dia he apeçonhentado nom come mujto. I (b3,8) porque o homem ja apeçonhentado em todas as horas teem grande desejo de dormir. I $\left(\mathrm{b} 3^{\mathrm{v}}, 6\right)$ Item o homem que se sangra ou tenha pestenença ou nom. em nenhũa maneyra nom deue de dormir $\mid(b 4,26)$ tal apostema lança o mal de fora \& faz o homem ser muyto saão.I (b4v, 19) emtom obra milhor em o homem. I $(\mathrm{a} 4,1)$ \& daquella villa morrem homens \& daqueloutra nom. I $(a 5 \mathrm{v}, 5)$ \& daqui veem que em tal casa como esta morrem os homens mais azinha \& em outra nom $\mid(\mathrm{a} 4,19) \&$ os homens que se muyto esqueentam com grande trabalho ou grande yra. । (a3, 7-8) emtanto que senssualmente pareçe aos homens mudança do aar. pron. indef. Alguém: (a4v', 1) \& por tanto deue homem de fugir dos aares peçonhentos $1(\mathrm{a} 5,3)$ agora ajamos de veer per que modo \& como se deue home $m$ de guardar da pestilencia I $(a 5,7)$ scilicet. que homem primeiramente ha de confessar seus pecados humildosamente. I $(\mathrm{a} 6,11)$ se nom apeçonhente homem do aar apeçonhentado. I $(a 6,13)$ emtam huse homem dos remedios abayxo scriptas $\mid\left(a^{v}, 25\right)$ Os olhos do aar empeçonhentado logo escureçem se estas cousas nom trouuer homem em ha maão $\mid(\mathrm{b} 2,10)$ deue se homem de guardar $\mid$ $\left(b 2^{v}, 16\right)$ se homem quiser dormir ha de beber hũa bõa vez de vinho ou çerueja ante de dormir. I (b2v , 910) se o homem deue de euitar ho somno que fara homem se teuer o somno natural.l (b2v, 22) como 
sintira homem que está apeçonhentado \& ferido da pestilençia. I (b3, 12) Ergo per estes signaaes se sente homem apeçonhentado. I (b3v 1$)$ \& se homem nom quiser cortar muytas veas juntamente: | (b4,9) E todas estas cousas se façam se homem nom dormir antes que conheça que tem a postema

HORA. [lat. hora, -ae.] sf. @hora; horas, S. XIV. Fechem se ergo as frestas ou genelas como dito he que vaam ou estam pera o sul atee hũa hora depois do meo dia I (b2v, 15) em modo que o somno natural se possa tomar per hũa hora despois de comer. Período indeterminado de tempo: $(\mathrm{b} 3,9)$ porque o homem ja apeçonhentado em todas as horas teem grande desejo de dormir

HORIZONTE. [<lat. horizon, -ontis.] sm. Linha imaginária em que céu e terra parecem unir-se. $\bullet$ orizonte, S. XV: $\left(a 4^{v}, 24\right)$ se for neçessario que saya este em casa atee que saya o sol \& suba huũ boõ espaço sobre o nosso orizonte

Humildosamente.[de humildoso] adv. Com humildade, humildemente. $\bullet$ humildosamente, s.xv: (a5, 8) primeiro se deue o homem de afastar do mal \& inclinar se ao bem. scilicet. que homem primeiramente ha de confessar seus pecados humildosamente

HUMOR. [<lat. humor,-is.] sm. Segundo a tradição médica antiga, que tem como expoentes Hipócrates de Cós (ca. 410 a.C.) e Galeno de Pérgamo (129-216), cada um dos compontentes de um sistema de quatro fluidos (sangue, fleugma, bílis e cólera/melacolia) que, se em desequilíbrio ou excesso no corpo humano, constituem-se em causa de doença. Além desses quatro elementos, ainda vieram a ser considerados humores outros elementos úmidos, como a saliva, o esperma, o leite. $\bullet$ humores, S. XIV: $(\mathrm{a} 4,16)$ \& os corpos peçonhentos que tem os poros opilados: \& çarrados de mujtos humores. I $(\mathrm{a} 4,25)$ porque dos corpos apeçonhentados procedem humores \& fumos peçonhentos I $(a 6,2)$ porque os corpos cheos dos maaos humores sam mais asinha empeçonhentados. $\mid\left(a 6^{v}, 10\right)$ as cousas azedas \& os cheyros taaes opilam \& çarram os poros \& os meatos \& os caminhos dos humores $\mid\left(\mathrm{b}^{\mathrm{v}}, 1\right)$ porque a sobeja abastança \& grande inchamento tras apodrentamento dos humores. I $\left(b^{v}, 9\right)$ o alho posto: alimpe da freuma \& lança fora os maaos humores. I (b2v, 19) \& estes maaos

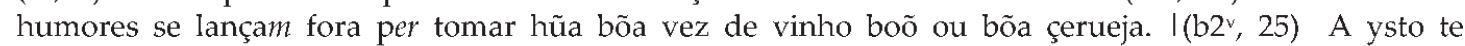
respondo que o homem que em tal dia he apeçonhentado nom come mujto. porque he cheo de maos humores. $\rightarrow$ HUMOR VISCOSO. Os humores [vide HUMOR] grossos e com viscosidade, como o escarro e a remela. humores vis<c>osos: $\left(b^{v}, 4-5\right)$ E em os mantijmentos guarte das cousas queentes. assi como som pigmenta $\&$ alhos. ajnda que pigmenta purga o çerebro da freuma \& os outros membros speciaaes dos humores vis $<$ c $>$ osos

HUŨ. vide UM. 


\section{I}

IGUARIA. [or. obsc.] sf. Comida preparada para ser servida à mesa. yguaria, s. XV: (b, 24) E ysso meesmo deues de comer boõ manjar \& bõa yguaria com boõ vinho puro \& a meude

IMAGINAÇÃO. [<lat. imaginatio, -onis.] Sf. Fantasia. \ymaginaçam: $(b 2,12)$ nenguem nom tema morte. sem teer infirmidade pestilencial. porque ymaginaçam faz causa \& perijgo

IMIGO. [<lat. inimicus,-a,-um.] sm. Adversário. - jmigos:(a2v , 17) A morte se ensanha ha çidade se filha \& toma dos jmigos

IMPEDIMENTO. vide IMPEDIR.

IMPEDIR. [<lat, impedire.] v. Obstruir. - impedir; $(b 2 v, 13)$ logo despois de comer, se alguũ teuer desejo de dormir: que tal desejo se deue reuogar \& impedir. - IMPEDIMENTo. sm. Obstáculo; embaraço. impedimento: (b, 11-12) Em casa sempre este fogo açeso. porque clarifica muyto ho aar \& poõe grande impedimento aa maa influencia do çeeo. $\rightarrow$ IMPIDOSo. adj. Que tem impedimento ou proibiçâa. • jnpidoso: $\left(b^{v}, 13\right) \&$ por ysso nom pareçe se neçessario mas antes jnpidoso. a pestilençia que veem per causa queente ameude se acreçenta

IMPIDOSO. vide IMPEDIR.

IMPRESSÃo. [< lat. impressio, -onis.] sf. "Calidade de qualquer corpo Astral, ou elemental, que se communica a outros corpos, \& nelles produz algum effeito" (Bluteau: $I V, 77)$. jmpressam, s. XV: $\left(\mathrm{a}^{\mathrm{y} v}, 6\right)$ Da rayz superior \& jnferior juntamente proçede quando da jmpressam celestrial corrompente ho aar. \& podridam dos corpos mortos. ou lugares çujos se causa ho morbo ou ha chagua em ho homem

INCHADO. [de inchar.] adj. Que faz aumentar o peso. - inchado: $\left(\mathrm{a4}^{\mathrm{v}}{ }^{2}, 18\right)$ Ho sul he vento inchado $\rightarrow$ INCHAMENTO. sm. Aumento do volume. - inchamento; inchamento: (a5v , 25) Item per esta meesma $c a<\mathrm{u}>\mathrm{sa}$ se euite \& esquiue: todo ho inchamento do ventre que veem per muyto comer. I $(\mathrm{b}, 26)$ porque a sobeja abastança \& grande inchamento tras apodrentamento dos humores

INCHAMENTO. vide INCHADO.

INCLINAR. [<lat. inclinare.] v. Predispor. $\bullet$ inclinar: $(\mathrm{a} 5,6)$ segundo diz o grande medico scilicet. dauid. que primeiro se deue o homem de afastar do mal \& inclinar se ao bem

INDIRAMÇE. [?]. O termo não foi encontrado em outra parte. Costa Roque (1979:325) apresenta a leitura indiram-se. Em nota afirma que "jndiramçe as cousas de dentro" está por "quia sic interiora ratificat" e, na versão francesa, por "car elle [fumée] ratifie, afermist et côfort le cueur et les entrailles dedans la personne". Na versão inglesa encontramos a mesma interpretação apresentada por Roque para o latim e o francês: "whose fumygations must be receyuyd by the mouthe and nose, for they do strengthe, fortifie, and comforte the hart and the interyour parties of man" (fo. A5v). A seguirem-se essas leituras, o termo português equivaleria a 'fortalecer'. Uma outra possibilidade seria relacionar a ocorrência a en de re çar $r$ [q.v.], cuja transitividade está de acordo com a desta forma (todas as outras heruas que endereçam ho spirito interior - $\mathrm{a} 6^{\mathrm{v}}, 19$ ). jndiramçe: $\left(a 5^{v}, 23\right)$ E tal fumo entre per a boca \& per os narizes. porque assi jndiramçe as cousas de dentro

INDISPOSIÇÃO. [de indispor.] sf. Ordenamento desfavorável. • jndisposiçam, S. XV: (a3v, 1) \& de tal diz auicena no quarto liuro que muy ligeyramente se empeçonhentam os corpos da jndisposiçam ou da maa desposiçam dos çeos 
INFERIOR. [<lat. inferior, -ius.] adj. Que procede da parte que está embaixo. $\bullet$ jnferior, s. XV: (a3, 7) \& as vezes proçede da rayz jnferior. I (a3, 9) \& as vezes veem dambos de dous .scilicet. da rayz superior \& da rayz jnferior juntamente. I (a3, 10) Da rayz jnferior proçede segundo nos veemos que da priuada que esta açerca da camera ou de alguũ fedor particular de alguũ canno çujo se corrompe ho aar em substançia \& qualidade. I $\left(\mathrm{a}^{\mathrm{v}}, 6\right)$ Da rayz superior \& jnferior juntamente proçede quando da jmpressam celestrial corrompente ho aar. \& podridam dos corpos mortos. ou lugares çujos se causa ho morbo ou ha chagua em ho homem

INFLUÊNCIA. [<lat. influentia,ae.] sf. "Virtude, ou calidade, que dos Astros, \& corpos celestes, por meyo da sua luz, \& do seu calôr influe nos corpos Sublunares" (Bluteau: $I V, 128$ ). influencia; jnfluençia: (b, 12) Em casa sempre este fogo açeso. porque clarifica muyto ho aar \& poõe grande impedimento aa maa influencia do çeeo. I $(\mathrm{a} 4,8)$ Da parte do agente quando aquella jnfluençia sobre celestial mays dereytamente fere \& sguarda aquelle ou aquel outro

INSPIRADO. [<lat. inspiratus, -a,-um. ] adj. Levado aos pulmões. - jnspirado: $\left(\mathrm{a} 3^{\mathrm{v}}, 11\right)$ porque ho aar jnspirado as vezes he peçonhento

INTERIOR. [<lat. interior, -ius.] adj. Que está dentro; interno. - interior: (a6v, 20) AS cousas canfortatiuas sam estas .scilicet. açafram. cassiafistola. chantagem. com todas as outras heruas que endereça $m$ ho spirito interior

INTRÍNSECO. [<lat. intrinsecus, - $a$, -um. ] adj. Inerente. - intrinseca, S. XV: (b2v, 4) porque em ho somno ha queentura intrinseca. caladamente traz a peçonha ao coraçam $I(b 3,10)$ porque a peçonha intrinseca pertorua o sprito vital. em modo que sempre deseja folgança

INVERNO. [<lat. hibernum, -i.] sm. A estação mais fria do ano. • inuerno: (a6v , 2) \& tambem he boõ assi em ho inuerno como no veraão cheirar cousas azedas

IR. [<lat. ire. ] o. -yr; vay; vaam. Dirigir-se: $\left(\mathrm{a}^{\mathrm{v}}{ }^{\mathrm{v}}, 17\right)$ \& jsto porque apareçem bõas ourinas \& boõas augoas. \& bõas digestiões. empero ho enfermo vay caminho da morte. I (b4v, 13$)$ toma chantagem \& siligem (vay te ao boticayro) I \& os que vaam ameude a os banhos. I (a5, 19) Fechem se ergo as frestas ou genelas como dito he que vaam ou estam pera o sul atee hũa hora depois do meo dia $\mathbb{1}$ Estar, ficar: $\left(b^{v}, 2\right)$ \& se homem nom quiser cortar muytas veas juntamente: emtam leyxe yr a vea aberta ou ferida atee o retardamento do sangue

IRA. [<lat. ira, -ae.] sf. Cólera. -yra: $(\mathrm{a} 4,20)$ \& os homens que se muyto esqueentam com grande trabalho ou grande yra. teem os corpos mais dispostos pera reçeber ha pestilencia

ISSO. [<lat. ipsum.]. pron. demonstr. $\rightarrow$ ISSO MESMO. Item; além disso. - ysso meesmo; ysso mesmo; jsso mesmo; isso mesmo: $(a 6,24)$ \& em special em o alto veraão com vinagre rosado \& folhas de vinhas. \& ysso meesmo he muyto boõ ameude lauar as maãos com augoa \& vinagre. I (b, 23) \& nom jantaras atee ho meo dia porque possa a triaga em o corpo fazer sua operaçam. E ysso meesmo deues de comer boõ manjar \& bõa yguaria com boõ vinho puro \& a meude. $\mid$ (b3, 1) \& sente debayxo de frio grande quententura. \& ysso mesmo tem grande door em ha parte dianteira da cabeça. I (b4, 26) porque tal apostema lança o mal de fora \& faz o homem ser muyto saão.E ysso mesmo por que a apostema mais çedo \& milhor seja madura \& seja rompida faça se meezinha em tal maneira. I (b4v, 12) Tomaras hũa herua que chamam barbajouis. \& outro que chamam serpillo que acharas ao boticairo.\& ysso mesmo toma chantagem \& siligem $\mid(b v, 8)$ melhor me pareçe soo a cousa amargosa que queentura cheyro \& sabor, ysso mesmo o alho posto: alimpe da freuma \& lança fora os maaos humores. \& prouoca o apetito de comerl (a3, 17) As vezes jsso mesmo veem de corpos mortos. I (bv, 20) Em tempo da pestilencia valem mais cousas azedas que todalas mezinhas Isso mesmo se euitem todos os fructos se nom forem azedos. assi como sam çirejas. $\rightarrow$ POR ISSO. vide POR. 
MARIA CARLOTAET AL

ITEM. [<lat, item.] adv. Também; além disso. - Item; Item: $\left(\mathrm{a}^{\mathrm{v}} \mathrm{v}, 24\right)$ Item per esta meesma ca<u>sa se euite \& esquiue: todo ho inchamento do ventre I $(a 6,6)$ Item per esta mesma causa se deue euitar ho banho de cada dia. I $\left(\mathrm{b}^{\mathrm{v}}, 6\right)$ Item o homem que se sangra ou tenha pestenença ou nom. em nenhũa maneyra nom deue de dormir per todo o dia atee mea noytel $\left(\mathrm{b} 4^{v}, 10\right)$ Item outro remedio I $\left(\mathrm{b} 4^{*}, 19\right)$ Item quando a postema primeyro apareçer. tome auelaãs. figos passados \& aruda \& tudo bem pisado: pom lho em çima da apostema 


\section{$\mathrm{J}$}

JANELA. [<lat. *januella,-ae.] sf. Abertura na parede para iluminação ou ventilação [cf. FRESTA]. - genela; genelas: $\left(\mathrm{a}^{\vee}, 7\right)$ os medicos prudentes quando visitam os enfermos deuem de star afastados delles: teendo o rostro pera genela ou fresta: I $\left(a 4^{v}, 12\right) \&$ as genelas ou frestas pera ho meo dia ou pera ho sul estem çarradas. I $(\mathbf{a} 5,19)$ Fechem se ergo as frestas ou genelas como dito he que vaam ou estam pera o sul

JANTAR. [<lat. jantare.] v. Comer a principal refeição que se faz pela manhã, por volta de 10, 11 horas. Segundo Marques (1964: 7), antes do século XIV o jantar era ainda comido mais cedo, em torno das oito ou nove horas da manhã. jantaras: $(\mathrm{b}, 21) \&$ nom jantaras atee ho meo dia porque possa a triaga em o corpo fazer sua operaçam

JARDIM. [<fr. jardin.] sm. Canteiro para cultivo de flores. $\bullet$ jardijs: $(b 2 v, 14)$ logo despois de comer. se alguũ teuer desejo de dormir: que tal desejo se deue reuogar \& impedir per alguũ andar em jardijs ou em campos

JEJUM. [<lat. jejunus, - $a$,-um.] adj. Privado de alimento. - gejuum, s. XIV: (b4", 18) toma aquelle çumo \& mistura ho com leyte de mulher \& da ho a beber aquelle que teuer a postema. \& ysto com o estamago gejuum

JESUS. [<gr. Iêsous, trad. do hebr. Yeshoua ou Yehoshoua, 'Deus salva', pelo lat. Yesu.] antrop. A Segunda Pessoa da Trindade. O termo Cristo [ $<$ gr. Christos, trad. do hebr. mashiah, 'ungido, consagrado por uma missão', pelo lat. Christus.], originariamente um epíteto ('Messias') raro nos Evangelhos, passou a se associar ao nome lesus. - jesu christo: $\left(b 4^{v}, 24\right)$ \& qualquer que se per este modo reger escapara muytos perijgos da pestilencia com virtude \& meezinha de nosso senhor jesu christo. sem o qual nom ha hy saude

JUNTAMENTE. vide AJUNTAMENTO.

JUNÍPERO. [<lat. juniperus, $-i$. ] sm. Juniperus communis Linnaeus, família das Coníferas, Gimnospermas. Arbusto ou pequena árvore amplamente distribuída no Hemisfério Norte, cujas sementes apresentam-se reunidas em cones preto-azulados, globosos ou ovóides. O óleo essencial do junípero é conhecido como zimbro. Apresenta propriedades diuréticas, carminativas. Na Inglaterra, queimava-se junipero para espantar bruxas e demônios. -junipero, s. Xv: (a5v, 18) \& faça se tambem com fumo de boõas heruas aqui scriptas .scilicet. baga de louro. junipero. vberiorgano. as quaaes acharas aos apotecayros 


\section{$\mathrm{L}$}

LADO. [<lat. latus, -eris.] sm. Região lateral do corpo. $\bullet$ lado: (b3v, 18) E se açerca das partes vergonçosas. sangre se em o pee daquelle mesmo lado açerca do calcanhar. I (b3v, 21$)$ E se a apostema for em ho pescoço. seja sangrado em a vea de çephalica açerca do dedo polegar em a maão daquelle meesmo lado. I (b3v, 23) ou na maão daquelle meesmo lado açerca do dedo menor. I (b3v, 25) E se pela ventura apareçer açerca da orelha: faça se a sangria de çephalica daquelle meesmo lado

LANÇAR. [<lat. lanceare.] v. Pôr.๑ lança: $(\mathrm{b} 4,25)$ E se despois creçer a postema: nom tema. porque tal apostema lança o mal de fora \& faz o homem ser muyto saão. I (b4v,7) alguũs çirogiaães querem que lhe ponham triaga mas eu rogo mujto que se nom ponha. porque a triaga lança a peçonha fora. $\rightarrow$ LANÇAR FORA. Expelir. - lança; lançam: (bv , 8-9) ysso mesmo o alho posto: alimpe da freuma \& lança fora os maaos humores. I $\left(b 2^{v}, 20\right)$ \& estes maaos humores se lançam fora per tomar hũa bõa vez de vinho boõ ou bõa çerueja

LARGo. [<lat. largus, $-a_{\text {, }}$ um.] adj. Dilatado. - largos: $(\mathrm{a} 4,14)$ \& por tanto deues de notar que os corpos mays despostos a jnfirmidade \& a morte sam os corpos queentes \& que tee $m$ os poros mays largos

LATIM. [<lat. latine, 'em língua latina'.] sm. A língua latina. - latim: (a2, 6) E tralladado de latim em lingoagem per ho reuerendo padre frey Luys de ras

LAVAR. [<lat. lavare.] v. Passar por água. - lauar; laue; lauada: (a6, 25) \& ysso meesmo he muyto boõ ameude lauar as maãos com augoa \& vinagre. I $(b, 1)$ Muyto saã cousa he que se laue a boca \& os olhos \& as maãos ameude cada dia com agoa rosada mesturada com vinagre. I $(a 6,15)$ de manhaã quando se alguũ aleuantar logo coma da aruda lauada em agoa limpa espargida com sal

LEITE. [<lat. lacte, lactis.] sm. Líqüido segregado pelas glândulas mamárias das fêmeas de mamíferos. $\bullet$ leyte, s. XIII: $\left(b 4^{v}, 16\right)$ emtom toma aquelle çumo \& mistura ho com leyte de mulher

LEIXAR. [<lat. laxare.] v. Deixar. - leyxe: $\left(b_{3}{ }^{v}, 2\right)$ emtam leyxe yr a vea aberta ou ferida atee o retardamento do sangue

LENHA. [<lat. ligna, -orum.] sf. Ramos ou pedaços de tronco partidos. $\bullet$ lenha: $\left(\mathrm{a} 5^{\mathrm{v}}, 17\right)$ \& faça se fogo claro de lenha. $\rightarrow$ LENHO. [<lat. lignum, -i.] sm. Pedaço de tronco ou caule, limpo da rama. $\bullet$ lenho: $\left(a 5^{\vee}, 20\right)$ \& faça se tambem com fumo de boõas heruas aqui scriptas .scilicet. baga de louro. junipero. vberiorgano. as quaaes acharas aos apotecayros. \& de alosna \& ysope \& arruda. \& artamija. \& com lenho de aloes

LEVANTE, vide ALEVANTAR.

Levar. [<lat. levare.] v. Portar. leuaua: $\left(a 6^{\mathrm{v}}, 6\right)$ \& emtam leuaua commigo huũa sponja ou paão enssopado em vinagre

LEVE. [<lat. lezis,-e.] adj. Fácil de digerir. - leue: $\left(\mathrm{b}^{\mathrm{v}}, 16\right)$ \& por tanto todos os mantijmentos quanto som de mais leue digestam tanto som milhores

LHE. [<lat. illi.] pron. pessoal. Nele(s), nela(s). - Ihe: $\left(\mathrm{b} 4{ }^{\mathrm{v}}, 6\right)$ posto que alguũs çirogiaães querem que lhe ponham triaga mas eu rogo mujto que se nom ponha. $\rightarrow$ LHO. pron. pessoal + pron. pessoal. Lhe $(s)+o . \rightarrow 1$ ho: $\left(\mathrm{b} 4^{v}, 21\right)$ tome auelaãs. figos passados \& aruda \& tudo be $m$ pisado: pom lho e $m$ çima da apostema

LigeIRAmente. [de ligeiro.] adv. Com rapidez. - ligeyramente; lygeyramente: $\left(a 6^{v}, 21\right)$ \& estas cousas presta $m$ pera antre pouoo onde ligeyramente se aconteçe huũ seer empeçonhentado do outro. I (a $\left.3^{v}, 1\right)$ 
muy ligeyramente se empeçonhentam os corpos da jndisposiçam ou da maa desposiçam dos çeos. I $\left(3^{v}, 20\right)$ E por tanto muytos medicos que em os enfermos soomente esguardam as ourinas superficialmente falam. \& lygeyramente sam emganados

LIMPO. [< lat. limpidus, -a, -um ] adj. - limpa; limpas, S.XIV. Que não foi usado anteriormente: de manhaã quando se alguũ aleuantar logo coma da aruda lauada em agoa limpa espargida com sal Livre de outras substâncias: $(a 6,17)$ e noz nozcada hũa ou duas bem limpas $\rightarrow$ ALIMPAR. v. Retirar impurezas. alimpar; alimpe, s..XIII.: $(a 6,25)$ he muyto boõ ameude lauar as maãos com augoa \& vinagre. \& alimpar o rostro $\mid\left(b^{v}, 8\right)$ ysso mesmo o alho posto: alimpe da freuma \& lança fora os maaos humores

LINGUAGEM. [<prov. lenguatge.] sm. Até cerca do final do século XV, lingua que se considerava não ter gramática, apropriada à fala, mas não à escrita. O português era então o linguagem português ou, simplesmente, linguagem. - lingoagem: $(\mathrm{a} 2,6) \mathrm{E}$ tralladado de latim em lingoagem per ho reuerendo padre frey Luys de ras

LIVRo. [<lat. liber, libri.] sm. Um dos tipos de divisão numa obra. - liuro: $(\mathrm{a} 3,25)$ \& de tal diz auicena no quarto liuro que muy ligeyramente se empeçonhentam os corpos da jndisposiçam ou da maa desposiçam dos çeos I (a $\left.4^{v}, 17\right)$ assi como se escreue em o terçeyro liuro dos amforismos Ho sul he vento inchado \& agraua o ouuido fere o coraçam

LOGo. [<lat. (in) loco.] $a d v$. - logo. Imediatamente: $(\mathrm{a} 6,15)$ de manhã quando se alguũ aleuantar logo coma da aruda lauada I (a $\left.6^{v}, 24\right)$ Os olhos do aar empeçonhentado logo escureçem $\mid\left(\mathrm{b} 2^{v}, 11\right)$ em tempo da pestilencia. logo despois de comer. se alguũ teuer desejo de dormir: que tal desejo se deue reuogar \& impedir I $\left(b 2^{v}, 25\right)$ o homem que em tal dia he apeçonhentado nom come mujto. porque he cheo de maos humores. \& logo despois de comer tem desejo de dormir. I (b3, 14) mas se alguũ nom quiser creer: spere per huũ meo dia \& logo sentira apostema de bayxo dos braços. Estantes ergo assi estas cousas quando se homem sente ser tocado da peçonha pestilençial. logo naquelle meesmo dia mingue ho sangue: \& se sangre atee esmoreçer

LOSNA. [<lat. tard. alŏx na; segundo Meyer Lübke, do ár. aloshna, 'musgo herbóreo'.] sf. Artemisia absinthium Linnaeus, familia das Compostas. Absinto. Erva ou sub-arbusto cultivado de origem européia, com folhas esbranquiçadas, obtusas, pilosas, inteiras ou lanceoladas, flores amarelas em cachos de capitulos e frutos de cheiro desagradável. Possui propriedade terapêtutica como vermifugo e como tônico contra a clorose e a anemia. Eroa digestiva, suas folhas podem ser utilizadas no preparo de licores (licor de absinto) e vinhos (Balmé, 1978; Cruz, 1979). • alosna, S. XIV: (a5vi 19-20) \& de alosna \& ysope \& arruda. \& artamija

LOURO.[<lat. laurus, $-i$ ou -us.] sm. Laurus nobilis Linnaeus, família das Lauráceas. Árvore de até 60 pés de altura. Sua casca é verde e as folhas, amarelo-esverdeadas, são pequenas e lanceoladas. Tem flores amarelas $e$ pequenas, frutos-bagas negros e com óleo. Suas folhas são utilizadas como condimento na culinária. Apresenta propriedades excitantes, narcóticas, emenagogas, carminativas e digestivas. Consagrada ao deus Apolo na antiguidade greco-romana, as folhas de louro eram utilizadas na confecção de coroas para atletas vencedores, heróis, poetas e imperadores. - louro: $\left(\mathrm{a} 5^{\mathrm{v}}, 18\right)$ \& faça se fogo claro de lenha. \& faça se tambem com fumo de boõas heruas aqui scriptas .scilicet. baga de louro. junipero. vberiorgano. as quaaes acharas aos apotecayros

LOUVOR. [<port. ant. loor.] sm. Glorificação. - louuor: (a2, 9) EM louuor da santissima trijndade. I (b4v, 26) \& da benta virgem maria sua madre seja gloria \& louuor pera sempre

LUGAR. [<lat. localis, -e.] sm. Local. • lugar; lugares, s. XIII: (a4, 10) Da parte do agente quando aquella jnfluençia sobre celestial mays dereytamente fere \& sguarda aquelle ou aquel outro. que aquelle ou aqueloutro lugar ou homem. I (a5, 12) muyto boõ remedio he fugir \& mudar o lugar apeçonhentado. $(\mathrm{a} 5,14)$ mas porque muytos sem grande perda nom podem mudar o lugar. I $\left(\mathrm{a} 5^{\mathrm{v}}, 14\right)$ ho aar apeçonhentado he humido \& faz podridom em a casa ou em lugar onde dormem. I (a3, 20) \& 
MARIA CARLOTA ET AL

esto aconteçe muytas vezes onde ha lugares podres \& corruptos. I (a3v, 8) da jmpressam celestrial corrompente ho aar. \& podridam dos corpos mortos. ou lugares çujos se causa ho morbo ou ha chagua em ho homem $\rightarrow$ EM LUGAR DE. Em vez de. em lugar de: $\left(b^{v}, 23\right)$ ou huũ pequeno de pero ou maçaã em lugar de meezinha

LUXÚRIA.[<lat. luxuria, -ae.] sf. Comportamento sexual que pode equivaler à fornicação ou ainda ao estupro, ao adultério, rapto, incesto, sodomia e bestialidade (vide Bluteau: $V, 212$, que remete a S. Tomás). - luxuria, S. XV: $(a 4,18)$ E portanto dos quaaes se faz ha grande resoluçam assy como sam os corpos desordenados em Iuxuria \& coyto. I $(\mathrm{a} 5,17)$ E per conseguinte todo o coyto \& toda luxuria 


\section{$\mathrm{M}$}

MAÇã. [<lat. (mala) mattiana, 'pomo de Mattium', cidade germânica.] sf. Fruto da macieira. maçaã, S.XIII: (bv , 23) Isso mesmo se euitem todos os fructos se nom forem azedos. assi como sam çirejas. romaãs. ou huũ pequeno de pero ou maçaã em lugar de meezinha

MADRE. [< lat. mater,-tris. ] sf. Mãe "em materias espirituaes, ou moraes" (Bluteau: V, 241). $\bullet$ madre: (b4", 25) \& da benta virgem maria sua madre seja gloria \& louuor pera sempre

MADURo. [<lat. maturus, $-a,-u m$.] adj. (Abscesso) que tem flutuação e bordos bem determinados, em condições ótimas para ser drenado. $\bullet$ madura: $\left(\mathbf{b} 4^{\mathrm{v}}\right.$, 1) E ysso mesmo por que a apostema mais çedo \& milhor seja madura \& seja rompida

MAIORMENTE. [de maior] adv. Principalmente, mormente. - mayormente, S. XIV: (a2v, 21) Quinto sinal. he quando se faze $m$ mujtas relampados \& trouoadas. \& mayormente se vee $m$ da parte do meo dia .scilicet. do sul. I $(\mathbf{a} 6, \mathbf{1 9})$ E ysto nom poder auer. emtam coma paão ou hũa sopa molhada em vinagre. \& ysto seja mayormente em tempo de neuoeiro \& chuuoso

MAIs. [<lat. magis, 'mais, de preferência'.] adv. - mais; mays, S. XIII. [1 Em maior grau: (a2, 14) Quero algũas cousas da pestenença que nos ameude fere: dos ditos dos mays autenticos medicos: screuer I (a4, 12) os corpos mays despostos a jnfirmidade \& a morte sam os corpos queentes I (a4, 14) \& que teem os poros mays largos $\mid(\mathbf{a 4}, \mathbf{2 0 )} \&$ os homens que se muyto esqueentam com grande trabalho ou grande yra. teem os corpos mais dispostos pera reçeber ha pestilencia. I $\left(\mathbf{b}^{v}, \mathbf{1 5}\right)$ \& por tanto todos os mantijmentos quanto som de mais leue digestam tanto som milhores. I (b4v, 1)E ysso mesmo por que a apostema mais çedo \& milhor seja madura I $\left(\mathbf{b} 3^{v}, 5\right)$ porque pequena sangria: ou pequena sayda de sangue. mais fortemente esperta a peçonha segundo dicto he. I (a5 $\left.{ }^{\mathrm{v}}, \mathbf{5}\right)$ \& daqui veem que em tal casa como esta morrem os homens mais azinha \& em outra nom como dito he I $(\mathbf{a 6}, \mathbf{2})$ porque os corpos cheos dos maaos humores sam mais asinha empeçonhentados. $\rightarrow$ MAIS PEQUENo. vide DEDO. $\rightarrow$ MAIS .....QUE. Acima de: $(b, 17)$ nem se tome mais da triaga que a quantidade de huũ piseo Indica uma comparaçẫo com os dois termos explícitos: $(\mathbf{a} 4, \mathbf{8})$ Da parte do agente quando aquella jnfluençia sobre celestial mays dereytamente fere \& sguarda aquelle ou aquel outro. que aquelle ou aqueloutro lugar ou homem.I $(\mathbf{a 4}, \mathbf{1 1})$ Da parte do paciente que aquelle he mays desposto aa morte que aquel outro. VALER MAIS ....QUE. vide VALER.

MAL. [<lat. male.] sm. - mal, s. XIII. $₫$ Aquilo que distancia de Deus: (a5, 6) que primeiro se deue o homem de afastar do mal \& inclinar se ao bem. Doença, enfermidade: $(\mathbf{b 4 , 2 5 )}$ E se despois creçer a postema: nom tema. porque tal apostema lança o mal de fora \& faz o homem ser muyto saão

MANEIRA. [<lat. manaria. ] sf. Modo, forma. - maneira, s. XIII; manejra; maneyra, s. XIV: (a3v, 13) \& assy corrupto feere ho coraçom. em tanto que ha natureza he per muytas manejras agrauada $\rightarrow$ EM MANEIRA QUE. De forma que. - em maneira que: (b4, 18-19) em maneira que sempre se mingue o sangue per modo contrayro $\rightarrow$ EM NENHUMa MANEIRA. De modo algum. em nenhũa maneyra: $\left(b^{2}{ }^{v}, 7\right)$ Item o home $m$ que se sangra ou tenha pestenença ou nom. em nenhũa maneyra nom deue de dormir per todo o dia atee mea noyte $\rightarrow$ EM TAL MANEIRA. Do seguinte modo. $\bullet$ em tal maneira: $\left(\mathbf{b 4}^{\mathbf{v}}{ }^{2} \mathbf{2}\right)$ que a apostema mais çedo \& milhor seja madura \& seja rompida faça se meezinha em tal maneira. $\rightarrow$ EM TODA MANEIRA. De todos os modos. em toda maneyra: $(\mathbf{b} 2 \mathrm{v}, 2)$ \& se alguũ se agrauar de apostema ou sentir agrauado: ou se sentir apeçonhentado. em toda maneyra tal como este euite o somno $\mid\left(\mathbf{a} 6^{v}, 22-23\right) \mathrm{E}$ por ysso te digo que em toda maneyra te guardes que nom reçebas do baffo de outrem

MANHÃ. [<lat. (hora) *maneana, 'em hora matutina'.] sf. Princípio do dia. $\bullet$ manhaã, S. XV: (a2v, 1) Primeiro quando em huũ dia do estio \& do alto veraão se muda a manhaã muytas vezes. $\rightarrow$ DE MANHÃ. Entre 0 
amanhecer e o meio-dia. @ de manhaã; de manhaã: (a2v, 1-2) em modo que de manhaã pareçe chuuosa \& chea neuoa. \& depois ventosa. I $(\mathbf{a 6}, 14)$ emtam huse homem dos remedios abayxo scriptas .scilicet. de manhaã quando se algũ̃ aleuantar logo coma da aruda lauada em agoa limpa espargida com sal $\rightarrow$ PELA MANHÃ. De manhã. $\bullet$ pela manhaã: $\left(\mathbf{b}^{v}, \mathbf{1 6}\right)$ pela manhaã sejam os manjares cozidos: \& de noyte assados caldos. polmes. \& potagios se euitem

MANIFESTO. [<lat. manifestus, - $a$,-um. ] adj. Claro, evidente. manifesto: (b3, 19-20) \& assi segundo estas cousas he assaz manifesto: que em o tempo do somno o sprito vital repousa

MANJAR. [<lat. manducare.] sm. Comida, mantimento. - manjar; manjares: (b, 24) E ysso meesmo deues de comer boõ manjar \& bõa yguaria com boõ vinho puro \& a meude. I ( $\mathbf{b}^{v}, \mathbf{1 7 )}$ pela manhaã sejam os manjares cozidos: \& de noyte assados caldos. polmes. \& potagios se euite $m$ : se nom forem azedos

MANTIMENTo. [de manter.] sm. Manutenção da saúde. $\bullet$ mantijmento, s. XIV: $(\mathbf{b}, \mathbf{1 3})$ Quanto he ao teu mantijmento digo te que a triaga te he muyto proueytosa $P$. $\bullet$ mantijmentos, mantijmentos, S. XIV. [1. Alimentos: $\left(\mathbf{b}^{\mathrm{v}}, \mathbf{1}\right) \mathrm{E}$ em os mantijmentos guarte das cousas queentes $\mid\left(\mathbf{b}^{\mathrm{v}}, \mathbf{1 5}\right)$ \& por tanto todos os mantijmentos quanto som de mais leue digestam tanto som milhores

MÃo. [<lat. manus, - us.] sf. Extremidade do braço. - maão; maãos, S. XIII: (b3v, 21) E se a apostema for em ho pescoço. seja sangrado em a vea de çephalica açerca do dedo polegar em a maão daquelle meesmo lado I (b3y , 22) ou na maão daquelle meesmo lado açerca do dedo menor. I $(\mathbf{a 6}, \mathbf{2 5})$ \& ysso meesmo he muyto boõ ameude lauar as maãos com augoa \& vinagre.| $\left(\mathbf{a 6}^{\mathrm{v}}, \mathbf{1 )}\right.$ \& alimpar o rostro \& despois cheyrar as maãos. $\mid(\mathbf{b}, \mathbf{2})$ Muyto saã cousa he que se laue a boca \& os olhos \& as maãos ameude cada dia com agoa rosada mesturada com vinagre.l $\rightarrow$ TRAZER NA MÃo. vide TRAZER.

MAR. [<lat. mare, -is.] sm. Grande porção de água salgada. mar, S. XIII: (a2v, 18) A morte se ensanha ha çidade se filha \& toma dos jmigos. ho mar se faz cruel. \& ho sol se cobre

\section{MARIA. vide VIRGEM MARIA.}

MAS. [<lat. magis.] conj. - mais, S. XIII; mas, S. XIII. @ E; que [elemento encadeador da narração]: (a4v,2) \& por tanto deue homem de fugir dos aares peçonhentos. mais ajnda digo que em o tempo pestilençial nenhuũ nom deue de star em ajuntamento do pouoo. I $\left(\mathrm{a}^{\mathrm{v}}{ }^{\mathrm{v}}, 14\right)$ \& assy corrupto feere ho coraçom. em tanto que ha natureza he per muytas manejras agrauada: mas ajnda tam sobejamente se agraua ha natureza que nom sinte sy ser ferida nem emferma. I (b2v, 8) Mas dira alguũ. se o homem deue de euitar ho somno que fara homem se teuer o sonno natural. I (b2v, 21) Mas diras tu. como sintira homem que está apeçonhentado \& ferido da pestilençia. I (a6, 20) \& ysto seja mayormente em tempo de neuoeiro \& chuuoso Mas em tempo de pestilencia milhor he estar em casa que andar fora $\mid(\mathbf{b} 3,13)$ Ergo per estes signaaes se sente homem apeçonhentado. mas se alguũ nom quiser creer: spere per huũ meo dia $\mid(\mathbf{b} 3,2)$ \& ysso mesmo tem grande door em ha parte dianteira da cabeça. mas todas estas cousas pode muyto bem euitar \& de sy lançar andando ou espaçando huũ pouco antre ho comer \& o dormir. Indicação de contraste ou oposição: $(\mathbf{a 5}, \mathbf{1 3})$ Empero prometo te que muyto boõ remedio he fugir \& mudar o lugar apeçonhentado. mas porque muytos sem grande perda nom podem mudar o lugar. I $\left(\mathbf{b}^{v}, 5\right)$ ajnda que pigmenta purga o çerebro da freuma \& os outros membros speciaaes dos humores vis $<\mathrm{c}>$ osos. mas porque muyto aqueenta. \& a queentura traz podridom. melhor me pareçe soo a cousa amargosa que queentura cheyro \& sabor. I $\left(\mathbf{b}^{v}, \mathbf{1 3}\right) \&$ por ysso nom pareçe se neçessario mas antes jnpidoso $(\mathrm{b} 2,13)$ porque ymaginaçam faz causa \& perijgo. mas qualquer com muy to prazer \& alegria sempre espere de muyto viuer. $\mid\left(\mathbf{b} 4^{\mathrm{v}}, 6\right)$ posto que alguũs çirogiaães querem que lhe ponham triaga mas eu rogo mujto que se nom ponha. I $\left(\mathbf{b} 4^{\mathrm{v}}, \mathbf{7 )}\right.$ porque a triaga lança a peçonha fora. mas eu queria antes que quando alguũ teuesse tal apostema que soruesse em si toda a triaga 
MASSA. [<lat. massa,-ae.] sf. O conjunto, o todo. - massa: $(\mathbf{a 6}, \mathbf{8 )}$ Item per esta mesma causa se deue euitar ho banho de cada dia. porque pouco creçente apeçonhenta toda a massa

MAU. [<lat. malus, -a, -um.] adj. Nocivo, funesto. - maa, s. XIII; maos, s. XIV; maaos, S. XIII: (a3 $\left.{ }^{v}, 2\right)$ ligeyramente se empeçonhentam os corpos da jndisposiçam ou da maa desposiçam dos çeos. I (b, 12) Em casa sempre este fogo açeso. porque clarifica muyto ho aar \& poõe grande impedimento aa maa influencia do çeeo. I $\left(\mathbf{b} \mathbf{2}^{\mathrm{v}}, \mathbf{2 5}\right)$ porque he cheo de maos humores. I $(\mathbf{a 6}, \mathbf{1 - 2})$ porque os corpos cheos dos maaos humores sam mais asinha empeçonhentados. I ( $\left.\mathbf{b}^{v}, 9\right)$ ysso mesmo o alho posto: alimpe da freuma \& lança fora os maaos humores $\mid\left(\mathbf{b} 2^{\mathrm{v}}, 20\right)$ \& estes maaos humores se lançam fora per tomar hũa bõa vez de vinho boõ ou bõa çerueja

MEÃ. vide VEIA.

MEATo. [<lat. meatus, -us, 'passagem, caminho' ] sm. Poro. $\bullet$ meatos, S. XV: $\left(a 6^{v}, 10\right) \&$ os cheyros taaes opilam \& çarram os poros \& os meatos \& os caminhos dos humores

MEDICO. [<lat. medicus, -i.] sm. Clínico que visitava os doentes que não podiam sair da cama [cf. CIRURGİ̃o, FísICo]. Em geral, os pacientes recebiam tratamento em casa. Na Idade Média, o hospital, como o conhecemos, não existia. Para doenças contagiosas que exigiam isolamento, como a hanseniase, existiam gafarias e lazaretos, mas não se previa nestes a presença de médicos (Marques, 1964: 97). - medico; medicos: $(\mathbf{a} 5,5)$ pollo qual deues de notar que segundo diz o grande medico scilicet. dauid.। (b4, 3-4) ou da vea que he açerca do dedo menor: ou açerca do articulo que he de muytos medicos chamada basilica. I (a2, 15) Quero algũas cousas da pestenença que nos ameude fere: dos ditos dos mays autenticos medicos: screuer. I (a3, 15) \& daly procedem febres pestilençiaes. açerca das quaes muytos medicos sam emganados I (a3v $\left.{ }^{2} \mathbf{1 8}\right) \mathrm{E}$ por tanto muytos medicos que em os enfermos soomente esguardam as ourinas superficialmente falam. \& lygeyramente sam emganados

MEIA-NOITE. vide MEIO.

MEIO. [<lat. medius, -ii.] sm. - meo, s. XIII. A parte central: (b3v', 13) E se pella ventura naçer a apostema de bayxo do braço direyto. sangre se em ho meo daquelle braço da vea meaã. (b3, 13-14) se alguũ nom quiser creer: spere per huũ meo dia. $\rightarrow$ MEIO-DIA. $s m$. meo dia, s. XIV. $O$ Sul. (a2v, 22) \& mayormente se veem da parte do meo dia I (a2v, 23) Sexto sinal he quando veem muytos ventos do meo dia. I (a4v, 13) \& as genelas ou frestas pera ho meo dia ou pera ho sul estem çarradas. Período em que o Sol está mais alto no céu: $(\mathbf{a} 5,20)$ Fechem se ergo as frestas ou genelas como dito he que vaam ou estam pera o sul atee hũa hora depois do meo dia $\mid(\mathbf{b}, 22) \&$ nom jantaras atee ho meo dia $\mid(\mathbf{b} 4,22)$ emtom podera dormir despois do meo dia. \& sempre antes do meo dia sera em continuo mouimento $\rightarrow$ MEIA-NOITE. sf. A vigésima quarta hora do dia. $\bullet$ mea noyte, s. XIV: Item o homem que se sangra ou tenha pestenença ou nom. em nenhũa maneyra nom deue de dormir per todo o dia atee mea noyte

MEIO-DIA. vide MEIO.

MELHOR. [<lat. melior, -oris.] -milhor; milhores; melhor. $\square$ adj. Preferível: $\left(\mathbf{b}^{\mathrm{v}}, \mathbf{1 6}\right)$ \& por tanto todos os mantijmentos quanto som de mais leue digestam tanto som milhores I (a5v, 21)\& faça se tambem com fumo de boõas heruas aqui scriptas scilicet. baga de louro. junipero. vberiorgano. as quaaes acharas aos apotecayros. \& de alosna \& ysope \& arruda. \& artamija. \& com lenho de aloes que he melhor de tudo [1] adv. Mais bem: $\left(\mathbf{b} 4^{\mathrm{v}}, \mathbf{1 8 )}\right.$ \& ysto com o estamago gejuum. porque emtom obra milhor em o homem. I $(\mathbf{b} 4$ v , 1) E ysso mesmo por que a apostema mais çedo \& milhor seja madura $\rightarrow$ MELHor .... QuE. Indica comparação. - milhor.... que; melhor .... que; melhores que: (a6, 20) Mas em tempo de pestilencia milhor he estar em casa que andar fora. I $\left(\mathbf{b}^{\mathrm{v}}, \mathbf{6}\right)$ mas porque muyto aqueenta. \& a queentura traz podridom. melhor me pareçe soo a cousa amargosa que queentura cheyro \& sabor. I (a5, 10-11) a sancta penitencia \& a confissam as quaaes preçedem \& sam muyto melhores que todas as mezinhas 
MEMBro. [<lat. membrum, -i.] sm. Parte do corpo. - membros: $(\mathbf{b} 3, \mathbf{2 1})$ \& emtom a peçonha espalha se per os membros de toda partel $\left(\mathbf{a}^{\mathrm{v}}, \mathbf{1 6}\right)$ Das conformidades do coraçam \& dos outros membros. $\rightarrow$ MEMBROS ESPECIAIS. Membros principais. membros speciaaes: E em os mantijmentos guarte das cousas queentes. assi como som pigmenta \& alhos. ajnda que pigmenta purga o çerebro da freuma \& os outros membros speciaaes dos humores vis $<\mathrm{c}>0 \cos \mid\left(\mathbf{b} 2^{\mathrm{v}}, 5-6\right)$ porque em ho somno ha queentura intrinseca. caladamente traz a peçonha ao coraçam \& aos outros membros speciaaes. $\rightarrow$ MEMBRos PRINCIPAIS. O coração, o fígado, o cérebro. - prinçipaes membros. (a2, 20) Quarto das conformidades do coraçam: \& dos prinçipaes membros

MENOR. vide DEDO.

MERIDIONAL. [<lat. meridionalis, -e.] adj. Do Sul. - meridional: $(\mathbf{a} 5,17)$ \& tambem o vento meridional ou sul: o qual naturalmente apeçonhenta. $\mid\left(\mathbf{a} 2^{\mathrm{v}}, 3-4\right)$ \& prinçipalmente quando he ho vento meridional. ou da parte de estrela do Sul

MES. [<lat. mensis, -is.] sm. Cada uma das doze divisões do ano. $\bullet$ mes: (b2, 16) SAngria huũa vez em huũ mes se pode bem fazer. se nom se a ydade ou outra cousa for em contrayro

MESMO. [<lat. * metipsimus, $-a_{\text {s }}$-um.] - meesmo; meesma; mesmo; mesma. $\mathbb{~}$ adj. Exato, preciso [reforço enfático do demonstrativo]: $(\mathbf{b 3}, \mathbf{2 5})$ logo naquelle meesmo dia mingue ho sanguel $\left(\mathbf{b} 3^{\mathrm{v}}, \mathbf{1 5}\right)$ Se de bayxo do braço seestro ou esquerdo. sangre se em ha vea meaã daquelle meesmo braço $\mid\left(\mathbf{b} 3^{v},{ }^{2}\right)$ ou na meaã daquelle meesmo braço. I (b3v , 23) ou na maão daquelle meesmo lado açerca do dedo menor. I (b3 $\mathbf{2}, \mathbf{2 5})$ E se pela ventura apareçer açerca da orelha: faça se a sangria de çephalica daquelle meesmo lado. I (b3' ${ }^{\mathbf{}}$, 21) E se açerca das partes vergonçosas. sangre se em o pee daquelle mesmo lado açerca do calcanhar. I \& sempre naquella meesma parte do corpo: em a qual ha doença ou chaga apareçer se deue de sangrar \& abrir a vea.I $\left(a^{v}\right.$, 24$)$ Item per esta meesma ca<u>sa se euite \& esquiue: todo ho inchamento do ventre que veem per muyto comer. $\mid(\mathbf{a 5}, \mathbf{2 1})$ \& per esta mesma causa euitaras \& esquiuaras todo ho fedor $\mid(\mathbf{a 6}, 6)$ Item per esta mesma causa se deue euitar ho banho de cada dia. I @्] adj. Próprio: (b3, 22) Estas cousas per my mesmo prouey. $\mathbb{Q}$ adv. Até: $\left(\mathbf{a} 5^{\mathrm{v}}, \mathbf{6}\right)$ \& daqui veem que em tal casa como esta morrem os homens mais azinha \& em outra nom como dito he mesmo onde se lançam verças \& caldos podres que sobejam em taaes casas. $\rightarrow$ ISSO MESMO. vide ISSO.

MESTRE. [<lat. magister, -tri.] sm. Título que se dava aos que ensinavam nas universidades e colégios, mas especialmente aos que ensinavam Teologia. - mestre, s. xv; (a2,7) E tralladado de latim em lingoagem per ho reuerendo padre frey Luys de ras: mestre em sancta theologia da orde $m$ de sam francisco

METAuros. [<lat. meteora, 'fenômenos, espaços e corpos celestes' pela forma tardia methauris.] sm. Os meteoros (ou Meteororum; ou ainda Meteorologica ou Meteorologicorum), uma das obras de A ris tóte le s [q.v.], escrita por volta de 350 a. C. metauros: $\left(\mathbf{a} 2^{\mathrm{v}}, \mathbf{1 3}\right)$ \& segundo diz aristoteles em os metauros. quando ha cometa apareçe aconteçem mortes de gentes em bathalhas \&c

MEU. [<lat. meus, -a, um.] pron. possess. Que pertence àquele que fala. $\bullet$ meos, S. XIv; minha:(a6v, 12) assi escapey de tal pestilencia. que os meos companheiros nom podiam creer que eu podesse viuer \& escapar $\mid\left(\mathbf{a}^{\mathrm{v}}, 5\right)$ Em monpilher nom me pude escusar de companhia de gente. porque andaua de casa em casa curando enfermos por causa da minha pobreza

MEZINHA. [<lat. medicina, -ae.] sf. Medicamento sob forma de xarope ou de emplastro. A divulgação das receitas de mezinhas e a facilidade em obter seus ingredientes fez com que muitos que nãa um boticário ou a p o te cá $r i$ $o$ [q.v.] as preparassem. No caso das mais complexas, o boticário sofreu a concorrência, no fabrico e na venda, do 
fís i co [q.v.] (Marques, 1964: 103). - meezinha; meezinhas; mezinhas: $\left(b^{v}, 23\right)$ ou huũ pequeno de pero ou maçaã em lugar de meezinha.l $\left(\mathbf{b 4} \mathbf{4}^{\mathrm{v}}, \mathbf{2}\right)$ faça se meezinha em tal maneira $\left(\mathbf{b} \mathbf{4}^{\mathrm{v}}\right.$, 24) \& qualquer que se per este modo reger escapara muytos perijgos da pestilencia com virtude \& meezinha de nosso senhor jesu christo. I ( $\left.\mathbf{b}^{v}, 20\right)$ Em tempo da pestilencia valem mais cousas azedas que todalas meezinhas $\mid(\mathbf{a} 5, \mathbf{1 1})$ polla qual causa grande remedio he em tempo da pestilençia a sancta penitencia \& a confissam as quaaes preçedem \& sam muyto melhores que todas as mezinhas

MIM. [<lat. mihi.] pron. pess. $\star$ my, S. XIII: $(\mathbf{b 3}, \mathbf{2 2})$ Estas cousas per my mesmo prouey

MINGUAR. [<lat. minuare.] v. Diminuir. $\bullet$ minguam; minguaras; mingua; mingue: $(\mathbf{a 6}, 5)$ aquelles que sempre querem encher seus ventres que abreuiam seus dias \& tempos da sua fim \& minguam sua vida I (b4, 5) E se polla ventura for açerça das espadoas: minguaras o sangue com ventosas.| $(\mathbf{b 4}, \mathbf{6})$ \& primeiramente minguaras a meaã $\mid(\mathbf{b} 4,19)$ em maneira que sempre se mingue o sangue per modo contrayro I $(\mathbf{b} 3,25)$ quando se homem sente ser tocado da peçonha pestilençial. logo naquelle meesmo dia mingue ho sangue: I (b4, 7) E se for em o espinhaço mingua sobre a vea que he chamada a pedica grande. $\rightarrow$ Minguamento. sm. Diminuição. minguamento: $(\mathbf{b 3}, \mathbf{2 6}) \&$ se sangre atee esmoreçer. porque pouco minguamento de sangue esperta a peçonha

MINUIR. [<lat. minuere.] v. Diminuir. - menuyr; menuido: $(\mathbf{b 4}, \mathbf{1 1})$ E se pella ventura sentir chagas despois de dormir: emtom ha de menuyr o sangue em a parte crucifixa $\mid(\mathbf{b 4}, \mathbf{2 0 )}$ E despois do sangue menuido se for muy to fraco emtom podera dormir despois do meo dia

MISTURAR. [de mistura.] v. Juntar. - mistura; misturem; misturado; mesturada, S. XIII: (b4v ${ }^{\text {, }} \mathbf{1 6}$ ) toma aquelle çumo \& mistura ho com leyte $\mathrm{d} e$ mulher $\mid(\mathbf{b} 2,6) \mathrm{E}$ se nom forem muyto pobres: tomem cuminhos \& açafram \& misturem tudo com vinagre emtom $\mid(\mathbf{b} 2,4)$ \& todo misturado com vinagre faz muy bõa salsa | $(\mathbf{b}, 3)$ Muyto saã cousa he que se laue a boca \& os olhos \& as maãos ameude cada dia com agoa rosada mesturada com vinagre

MODo. [<lat. modus, -i.] sm. Maneira, forma. - modo: (a5, 2)VIstas as causas da pestilencia. agora ajamos de veer per que modo \& como se deue homem de guardar da pestilencia I $(\mathbf{b} 4,19)$ em maneira que sempre se mingue o sangue per modo contrayro. I $\left(b 4^{v}, 22\right)$ \& qualquer que se per este modo reger escapara muytos perijgos da pestilencia $\rightarrow$ EM MODo QUE. De sorte que. $\bullet$ em modo que; em modo que: $\left(a 2^{v}, 1\right)$ Primeiro quando em hũu dia do estio \& do alto veraão se muda a manhaã muytas vezes. em modo que de manhaã pareçe chuuosa \& chea neuoa $\mid\left(\mathbf{a} 2^{v}, 6\right)$ e $m$ modo que pareçe que quer chouuer e nom choue I (b2v, 14) em modo que o somno natural se possa tomar per hũa hora despois de comer. I $(\mathbf{b} 2$ v, 6) em modo que escassamente pode nenhũa herua tal peçonha reuogar. I $(\mathbf{b 3}, \mathbf{1 1})$ porque a peçonha intrinseca pertorua o sprito vital. em modo que sempre deseja folgança

MOLHADO. [de molhar.] adj. Embebido. - molhada: $(\mathbf{a} 6,18)$ E ysto nom poder auer. emtam coma paão ou hũa sopa molhada em vinagre

MONPILHER. vide MONTPELLIER.

MONTPELLIER. [<lat. Mons *pestellarius, der. de *pestellum ou pastellum, 'pastel'.] topôn. Cidade francesa, famosa pelo ensino da Medicina desde o século XII. Segundo Costa Roque (1979: 327 n51), considera-se a referência do texto à peste de Montpellier de 1348. - monpilher: $\left(\mathbf{a 6}^{\mathrm{v}}\right.$, 3) Em monpilher nom me pude escusar de companhia de gente

MORBo. [<lat. morbus, -i.] sm. Doença [q.v.]. - morbo, s. XV: (a3v, 8) da jmpressam celestrial corrompente ho aar. \& podridam dos corpos mortos. ou lugares çujos se causa ho morbo ou ha chagua em ho homem $\mid\left(\mathbf{a 3}^{\mathbf{v}}, \mathbf{9 )} \&\right.$ tal morbo ou jnfirmidade as vezes he febre. \& as vezes apostema \& jsto em os demais 
MORRER. [<lat. morere.] v. Falecer. $\bullet$ morre; morrem: $\left(\mathrm{a3}^{\mathrm{v}}\right.$, 25) Porque he assy que huũ morre \& ho outro nom. $\mid(\mathbf{a} 4, \mathbf{1})$ \& daquella villa morrem homens \& daqueloutra nom.| $\mathbf{( a 4 , 2 )} \&$ daquella casa morrem \& daqueloutra nom. $\mid\left(\mathbf{a 5}^{\mathrm{v}}, \mathbf{5}\right)$ \& daqui veem que em tal casa como esta morre $m$ os homens mais azinha \& em outra nom $\rightarrow$ MORTo. adj. Sem vida. - mortos; mortos: $(a 3,18)$ As vezes jsso mesmo veem de corpos mortos | (a3v, 8) Da rayz superior \& jnferior juntamente proçede quando da jmpressam celestrial corrompente ho aar. \& podridam dos corpos mortos. I $(\mathbf{a 5}, \mathbf{2 4 )}$ em special donde ha hi corpos mortos \& podres. $\rightarrow$ MORTE. sf. Falecimento. - morte; mortes: $($ a2v, 16) A morte se ensanha ha çidade se filha \& toma dos jmigos. I $\left(\mathbf{a}^{\mathbf{v}}, \mathbf{1 8}\right)$ apareçem bõas ourinas \& boõas augoas. \& bõas digestiões. empero ho enfermo vay caminho da morte I $(\mathbf{a 4}, \mathbf{1 1})$ Da parte do paciente que aquelle he mays desposto aa morte que aquel outro. $\mid(\mathbf{a 4}, \mathbf{1 3})$ \& por tanto deues de notar que os corpos mays despostos a jnfirmidade \& a morte sam os corpos queentes I $(\mathbf{b} 2, \mathbf{1 1})$ em tempo da pestilencia que nenguem nom tema morte. sem teer infirmidade pestilencial. I (a2v, 14) quando ha cometa apareçe aconteçem mortes de gentes em bathalhas \&c

mosca. [<lat. musca, -ae.] sf. Termo geral empregado para designar numerosos insetos de diversos grupos distintos. Na passagem em foco, contudo, tal referência parece dizer respeito à mosca caseira, Musca domestica Linnaeus, 1758 (Diptera, Muscidae), que freqüenta as habitaçôes humanas e suas cercanias desde tempos imemoriais. De acordo com o original, ao fugir dos pretensos "eflúvios malignos" de uma atmosfera contaminada pela peste, as moscas terminariam por pousar no solo em grande quantidade, anunciando a chegada da doença. moscas: $\left(\mathrm{a} 2^{\mathrm{v}}, 9\right)$ Tercio he quando ha hy muytas moscas em ha terra

MOSTARDA. [<fr. ant. mostarde.] sf. Sinapis nigra Linnaeus,família das Crucíferas. Arbusto de caule piloso, folhas alternadas, flores amarelas reunidas em espigas, fruto vagem com pequenas sementes avermelhadas ou escuras, arredondadas e com sabor picante, utilizadas como condimento na culinária e no preparo de cataplasma conhecido como sinapismo. Apresenta propriedades estimulante, amenorréica, cardiotônica, anti-reumática. Embora classificada no quarto grau de calor, foi considerada antídoto ao escorbuto e por isso tinha presença obrigatória no tempero de carnes salgadas, vistas como causadoras dessa doença (Flandrin 1996:494). mostarda: (b4v , 3-4) Toma folhas de sabugo pisadas \& com mostarda pisada \& faze emprasto

MOVER. [<lat. movere.] v. Apresentar, levantar. - mouem: (a3v, 24) Aqui se mouem duas questões. $\rightarrow$ Movimento. sm. Ação de mover(-se). mouimento; mouimento: $(\mathbf{b} 2 \mathbf{v}, 8)$ em modo que escassamente pode nenhũa herua tal peçonha reuogar. a qual cousa nom se faria se o homem andar em mouimento. I $(\mathbf{b} 4,23)$ \& sempre antes do meo dia sera em continuo mouimento

MUDAR. [<lat. mutare.] v. $\bullet$ muda; mudar. $\llbracket$ Modificar: $\left(\mathbf{a} \mathbf{2}^{v}\right.$, 1) Primeiro quando em huũ dia do estio \& do alto veraão se muda a manhaã muytas vezes $\mid\left(\mathbf{a} 2^{\mathrm{v}}, 19\right)$ ho regno se muda. ho pouoo padeçe fame \& pestilencia. Trocar: $(\mathrm{a} 4 \mathrm{v}, 10) \mathrm{E}$ por tanto digo que a tal doente de pestilençia he boõ per alguũs dias mudar a camera I $(\mathbf{a 5}, \mathbf{1 2})$ muyto boõ remedio he fugir \& mudar o lugar apeçonhentado.I $(\mathbf{a 5}, \mathbf{1 4})$ mas porque muytos sem grande perda nom podem mudar o lugar. $\rightarrow$ MUDANÇA. sf. Transformação: $(\mathbf{a} 3,8)$ em tanto que senssualmente pareçe aos homens mudança do aar

MUI. vide MUITO.

MUITo. [<lat. multus, -a, -um.] \muyto; muytos; muytos; muytas; mujto; mujtas; muito. @ pron. indef. Em quantidade: \& despois que a vea for ferida ou aberta aproueyta muyto tomar muyto prazer. I (b2, 13) mas qualquer com muyto prazer \& alegria sempre espere de muyto viuer. $1\left(\mathbf{a} \mathbf{2}^{\mathrm{v}}, \mathbf{2 3}\right)$ Sexto sinal he quando veem muytos ventos do meo dia.l $\left(\mathbf{b} 4^{v}, 23\right)$ qualquer que se per este modo reger escapara muytos perijgos da pestilencia $\mid\left(\mathbf{b} 2^{\mathrm{v}}, 19\right)$ porque o homem estando em o somno traz em si muytos vapores. I (a2v, 11) porque emtam pareçe ho aar ser empeçonhentado. \& que sobem muytos vapores peçonhentos ao aar, I $(\mathbf{a} 3, \mathbf{1 5})$ \& daly procede $m$ febres pestilençiaes, açerca das quaes muytos medicos sam emganados. $\left(\mathbf{a}^{\mathrm{v}}, \mathbf{1 8}\right)$ E por tanto muytos medicos que em os enfermos soomente esguardam as ourinas superficialmente falam. I (b4,3) ou da vea que he açerca do dedo menor: ou açerca do articulo que he de muytos medicos chamada basilica. I (a2v, 9) Tercio he quando ha hy muytas moscas em ha 
terra. | $\left(\mathbf{b}^{\mathbf{v}}, \mathbf{2}\right)$ \& se homem nom quiser cortar muytas veas juntamente: emtam leyxe yr a vea aberta ou ferida atee o retardamento do sangue. $\mid(\mathbf{b} 4, \mathbf{1})$ por que muytas cousas peçonhentas nom destruam o çerebro. I $\left(\mathbf{a} 3^{\mathbf{v}}, \mathbf{1 3}\right)$ em tanto que ha natureza he per muytas manejras agrauada: I (a2v, 1) Primeiro quando em huũ dia do estio \& do alto veraão se muda a manhaã muytas vezes. I (a2v, 5) Segundo sinal he quando em tal estio muytas vezes escureçem: ou pareçem escureçer os dias $\mid$ (a3, 20) \& esto aconteçe muytas vezes onde ha lugares podres \& corruptos. I $(\mathbf{a} 4 \mathbf{v}, \mathbf{1 1})$ \& muytas vezes teer as frestas pera ho norte ou pera o leuante abertas. I (a2 $\left.{ }^{v}, 20\right)$ Quinto sinal. he quando se fazem mujtas relampados \& trouoadas. 1 adv. Em alto grau: $(\mathbf{b}, 11)$ Em casa sempre este fogo açeso. porque clarifica muyto ho aar I \& despois que a vea for ferida ou aberta aproueyta muyto tomar muyto prazer. I $\left(\mathbf{a}^{\mathrm{v}}\right.$, 8) \& por serem assi podres causam tal fedor \& doença que muyto empeçe.l $(\mathbf{b}, 25)$ empero nom muyto juntamente. I $(\mathbf{a} 6, \mathbf{1})$ se euite \& esquiue: todo ho inchamento do ventre que veem per muyto comer. I $(\mathbf{a} 4,19)$ \& os homens que se muyto esqueentam com grande trabalho ou grande yra. $\mid\left(\mathrm{b}^{\mathrm{v}}, 5\right)$ mas porque muyto aqueenta. I (b2,14) mas qualquer com muyto prazer \& alegria sempre espere de muyto viuer. | $(\mathbf{b} 2,23)$ \& despois que a vea for ferida ou aberta aproueyta muyto tomar muyto prazer. I (b3, 3) mas todas estas cousas pode muyto bem euitar \& de sy lançar andando ou espaçando huũ pouco antre ho comer \& o dormir. I (b4v, 14) toma chantagem \& siligem (vay te ao boticayro) \& pisa todo muyto bem I $(\mathbf{b}, \mathbf{1 4 )}$ Quanto he ao teu mantijmento digo te que a triaga te he muyto proueytosa $\mid(\mathbf{a} 2,1)$ Começa se huũ boõ regimento muyto neçessario | $(\mathbf{a} 2,2)$ \& muyto proueitoso aos viuentes. I $(\mathbf{a} 5,10)$ grande remedio he em tempo da pestilençia a sancta penitencia \& a confissam as quaaes preçedem \& sam muyto melhores que todas as mezinhas. I $(\mathbf{a} 5,12)$ Empero prometo te que muyto boõ remedio he fugir \& mudar o lugar apeçonhentado. I (a6, 24) ysso meesmo he muyto boõ ameude lauar as maãos com augoa \& vinagre. $\mid(\mathbf{b} 2,7) \&$ tal salsa he muyto boõa $\mid(\mathbf{b} 2,1)$ busquem se pera os ricos muyto bõas salsas ou salseamentos. I (b, 1) Muyto saã cousa he que se laue a boca \& os olhos \& as maãos ameude cada dia com agoa rosada mesturada com vinagre. I $(\mathbf{b} 4,26)$ tal apostema lança o mal de fora \& faz o homem ser muyto saão.। $\left(\mathbf{a} 2^{\mathrm{v}}, 24\right)$ porque taes ventosidades sam muyto çujas $\mid(\mathrm{b} 2,19)$ como he em as molheres que som prenhes, ou em alguñ muyto fraco $I(\mathbf{b} 4,21)$ E despois do sangue menuido se for muyto fraco emtom podera dormir despois do meo dia. I $(\mathbf{b} 2,5)$ E se nom forem muyto pobres: tomem cuminhos \& açafram \& misturem tudo com vinagre. I $(\mathbf{b} 3,7)$ por a grande pigriça do corpo \& muyto grande peso \& carrega corporal. $\mid(\mathrm{a} 2 \mathrm{v}, 7)$ \& emtam se isto mujto durar he pera temer de vijr grande pestilençia.। (b2v, 24$)$ o homem que em tal dia he apeçonhentado nom come mujto. I (b4v, 6) posto que alguũs çirogiaães querem que lhe ponham triaga mas eu rogo mujto que se nom ponha. (a2v, 24) \& muito velhacas. Pl. $\mathrm{sm}$. Grande quantidade de indivíduos: $(\mathbf{a} 5,13)$ mas porque muytos sem grande perda nom podem mudar o lugar. $\rightarrow$ MUI. adv. Muito. $\bullet$ muy: $(\mathbf{a} 3,25)$ \& de tal diz auicena no quarto liuro que muy ligeyramente se empeçonhentam os corpos da jndisposiçam ou da maa desposiçam dos çeos. I (a4, 23) A segunda questam digo que taaes infirmidades pestilençiaaes sam contagiosas \& apegam se muy asinha. $\mid(\mathbf{b} 2,4)$ todo misturado com vinagre faz muy bõa salsa $\mid(\mathbf{b} 2,24)$ beber muy boõ vinho ou bõa çerueja

MULHer. [<lat. mulier, -is.] sf. Individuo do sexo feminino. $\bullet$ molheres, s. XIII; mulher: (b2, 19) se nom se a ydade ou outra cousa for em contrayro. assy como he em as molheres que som prenhes. ou em alguũ muyto fraco I $(\mathbf{b} 4 \mathbf{v}, \mathbf{1 6})$ emtom toma aquelle çumo \& mistura ho com leyte de mulher

MULTIDÃo. [<lat. multitudo, -inis.] sm. Grande número. $\star$ multidom, S. XIV: $(\mathbf{a 6}, 9)$ onde finalmente digo que toda multidom de pouoo \& comunidade em tal tempo se deue de euitar em quanto for possiuel 
NÃo. [<lat. non. ] adv. Indica negação. •nom, s. XIII; nom: $\left(\mathbf{a}^{\mathrm{v}}{ }^{\mathrm{v}}, \mathbf{2 5}\right)$ Porque he assy que huũ morre \& ho outro nom. I (a4, 1) \& daquella villa morrem homens \& daqueloutra nom.l (a4, 2) \& daquella casa morrem \& daqueloutra nom. $\left(\mathbf{a}^{\mathrm{v}}, \mathbf{5}\right)$ \& daqui veem que em tal casa como esta morrem os homens mais azinha \& em outra nom como dito he $\mid\left(\mathbf{b} 3^{\mathrm{v}}, 7\right)$ o homem que se sangra ou tenha pestenença ou nom. I $(\mathbf{b} 2,17)$ SAngria huũa vez em huũ mes se pode bem fazer. se nom se a ydade ou outra cousa for em contrayro. I $(\mathbf{b}, \mathbf{2 5})$ deues de comer boõ manjar \& bõa yguaria com boõ vinho puro \& ameude. empero nom muyto juntamente. I (b3v, 7) em nenhũa maneyra nom deue de dormir | $\left(\mathbf{a} 4^{\mathrm{v}}, 3\right)$ em o tempo pestilençial nenhuũ nom deue de star em ajuntamento do pouoo. I (a2v, 7) em modo que pareçe que quer chouuer \& nom choue. I ( $\left.\mathbf{b}^{v}, 12\right)$ \& por ysso nom pareçe se neçessario mas antes jnpidoso, I $(\mathbf{a} 3,2)$ se ho senhor deus todo poderoso ho nom quitar \& estoruar. I $(\mathbf{3} 3, \mathbf{1 6})$ muytos medicos sam emganados. porque nom conheçe $m$ taes febres serem pestilençiaes $(\mathbf{a} 5, \mathbf{1 4})$ mas porque muytos sem grande perda nom podem mudar o lugar $\mid\left(\mathbf{a} 5^{v}, 21\right)$ \& com lenho de aloes que he melhor de tudo posto que se nom pode comprar por pequeno preço. I $(\mathbf{a 6}, \mathbf{1 7}) \mathrm{E}$ ysto nom poder auer. emtam coma paão ou hũa sopa molhada em vinagre. I (b, 3) \& se estas cousas nom poder auer faça se com vinagre. I (a6v, 3) Em monpilher nom me pude escusar de companhia de gente. $\mid\left(\mathrm{a}^{\mathrm{v}}, 12\right)$ os meos companheiros nom podiam creer que eu podesse viuer \& escapar. $\mid(b, 7)$ se o ventre naturalmente se nom poder vazar. toma huũ cristel. I $(\mathbf{b} 3,5)$ Posto que tal como este nom pode andar em cauallo ou besta. I $\left(\mathbf{a}^{\mathbf{v}}, \mathbf{1 5}\right)$ mas ajnda tam sobejamente se agraua ha natureza que nom sinte sy ser ferida nem emferma. I $\left(\mathbf{a}^{\mathrm{v}}{ }^{\mathrm{v}}, \mathbf{1 0}\right)$ porque as cousas azedas \& os cheyros taaes opilam \& çarram os poros \& os meatos \& os caminhos dos humores \& nom consintem entrar as cousas peçonhentas. I (bv, 10) \& nom consinta emtrar ho aar seco. I (a5v, 12) porque nom entre em ella ho aar peçonhentado I $(\mathrm{a} 6,11)$ por que se nom apeçonhente homem do aar apeçonhentado. I $\left(\mathbf{a} 6^{v}, 23\right)$ em toda maneyra te guardes que nom reçebas do baffo de outrem. I $\left(\mathbf{a}^{\mathbf{v}}\right.$, 25) Os olhos do aar empeçonhentado logo escureçem se estas cousas nom trouuer homem em ha maão I $(\mathbf{b}, \mathbf{2 1})$ \& nom jantaras atee ho meo dia porque possa a triaga em o corpo fazer sua operaçam $\mid\left(\mathbf{b}^{v}, \mathbf{1 8}\right)$ \& potagios se euite $m$ : se nom forem azedos $\mid\left(\mathbf{b}^{\mathbf{v}}, \mathbf{2 1 )}\right.$ Isso mesmo se euite $m$ todos os fructos se nom forem azedos. I $(\mathbf{b} 2,5)$ E se nom fore $m$ muyto pobres: tomem cuminhos \& açafram \& misture $m$ tudo com vinagre. | (b2, 11) nenguem nom tema morte. sem teer infirmidade pestilencial. | (b4, 25) E se despois creçer a postema: nom tema. ||$(\mathbf{b} 2,25)$ \& nom conuem dormir em aquelle dia que se sangrar \& abrir a vea. | (b2v, 7) a qual cousa nom se faria se o homem andar em mouimento. I $\left(b 2^{v}, 24\right) 0$ home $m$ que em tal dia he apeçonhentado nom come mujto. | $(\mathbf{b} 3, \mathbf{1 3 )}$ mas se alguũ nom quiser creer: spere per huũ meo dia \& logo sentira apostema $\mid\left(\mathbf{b} 3^{v}, \mathbf{1}\right)$ \& se homem nom quiser cortar muytas veas juntamente: emtam leyxe yr a vea aberta ou ferida atee o retardamento do sangue. I (b4, 1) por que muytas cousas peçonhentas nom destruam o çerebro. I (b4,9) E todas estas cousas se façam se homem nom dormir antes que conheça que tem a postema. I $\left(\mathbf{b} \mathbf{4}^{\mathrm{v}}, \mathbf{6 )}\right.$ mas eu rogo mujto que se nom ponha. porque a triaga lança a peçonha fora. I (b4v , 24) \& qualquer que se per este modo reger escapara muytos perijgos da pestilencia com virtude \& meezinha de nosso senhor jesu christo. sem o qual nom ha hy saude

NAQUELE. vide EM.

NARIZEs. [<lat. naricae, -arum.] sm.pl. Narinas. narizes, S. XV: $\left(\mathbf{a 5}^{\mathrm{v}} \mathbf{v}, \mathbf{2 3}\right)$ E tal fumo entre per a boca \& per os narizes. I $\left(\mathbf{a} \mathbf{6}^{\mathrm{v}}, \mathbf{8}\right) \&$ emtam leuaua commigo huũa sponja ou paão enssopado em vinagre: \& sempre no punha nos narizes \& na boca

NASCER. [<lat, nascere.] v. Surgir, brotar. - naçer, $\mathrm{S}, \mathrm{XV} ;\left(\mathbf{b} 3^{\mathrm{v}}, \mathbf{1 1}\right)$ E se pella ventura naçer a apostema de bayxo do braço direyto. sangre se em ho meo daquelle braço da vea meaã

NATURAL. [<lat. naturalis, -e.] adj. Espontâneo, normal. - natural: (b2v, 10) Mas dira alguũ. se o homem deue de euitar ho somno que fara homem se teuer o somno natural. $\rightarrow$ NATURALMENTE. adv. De modo espontâneo. - naturalmente; naturalmente:(a5v, 18) \& tambem o vento meridional ou sul: o qual 
naturalmente apeçonhenta. I $\left(\mathrm{a}^{\mathrm{v}} \mathrm{,}, \mathbf{1 5}\right)$ ho aar apeçonhentado he humido \& faz podridom em a casa ou em lugar onde dormem. \& ysso naturalmente. $\mid(\mathbf{b}, \mathbf{7})$ \& se o ventre naturalmente se nom poder vazar. toma huũ cristel

NATUREZA. sf. Virtude que conserva o corpo em todos os momentos e que é o principal fator na cura de uma do $e n$ f̧ $a$ [q.v.]. - natureza: $\left(\mathbf{a 3}^{\mathrm{v}}, \mathbf{1 3}\right)$ porque ho aar jnspirado as vezes he peçonhento: \& assy corrupto feere ho coraçom. em tanto que ha natureza he per muytas manejras agrauada:I (a3v, 14-15) mas ajnda tam sobejamente se agraua ha natureza que nom sinte sy ser ferida nem emferma

NECESsário. [<lat. necessarius, $-a,-u m$.] adj. neçessario, S. XV. Imperioso: (a3v, 21) Ergo he neçessario que todo enfermo se proueja de boõ fisico \& bem esperto. $\left(\mathbf{a} 4^{\mathrm{v}}, 22\right)$ boõ he ao saão em tempo da pestilençia quando venta vento sul estar em casa per todo o dia: \& se for neçessario que saya este em casa atee que saya o sol \& suba huũ boõ espaço sobre o nosso orizonte útil, preciso: (a2, 1-2) Começa se huũ boõ regimento muyto neçessario \& muyto proueitoso aos viuentes $\mid\left(\mathbf{b}^{v}, 13\right) \&$ por ysso nom pareçe se neçessario mas antes jnpidoso

NEM. [<lat. nec.] conj. - nem; nem. $[$ não: $(\mathbf{a 6}, 21)$ Mas em tempo de pestilencia milhor he estar em casa que andar fora. ne $m$ he saão andar per a villa ou çidade. I $(\mathbf{b}, \mathbf{1 7})$ toma se ergo duas vezes no dia com boõ vinho claro \& auguado. ou com augoa crara de rosas ou com çerueja crara. nem se tome mais da triaga que a quantidade de huũ piseo 0 [em enunciados em que as alternativas são negadas, a primeira por nom e a segunda, por nem]: $(\mathbf{a} 3,17)$ porque nom conheçe $m$ taes febres sere $m$ pestilençiaes. nem ho creem. I ( $\left.\mathbf{a 3}^{\mathrm{v}}, \mathbf{1 5}\right)$ mas ajnda tam sobejamente se agraua ha natureza que nom sinte sy ser ferida nem emferma. I $(\mathbf{b} 3, \mathbf{6})$ Posto que tal como este nom pode andar em cauallo ou besta. nem andar grande caminho por a grande pigriça do corpo \& muyto grande peso \& carrega corporal

NÉvoA. [<lat. nebula, -ae.] sf. Bruma; cerração pouco espessa. • neuoa, s. xIV: (a2v, 2) Primeiro quando em huũ dia do estio \& do alto veraão se muda a manhaã muytas vezes. em modo que de manhaã pareçe chuuosa \& chea neuoa. \& depois ventosa. $\rightarrow$ NEvoeIro. sm. Névoa espessa. • neuoeiro, S. XIV: (a6, 19) \& ysto seja mayormente em tempo de neuoeiro \& chuuoso

NINGUÉM. [ < lat. nec quem.] pron. indef. • nenguem: $(\mathbf{b} 2, \mathbf{1 1})$ polla qual cousa deue se homem de guardar em tempo da pestilencia que nenguem nom tema morte. sem teer infirmidade pestilencial

NO. vide EM.

NOITE. [<lat. nox, -ctis.] sf. Período do dia compreendido entre o pôr-do-sol e o nascer do sol. •noyte: $\left(\mathbf{b}^{\mathbf{v}}, \mathbf{1 7}\right)$ pela manhaã sejam os manjares cozidos: \& de noyte assados $\rightarrow$ MEIA-NOITE. vide MEIO.

NORTE. [<fr. ant. nort.] sm. Ponto cardeal que se opõe ao Sul. $\bullet$ norte, S. XV: $\left(\mathbf{a 4}^{\mathrm{v}}\right.$, 11) E por tanto digo que a tal doente de pestilençia he boõ per alguũs dias mudar a camera: \& muytas vezes teer as frestas pera ho norte ou pera o leuante abertas. I (a5, 21) Fechem se ergo as frestas ou genelas como dito he que vaa $m$ ou estam pera o sul atee hũa hora depois do meo dia \& abram se as que stam pera o norte

Nós. [<lat. nos.] pron. pessoal. Eu e outra(s) pessoa(s). - nos: $(\mathbf{a 3}, \mathbf{1 0})$ Da rayz jnferior proçede segundo nos veemos que da priuada que esta açerca da camera ou de alguũ fedor particular de alguũ canno çujo se corrompe ho aar em substançia \& qualidade. $\rightarrow$ Nos. pron. pessoal. A nós. • nos: (a2, 14) Quero algũas cousas da pestenença que nos ameude fere: dos ditos dos mays autenticos medicos: screuer

NOSSO. [<lat. “nossus.] pron. possess. Que pertence a nós. $\bullet$ nosso, S. XIII: (a4v, 24) \& se for neçessario que saya este em casa atee que saya o sol \& suba huũ boõ espaço sobre o nosso orizonte. $\rightarrow$ NOSSO SENHOR. Apelativo para Jesus. - nosso senhor: $(b 4 v, 24)$ \& qualquer que se per este modo reger escapara muytos perijgos da pestilencia com virtude \& meezinha de nosso senhor jesu christo 
NOTAR. [<lat. notare.] v. Observar, atentar. $\bullet$ notar: $(\mathbf{a} 4, \mathbf{1 2})$ \& por tanto deues de notar que os corpos mays despostos a jnfirmidade \& a morte sam os corpos queentes \& que teem os poros mays largos: \& os corpos peçonhentos que tem os poros opilados: \& çarrados de mujtos humores.l $(\mathbf{a} 5,4)$ pollo qual deues de notar que segundo diz o grande medico scilicet. dauid. que primeiro se deue o homem de afastar do mal \& inclinar se ao bem

NOz-Moscada. [or. obsc.] sf. Myristica fragrans Houtt, família das Miristicáceas. Arvore de até $10 \mathrm{~m}$ de altura, folhas oblongas, flores pequenas e amareladas. Tem fruto amarelo ou avermelhado e drupa globosa. A semente ou noz, a que se refere o texto, é dura, lenhosa, aromatizante e repleta de óleo, sendo de ampla utilização na culinária. É estimulante gastro-intestinal. Como qualquer especiaria [vide ESPÉCIA], a noz-moscada foi classificada como quente, mas apenas no segundo grau de calor, o que indicava que não era perigosa como a pimenta. • noz nozcada; noz nozcadas: $(\mathbf{a 6}, \mathbf{1 6})$ de manhaã quando se alguũ aleuantar logo coma da aruda lauada em agoa limpa espargida com sal \& noz nozcada hũa ou duas bem limpas. I (b2, 3) se forem pobres contentem se com arruda \& salua. noz nozcadas. pere $<x>$ il \& todo misturado com vinagre faz muy bõa salsa

NUVEM. [<lat. nubes. -is.] sf. Grande conjunto de partículas de água ou gelo na atmosfera. •nuueens, S. XIV: $\left(\mathbf{a} 2^{v}, 18\right)$ A morte se ensanha ha çidade se filha \& toma dos jmigos. ho mar se faz cruel. \& ho sol se cobre scilicet. de nuueens 


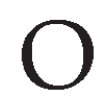

$\mathbf{O}^{1}$. [<lat. illu(m).] art. def. $\bullet$ ho; o; os: (a2,4)Feyto per ho reuerendissimo Senhor dom Raminto | (a2, 6)E tralladado de latim em lingoagem per ho reuerendo padre frey Luys de ras: $\mid\left(\mathbf{a} 2^{\mathrm{v}}, 3\right)$ \& prinçipalmente quando he ho vento meridional. I (a2v, 10) emtam pareçe ho aar ser empeçonhentado. I (a2v, 15) \& por isso diz ho verso poetico falando do apareçimento da cometa. I (a2v, 17) ho mar se faz cruel. I $\left(\mathrm{a} 2^{\mathrm{v}}, \mathbf{1}^{\mathrm{v}}\right)$ \& ho sol se cobre $\mid\left(\mathrm{a}^{\mathrm{v}} \mathrm{v}, \mathbf{1 8}\right)$ ho regno se muda. I $\left(\mathrm{a}^{\mathrm{v}}{ }^{\mathrm{V}}, \mathbf{1 9 )}\right.$ ho pouoo padeçe fame \& pestilencia. $\mid(\mathrm{a} 3, \mathbf{1})$ se ho senhor deus todo poderoso ho nom quitar \& estoruar I $(\mathbf{a} 3,12)$ de alguũ fedor particular de alguũ canno çujo se corrompe ho aar em substançia \& qualidade. I $\left(\mathbf{a}^{\mathrm{v}} \mathbf{3}, \mathbf{3}\right)$ por ha empressam dos çeos corrompe ho aar. I $\left(\mathbf{a 3}^{\mathrm{v}} \mathrm{v}, 4\right)$ \& ha empresam do aar corrompe os spiritos vitaes em ho home $m \mid\left(\mathbf{a} 3^{\mathrm{v}}, \mathbf{7}\right)$ juntamente proçede quando da jmpressam celestrial corrompente ho aar. \& podridam dos corpos mortos. ou lugares çujos $\mid\left(\mathbf{a}^{\mathrm{v}} \mathrm{v}, 8\right)$ se causa ho morbo ou ha chagua em ho homem $\mid\left(\mathrm{a}^{\mathrm{v}}, \mathbf{1 1}^{1}\right)$ porque ho aar jnspirado as vezes he peçonhento: $\mid\left(\mathrm{a}^{\mathrm{v}}{ }^{\mathrm{v}}, 12\right) \&$ assy corrupto feere ho coraçom. $\mid\left(\mathrm{a}^{\mathrm{v}} \mathrm{v}, 17\right)$ empero ho enfermo vay caminho da morte.l $\left(\mathbf{a}^{\mathbf{v}}, \mathbf{2 5}\right)$ Porque he assy que huũ morre \& ho outro nom. $\mid\left(\mathbf{a} 4^{\mathbf{v}}, \mathbf{1}\right)$ dos corpos apeçonhentados procedem humores \& fumos peçonhentos que corrompem ho aar. I (a4) $\left.\mathbf{4}^{\mathrm{v}} \mathbf{1 1}\right) \&$ muytas vezes teer as frestas pera ho norte ou pera o leuante abertas. I $\left(\mathbf{a} 4^{\mathrm{v}}, \mathbf{1 2}\right) \&$ as genelas ou frestas pera ho meo dial $\left(\mathrm{a} 4^{\mathrm{v}}, \mathbf{1 3}\right)$ ou pera ho sul estem çarradas. I $\left(\mathrm{a} 4^{\mathrm{v}}, \mathbf{1 8}\right)$ Ho sul he vento inchado I $(\mathrm{a} 5,22) \&$ per esta mesma causa euitaras \& esquiuaras todo ho fedor . I (a5v, 12) porque nom entre em ella ho aar peçonhentado I $(\mathbf{a 5 v}, \mathbf{1 3})$ porque ho aar apeçonhentado he humido I $\left(\mathbf{a 5}{ }^{\mathrm{v}}, \mathbf{2 5}\right)$ Item per esta meesma ca<u>sa se euite \& esquiue; todo ho inchamento do ventre I $(\mathbf{a} 6,7)$ Item per esta mesma causa se deue euitar ho banho de cada dia. I $\left(\mathbf{a}^{\mathbf{v}}, \mathbf{1 9}\right) \mathrm{com}$ todas as outras heruas que endereçam ho spirito interior. I $(b, 11)$ Em casa sempre este fogo açeso. porque clarifica muyto ho aar $\mid(\mathbf{b}, \mathbf{2 0})$ \& a triaga seja delida em ho vaso ou copo em que ha tomares. $\mid(\mathbf{b}, \mathbf{2 1})$ \& nom jantaras atee ho meo dia $\mid\left(\mathbf{(} \mathbf{b}^{\mathbf{v}}, \mathbf{1 0}\right)$ \& nom consinta emtrar ho aar seco. I ( $\mathbf{b}^{\mathrm{v}}$, 23) porque todo ho fructo traz podridom. I $(\mathbf{b} 2 \mathbf{v}, \mathbf{9})$ se o homem deue de euitar ho somno que fara homem se teuer o somno natural | $(\mathbf{b 3}, 4)$ pode muyto bem euitar \& de sy lançar andando ou espaçando huũ pouco antre ho comer \& o dormir. I $(\mathbf{b} 3,25)$ logo naquelle meesmo dia mingue ho sanguel $\left(\mathbf{b} 3^{v}, 26\right)$ ou da vea que esta antre o dedo demostrador \& ho dedo polegar. I $\left(\mathrm{a} 4^{\mathrm{v}}, 7\right)$ teendo o rostro pera genela ou fresta $\mid\left(\mathrm{a} 4^{\mathrm{v}}, 12\right)$ pera ho norte ou pera o leuante abertas.| (a $4^{\mathrm{v}}$, 13) porque $\mathbf{o}$ vento do sul teem em si duas causas de de apodrentar I (a4v, 17) A segunda que assi como se escreue em o terçeyro liuro dos amforismos I (a4, 22) estar em casa per todo o dia $\mid$ (a4 ${ }^{\mathrm{v},}$ 18) \&

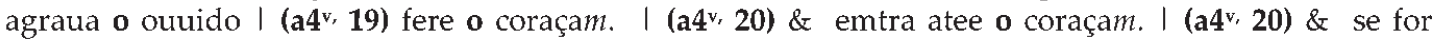
neçessario que saya este em casa atee que saya o sol $\mid\left(\mathbf{a} 4^{\mathbf{v}}, \mathbf{2 0}\right)$ \& suba huũ boõ espaço sobre o nosso orizonte. | $(\mathbf{a} 5,5)$ segundo diz o grande medicol $(\mathbf{a} 5,6)$ primeiro se deue o homem de afastar do mal | $(\mathbf{a} 5,12)$ boõ remedio he fugir \& mudar o lugar apeçonhentado. I (a5, 14) muytos sem grande perda nom podem mudar o lugar. I (a5, 16) E per conseguinte todo o coyto \& toda luxuria. I $(\mathbf{a} 5, \mathbf{1 7})$ \& tambem o vento meridional ou sul I $(\mathbf{a 5}, \mathbf{2 0 )}$ Fechem se ergo as frestas ou genelas como dito he que vaam ou estam pera o sul $\mid(\mathbf{a} 5,21) \&$ abram se as que stam pera o norte. I (a5v, 10) E assi como per ho boõ cheyro \& aromatico: se recrea o coraçom \& o sprito do homem. $\left|\left(\mathbf{a} 6^{\mathrm{v}}, \mathbf{1}\right)\right|$ he muyto boõ ameude lauar as maãos com augoa \& vinagre. \& alimpar o rostro $\mid(\mathbf{b}, \mathbf{6}) \mathrm{E}$ tambem he grande remedio vazar $\mathbf{o}$ ventre $\mid(\mathbf{b}, 7)$ \& se o ventre naturalmente se nom poder vazar. $\mid\left(\mathbf{b}^{\mathbf{v}}, 3\right)$ pigmenta purga o çerebro da freuma $\mid\left(\mathbf{b}^{v}, 8\right)$ ysso mesmo o alho $\mid\left(\mathbf{b}^{v}, 9\right)$ \& prouoca o apetito de comer $\mid\left(\mathbf{b} 2^{v}, 3\right)$ tal como este euite o somno | (b2 $\left.{ }^{v}, 8\right)$ a qual cousa nom se faria se o home $m$ andar em mouimento. | (b2 $\left.{ }^{v}, 9\right)$ Mas dira alguũ. se $\mathbf{o}$ homem deue de euitar ho somno $\mid\left(\mathbf{b} 2^{\mathrm{v}}, \mathbf{1 0}\right)$ que fara homem se teuer o somno natural $\mid\left(\mathbf{b} 2^{\mathrm{v}}, \mathbf{1 4}\right) \mathbf{o}$ somno natural se possa tomar per hũa hora despois de comer $\mid\left(\mathbf{b} 2^{\mathrm{v}}, \mathbf{1 8}\right) \mathbf{o}$ homem estando em o somno traz em si muytos vapores. I (b2v, 23) o homem que em tal dia he apeçonhentado nom come mujto. I $(\mathbf{b} 3,4)$ antre ho comer \& o dormir. I (b3, 8) o homem ja apeçonhentado em todas as horas teem grande desejo de dormir. I $(\mathbf{b} 3, \mathbf{1 0})$ a peçonha intrinseca pertorua o sprito vital. I $(\mathbf{b} 3, \mathbf{1 8})$ que escuse o somno | $(\mathbf{b} 3, \mathbf{2 0})$ em o tempo do somno o sprito vital repousa I $\left(\mathbf{b} 3^{\mathrm{v}}, \mathbf{3}\right)$ emtam leyxe yr a vea aberta ou ferida atee $\mathbf{o}$ retardamento do sangue. I (b3 $\left.\mathbf{3}^{\mathbf{v}}, \mathbf{6}\right)$ Item o homem que se sangra $\mid\left(\mathbf{b} 3^{v}, 8\right)$ per todo $\mathbf{o}$ dia atee mea noyte $\mid\left(\mathbf{b 3}^{\mathrm{v}}, \mathbf{2 6}\right)$ ou da vea que esta antre o dedo demostrador $\mid(\mathbf{b} 4,2)$ por que muytas cousas peçonhentas nom destruam o çerebro. I (b4, 5) minguaras o sangue com ventosas. I $(\mathbf{b} 4, \mathbf{1 2})$ emtom ha de menuyr o sangue em a parte crucifixa $\mid(\mathbf{b 4}, \mathbf{1 9 )}$ que sempre se mingue o sangue per modo contrayro. I $(\mathbf{b} 4,25)$ tal apostema lança o mal de fora I $(\mathbf{b} 4,26)$ \& faz o homem ser muyto saão. I (b4v , 
18) \& ysto com o estamago gejuum. | $\left(\mathrm{a} 2^{\mathrm{v}}, 6\right)$ muytas vezes escureçem: ou pareçem escureçer os dias । $\left(\mathbf{a} 3, \mathbf{2 4 )}\right.$ dos quaaes se corrompem os spiritos vitaes I $\left(\mathbf{a} \mathbf{3}^{\mathrm{v}}, \mathbf{1}\right)$ ligeyramente se empeçonhentam os corpos | $\left(\mathbf{a} 3^{\mathbf{v}}, \mathbf{4}\right)$ \& ha empresam do aar corrompe os spiritos vitaes em ho homem $\mid$ (a3 $\left.{ }^{\mathrm{v}}, \mathbf{1 1}\right)$ \& jsto em os demais. I (a3 $\left.{ }^{v}, 18\right)$ muytos medicos que em os enfermos soomente esguardam as ourinas $\mid(a 4,12)$ os corpos mays despostos a jnfirmidade \& a morte $\mid(\mathbf{a} 4, \mathbf{1 3})$ sam os corpos queentes I (a4, 14) \& que teem os poros mays largos: \& os corpos peçonhentos | $(\mathbf{a} 4, \mathbf{1 5})$ que tem os poros opilados: \& çarrados de mujtos humores. I (a4, 17) assy como sam os corpos desordenados em luxuria \& coyto.l (a4, 19) \& os homens que se muyto esqueentam com grande trabalho ou grande yra. I (a4, 20) teem os corpos mais dispostos pera reçeber ha pestilencia. I $\left(\mathbf{a 4}^{\mathrm{v}}, \mathbf{5}\right)$ os medicos prudentes $\mid\left(\mathrm{a} 4^{\mathrm{v}}, \mathbf{6}^{6}\right)$ quando visitam os enfermos deuem de star afastados delles: I $\left(\mathbf{a} 4^{\mathrm{v}}, \mathbf{8 )} \&\right.$ assi ho deuem de fazer os seruidores dos

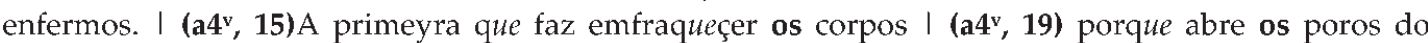
homem $\mid\left(\mathbf{a 5}^{\mathrm{v}}, \mathbf{5}\right) \mathrm{em}$ tal casa como esta morrem os homens mais azinha $\mid(\mathbf{a} 6, \mathbf{1})$ porque os corpos cheos dos maaos humores sam mais asinha empeçonhentados. I $\left(\mathbf{a} \mathbf{6}^{\mathrm{v}}, \mathbf{9 )}\right.$ porque as cousas azedas \& os cheyros taaes opilam \& çarram os poros \& os meatos \& | (a $\left.\mathbf{6}^{\mathrm{v}}, \mathbf{1 0}\right)$ os caminhos dos humores $\mid$ $\left(\mathbf{a} 6^{v}, 12\right)$ os meos companheiros nom podiam creer $\mid\left(\mathbf{a} 6^{v}, 24\right)$ Os olhos do aar empeçonhentado logo escureçem $\mid(\mathbf{b}, \mathbf{1})$ Muyto saã cousa he que se laue a boca \& os olhos I ( $\left.\mathbf{b}^{\mathrm{v}}, 4\right)$ pigmenta purga o çerebro da freuma \& os outros membros speciaaes dos humores vis<c $>$ osos $\mid\left(\mathbf{b}^{v}\right.$, 9) ysso mesmo o alho posto: alimpe da freuma \& lança fora os maaos humores. I (bv, 11) \& nom consinta emtrar ho aar seco. empero contorua os olhosl $\left(b^{v}, 15\right) \&$ por tanto todos os mantijmentos quanto som de mais leue

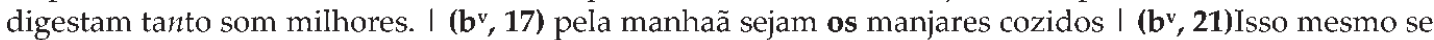
euite $m$ todos os fructos se nom forem azedos. $\mid(\mathbf{b} 2, \mathbf{1})$ busquem se pera os ricos $\rightarrow$ AO. vide A. $\rightarrow$ DO. vide DE. $\rightarrow$ EM O. vide EM. $\rightarrow$ NO. vide EM. $\rightarrow$ PER O. vide PER.

$\mathrm{O}^{2}$. [<lat. illu(m).] pron. pessoal. $\bullet$ ho, S. XIII; no: $(\mathbf{a} 3, \mathbf{2})$ se ho senhor deus todo poderoso ho nom quitar \& estoruar $\mid\left(\mathbf{a} 4^{v}, \mathbf{8}\right) \&$ assi ho deuem de fazer os seruidores dos enfermos. $\mid(\mathbf{a} 3,17)$ nem ho creem. I ( $\mathbf{b}^{\mathrm{v}}$, 12) squeenta a cabeça de cada huũ que ho ameude come. I (b3, 18) que escuse o somno \& ho euite quanto poder. $\mid\left(\mathbf{b} 4^{\mathrm{v}}, \mathbf{1 6}\right)$ toma aquelle çumo \& mistura ho com leyte de mulher $\mid\left(\mathbf{b} 4^{\mathrm{v}}\right.$, $\left.\mathbf{1 7}\right)$ \& da ho a beber aquelle que teuer a postema.l $(\mathbf{a} 6 \mathbf{v}, 7) \&$ sempre no punha nos narizes \& na boca

$\mathrm{O}^{3}$. [<lat. illu(m).] pron. pessoal. $\bullet$ os: $(\mathbf{a} 4, \mathbf{1 8})$ \& os que vaam ameude a os banhos

OBRAR. [<lat. operare.] v. Fazer efeito. $\bullet$ obra: $\left(\mathbf{b} \mathbf{4}^{\mathbf{v}}, \mathbf{1 8}\right)$ \& ysto com o estamago gejuum. porque emtom obra milhor em o homem

olHo, [<lat. oculus, -i.] sm. Órgão da visãa. • olhos: $\left(\mathbf{a}^{\mathrm{v}}\right.$, 24) Os olhos do aar empeçonhentado logo escureçem | (b, 2) Muyto saã cousa he que se laue a boca \& os olhos \& as maãos ameude cada dia com agoa rosada mesturada com vinagre.l $\left(\mathbf{b}^{v}, \mathbf{1 1 )} \&\right.$ nom consinta emtrar ho aar seco. empero contorua os olhos

ONDE. [<lat. unde, 'de onde'.] adv. $\bullet$ onde. $\square$ No lugar em que: $\left(\mathbf{a}^{\mathbf{v}}, \mathbf{6}\right)$ mesmo onde se lançam verças \& caldos podres $\mid(\mathbf{a} 3,20)$ \& esto aconteçe muytas vezes onde ha lugares podres \& corruptos. $\mid\left(\mathbf{a}^{\mathrm{v}}{ }^{\mathrm{N}}, \mathbf{2 1}\right)$ \& estas cousas prestam pera antre pouoo onde ligeyramente se aconteçe huũ seer empeçonhentado do outro. Em que: $\left(\mathrm{a}^{\mathrm{v}}, \mathbf{1 4}\right)$ porque ho aar apeçonhentado he humido \& faz podridom em a casa ou em lugar onde dormem. Por conseguinte: $(\mathbf{a} 6, \mathbf{8})$ Item per esta mesma causa se deue euitar ho banho de cada dia. porque pouco creçente apeçonhenta toda a massa. onde finalmente digo que toda multidom de pouoo \& comunidade em tal tempo se deue de euitar

OPERAÇÃo. [<lat. operatio, -onis.] sf. Trabalho. @operaçam:(b, 23) \& nom jantaras atee ho meo dia porque possa a triaga em o corpo fazer sua operaçam.

OPILAR. [<lat. oppilare.] v. Obstruir, fechar. - opilam: $\left(\mathbf{a} \mathbf{6}^{\mathrm{v}}, \mathbf{9 )}\right.$ as cousas azedas \& os cheyros taaes 
opilam \& çarram os poros $\rightarrow$ opILADo. adj. Obstruído. $\bullet$ opilados: $(\mathbf{a} 4, \mathbf{1 5}) \&$ os corpos peçonhentos que tem os poros opilados: \& çarrados de mujtos humores

ORDEM. [<lat. ordo, -inis.] sf. Sociedade de religiosos que pronunciaram votos solenes. $\bullet$ ordem, S. XIV: $(\mathbf{a} 2,7)$ mestre em sancta theologia da ordem de sam francisco

orelHA. [<lat. auricula, -ae.] sf. Parte mais externa do aparelho auditivo. - orelha; orelhas: (b3v, 24) E se pela ventura apareçer açerca da orelha: faça se a sangria de çephalica daquelle meesmo lado. | (b3, 16) \& logo sentira apostema de bayxo dos braços. ou açerca das partes vergonçosas. ou açerca das orelhas.

ou. [<lat. aut.] conj. @ou. 四 Antecede uma alternativa: $\left(\mathbf{a} 2^{\mathrm{v}}\right.$, 6) Segundo sinal he quando em tal estio muytas vezes escureçem: ou pareçem escureçer os dias $\mid(\mathbf{a} 3,11)$ Da rayz jnferior proçede segundo nos veemos que da priuada que esta açerca da camera ou de alguũ fedor particular de alguũ canno çujo se corrompe ho aar em substançia \& qualidade. $(\mathbf{a} 3,18)$ As vezes jsso mesmo veem de corpos mortos. ou de corrupçom de pauees I $(\mathbf{a} 3,19)$ \& charcos ou chafarizes çujos podres \& federentos. I (a3v, 8) quando da jmpressam celestrial corrompente ho aar. \& podridam dos corpos mortos. ou lugares çujos I (a4, 9) aquella jnfluençia sobre celestial mays dereytamente fere \& sguarda aquelle ou aquel outro.l (a4, 10) que aquelle ou aqueloutro lugar ou homem. $\mid(\mathbf{a} 4, \mathbf{2 0 )} \&$ os homens que se muyto esqueentam com grande trabalho ou grande yra. teem os corpos mais dispostos pera reçeber ha pestilencia. I (a4v, 11) \& muytas vezes teer as frestas pera ho norte ou pera o leuante abertas I $\left(\mathbf{a 5}^{\mathrm{v}}{ }^{\mathbf{1}}, \mathbf{1 4}\right)$ porque ho aar apeçonhentado he humido \& faz podridom em a casa ou em lugar onde dormem. I (a6, 16) quando se alguũ aleuantar logo coma da aruda lauada em agoa limpa espargida com sal \& noz nozcada hũa ou duas bem limpas $\mid(\mathbf{a 6}, \mathbf{1 8})$ E ysto nom poder auer. emtam coma paão ou hũa sopa molhada em vinagre. $(\mathbf{a 6}, \mathbf{2 1})$ nem he saão andar per a villa ou çidade. $\left(\mathbf{a} \mathbf{6}^{\mathrm{v}}, \mathbf{6}\right)$ \& emta $m$ leuaua commigo huũa sponja ou paão enssopado em vinagrel $(b, 16)$ toma se ergo duas vezes no dia com boõ vinho claro \& auguado. ou com augoa crara de rosas $\mid(\mathbf{b}, 17)$ ou com çerueja crara. $\mid(\mathbf{b}, 19)$ \& do vinho ou augoa ou çerueja tomaras quantidade de duas colhares. I $\left(\mathbf{b}^{\mathrm{v}}, \mathbf{2 2}\right)$ assi como sam çirejas. romaãs. ou huũ pequeno de pero ou maçaã em lugar de meezinha. |(b2, 17) SAngria huũa vez em huũ mes se pode bem fazer. se nom se a ydade ou outra cousa for em contrayro.l $(\mathbf{b} 2, \mathbf{1 9 )}$ assy como he em as molheres que som prenhes. ou em alguũ muyto fraco. I $(\mathbf{b} 2,21)$ Faça se ergo a sangria em a vea destra ou seestra ante de comer. I (b2, 24) beber muy boõ vinho ou bõa çerueja. I $(\mathbf{b 2 v}, \mathbf{1 4})$ tal desejo se deue reuogar \& impedir per alguũ andar em jardijs ou em campos. I (b2v $\mathbf{1 7})$ se homem quiser dormir ha de beber hũa bõa vez de vinho ou çerueja ante de dormir. $\mid\left(\mathbf{b} 2^{\mathrm{v}}, \mathbf{2 1}\right)$ \& estes maaos humores se lançam fora per tomar hũa bõa vez de vinho boõ ou bõa çerueja. $\mid(\mathbf{b} 3,4)$ mas todas estas cousas pode muyto bem euitar \& de sy lançar andando ou espaçando huũ pouco antre ho comer \& o dormir. | $(\mathbf{b} 3,6)$ Posto que tal como este nom pode andar em cauallo ou besta. I $(\mathbf{b} 3, \mathbf{1 5})$ \& logo sentira apostema de bayxo dos braços. ou açerca das partes vergonçosas. ou açerca das orelhas. I $(\mathbf{b 3}, \mathbf{1 7})$ He ergo gramde remedio sy se alguem sentir apeçonhentado ou em tempo de pestilencia sentir estas cousas que escuse o sonno $\mid\left(b^{2}{ }^{v}, 6\right)$ Item o homem que se sangra ou $\mid\left(\mathbf{b} 3^{v}, 7\right)$ tenha pestenença ou nom. $\mid\left(\mathbf{b} 3^{\mathbf{v}}, \mathbf{1 0}\right)$ \& sempre naquella meesma parte do corpo: em a qual ha doença ou chaga apareçer se deue de sangrar \& abrir a vea. I (b3 $\left.{ }^{v}, 14\right)$ Se de bayxo do braço seestro ou esquerdo. $\mid\left(b^{v}, 15\right)$ sangre se em ha vea meaã daquelle meesmo braço. ou na vea epatica . I ((b3v, 21$)$ seja sangrado em a vea de çephalica açerca do dedo polegar em a maão daquelle meesmo lado. ou na meaã daquelle meesmo braço.। $\left(\mathbf{b} 3^{v}, 22\right)$ ou na maão daquelle meesmo lado | ((b3v , 25) faça se a sangria de çephalica daquelle meesmo lado. ou da vea que esta antre o dedo demostrador \& ho dedo polegar.I $(\mathbf{b 4}, \mathbf{2})$ por que muytas cousas peçonhentas nom destruam o çerebro. ou da vea que he açerca do dedo menor:| $(\mathbf{b 4}, \mathbf{3})$ ou açerca do articulo que he de muytos medicos chamada basilica. | (b4, 14) que se sangre em o braço esquerdo do figado: ou basilica: | $(\mathbf{b 4}, \mathbf{1 5})$ ou da meaã. I (b4, 23) \& sempre antes do meo dia sera em continuo mouimento: ou caualgando: ou andando temperadamente. $(\mathbf{a} 5, \mathbf{1 9})$ Fechem se ergo as frestas ou genelas como dito he que vaam ou estam pera o sul Introduz um sinônimo, deixando, lado a lado, um termo mais erudito e um mais coloquial: $\left(\mathrm{a}^{\mathrm{v}}, \mathbf{8}\right)$ se causa ho morbo ou ha chagua em ho homem $\mid\left(\mathbf{a}^{\mathrm{v}}, 9\right)$ \& tal morbo ou jnfirmidade as vezes he febre. \& as vezes apostema $\mid\left(\mathbf{a} 2^{v}, 4\right)$ quando he ho vento meridional. ou da parte de estrela do Sul.I $\left(\mathbf{a} 3^{v}, \mathbf{2}^{2}\right)$ 
ligeyramente se empeçonhentam os corpos da jndisposiçam ou da maa desposiçam dos çeos. | (a4v, 5) porque podera ser que alguũ delles sera apeçonhentado ou ferido $\mid\left(\mathbf{a} 4^{\mathrm{v}}, \mathbf{8}\right)$ quando visitam os enfermos deuem de star afastados delles: teendo o rostro pera genela ou fresta $\mid\left(\mathbf{a} 4^{\mathrm{v}}, \mathbf{1 2}\right)$ \& as genelas ou frestas pera ho meo dia ou pera ho sul estem çarradas. $(\mathbf{a} 5,17)$ \& tambem o vento meridional ou sul: o qual naturalmente apeçonhenta. I (a5v, 16) Apure se ergo \& asutileze se a casa per clara chama ou flama | $(\mathbf{b}, \mathbf{5})$ \& assi guardando estas cousas seguramente entraras em pouoo ou amtre gente.| (b, 20) \& a triaga seja delida em ho vaso ou copo em que ha tomares. I $(\mathbf{b} 2,2)$ estas cousas busquem se pera os ricos muyto bõas salsas ou salseamentos. $\mid(\mathbf{b} 2,7) \&$ tal salsa he muyto boõa \& destruye \& quita ou tira toda podridom. I (b2, 20) em alguũ que teem corrença ou fluxu do ventre. | (b2, 22) \& despois que a vea for ferida ou aberta aproueyta muyto tomar muyto prazer. $I\left(\mathbf{b} \mathbf{2}^{\mathrm{v}}, \mathbf{1}\right)$ \& se alguũ se agrauar de apostema ou sentir agrauado: ou se sentir apeçonhentado. em toda maneyra tal como este euite o somno I (b3 $\left.{ }^{v}, 3\right)$ emtam leyxe yr a vea aberta ou ferida atee o retardamento do sangue. I $\left(\mathbf{b} 3^{v}, 4\right)$ porque pequena sangria: ou pequena sayda de sangue. mais fortemente esperta a peçonha I (b4 $\left.{ }^{\mathrm{v}}, \mathbf{1 5}\right) \&$ pisa todo muyto bem atee que vejas que quer pareçer que say destas cousas assy pisadas augoa ou çumo

OUTRo. [<lat. alter, -era, -erum.] pron. indef. • outro; outra; outros, S. XIII. $\llbracket$ Qualquer: (b2, 16) SAngria huũa vez em huũ mes se pode bem fazer. se nom se a ydade ou outra cousa for em contrayro. $\square$ Mais um: $\left(\mathbf{b} 4^{v}, \mathbf{1 0}\right)$ Item outro remedio | $\left(\mathbf{b} 4^{\mathrm{v}}, \mathbf{1 1 )}\right.$ Tomaras hũa herua que chamam barbajouis. \& outro que chamam serpillo $\llbracket$ Demais: $\left(\mathbf{a}^{\mathrm{v}} \mathrm{v}, \mathbf{1 6}\right)$ Das conformidades do coraçam \& dos outros membros. I (a6 , 19) AS cousas canfortatiuas sam estas scilicet. açafram. cassiafistola. chantagem. com todas as outras heruas que endereçam ho spirito interior. I $\left(\mathbf{b}^{\mathrm{v}}, \mathbf{4}\right)$ ajnda que pigmenta purga o çerebro da freuma \& os outros membros speciaaes dos humores vis $<\mathrm{c}>\operatorname{osos} \mid\left(\mathbf{b} 2^{\mathrm{v}}, \mathbf{5}\right)$ caladamente traz a peçonha ao coraçam \& aos outros membros speciaaes. I (b4, 17) emtom faça se como dito he do braço esquerdo. \& assi dos outros lugares em os quaaes apareçer a apostema Segundo elemento de uma correlação: (a3v, 25) Porque he assy que huũ morre \& ho outro nom. I $\left(\mathbf{a}^{\mathrm{v}} \mathbf{2}, \mathbf{2 2 )}\right.$ onde ligeyramente se aconteçe huũ seer empeçonhentado do outro. I $\left(\mathrm{a}^{\mathrm{v}}, \mathbf{5}\right)$ \& daqui vee $m$ que em tal casa como esta morrem os homens mais azinha \& em outra nom $\rightarrow$ AQUELOUTRO. vide AQUELE.

OUTREM. [< lat. alter, -era $a_{r}$-erum.] pron. indef. Outra pessoa. $\bullet$ outrem, S. XIII: $\left(\mathbf{a} 6^{\mathrm{v}}, \mathbf{2 4 )}\right.$ E por ysso te digo que em toda maneyra te guardes que nom reçebas do baffo de outrem

ouvido. [de ouvir.] sm. Órgão da audição. ouuido:(a4v $\left.{ }^{\mathrm{a}}, \mathbf{1 8}\right)$ Ho sul he vento inchado \& agraua o ouuido fere o coraçam 


\section{$\mathrm{P}$}

PACiENTE. [<lat. patiens, -entis.] sm. Aquele que sofre uma ação. paçiente; paciente: (a4, 7) esto pode aqueçer por duas causas scilicet. por parte do agente \& por parte do paçiente I (a4, 10) Da parte do paciente que aquelle he mays desposto aa morte que aquel outro

PADECER. [<lat. * patescer.] v. Sofrer. • padeçe, S. XIII: $\left(\mathbf{a} 2^{\mathrm{v}}\right.$, 19) ho mar se faz cruel. \& ho sol se cobre scilicet. de nuueens. ho regno se muda. ho pouoo padeçe fame \& pestilencia

PADRE. [<lat. pater, -tris.] sm. Sacerdote. •padre, S. XIII: $(\mathbf{a} 2, \mathbf{6})$ E tralladado de latim em lingoagem per ho reuerendo padre frey Luys de ras

PÃo. [<lat. panis, -is.] sm. Alimento feito com massa de farinha. paão, S. XIV: $(\mathbf{a 6}, 18)$ E ysto nom poder auer. emtam coma paão ou hũa sopa molhada em vinagre. I $\left(\mathbf{a}^{\mathrm{v}}, \mathbf{7}\right) \&$ emtam leuaua commigo huũa sponja ou paão enssopado em vinagre

PARECER. [<lat. parere.] v. - pareçe; pareçem; pareçer. Dar a impressão de: (a2 $\left.{ }^{\mathrm{v}}, 2\right)$ em modo que demanhaã pareçe chuuosa \& chea neuoa. \& depois ventosa. I $\left(a 2^{\mathrm{v}}, 6\right)$ Segundo sinal he quando em tal estio muytas vezes escureçem: ou pareçe $m$ escureçer os dias $\mid$ em modo que pareçe que quer chouuer \& nom choue. I $\left(\mathbf{a} 2^{v}, 10\right)$ Tercio he quando ha hy muytas moscas em ha terra. porque emtam pareçe ho aar ser empeçonhentado. I (a2v, 12) Quarto sinal he quando ha cometa pareçe voar. I (a3, 7) \& as vezes proçede da rayz jnferior. emtanto que senssualmente pareçe aos homens mudança do aar I (b4v ${ }^{\mathrm{v}}, \mathbf{1 4 )} \&$ pisa todo muyto bem atee que vejas que quer pareçer que say destas cousas assy pisadas augoa ou çumo Afigurar-se: $(\mathrm{bv}, 6)$ mas porque muyto aqueenta. \& a queentura traz podridom. melhor me pareçe soo a cousa amargosa que queentura cheyro \& sabor $\mid\left(\mathbf{b}^{v}, 12\right)$ \& por ysso nom pareçe se neçessario mas antes jnpidoso

PARTE. [<lat. pars, -tis.] sf. -parte. [E] Área ou região: $(\mathbf{a} 2 \mathrm{v}, 4)$ \& prinçipalmente quando he ho vento meridional. ou da parte de estrela do Sul. I $(\mathbf{b 3}, 2)$ \& ysso mesmo tem grande door em ha parte dianteira da cabeça. I (b3, 22) em o tempo do somno o sprito vital repousa: \& emtom a peçonha espalha se per os membros de toda parte. I (b3v, 9) \& sempre naquella meesma parte do corpo: em a qual ha doença ou chaga apareçer se deue de sangrar \& abrir a vea.I (emtom ha de menuyr o sangue em a parte crucifixa que he a parte contrayra. Causa: A primeyra questam: digo que esto pode aqueçer por duas causas scilicet. por parte do agente \& por parte do paçiente Da parte do agente quando aquella jnfluençia sobre celestial mays dereyta mente fere \& sguarda aquelle ou aquel outro. que aquelle ou aqueloutro lugar ou homem. Da parte do paciente que aquelle he mays desposto aa morte que aquel outro. $\rightarrow$ PARTES VERGONÇOSAS. Genitália. • partes vergonçosas: $(b 3,15)$ spere per huũ meo dia \& logo sentira apostema de bayxo dos braços. ou açerca das partes vergonçosas. ou açerca das orelhas | (b3' 17) E se açerca das partes vergonçosas. sangre se em o pee daquelle mesmo lado açerca do calcanhar

PARTICUlar. [<lat. particularis, -e.] adj. Próprio. •particular: $(\mathbf{a} 3,12)$ Da rayz jnferior proçede segundo nos veemos que da priuada que esta açerca da camera ou de alguũ fedor particular de alguũ canno çujo se corrompe ho aar em substançia \& qualidade. I (a3, 13-14) \& esta causa particular \& pode aconteçer cada dia. I $(\mathbf{a} 3,22)$ \& esto aconteçe muytas vezes onde ha lugares podres \& corruptos. \& tambem esta causa he as vezes particular

PASsado. [de passar.] adj. (Fruto) seco pelo calor. - passados: $(\mathbf{b} 4 \mathbf{v}, \mathbf{2 0 )}$ tome auelaãs. figos passados \& aruda

Paul. [<lat. palude-.] sm. Charco; brejo. - pauees, s.XV: $(\mathrm{a} 3,18)$ As vezes jsso mesmo veem de corpos mortos. ou de corrupçom de pauees \& charcos ou chafarizes çujos podres \& federentos 
PÉ. [<lat. pes, -dis.] sm. Extremidade da perna. - pee: $\left(\mathbf{b} \mathbf{3}^{\mathbf{v}}, \mathbf{1 8}\right) \mathbf{E}$ se açerca das partes vergonçosas. sangre se em o pee daquelle mesmo lado açerca do calcanhar

PECADo. [<lat. peccatum, -i.] sm. Transgressão de preceito religioso. - pecados, s. xIV: (a5, 7-8) que homem primeiramente ha de confessar seus pecados humildosamente

PEÇONHA. [<lat. *pōtiōnea, 'beberagem, mezinha, poção mágica'.] sf. Veneno. - peçonha, s. XIV: (b2v, 5) porque em ho somno ha queentura intrinseca. caladamente traz a peçonha ao coraçam \& aos outros membros speciaaes | (b2v, 7) em modo que escassamente pode nenhũa herua tal peçonha reuogar | (b3, 10) porque a peçonha intrinseca pertorua o sprito vital. I $(\mathbf{b 3}, \mathbf{2 1})$ que em o tempo do somno o sprito vital repousa: \& emtom a peçonha espalha se per os membros de toda parte. I (b3, 24) Estantes ergo assi estas cousas quando se homem sente ser tocado da peçonha pestilençial. logo naquelle meesmo dia mingue ho sangue | $\left(\mathbf{b} 3^{v}, \mathbf{1}\right)$ porque pouco minguamento de sangue esperta a peçonha. $\mid\left(\mathbf{b} 3^{v}, 5\right)$ pequena sangria: ou pequena sayda de sangue, mais fortemente esperta a peçonha segundo dicto he. I $\left(\mathbf{b} \mathbf{4}^{\mathrm{v}}, \mathbf{7}\right)$ porque a triaga lança a peçonha fora. I $\left(\mathbf{b} 4^{v}, \mathbf{9}\right)$ \& assy lança a peçonha. $\rightarrow$ PEÇONHENTO. [de peçonha.] adj. Que contagia com peçonha; venenoso. - peçonhento; peçonhentos; peçonhentas, s. XIV: (a3, 12) porque ho aar jnspirado as vezes he peçonhento | (a4, 25) \& que sobem muytos vapores peçonhentos ao aar.l (a4, 25) porque dos corpos apeçonhentados procedem humores \& fumos peçonhentos $\mid(\mathbf{a} 4, \mathbf{1 4}-15)$ os corpos mays despostos a jnfirmidade \& a morte sam os corpos queentes \& que teem os poros mays largos: \& os corpos peçonhentos que tem os poros opilados: \& çarrados de mujtos humores. I $\left(\mathrm{a}^{\mathrm{v}} \mathrm{v}, \mathbf{2}\right)$ \& por tanto deue homem de fugir dos aares peçonhentos. I (a6 ${ }^{\mathrm{v}}$, 11) os cheyros taaes opilam \& çarram os poros \& os meatos \& os caminhos dos humores \& nom consintem entrar as cousas peçonhentas. I $(\mathbf{b 4}, \mathbf{1})$ por que muytas cousas peçonhentas nom destruam o çerebro. $\rightarrow$ PEÇonHENTADo. adj. Tornado peçonhento; envenenado. peçonhentado: $\left(5^{\mathrm{v}}, 12\right)$ \& por tanto se deue bem de guardar a casa: porque nom entre em ella ho aar peçonhentado. $\Rightarrow$ APEÇONHENTAR $v$. Encher de peçonha, de peste; empeçonhentar; peçonhentar. - apeçonhenta; apeçonhente; apeçonhentado, S. XIV: (a5, 18) \& tambem o vento meridional ou sul: o qual naturalmente apeçonhenta. I (a6, 7-8) Item per esta mesma causa se deue evitar ho banho de cada dia. porque pouco creçente apeçonhenta toda a massa.l (a6, 11) toda multidom de pouoo \& comunidade em tal tempo se deue de euitar em quanto for possíuel. porque se nom apeçonhente homem do aar apeçonhentado. I (b2v, 24) A ysto te respondo que o homem que em tal dia he apeçonhentado nom come mujto $\rightarrow$ APEÇONHENTADO. adj. Peçonhentado. - apeçonhentado; apeçonhentados: $(\mathbf{a} 5,13)$ muyto boo remedio he fugir \& mudar o lugar apeçonhentado.I $\left(\mathbf{a} 5^{v}, 13\right)$ porque ho aar apeçonhentado he humidol $\left(\mathbf{b} 2^{v}\right.$, 22) como sintira homem que esta apeçonhentado | $(\mathbf{a 6}, \mathbf{1 1})$ toda multidom de pouoo \& comunidade em tal tempo se deue de euitar em quanto for possíuel. porque se nom apeçonhente homem do aar apeçonhentado. I (b3, 8-9) porque o homem ja apeçonhentado em todas as horas teem grande desejo de dormir. I (b3, 12) Ergo per estes signaaes se sente homem apeçonhentado.l (b2v, 2) se agrauar de apostema ou sentir agrauado: ou se sentir apeçonhentado. em toda maneyra tal como este euite o somno I (a4, 24) porque dos corpos apeçonhentados procedem humores \& fumos peçonhentos $\rightarrow$ EMPEÇONHENTAR. $v$. Apeçonhentar. empeçonhentam; empeçonhentados, s. XIV: (a3v, 1) ligeyramente se empeçonhentam os corpos da jndisposiçam ou da maa desposiçam dos çeos. I $(\mathbf{a} 6,2)$ porque os corpos cheos dos maaos humores sam mais asinha empeçonhentados. $\rightarrow$ EMPEçonHENTADo.adj. Peçonhentado. empeçonhentado: (a2 $\left.{ }^{v}, \mathbf{1 0 - 1 1}\right)$ porque emtam pareçe ho aar ser empeçonhentado. 1 (a6 $\left.{ }^{\mathrm{r}}, 24\right)$ Os olhos do aar empeçonhentado logo escureçem

PÉDICA. vide VEIA.

PENITÊNCIA. [<lat. poenitentia, -ae,'arrependimento'.] sf. Expiação de culpas pela mortificação corporal. • penitencia: $(\mathbf{a} 5,9)$ polla qual causa grande remedio he em tempo da pestilençia a sancta penitencia \& a confissam

PEQUENo. [or. obscur.] adj. - pequeno; pequena. $\square$ De pouco volume: (b3v, 4) pequena sangria: ou pequena sayda de sangue. mais fortemente esperta a peçonha $\llbracket$ Baixo, de pouco valor: (a5v, 22) \& com 
lenho de aloes que he melhor de tudo posto que se nom pode comprar por pequeno preço. $\rightarrow$ MaIs PEQUENO. vide DEDO. $\rightarrow$ UM PEQUENO DE. Um bocado. • huũ pequeno de: $\left(\mathbf{b}^{\mathbf{v}}, \mathbf{2 2}\right)$ Isso mesmo se euitem todos os fructos se nom forem azedos. assi como sam çirejas. romaãs. ou huũ pequeno de pero ou maçaã em lugar de meezinha

PER. [<lat. per, 'através de, por meio de".] prep. • per [em boa parte das ocorrências, está abreviada como um $<p>$ com um pequeno til que sai da haste inferior, para a direita]; pela. 4 Através de; por meio de: $(\mathbf{a} 5,2)$ VIstas as causas da pestilencia. agora ajamos de veer per que modo \& como se deue homem de

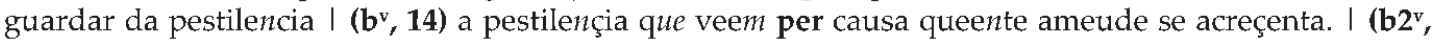
13) que tal desejo se deue reuogar \& impedir per alguũ andar em jardijs ou em campos.l (b3, 12) Ergo per estes signaaes se sente homem apeçonhentado. I $(\mathbf{b} 3, \mathbf{2 1 )}$ em o tempo do somno o sprito vital repousa: \& emtom a peçonha espalha se per os membros de toda parte. I (a3v, 13)em tanto que ha natureza he per muytas manejras agrauada I $(b 4,19)$ \& assi dos outros lugares em os quaaes apareçer a apostema: em maneira que sempre se mingue o sangue per modo contrayro. I $\left(\mathbf{a 5}^{\mathrm{v}}, \mathbf{2 3}\right) \mathrm{E}$ tal fumo entre per a boca $\mid\left(\mathrm{a}^{\mathrm{v}}, \mathbf{2 4}\right)$ \& per os narizes. I $\left(\mathrm{a}^{\mathrm{v}}, \mathbf{9}\right)$ E assi como per ho boõ cheyro \& aromatico: se recrea o coraçom \& o sprito do homem. I $\left(a 5^{v}, 11\right)$ assi emfraqueçe per o çujo fedor. I $\left(\mathbf{a} 5^{v}, 16\right)$ Apure se ergo \& asutileze se a casa per clara chama ou flama $\mid(\mathbf{a 6}, \mathbf{2 1})$ Mas em tempo de pestilencia milhor he estar em casa que andar fora. nem he saão andar per a villa ou çidade. $\mid\left(\mathbf{b} 2^{\mathrm{v}}, \mathbf{2 0}\right)$ \& estes maaos humores se lançam fora per tomar hũa bõa vez de vinho boõ ou bõa çerueja.l $(\mathrm{b} 4 \mathrm{v}, 22)$ \& qualquer que se per este modo reger escapara muytos perijgos da pestilencial $(\mathbf{b} 3,22)$ Estas cousas per my mesmo prouey. $\square$ Em razão de: $(\mathbf{a} 5,21)$ \& per esta mesma causa euitaras \& esquiuaras todo ho fedor $\mid\left(\mathbf{a} 5^{v}, 24\right)$ Item per esta meesma ca<u>sa se euite \& esquiue: todo ho inchamento do ventre | $(\mathbf{a} 6,6)$ Item per esta mesma causa se deue euitar ho banho de cada dia. $\mid\left(\mathbf{a} 3^{v}, 5\right)$ \& assy se geera ha pestilençia per esta causa. | $\left(\mathbf{a} 3^{v}, 13\right)$ em tanto que ha natureza he per muytas manejras agrauada Durante: $\left(\mathbf{b}^{\mathbf{v}}{ }^{\mathrm{v}}, \mathbf{8}\right)$ em nenhũa maneyra nom deue de dormir per todo o dia atee mea noyte $\mid(\mathbf{b 3}, \mathbf{1 2})$ spere per huũ meo dia \& logo sentira apostema de bayxo dos braços. I $\left(\mathrm{a}^{\mathrm{v}}{ }^{\mathrm{n}}, 10\right)$ E por tanto digo que a tal doente de pestilençia he boõ per alguũs dias mudar a camera: $\mid\left(\mathbf{a} 4^{\mathrm{v}}, \mathbf{2 2}\right)$ em tempo da pestilençia quando venta vento sul estar em casa per todo o dia: I (a5v , 1) em algũas casas estam as agoas çujas per dous \& tres dias $\mid\left(\mathrm{a}^{\mathrm{v}}, \mathbf{}^{\mathrm{v}}\right)$ \& as lançam per canos \& regos soterranhos I (b2v, 14-15) em modo que o somno natural se possa tomar per hũa hora despois de comer. I ( $\left.\mathbf{b}^{v}, \mathbf{1 7}\right)$ pela manhaã sejam os manjares cozidos $\subseteq$ Indica o agente: (a2, 6) E tralladado de latim em lingoagem per ho reuerendo padre frey Luys de ras |(a2, 4) Feyto per ho reuerendissimo Senhor dom Raminto @u Para: $(\mathrm{a} 2,2)$ Começa se huũ boõ regimento muyto neçessario \& muyto proueitoso aos viuentes. \& per conseruaçam de suas saudes \& segurança das pestinençias [ $c f$. POR.] $\rightarrow$ PELA VENTURA. Porventura. - pella ventura; polla ventura: $\left(b^{v} v, 11\right)$ E se pella ventura naçer a apostema de bayxo do braço direyto. sangre se em ho meo daquelle braço da vea meaã.l $(\mathbf{b} 4,10) E$ se pella ventura sentir chagas despois de dormir: emtom ha de menuyr o sangue em a parte crucifixa I $(b 4,4) E$ se polla ventura for açerca das espadoas: minguaras o sangue com ventosas. $\rightarrow$ PER VIRTUDE DE. Em razão de. - per virtude de: $(\mathbf{a} 3,23)$ Da rayz superior veem \& aconteçe a pestilençia per virtude dos corpos de çima dos çeos

PERA. [<lat. per ad.] prep. Para. - pera; [em boa parte das ocorrências, está abreviada como um <p> com um pequeno til que sai da haste inferior, para a direita, seguido de $\left\langle a>\right.$ ]: $\quad\left(\mathbf{a} 2^{\mathrm{v}}, \mathbf{8}\right)$ \& emtam se isto mujto durar he pera temer de vijr grande pestilençia.l $\left(\mathbf{a} 2^{v}, 25\right)$ Quando ergo estes signaes apareçerem. he pera temer grande pestilencia. I $(\mathbf{a} 4, \mathbf{2 1 )} \&$ os homens que se muyto esqueentam com grande trabalho ou grande yra. teem os corpos mais dispostos pera reçeber ha pestilencia. I $\left(\mathrm{a4}^{\mathrm{v}}, \mathbf{7}\right)$ por razam do qual os medicos prudentes quando visitam os enfermos deuem de star afastados delles: teendo o rostro pera genela ou fresta $\mid\left(\mathbf{a} 4^{\mathrm{v}}, \mathbf{1 1}\right)$ \& muytas vezes teer as frestas pera ho norte ou pera o leuante abertas.| (a4 $\left.{ }^{\mathrm{v}}, \mathbf{1 2}\right)$ \& as genelas ou frestas pera ho meo dia I (a4v, 13)ou pera ho sul estem çarradas. I $(\mathbf{a} 5,20)$ Fechem se ergo as frestas ou genelas como dito he que vaam ou estam pera o sul atee hũa hora depois do meo dia I (a5, 21) \& abram se as que stam pera o norte. $\mid\left(\mathbf{a 6}^{\mathrm{v}}, \mathbf{2 0 )} \&\right.$ estas cousas presta $m$ pera antre pouoo $\mid(\mathbf{b} \mathbf{2}, \mathbf{1})$ estas cousas busquem se pera os ricos $1(\mathbf{b} 2,8) \mathrm{E}$ tambem a alegria do coraçom he gram remedio pera a saude do corpo. I (b4v, 22) E estas cousas abastem pera a pestilença. I $\left(\mathbf{b} 4^{\mathrm{v}}, \mathbf{2 6}\right)$ \& da benta virgem maria sua madre seja gloria \& louuor pera sempre 
PERDA. [ or. obscur.] sf. Prejuízo. - perda: (a5, 13-14) mas porque muytos sem grande perda nom pode $m$ mudar o lugar

PERIGO. [<lat. periculum, -i.] sm. Risco. eperijgo; perijgos: (b2, 13) porque ymaginaçam faz causa \& perijgo. I $\left(\mathbf{b} 4^{\mathrm{v}}, \mathbf{2 3}\right)$ \& qualquer que se per este modo reger escapara muytos perijgos da pestilencia

PERo. [<lat.pirum,-i.] sm. Variedade de maçã. • pero: $\left(b^{v}, 22\right)$ Isso mesmo se euitem todos os fructos se nom forem azedos. assi como sam çirejas. romaãs. ou huũ pequeno de pero ou maçaã em lugar de meezinha

PERREXIL. [<prov. pe(i)ressill.] sm. Perrexil-do-mar, funcho marítimo, erva-de-são-pedro. Crithmum maritimum Linnaeus, da família das Apiáceas (Umbelíferas). Planta herbácea, 25 a $50 \mathrm{~cm}$ de altura, nativa do norte da Europa, que cresce sobre rochas e encostas marinhas em toda a costa européia desde o Oceano Atlântico até o Mar Negro. Possui raiz rizomatosa e carnosa, caule esverdeado de consistência carnosa e fortemente lignificado, folhas pequenas, suculentas, glabras, deltóides, flores minúsculas brancas, esverdeadas ou róseas reunidas em umbelas, frutos ovais purpúreos, pequenos. Toda a planta é aromática e mostra sabor salgado levemente picante. Muito utilizada em picles e em saladas nos séculos XVI e XVII na Inglaterra, na França e em muitos países do sul da Europa. Ainda hoje é apreciada no Mediterrâneo. Atribuem-se a ela propriedades aperitiva, diurética, emenagoga e no tratamento de cálculos renais (Piterá, 1999). - perexil: $(\mathbf{b} 2,3)$ noz nozcadas. perexil \& todo misturado com vinagre faz muy bõa salsa

Perturbar. [<lat. perturbare.] v. Causar desordem. •pertorua:(b3, 10) porque a peçonha intrinseca pertorua o sprito vital

PEscoço. [<esp. ant. pescoço.] sm. Parte do corpo entre a cabeça e o tronco. epescoço: (b3v, 19) E se a apostema for em ho pescoço. seja sangrado em a vea de çephalica açerca do dedo polegar em a maão daquelle meesmo lado

PESO. [<lat. pensum, -i.] sm. Carga de humores. - peso: (b3, 7-8) Posto que tal como este nom pode andar em cauallo ou besta. nem andar grande caminho por a grande pigriça do corpo \& muyto grande peso \& carrega corporal

PESTILÊNCIA. [<lat. pestilentia, -ae.] sm. Epidemia. Peste, pestenença ou pestilência não denominavam, necessariamente, a peste bubônica que, quase certamente, grassou em Portugal em 1348, 1384 e 1415. Várias outras epidemias aconteceram em Portugal na Idade Média, e registraram-se ocorrências de peste para os anos de $1190-1191,1202,1223,1333,1356,1384,1423,1433,1435,1437-1438,1448,1458,1464,1477,1480-1497 . \bullet$ pestilença; pestilencia; pestilencia; pestilençia; pestenença; pestinençias: $(b 4 v, 22)$ E estas cousas abastem pera a pestilença. $(\mathbf{a} 2,23)$ SIgnaes pronosticos da pestilencia quanto ao presente pertençe: sam sete.I (a2v, 19-20) ho pouoo padeçe fame \& pestilencia. I (a3, 1) Quando ergo estes signaes apareçerem. he pera temer grande pestilencia. I (a3,4) TRes sam as causas da pestilencia. I $(\mathbf{a} 3,5)$ as vezes veem \& proçede ha pestilencia da rayz superior. I $(\mathbf{a} 4, \mathbf{2 1})$ \& os homens que se muyto esqueentam com grande trabalho ou grande yra. teem os corpos mais dispostos pera reçeber ha pestilencia. I $(\mathbf{a} 5, \mathbf{1})$ VIstas as causas da pestilencia. I $(\mathbf{a} 5,3)$ agora ajamos de veer per que modo \& como se deue homem de guardar da pestilencia I $(\mathbf{a 6}, 20)$ Mas em tempo de pestilencia milhor he estar em casa que andar fora. I $\left(\mathbf{a}^{\mathbf{v}}\right.$, $12) \&$ assi escapey de tal pestilencia. I $\left(b^{v}, 19\right)$ Em tempo da pestilencia valem mais cousas azedas que todalas meezinhas I (b2, 10-11) polla qual cousa deue se home $m$ de guardar em tempo da pestilencia I (b2v, 11) em tempo da pestilencia. logo despois de comer. se alguũ teuer desejo de dormir: que tal desejo se deue reuogar I $(\mathbf{b} 3, \mathbf{1 7}) \mathrm{He}$ ergo gramde remedio sy se alguem sentir apeçonhentado ou em tempo de pestilencia sentir estas cousas que escuse o somno l $\left(\mathbf{b} 4^{\mathrm{v}}, \mathbf{2 3}\right)$ \& qualquer que se per este modo reger escapara muytos perijgos da pestilencia I (a2, 16) Dos signaes pronosticos da pestilençia. I (a2v, 8) \& emtam se isto mujto durar he pera temer de vijr grande pestilençia. I (a3, 3) Das causas da 
pestilençia. I $\left(\mathbf{a}^{\mathrm{v}}\right.$, 5) \& assy se geera ha pestilençia per esta causa. I (a3v, 23) E estas cousas sam assy ditas das causas das pestilençia. I $\left(\mathrm{a}^{\mathrm{v}}, \mathbf{9 - 1 0}\right)$ E por tanto digo que a tal doente de pestilençia he boõ per alguũs dias mudar a camera $\mid\left(\mathbf{a} 4^{\mathrm{v}}, \mathbf{2 1}\right)$ pola qual cousa boõ he ao saão em tempo da pestilençia quando venta vento sul estar em casa per todo o dia I (a4v, 25)Dos remedios da pestilençia | $(\mathbf{a 5}, 9)$ polla qual causa grande remedio he em tempo da pestilençia a sancta penitencia $\mid\left(\mathbf{b}^{v}, 13\right)$ a pestilençia que veem per causa queente ameude se acreçenta. I (b2v, 22-23) como sintira homem que esta apeçonhentado \& ferido da pestilençia. I $(\mathbf{a} 2,14)$ Quero algũas cousas da pestenença que nos ameude fere: dos ditos dos mays autenticos medicos: screuer. I $\left(\mathbf{b} 3^{v}, 7\right)$ Item o homem que se sangra ou tenha pestenença ou nom. em nenhũa maneyra nom deue de dormir per todo o dia atee mea noyte: | $(\mathbf{a} 2,3)$ Começa se huũ boõ regimento muyto neçessario \& muyto proueitoso aos viuentes. \& per conseruaçam de suas saudes \& segurança das pestinençias. $\rightarrow$ PESTILENCIAL. adj. pestilençial; pestilencial; pestilençiaes; pestilençiaaes. Que tem ou transmite peste: $\left(\mathrm{a}^{\mathrm{v}}{ }^{\mathrm{r}} \mathbf{2 - 3}\right)$ mais ajnda digo que em o tempo pestilençial nenhuũ nom deue de star em ajuntamento do pouoo. I (b3, 24) quando se homem sente ser tocado da peçonha pestilençial, logo naquelle meesmo dia mingue ho sangue $\mid(\mathbf{b} 2, \mathbf{1 2})$ que nenguem nom tema morte. sem teer infirmidade pestilencial.l(a3, 15) \& daly procedem febres pestilençiaes. | (a4,4) Se taaes jnfirmidades pestilençiaes sam contagiosas | (a4, 23) A segunda questam digo que taaes infirmidades pestilençiaaes sam contagiosas Destinado à peste: (b, 8-9) \& tambem tomaras pirolas pestilençiaaes as quaaes acharas aos apotecayros

Pílula. [<lat. pilula, -ae.] sf. Remédio em forma de bolinhas do tamanho de avelãs "inventados para engulir mais facilmente algüs remedios, desagradaveis ao gosto" (Bluteau:VI, 507). pirolas, S. XV: (b, 8-9) \& tambem tomaras pirolas pestilençiaaes as quaaes acharas aos apotecayros

PIMENTA. [<lat. pigmenta, -orum.] sf. Muito possivelmente a referência se faz à pimenta-do-reino, Piper nigrum Linnaeus, da família das Piperáceas. Arbusto, trepadeira, originária da India Oriental, possui raizes negras e fibrosas, folhas ovais, flores agrupadas em espigas, frutos drupas, roxos até quase negros, pequenos. Utilizada como condimento. Apresenta propriedade tônica e sudorifera. Quando utilizada em pequenas doses possui ação excitante sobre os órgãos digestivos. Houve um tempo em que se misturava a pimenta-do-reino à gordura de porco para fazer um ungüento com o qual se curavam certos males e erupçóes da pele (Balmé, 1978). Considerada "a mais forte das especiarias", a pimenta-do-reino desapareceria "dos livros de cozinha aristocráticos franceses nos séculos XIV e XV, sendo utilizado apenas pelos mais pobres. Para as pessoas delicadas das elites sociais, os cozinheiros franceses só usavam a pimenta malagueta — enquadrada no terceiro grau de calor —e eles a suavizavam sempre misturando-a a outras especiarias menos picantes" (Flandrin 1996: 482). • pigmenta: (bv, 2-3)E em os mantijmentos guarte das cousas queentes. assi como som pigmenta \& alhos.l $\left(\mathrm{b}^{\mathrm{v}}, 3\right)$ ajnda que pigmenta purga o çerebro da freuma

PISADO. [de pisar.] adj. Macerado. - pisado; pisada; pisadas: $\left(\mathbf{b 4}^{\mathrm{v}}{ }^{\text {, 3) }}\right.$ Toma folhas de sabugo pisadas I $\left(\mathrm{b} 4^{\mathrm{v}}, 4\right)$ \& com mostarda pisada \& faze emprasto. $\mid\left(\mathbf{b} 4^{\mathrm{v}}, \mathbf{1 5}\right) \&$ pisa todo muyto bem atee que vejas que quer pareçer que say destas cousas assy pisadas augoa ou çumo

PISEO. sm. Não é muito claro o significado desse trecho. Uma possibilidade é a de que a forma equivalha a pichel [<fr. ant. pichier], 'vaso pequeno para beber vinho'. Como a triaga deveria ser diluída num copo, esse copo poderia ser a medida a ser tomada. A forma piseo [<lat. pisum] está registrada em Bluteau (VI, 534) como "Casta de Eroilha, mayor que as ordinarias", que Costa Roque (1979: 330,n.63) adota. episeo: (b, 18) nem se tome mais da triaga que a quantidade de huũ piseo \& do vinho ou augoa ou çerueja tomaras quantidade de duas colhares. \& a triaga seja delida em ho vaso ou copo em que ha tomares

POBRE. [<lat. pauper, -eris.] adj. Que não ganha com que se sustente. Numa das leis de D. Afonso IV (13251357), aqueles que näo "podem guaanhar per que uyuan" (Apud Tavares, s.d.: 19), como os velhos, os doentes $e$ os mancos, coxos, aleijados e cegos, mas também os "que guaanhauam dinheiros por affam de seus corpos", trabalhando "em oficios e serviços diversos, como cavar, podar, lavrar, segar, vindimar, guardar os gados [....]" (Tavares, s.d.: 26-27). Por pobre designou-se, portanto, o povo em geral: assalariados (como os criados dos 
burgueses, os jornaleiros), os que mendigavam, os que viviam à margem da sociedade, como as prostitutas e os estropiados, mas também os mestres de ofício dependentes de mercadores. opobres: (b2, 2) estas cousas busquem se pera os ricos muyto bõas salsas ou salseamentos. porque se forem pobres contentem se com arruda \& salua. I (b2,5) E se nom forem muyto pobres: tomem cuminhos \& açafram \& misturem tudo com vinagre. $\rightarrow$ POBREzA. sf. Falta do necessário. A mobilidade constante de que fala o narrador do Regimento no excerto a seguir foi apontada como uma das características da pobreza na Idade Média (Tavares, s.d.:22). pobreza: $\left(\mathbf{a} 6^{\mathrm{v}}, 6\right)$ Em monpilher nom me pude escusar de companhia de gente. porque andaua de casa em casa curando enfermos por causa da minha pobreza

PODER. [<lat. " potere.] v. Ter a possibilidade de. • poder; pode; podem; pude; podiam; podera; podesse; possa: $(\mathbf{a} 6, \mathbf{1 7})$ E ysto nom poder auer. emtam coma paão ou hũa sopa molhada em vinagre. | (b,4) \& se estas cousas nom poder auer faça se com vinagre. $\mid(\mathbf{b}, 7)$ \& se o ventre naturalmente se nom poder vazar. toma huũ cristel.I $(\mathbf{b 3}, \mathbf{1 9 )}$ sy se alguem sentir apeçonhentado ou em tempo de pestilencia sentir estas cousas que escuse o somno \& ho euite quanto poder $\mid(a 3,14)$ \& esta causa particular \& pode aconteçer cada dia. $\mid(\mathbf{a} 4, \mathbf{6})$ A primeyra questam: digo que esto pode aqueçer por duas causas .scilicet. por parte do agente \& por parte do paçiente $\mid\left(\mathbf{a 5}^{\mathbf{v}}, \mathbf{2 1}\right)$ \& com lenho de aloes que he melhor de tudo posto que se nom pode comprar por pequeno preço. I (b2, 16) SAngria huũa vez em huũ mes se pode bem fazer. I $(\mathbf{b} 2 \mathrm{v}, 6)$ em modo que escassamente pode nenhũa herua tal peçonha reuogar. I $(\mathbf{b} 3,3)$ mas todas estas cousas pode muyto bem euitar \& de sy lançar I (b3,5)Posto que tal como este nom pode andar e $m$ cauallo ou besta. $\mid(\mathbf{a} 5,14)$ muyto boõ remedio he fugir \& mudar o lugar apeçonhentado. mas porque muytos sem grande perda nom podem mudar o lugar. I $\left(\mathbf{a}^{\mathrm{v}}, 3\right)$ Em monpilher nom me pude escusar de companhia de gente. porque andaua de casa em casa curando enfermosl (a6v" 12) os meos companheiros nom pódiam creer que eu podesse viuer \& escapar. I $(\mathbf{a} 4 \mathbf{v}, 4)$ em o tempo pestilençial nenhuũ nom deue de star em ajuntamento dopouoo. porque podera ser que algũ̃ delles sera apeçonhentado ou ferido: I (b4, 21) E despois do sangue menuido se for muyto fraco emtom podera dormir despois do meo dia. I $\left(\mathbf{a} 6^{\mathrm{v}}, \mathbf{1 3}\right)$ os meos companheiros nom podiam creer que eu podesse viuer \& escapar. $\mid(\mathbf{b}, \mathbf{2 2})$ \& nom jantaras atee ho meo dia porque possa a triaga em o corpo fazer sua operaçam. I $\left(\mathrm{b} 2^{\mathrm{v}}\right.$, 15) que tal desejo se deue reuogar \& impedir per alguũ andar em jardijs ou em campos. em modo que o somno natural se possa tomar per hũa hora despois de comer. $\rightarrow$ TODOPODERoso. adj. Que tudo pode. • todo poderoso, s. Xv:(a3, 1-2) Quando ergo estes signaes apareçerem. he pera temer grande pestilencia. se ho senhor deus todo poderoso ho nom quitar \& estoruar. $\rightarrow$ POssivel. adj. Que está ao alcance de ser feito. - possiuel: $(\mathbf{a 5}, \mathbf{1 5})$ \& por ysso quanto for possiuel taaes deuem de euitar \& de sy esquiuar as causas de tal podridom. I $(\mathbf{a 6}, \mathbf{1 0})$ toda multidom de pouoo \& comunidade em tal tempo se deue de euitar em quanto for possiuel

PODRE. [ <lat. putris, -e.] adj. Em decomposição; deteriorado. • podres, s. XIV: (a3, 19) As vezes jsso mesmo vee $m$ de corpos mortos. ou de corrupçom de pauees \& charcos ou chafarizes çujos podres \& federentos. I $(\mathbf{a} 5, \mathbf{2 4})$ \& per esta mesma causa euitaras \& esquiuaras todo ho fedor .scilicet. de estrebarias. de campos. de ruas. \& em special donde ha hi corpos mortos \& podres $\mid\left(\mathbf{a 5}^{\mathrm{v}}, \mathbf{7}\right)$ mesmo onde se lançam verças \& caldos podres que sobejam em taaes casas. $1(\mathbf{a} 5 \mathrm{v}, \mathbf{7 - 8})$ \& por serem assi podres causam tal fedor \& doença que muyto empeçe $\rightarrow$ PODRIDÃo. sf. Decomposição, deterioração. • podridom; podridom;podridam: $\left(\mathbf{b}^{\mathrm{v}}, \mathbf{6}\right)$ mas porque muyto aqueenta. \& a queentura traz podridom. melhor me pareçe soo a cousa amargosa que queentura cheyro \& sabor $\mid\left(\mathbf{b}^{v}, 24\right)$ todo ho fructo traz podridom. I $(\mathbf{a}, \mathbf{1 6})$ \& por ysso quanto for possiuel taaes deue $m$ de euitar \& de sy esquiuar as causas de tal podridom $\mid(\mathbf{a 5}, 25)$ \& em special donde ha hi corpos mortos \& podres. \& tambem donde ha hi podridom de agoas \& fedor dellas. $($ (a 5 v , 13-14) ho aar apeçonhentado he humido \& faz podridom em a casa ou em lugar onde dormem. I (a3 $\left.{ }^{v}, 7\right)$ da jmpressam celestrial corrompente ho aar. \& podridam dos corpos mortos. ou lugares çujos se causa ho morbo ou ha chagua em ho homem: $\rightarrow$ APODRENTAR. $v$. Apodrecer; corromper. - apodrentar, S. XIV: $\left(\mathrm{a}^{\mathrm{v}}{ }^{\mathrm{w}}, \mathbf{1 4}\right)$ porque o vento do sul teem em si duas causas de de

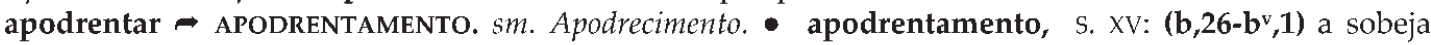
abastança \& grande inchamento tras apodrentamento dos humores

POÉtICo. [<lat. poeticus, $-a,-u m$.] adj. Relativo a poesia. - poetico: $\left(\mathbf{a} 2^{v}, 15\right)$ \& por isso diz ho verso poetico falando do apareçimento da cometa 
POLEGAR, vide DEDO.

Polme. [<lat. "pulmen.] sm. Alimento com a consistência de massa líqüida. polmes, s. xv: (bv, 18) caldos. polmes. \& potagios se euitem: se nom forem azedos

POR. [<lat. por.] prep. • por. [1] Para: $(\mathbf{a} 2, \mathbf{1 1})$ a proueyto do pouoo: por conseruaçam dos saãos | $(\mathbf{b} 4, \mathbf{1})$ faça se a sangria de çephalica daquelle meesmo lado. ou da vea que esta antre o dedo demostrador \& ho dedo polegar. por que muytas cousas peçonhentas nom destruam o çerebro. Em razão de : $\left(\mathrm{a}^{\mathrm{v}}{ }^{\mathrm{v}}, \mathbf{2}\right)$ ligeyramente se empeçonhentam os corpos da jndisposiçam ou da maa desposiçam dos çeos. por ha empressam dos çeos corrompe ho aar. $\mid\left(\mathbf{a 5}^{\mathbf{v}}, \mathbf{7}\right)$ \& por serem assi podres causam tal fedor \& doença que muyto empeçe. $(\mathbf{( b 3}, 6)$ Posto que tal como este nom pode andar em cauallo ou besta. nem andar grande caminho por a grande pigriça do corpo $₫$ Através de; por meio de: $(\mathbf{a} 4,6)$ A primeyra questam: digo que esto pode aqueçer por duas causas scilicet. por parte do agente $I(a 4,7)$ \& por parte do paçiente $\mid\left(\mathrm{a}^{\mathrm{v}}, \mathbf{2 2}\right)$ \& com lenho de aloes que he melhor de tudo posto que se nom pode comprar por pequeno preço. $\rightarrow$ POR CAUSA DE. Em conseqüência de. $\bullet$ por causa da: $\left(\mathbf{a} 6^{v}, 5\right)$ andaua de casa em casa curando enfermos por causa da minha pobreza

$\rightarrow$ POR CONSEguINTE. Por isso, $\bullet$ per conseguinte: $(\mathbf{a} 5, \mathbf{1 6}) \&$ por ysso quanto for possiuel taaes deuem de euitar \& de sy esquiuar as causas de tal podridom. E per conseguinte todo o coyto \& toda luxuria. $\rightarrow$ POR Isso. Por essa razão. - por isso; por ysso: $\left(\mathrm{a}^{\mathrm{v}}{ }^{\mathrm{v}}, 15\right)$ quando ha cometa apareçe aconteçem mortes de gentes em bathalhas \&c. \& por isso diz ho verso poetico falando do apareçimento da cometa. I (a5, 14) \& por ysso quanto for possiuel taaes deuem de euitar \& de sy esquiuar as causas de tal podridom. I $\left(\mathbf{a} 6^{v}, 22\right)$ E por ysso te digo que em toda maneyra te guardes que nom reçebas do baffo de outrem $\rightarrow$ POR RAZÃo DE. Por isso. $\bullet$ por razam do: $\left(\mathrm{a}^{\mathrm{v}}, \mathbf{5}\right)$ porque podera ser que alguũ delles sera apeçonhentado ou ferido: por razam do qual os medicos prudentes quando visitam os enfermos deuem de star afastados delles $\rightarrow$ POR TANTO. Por isso. - por tanto: $\left(\mathrm{a3}^{\mathrm{v}}, \mathbf{1 8 )}\right.$ E por tanto muytos medicos que em os enfermos soomente esguardam as ourinas superficialmente falam. I $(\mathbf{a 4}, 12)$ \& por tanto deues de notar que os corpos mays despostos a jnfirmidade \& a morte sam os corpos queentes.l (a4, 16) E por tanto dos quaaes se faz ha grande resoluçam $\mid\left(a 4^{\mathrm{v}}, 1\right)$ \& por tanto deue homem de fugir dos aares peçonhentos. I $\left(\mathbf{a}^{\mathbf{v}}, 9\right)$ E por tanto digo que a tal doente de pestilençia he boõ per alguũs dias mudar a camera | $\left(\mathrm{a}^{\mathrm{v}} \mathrm{v}, \mathbf{1 1}\right)$ \& por tanto se deue bem de guardar a casa: porque nom entre em ella ho aar peçonhentado I $(\mathbf{a} 6,3)$ E por tanto diz auiçena em o quarto do canone.I ( $\mathbf{b}^{\mathrm{v}}, \mathbf{1 4 - 1 5 )}$ \& por tanto todos os mantijmentos quanto som de mais leue digestam tanto som milhores. $\rightarrow$ Polo QuAL. Por isso. $\bullet$ pollo qual: $(\mathbf{a} 5,4)$ como se deue homem de guardar da pestilencia \& preseruar se della. pollo qual deues de notar que segundo diz o grande medico scilicet. dauid. $\rightarrow$ POLA QuAl CaUSA. Por isso. $\bullet$ polla qual causa: $(\mathbf{a} 5,8)$ que homem primeiramente ha de confessar seus pecados humildosamente. polla qual causa grande remedio he em tempo da pestilençia a sancta penitencia \& a confissam $\rightarrow$ POLA QUAL COUSA. Por isso. - polla qual cousa; pola qual cousa: $(\mathbf{a 4 v}, 20)$ Ho sul he vento inchado \& agraua o ouuido fere o coraçam. porque abre os poros do homem \& emtra atee o coraçam. pola qual cousa boõ he ao saão em tempo da pestilençia quando venta vento sul estar em casa per todo o dial $(\mathbf{b} 2,9)$ I E tambem a alegria do coraçom he gram remedio pera a saude do corpo. polla qual cousa deue se homem de guardar em tempo da pestilencia $\rightarrow$ PORQUE. - porque; porque. Para que: (a5v, 12) \& por tanto se deue bem de guardar a casa: porque nom entre em ella ho aar peçonhentado I (a6, 10-11) digo que toda multidom de pouoo \& comunidade em tal tempo se deue de euitar em quanto for possiuel. porque se nom se apeçonhente homem do aar apeçonhentado.l $(\mathbf{b}, 22)$ \& nom jantaras atee ho meo dia porque possa a triaga em o corpo fazer sua operaçam. I (b4,26-b4 $\left.{ }^{\mathrm{v}}, \mathbf{1}\right)$ E ysso mesmo porque a apostema mais çedo \& milhor seja madura $\square$ Causa ou explicação: $\left(\mathbf{a} 2^{v}, 10\right)$ Tercio he quando ha hy muytas moscas em ha terra. porque emtam pareçe ho aar ser empeçonhentado. I (a2v , 23) Sexto sinal he quando vee $m$ muytos ventos do meo dia. porque taes ventosidades sam muyto çujas \& muito velhacas. I $(\mathbf{a} 3, \mathbf{4 )}$ TRes sam as causas da pestilencia. porque as vezes vee $m$ \& proçede ha pestilencia da rayz superior. I (a3, 16) \& daly procedem febres pestilençiaes. açerca das quaes muytos medicos sam emganados. porque nom conheçem taes febres serem pestilençiaes. I $\left(\mathrm{a} 3^{\mathrm{v}}\right.$, 11) \& tal morbo ou 
jnfirmidade as vezes he febre. \& as vezes apostema \& jsto em os demais. porque ho aar jnspirado as vezes he peçonhento $\mid\left(\mathbf{a}^{\mathbf{v}}, \mathbf{1 1}\right)$ mas ajnda tam sobejamente se agraua ha natureza que nom sinte sy ser ferida nem emferma. \& jsto porque apareçem bõas ourinas \& boõas augoas. I (a4, 24) A segunda questam digo que taaes infirmidades pestilençiaaes sam contagiosas \& apegam se muy asinha. porque dos corpos apeçonhe $n$ tados procedem humores \& fumos peçonhentos I $\left(\mathbf{a} 4^{\mathrm{v}}\right.$, 4) em o tempo pestilençial nenhuũ nom deue de star em ajuntamento do pouoo. porque podera ser que alguũ delles sera apeçonhentado ou feridol $\left(\mathrm{a}^{\mathrm{v}}, \mathbf{1 3}\right) \&$ as genelas ou frestas pera ho meo dia ou pera ho sul estem çarradas. porque o vento do sul teem em si duas causas de de apodrentar $\mid\left(a 4^{v}, 19\right)$ Ho sul he vento inchado \& agraua o ouuido fere o coraçam. porque abre os poros do homem \& emtra atee o coraçam I $(\mathbf{a} 5,13)$ muy to boõ remedio he fugir \& mudar o lugar apeçonhentado. mas porque muytos sem grande perda nom podem mudar o lugar. $\mid(\mathbf{a 5}, \mathbf{2 5})$ \& tambem donde ha hi podridom de agoas \& fedor dellas. porque em algũas casas estam as agoas çujas per dous \& tres dias $\mid\left(\mathrm{a}^{\mathrm{v}}, \mathbf{1 3}\right)$ \& por tanto se deue bem de guardar a casa: porque nom entre em ella ho aar peçonhentado porque ho aar apeçonhentado he humido $\mid\left(\mathbf{a 5}^{\mathrm{v}}\right.$, 23) E tal fumo entre per a boca \& per os narizes. porque assi jndiramçe as cousas de dentro. $\mid(\mathbf{a} 6, \mathbf{1})$ Item per esta meesma $c a<u>s a$ se euite \& esquiue: todo ho inchamento do ventre que veem per muyto comer. porque os corpos cheos dos maaos humores sam mais asinha empeçonhentados. I $(a 6,7)$ Item per esta mesma causa se deue euitar ho banho de cada dia. porque pouco creçente a peçonhenta toda a massa. I $\left(\mathbf{a 6}^{\mathrm{v}}, \mathbf{4}\right) \mathrm{Em}$ monpilher nom me pude escusar de companhia de gente. porque andaua de casa em casa curando enfermos $\mid\left(\mathbf{a} \mathbf{6}^{\mathrm{v}}, \mathbf{8}\right)$ \& emtam leuaua commigo huũa sponja ou paão enssopado em vinagre: \& sempre no punha nos narizes \& na boca. porque as cousas azedas \& os cheyros taaes opilam \& çarram os poros \& os meatos \& os caminhos dos humores $\mid(\mathbf{b}, \mathbf{1 0})$ Em casa sempre este fogo açeso. porque clarifica muyto ho aar \& poõe grande impedimento aa maa influencia do çeeo. I $(\mathbf{b}, 25)$ deues de comer boõ manjar \& bõa yguaria com boõ vinho puro \& ameude. empero nom muyto juntamente. porque a sobeja abastança \& grande inchamento tras apodrentamento dos humores. I $\left(b^{v}, 5\right)$ ajnda que pigmenta purga o çerebro da freuma \& os outros membros speciaaes dos humores vis $<c>0$ osos. mas porque muyto aqueenta. I ( $\mathbf{b}^{\mathbf{v}}$, 23) Isso mesmo se euite $m$ todos os fructos se nom fore $m$ azedos. assi como sam çirejas. romaãs. ou huũ pequeno de pero ou maçaã em lugar de meezinha. porque todo ho fructo traz podridom.l $(\mathbf{b} 2,2)$ estas cousas busquem se pera os ricos muyto bõas salsas ou salseamentos. porque se forem pobres contentem se com arruda \& salua.I $(\mathbf{b} 2, \mathbf{1 2})$ que nenguem nom tema morte. sem teer infirmidade pestilencial. porque ymaginaçam faz causa \& perijgo. $\left(\mathbf{b 2} \mathbf{2}^{\mathrm{v}}, \mathbf{3}\right) \mathrm{em}$ toda maneyra tal como este euite o somno \& ysto em andando. porque em ho somno ha queentura intrinseca. caladamente traz a peçonha ao coraçam $\mid\left(\mathbf{b} \mathbf{2}^{\mathrm{v}}\right.$, 18) Empero diz auiçena que se homem quiser dormir ha de beber hũa bõa vez de vinho ou çerueja ante de dormir. porque o homem estando em o somno traz em si muytos vapores.। (b2v, 24) A ysto te respondo que o home $m$ que em tal dia he apeçonhentado nom come mujto. porque he cheo de maos humores. I (b3, 8) Posto que tal como este nom pode andar em cauallo ou besta. nem andar grande caminho por a grande pigriça do corpo \& muyto grande peso \& carrega corporal. porque o homem ja apeçonhentado $\mid(\mathbf{b} 3, \mathbf{1 0})$ em todas as horas teem grande desejo de dormir. porque a peçonha intrinseca pertorua o sprito vital. I $(\mathbf{b 3}, \mathbf{2 6 )} \&$ se sangre atee esmoreçer. porque pouco minguamento de sangue esperta a peçonha. I (bv3,4) emtam leyxe yr a vea aberta ou ferida atee o retardamento do sangue. porque pequena sangria: ou pequena sayda de sangue. mais fortemente esperta a peçonhal $(\mathbf{b} 4, \mathbf{1 3})$ emtom ha de menuyr o sangue em a parte crucifixa que he a parte contrayra. porque se apareçer despois em o braço direyto:que se sangre em o braço esquerdo $\mid(\mathbf{b 4}, \mathbf{2 5})$ E se despois creçer a postema:nom tema. porque tal apostema lança o mal de fora \& faz o home $m$ ser muyto saão. I (b4 $\left.\mathbf{b}^{\mathrm{v}}, \mathbf{7}\right)$ eu rogo mujto que se nom ponha. porque a triaga lança a peçonha fora.। $\left(\mathbf{b 4} \mathbf{4}^{\mathrm{v}}, \mathbf{1 8}\right)$ toma aquelle çumo \& mistura ho com leyte de mulher \& da ho a beber aquelle que teuer a postema. \& ysto com o estamago gejuum. porque emtom obra milhor em o homem. Introduz uma pergunta: (a3v, 25) Aqui se moulem duas questões. Ha primeyra he Porque he assy que hữ morre \& ho outro nom

PÔR. [<lat. ponere.] v. • punha; pom, S. XIII; poõe; ponha; ponham. @olocar sobre: (a6v, 7) \& sempre no punha nos narizes \& na boca. I $\left(\mathbf{b} 4^{v}, 21\right)$ \& tudo bem pisado: pom lho em çima da apostema. I (b4 ${ }^{v}$, 4) faze emprasto. \& despois poõe tudo na apostema. I $\left(\mathbf{b} 4^{v}, 6\right)$ posto que alguũs çirogiaães querem que lhe ponham triaga $\mid\left(b 4^{v}, 6-7\right)$ mas eu rogo mujto que se nom ponha. $@$ Criar, provocar: $(b, 11)$ Em casa 
sempre este fogo açeso. porque clarifica muyto ho aar \& poõe grande impedimento aa maa influencia do çeeo

PORo. [<lat. porus, -i.] sm. Pequenos orificios na pele, invisiveis a olho nu. •poros: $(\mathbf{a 4}, \mathbf{1 4 )}$ os corpos mays despostos a jnfirmidade \& a morte sam os corpos queentes \& que teem os poros mays largos। $(\mathrm{a} 4,15) \&$ os corpos peçonhentos que tem os poros opilados: \& çarrados de mujtos humores I $(\mathbf{a} 4 \mathrm{v}, 19)$ Ho sul he vento inchado \& agraua o ouuido fere o coraçam. porque abre os poros do homem \& emtra atee o coraçam. I $\left(\mathbf{a} 6^{v}, 9\right)$ as cousas azedas \& os cheyros taaes opilam \& çarram os poros \& os meatos \& os caminhos dos humores

POSSÍVEL. vide PODER.

POsTo. [<lat. positus,-a, -um.] conj. Se bem que. - posto: $\left(b^{v}, 8\right)$ ysso mesmo o alho posto: alimpe da freuma \& lança fora os maaos humores $\rightarrow$ POSTo QUE. Posto. - posto que; posto que: $\left(a^{\mathrm{v}}, 21\right)$ \& com lenho de aloes que he melhor de tudo posto que se nom pode comprar por pequeno preço. I $(\mathbf{b} 3, \mathbf{5})$ todas estas cousas pode muyto bem euitar \& de sy lançar andando ou espaçando huũ pouco antre ho comer \& o dormir. Posto que tal como este nom pode andar em cauallo ou besta. I (b4 ${ }^{\mathrm{v}}$, 5)\& despois poõe tudo na apostema. posto que alguũs çirogiaães quere $m$ que Ihe ponham triaga mas eu rogo mujto que se nom ponha

POTÁGıo. [<lat. potagium, -i.] sm. Fatias de pão embebidas no caldo da panela; s o p a [q.v.]. • potagios: (bv, 18) caldos. polmes. \& potagios se euitem: se nom forem azedos

Pouco. [<lat. paucus, -a, -um.] -pouco. [C] adj. Pequeno, reduzido: (a6, 7) porque pouco creçente apeçonhenta toda a massa.I $(\mathbf{b 3}, \mathbf{2 6 )} \&$ se sangre atee esmoreçer. porque pouco minguamento de sangue esperta a peçonha. pron. indef. Por pouco espaço de tempo: $(\mathbf{b} 3,4)$ mas todas estas cousas pode muyto bem euitar \& de sy lançar andando ou espaçando huũ pouco antre ho comer \& o dormir

Povo. [<lat. populus, -i.] sm. Gente. •pouoo, s. XIV: (a2, 11)EM louuor da santissima trijndade. \& da gloriosa virgem maria \& a proueyto do pouoo: por conseruaçam dos saãos: \& reformaça $m$ dos caydos. I $\left(2^{2}, 19\right)$ ho sol se cobre scilicet. de nuueens. ho regno se muda. ho pouoo padeçe fame \& pestilencia. I $\left(\mathbf{a} \mathbf{4}^{v}, 4\right)$ mais ajnda digo que em o tempo pestilençial nenhuũ nom deue de star em ajuntamento do pouoo. I $(\mathbf{a 6}, 9)$ onde finalmente digo que toda multidom de pouoo \& comunidade em tal tempo se deue de euitar $\mid\left(a 6^{v}, 20\right)$ \& estas cousas prestam pera antre pouoo onde ligeyramente se aconteçe huũ seer empeçonhentado do outro $\mid(\mathbf{b}, \mathbf{5})$ \& assi guardando estas cousas seguramente entraras em pouoo ou amtre gente

PRAZER. [<lat. placere.] sm. Satisfação. • prazer: $(\mathbf{b} 2,13)$ mas qualquer com muyto prazer \& alegria sempre espere de muyto viuer. I (b2, 23) \& despois que a vea for ferida ou aberta aproueyta muyto tomar muyto prazer. beber muy boõ vinho ou bõa çerueja

PREÇo. [<lat. pretium, -ii.] sm. Quantia. - preço: $\left(\mathbf{a} 5^{v}, 22\right)$ \& com lenho de aloes que he melhor de tudo posto que se nom pode comprar por pequeno preço

PREguiçA. [<lat. pigritia, -ae.] sf. Moleza. • pigriça: $(\mathbf{b} 3,7)$ Posto que tal como este nom pode andar em cauallo ou besta. nem andar grande caminho por a grande pigriça do corpo

PRENHE.[<lat. praegnas, -atis.] adj. Grávida. •prenhes, S. XIII: (b2, 19) SAngria huũa vez em huũ mes se pode bem fazer. se nom se a ydade ou outra cousa for em contrayro. assy como he em as molheres que som prenhes 
PRESERVAR. [<lat. praeservare.] v. Resguardar. epreseruar: (a5, 3-4) VIstas as causas da pestilencia. agora ajamos de veer per que modo \& como se deue homem de guardar da pestilencia \& preseruar se della

PRESTAR. [<lat. praestare.] v. Ser útil. •prestam: $\left(\mathbf{a}^{\mathrm{v}}, \mathbf{2 0 )}\right.$ com todas as outras heruas que endereçam ho spirito interior. \& estas cousas prestam pera antre pouoo

PRIMEIRo. [<lat. primarius, -a, -um.]• primeyro; primeyra; primeiro. num. Relativo a um: $(\mathrm{a} 2,22)$ Dos signaaes. Capitollo primeyro. I $\left(\mathrm{a}^{\mathrm{v}}{ }^{\mathrm{v}}, \mathbf{2 4 )}\right.$ Aqui se mouem duas questões. Ha primeyra he Porque he assy que huũ morre \& ho outro nom. $\mid(\mathbf{a} 4,5)$ A primeyra questam: digo que esto pode aqueçer por duas causas $\mid\left(\mathbf{a} 4^{v}, \mathbf{1 5}\right)$ porque o vento do sul teem em si duas causas de de apodrentar A primeyra que faz emfraqueçer os corpos assi dos saãos como dos enfermos. I $(\mathbf{a 2}, 24)$ SIgnaes pronosticos da pestilencia quanto ao presente pertençe: sam sete. Primeiro quando em huũ dia do estio \& do alto veraão se muda a manhaã muytas vezes. adv. Primeiramente: $\left(\mathbf{b} 4^{\mathrm{v}}, \mathbf{1}^{19)}\right.$ Item quando a postema primeyro apareçer. tome auelaãs. figos passados \& aruda \& tudo be $m$ pisado: pom Iho em çima da apostema. I (a5,5) pollo qual deues de notar que segundo diz o grande medico scilicet. dauid. que primeiro se deue o homem de afastar do mal \& inclinar se ao bem. $\rightarrow$ PRIMEIRAMENTE. adv. Antes de mais nada. - primeiramente; primeyramente: $(\mathbf{a} 5, \mathbf{7})$ scilicet. que homem primeiramente ha de confessar seus pecados humildosamente. I (b4, 6) minguaras o sangue com ventosas. \& primeiramente minguaras a meaã. I (a2, 15) E primeyramente. Dos signaes pronosticos da pestilençia

PRINCIPAL. vide MEMBRO,

PRINCIPALMENTE. [de principal.] adv. Em especial. • prinçipalmente: (a2v, 3) em modo que de manhaã pareçe chuuosa \& chea neuoa. \& depois ventosa. \& prinçipalmente quando he ho vento meridional. ou da parte de estrela do Sul

PRIVADA. [de privado.] sf. Latrina. A "quase totalidade das casas particulares medievais [....] não possuiam privadas" (Costa Roque, 1979: 206). Ainda segundo Costa Roque (1979:207) a Idade Média herdaria o modelo romano mais simples, em que um estrado com um buraco redondo dava diretamente para uma fossa latrinária, sem a presença de um cano intermediário. Nas casas mais ricas esse estrado, com cerca de três metros, ficava ao longo de uma parede, apresentando "quatro ou cinco buracos a seguir uns aos outros, munidos das respectioas tampas, tal e qual como se a família inteira pudesse ter necessidade de os utilizar simultaneamente", ou ainda, como se estivessem em acordo com o volume dos diferentes usuários (Costa Roque, 1979: 207). •priuada: (a3, 11) Da rayz jnferior proçede segundo nos veemos que da priuada que esta açerca da camera ou de alguũ fedor particular de alguũ canno çujo se corrompe ho aar em substançia \& qualidade

PROCEDER. [<lat. procedere.] v. Advir. - procedem; procedem; proçede: \& daly procedem febres pestilençiaes. I porque dos corpos apeçonhentados procedem humores \& fumos peçonhentos I TRes sam as causas da pestile $n$ cia. porque as vezes vee $m$ \& proçede ha pestilencia da rayz superior.I \& as vezes proçede da rayz jnferior. I Da rayz jnferior proçede segundo nos veemos que da priuada que esta açerca da camera ou de alguũ fedor particular de alguũ canno çujo se corrompe ho aar em substançia \& qualidade.I Da rayz superior \& jnferior juntamente proçede quando da jmpressam celestrial corrompente ho aar. \& podridam dos corpos mortos. ou lugares çujos se causa ho morbo ou ha chagua em ho homem

PRoGnóstico. [lat. prognosticus, $-a$, - um.] adj. Que faz prever; que é indício de. • pronosticos : Dos signaes pronosticos da pestilençia. I SIgnaes pronosticos da pestilencia quanto ao presente pertençe: sam sete

PROMETER. [<lat. promittere.] v. Afirmar. • prometo: Empero prometo te que muyto boõ remedio he fugir \& mudar o lugar apeçonhentado 
PROVAR. [<lat. probare.] v. Experimentar. • prouey: $\left(\mathbf{a} 6^{v}, 14\right)$ Eu çertamente todos estos remedios prouey. I $(\mathbf{b} 3,22)$ Estas cousas per my mesmo prouey

PRoveIto. [<lat. profectus, -us.] sm. Benefício. - proueyto: $(\mathbf{a} 2, \mathbf{1 1})$ EM louuor da santissima trijndade. \& da gloriosa virgem maria \& a proueyto do pouoo $\rightarrow$ PROVEITOSo. adj. Útil. $\bullet$ proueitoso; proueytosa: $(\mathbf{a} 2,2)$ Começa se huũ boõ regimento muyto neçessario \& muyto proueitoso aos viuentes | $(\mathbf{b}, \mathbf{1 4})$ Quanto he ao teu mantijmento digo te que a triaga te he muyto proueytosa $\rightarrow$ APROVEITAR. $v$. Trazer proveito, beneficiar. - aproueyta, S. XIV-XV: $(\mathbf{b} 2,23)$ \& despois que a vea for ferida ou aberta aproueyta muy to tomar muyto prazer. beber muy boõ vinho ou bõa çerueja

PRover. [<lat. providere.] v. Munir-se. - proueja: $\left(\mathbf{a 3}^{\mathrm{v}}{ }^{\mathrm{r}}, \mathbf{2 1 )}\right.$ Ergo he neçessario que todo enfermo se proueja de boõ fisico \& bem esperto

Provocar. [<lat. provocare.] v. Causar. - prouoca, s. Xv: $\left(\mathbf{b}^{\mathrm{v}}, \mathbf{9 )}\right.$ ysso mesmo o alho posto: alimpe da freuma \& lança fora os maaos humores. \& prouoca o apetito de comer

PRUDENTE. [<lat. prudens, -entis.] adj. Previdente, acautelado. • prudentes: $\left(\mathbf{a} 4^{\mathrm{v}}{ }^{\text {, 6) }}\right.$ por razam do qual os medicos prudentes quando visitam os enfermos deuem de star afastados delles

PURGAR. [<lat. purgare.] v. Limpar, livrar. - purga: (bv, 3) E em os mantijmentos guarte das cousas queentes. assi como som pigmenta \& alhos. ajnda que pigmenta purga o çerebro da freuma

PURo. [<lat. purus, -a, -um. ] adj. Não misturado. - puro: $(\mathbf{b}, \mathbf{2 4 )}$ E ysso meesmo deues de comer boõ manjar \& bõa yguaria com boõ vinho puro \& a meude. $\rightarrow$ APURAR. v. Limpar. $\bullet$ apure, S. XIV: $\left(\mathbf{a}^{\mathrm{v}}{ }^{\mathrm{v}}, \mathbf{1 5}\right)$ Apure se ergo \& assutileze se a casa per clara chama ou flama 


\section{Q}

QUAL. [<lat. qualis, -e.] pron. relat. Que. - qual; quaes; quaaes; quaaes: $(a 5,18)$ \& tambem o vento meridional ou sul: o qual naturalmente apeçonhenta. I (b4v, 24) sem o qual nom ha hy saude I (a5v, 19) \& faça se tambem com fumo de boõas heruas aqui scriptas .scilicet. baga de louro. junipero. vberiorgano. as quaaes acharas aos apotecayros $\mid(b, 9)$ \& tambem tomaras pirolas pestilençiaaes as quaaes acharas aos apotecayros $\mid(\mathbf{a} 5,10)$ polla qual causa grande remedio he em tempo da pestilençia a sancta penitencia \& a confissam as quaaes preçedem \& sam muyto melhores que todas as mezinhas । $\left(\mathbf{a} 4^{v}, 5\right)$ porque podera ser que alguũ delles sera apeçonhentado ou ferido: por razam do qual os medicos prudentes quando visitam os enfermos deuem de star afastados delles I (a3, 23) dos quaaes se corrompem os spiritos vitaes em ha creatura viuente I (a3, 24) Da rayz superior veem \& aconteçe a pestilençia per virtude dos corpos de çima dos çeos. dos quaaes se corrompem os spiritos vitaes em ha creatura viuente. $\mid(\mathbf{a} 3,15)$ \& daly procedem febres pestilençiaes. açerca das quaes muytos medicos sam emganados. $(\mathbf{a} 4,16)$ E por tanto dos quaaes se faz ha grande resoluçam $\mid\left(\mathrm{b}^{\mathrm{v}}\right.$, 9$)$ \& sempre naquella meesma parte do corpo: em a qual ha doença ou chaga apareçer se deue de sangrar \& abrir a vea.I $\left(\mathbf{a}^{v}, 3\right)$ em algũas casas estam as agoas çujas per dous \& tres dias \& as lançam per canos \& regos soterranhos: em os quaaes taes agoas çujas causam grandes fedores $\mid \mathbf{( b 4}, \mathbf{1 8 )}$ E se apareçer a apostema de bayxo do braço direyto: emtom faça se como dito he do braço esquerdo. \& assi dos outros lugares em os quaaes apareçer a apostema $\mid\left(b 4^{v}, 24\right)$ com virtude \& meezinha de nosso senhor jesu christo. sem o qual nom ha hy saude $\rightarrow$ A QUAL CoUSA. Isso $\bullet$ a qual cousa: $\left(\mathbf{b} 2^{v}, 7\right)$ em modo que escassamente pode nenhũa herua tal peçonha reuogar. a qual cousa nom se faria se o home $m$ andar em mouimento. $\rightarrow$ POLO QUAL. vide POR. $\rightarrow$ POLA QUAL CAUSA. vide POR. $\rightarrow$ POLA QUAL COUSA. vide POR.

QUALIDADE. [<lat. qualitas, -atis.] sf. Aquilo que determina a essência de algo. $\bullet$ qualidade: (a3, 13) Da rayz jnferior proçede segundo nos veemos que da priuada que esta açerca da camera ou de alguũ fedor particular de alguũ canno çujo se corrompe ho aar em substançia \& qualidade

QUALQUER. [de qual + quer.] pron. indef. Cada qual. $\bullet$ qualquer, s. xIV: (b2,13) mas qualquer com muyto prazer \& alegria sempre espere de muyto viuer $I\left(\mathbf{b} 4^{v}, 22\right)$ E estas cousas abastem pera a pestilença. \& qualquer que se per este modo reger escapara muytos perijgos da pestilencia

QUANDO. [<lat. quando.] conj. Indica habitualidade e permite a interpretação como equivalente a 'se' • quando, S. XIII: $(a 2,24)$ Primeiro quando em huũ dia do estio \& do alto veraão se muda a manhaã muytas vezes ( $\left(\mathbf{a} 2^{\mathrm{v}}, \mathbf{3}\right)$ \& prinçipalmente quando he ho vento meridional. ou da parte de estrela do Sul. | (a2v, 5) Segundo sinal he quando em tal estio muytas vezes escureçem: ou pareçem escureçer os dias $\mid\left(\mathbf{( a 2 ^ { \mathbf { v } } , \mathbf { 9 } )}\right.$ Tercio he quando ha hy muytas moscas em ha terra.l $\left(\mathbf{a 2}{ }^{\mathrm{v}}, 12\right)$ Quarto sinal he $q u a n d o$ ha cometa pareçe voar. $\mid\left(\mathbf{a} 2^{\mathrm{v}}, \mathbf{2 0}\right)$ Quinto sinal. he quando se fazem mujtas relampados \& trouoadas $\mid\left(\mathbf{a} 2^{\mathrm{v}}, \mathbf{2 2}\right)$ Sexto sinal he quando veem muytos ventos do meo dia $\mid\left(a 3^{v}, 6\right)$ Da rayz superior \& jnferior juntamente proçede quando da jmpressam celestrial corrompente ho aar $\mid\left(\mathbf{a} \mathbf{2}^{\mathrm{v}}, \mathbf{1 3}\right)$ \& segundo diz aristoteles em os metauros. quando ha cometa apareçe aconteçem mortes de gentes em bathalhas \&c.। $\left(\mathbf{a} 2^{v}, \mathbf{2 5}^{25}\right.$ Quando ergo estes signaes apareçerem. he pera temer grande pestilencia. I $\left(\mathbf{a} \mathbf{4}^{\mathrm{v}}, \mathbf{6}\right)$ os medicos prudentes quando visitam os enfermos deuem de star afastados delles $\mid\left(\mathbf{a} 4^{\mathrm{v}}, \mathbf{2 1}\right)$ boõ he ao saão em tempo da pestilençia quando venta vento sul estar em casa per todo o dia I $(\mathbf{a 6}, \mathbf{1 2})$ E quando assi for que companhia \& ajuntamento de pouoo se euite. I $(\mathbf{6} 6, \mathbf{1 4 )})$ de manhaã quando se alguũ aleuantar logo coma da aruda lauada em agoa limpa espargida com sal | (b3, 23) Estantes ergo assi estas cousas quando se homem sente ser tocado da peçonha pestilençial. logo naquelle meesmo dia mingue ho sangue | (b4v, 8) mas eu queria antes que quando alguũ teuesse tal apostema que soruesse em si toda a triaga | (b4 $\mathbf{v}^{\mathrm{v}}$, 19) Item $\mathbf{q u a n d o}$ a postema primeyro apareçer. tome auelaãs. figos passados \& aruda \& tudo bem pisado: põm Iho em çima da apostema

QUANTIDADE. [<lat. quantitas, -atis.] sf. Medida. - quantidade: $(\mathbf{b}, \mathbf{1 8})$ nem se tome mais da triaga que a quantidade de huũ piseo 
QUANTO. [<lat. quantum.] pron. indef. - quanto: Aquilo que: $(\mathbf{a} 5,14) \&$ por ysso quanto for possiuel taaes deue $m$ de euitar \& de sy esquiuar as causas de tal podridom I onde finalmente digo que toda multidom de pouoo \& comunidade em tal tempo se deue de euitar em quanto for possiuel. por que se nom apeçonhente homem do aar apeçonhentado. I He ergo gramde remedio sy se alguem sentir apeçonhentado ou e $m$ tempo de pestilencia sentir estas cousas que escuse o sonno \& ho euite quanto poder. $\rightarrow$ QUANTO A. Conforme. - quanto a: $(\mathbf{a} 2,23)$ SIgnaes pronosticos da pestilencia quanto ao presente pertençe: sam sete.I $(b, 13)$ Quanto he ao teu mantijmento digo te que a triaga te he muyto proueytosa: assi saãos como aos enfermos. $\rightarrow$ QUANTo .... TANTo. Indica correlação de intensidade. quanto .... tanto: $\left(\mathbf{b}^{\mathrm{v}}, \mathbf{1 5}\right)$ a pestilençia que veem per causa queente ameude se acreçenta. \& por tanto todos os mantijmentos quanto som de mais leue digestam tanto som milhores. $\rightarrow$ EM QUANTO. Naquilo que. em quanto: $(\mathbf{a} 6,10)$ digo que toda multidom de pouoo \& comunidade em tal tempo se deue de euitar em quanto for possiuel

QUARTO. [<lat. quartus, -a, -um.] num. Que ocupa a posição quatro numa série. $\bullet$ quarto: $(\mathbf{a} 2 \mathrm{v}, 12)$ Quarto das conformidades do coraçam: \& dos prinçipaes membros. | $(\mathbf{a} 3,25)$ \& de tal diz auicena no quarto liuro que muy ligeyramente se empeçonhentam os corpos da jndisposiçam ou da maa desposiçam dos çeos. I $(a 6,3)$ E por tanto diz auiçena em o quarto do canone. que aquelles que sempre querem encher seus ventres que abreuiam seus dias \& tempos da sua fim

QUE. [<lat. quid.] - que; que. @ron. relat. Equivale ao termo que serve de seu antecedente; o qual: $(\mathbf{a} 2,14)$ Quero algũas cousas da pestenença que nos ameude fere: dos ditos dos mays autenticos medicos: screuer I $(\mathbf{a} 3,11)$ Da rayz jnferior proçede segundo nos veemos que da priuada que esta açerca da camera ou de alguũ fedor particular de algũ̃ canno çujo se corrompe ho aar em substançia \& qualidade I $\left(\mathbf{a}^{\mathrm{v}} \mathbf{}, \mathbf{1 8}\right)$ E por tanto muytos medicos $\mathbf{q u e}$ em os enfermos soomente esguardam as ourinas superficialmente falam $\mid(\mathbf{a 4}, \mathbf{1 8})$ \& os que vaam ameude a os banhos. I (bv, 12) \& nom consinta emtrar ho aar seco. empero contorua os olhos \& squeenta a cabeça de cada huũ que ho ameude come I (a4, 19) \& os homens que se muyto esqueentam com grande trabalho ou grande yra. teem os corpos mais dispostos pera reçeber ha pestilencia. I $(\mathbf{a 4}, \mathbf{2 5})$ porque dos corpos apeçonhentados procedem humores \& fumos peçonhentos que corrompem ho aar $\mid(\mathbf{a} 5,19)$ Fechem se ergo as frestas ou genelas como dito he que vaam ou estam pera o sull $(\mathbf{a} 5,21) \&$ abram se as que stam pera o nortel $\left(\mathbf{a} 5^{\mathrm{v}}, \mathbf{7}\right)$ mesmo onde se lançam verças \& caldos podres que sobejam em taaes casas $\mid\left(a 5^{v}, 21\right)$ \& com lenho de aloes que he melhor de tudo $\mid\left(\mathbf{a 5}^{\mathbf{v}}, \mathbf{2 5}\right)$ Item per esta meesma ca<u>sa se euite \& esquiue: todo ho inchamento do ventre que veem per muyto comer I $(\mathbf{a} 6,4)$ E por tanto diz auiçena em o quarto do canone. que aquelles que sempre querem encher seus ventres que abreuiam seus dias \& tempos da sua fim I (a6v, 19) com todas as outras heruas que endereçam ho spirito interior $\mid(\mathbf{b}, \mathbf{2 1}) \&$ a triaga seja delida em ho vaso ou copo em que ha tomares I $\left(\mathbf{b}^{v}, \mathbf{1 3}\right)$ a pestilençia que veem per causa queente ameude se acreçenta $\mid\left(\mathbf{b}^{v}\right.$, 24) E as speçias que comuummente conuem a comer. sam gingiure. canela. cuminhos. froles de heruas cheyrosas. \& açafram. I (b2, 19) assy como he em as molheres que som prenhes. ou em alguũ muyto fraco $\mid(\mathbf{b} 2,20)$.scilicet. em alguũ que teem corrença ou fluxu do ventre $\mid(\mathbf{b} 2,26)$ \& nom conuem dormir em aquelle dia que se sangrar \& abrir a vea $\mid\left(\mathbf{b 2}{ }^{v}, 23\right)$ A ysto te respondo que o homem que em tal dia he apeçonhentado nom come mujto $\mid\left(\mathbf{b}^{v}, 6\right)$ Item o homem que se sangra $\mid\left(\mathbf{b}^{v}{ }^{v}, \mathbf{1 6}\right)$ em a vea $q u e$ he açerca do dedo mais pequeno $\mid(\mathbf{b} 4,2)$ ou da vea que he açerca do dedo menor $\mid\left(\mathbf{b} 3^{v}, 26\right)$ ou da vea que esta antre o dedo demostrador \& ho dedo polegar I $(\mathrm{b4}, 3)$ ou açerca do articulo que he de muytos medicos chamada basilica I (b4,7) E se for em o espinhaço mingua sobre a vea $q u e$ he chamada a pedica grande I $(\mathbf{b} 4, \mathbf{1 2})$ emtom ha de menuyr o sangue em a parte crucifixa que he a parte contrayra. I (b4v, 10) Tomaras hũa herua que chamam barba jouis.\& outro que chamam serpillo| $\left(\mathbf{b} 4^{v}, \mathbf{1 2}^{2}\right) \mathrm{q} u e$ acharas ao boticairo I $(\mathrm{b} 4 \mathrm{v}, 17)$ \& da ho a beber aquelle que teuer a postema I (b4v, 22) \& qualquer que se per este modo reger escapara muytos perijgos da pestilencia $\mathbb{\square}$ conj. Introduz uma complementação: $(b 4 v, 14)$ \& pisa todo muyto bem atee que vejas que quer pareçer que say destas cousas assy pisadas augoa ou çumo $\mid\left(\mathrm{a}^{\mathrm{v}}\right.$, 2$)$ mais ajnda digo que em o tempo pestilençial $\mid\left(\mathbf{a} 4^{\mathrm{v}}, 4\right)$ nenhuũ nom deue de star em ajuntamento do pouoo. porque podera ser que alguũ delles sera apeçonhentado ou feridol (b4v, 8) mas eu queria antes que quando alguũ teuesse tal apostema que soruesse em si toda a triagal $\left(\mathbf{b} 4^{\mathrm{v}}, 6\right)$ posto que alguũs çirogiaães quere $m$ que lhe ponham triaga mas eu rogo mujto que se nom ponha. I (b4, 
14) porque se apareçer despois em o braço direyto: que se sangre em o braço esquerdo do figado: ou basilica: ou da meaã. I (b4, 10) E todas estas cousas se façam se homem nom dormir antes que contheça que tem a postema. I $\left(\mathbf{b 2}^{\mathrm{v}}\right.$, 23) A ysto te respondo que o homem que em tal dia he apeçonhentado nom come mujto I $\left(\mathbf{b} 2^{v}, 22\right)$ Mas diras tu. como sintira homem que está apeçonhentado \& ferido da pestilençia I (b2v ${ }^{v}$ 16) Empero diz auiçena que se homem quiser dormir ha de beber hũa bõa vez de vinho I (b2v, 11) A ysto digo breuemente que em tempo da pestilencia. logo despois de comer. se alguũ teuer desejo de dormir: | (b2v, 12) que tal desejo se deue reuogar \& impedir $\mid(\mathbf{b} 2, \mathbf{1 1})$ em tempo da pestilencia que nengue $m$ nom tema morte. sem teer infirmidade pestilencial $\mid(\mathbf{b} 3, \mathbf{1 8})$ He ergo gramde remedio sy se alguem sentir apeçonhentado ou $\mathrm{e} m$ tempo de pestilencia sentir estas cousas que escuse o somno | $\left(\mathbf{a 3}^{\mathbf{v}}, \mathbf{2 5}\right)$ Porque he assy que huũ morre \& ho outro nom | $(\mathbf{b}, 1)$ Muyto saã cousa he que se laue a boca \& os olhos $\mid(\mathbf{b}, \mathbf{1 3 - 1 4})$ Quanto he ao teu mantijmento digo te que a triaga te he muyto proueytosa I $\left(\mathrm{a}^{\mathrm{v}}, 22\right)$ E por ysso te digo que em toda maneyra te guardes que nom reçebas do baffo de outrem $\mid(\mathbf{a 6}, 3)$ E por tanto diz auiçena em o quarto do canone. que aquelles que sempre querem encher seus ventres que abreuiam seus dias \& tempos da sua fim I $(\mathbf{a 6}, \mathbf{8})$ onde finalmente digo que toda multidom de pouoo \& comunidade em tal tempo se deue de euitar I (a6, 12) E quando assi for que companhia \& ajuntamento de pouoo se euite. I $\left(\mathrm{a}^{\mathrm{v}}, 4\right)$ \& daqui veem que em tal casa como esta morrem os homens mais azinha $\mid(\mathbf{a} 5,4)$ pollo qual deues de notar que segundo diz o grande medico scilicet. dauid. I $(\mathbf{a} 5,5)$ que primeiro se deue o homem de afastar do mal \& inclinar se ao bem .scilicet. I $(\mathbf{a 5}, 7)$ que homem primeiramente ha de confessar seus pecados humildosamente I (a4v, 9) E por tanto digo que a tal doente de pestilençia he boõ per alguũs dias mudar a camera $\mid(\mathbf{a} 4 \mathbf{v}, 2)$ mais ajnda digo que em o tempo pestilençial nenhuũ nom deue de star em ajuntamento do pouoo I (a4, 22) A segunda questam digo que taaes infirmidades pestilençiaaes sam contagiosas $\mid\left(\mathrm{a}^{\mathrm{v}}\right.$, 7) Segundo sinal he quando e $m$ tal estio muytas vezes escureçem: ou pareçem escureçer os dias em modo que pareçe que quer chouuer \& nom choue I $\left(\mathbf{a} 2^{\mathrm{v}}, \mathbf{1 1}\right)$ Tercio he quando ha hy muytas moscas em ha terra. porque emtam pareçe ho aar ser empeçonhentado. \& que sobem muytos vapores peçonhentos ao aar. I (a3, 10) Da rayz jnferior proçede segundo nos veemos que da priuada que esta açerca da camera ou de alguũ fedor particular de alguũ canno çujo se corrompe ho aar em substançia \& qualidade. I $(\mathbf{a} 3,25)$ \& de tal diz auicena no quarto liuro que muyligeyramente se empeçonhentam os corpos da jndisposiçam ou da maa desposiçam dos çeos. I $\left(\mathrm{a}^{\mathrm{v}}{ }^{\mathrm{v}}, \mathbf{2 1}\right)$ Ergo he neçessario que todo enfermo se proueja de boõ fisico \& bem esperto $\mid(\mathbf{a} 4, \mathbf{1 2}) \&$ por tanto deues de notar que os corpos mays despostos a jnfirmidade \& a morte sam os corpos queentes $\mid(\mathbf{a} 4,5)$ A primeyra questam: digo que esto pode aqueçer por duas causas $\mid$ $(\mathbf{a}, \mathbf{1 2})$ Empero prometo te que muyto boõ remedio he fugir \& mudar o lugar apeçonhentado $₫$ conj. Introduz uma explicação: $\left(\mathbf{a} 6^{\mathrm{v}}, \mathbf{1 2}\right)$ \& assi escapey de tal pestilencia. que os meos companheiros nom podiam creer que eu podesse viuer \& escapar I (b3, 19-20) \& assi segundo estas cousas he assaz manifesto: que em o tempo do somno o sprito vital repousa pron. inter. $\left(\mathbf{b} 2^{\mathrm{v}}\right.$, 9) Mas dira alguũ. se o home $m$ deue de euitar ho somno que fara homem se teuer o somno natural. $\rightarrow$ EM MANEIRA QUE. vide MANEIRA. $\rightarrow$ EM MODO QUE. vide MODO. $\rightarrow$ EM TANTO QUE. vide TANTO. $\rightarrow$ MAIS .....QUE. vide MAIS. $\rightarrow$ MELHOR .... QUE. vide MELHOR.

QUENTE. [<lat. calens, -tis] adj. Uma das quatro primeiras qualidades reconhecidas na tradição médica hipocrático-galênica — a saber, o quente, o frio, o úmido e o seco —, cujo equilíbrio era responsável pela saúde. - queente; queentes; queentes, S. XIV: $\left(b^{v}, 14\right)$ a pestilençia que veem per causa queente ameude se acreçenta. I ( $\left(\mathbf{b}^{v}, 2\right)$ E em os mantijmentos guarte das cousas queentes | $(\mathbf{a 4}, \mathbf{1 3})$ deues de notar que os corpos mays despostos a jnfirmidade \& a morte sam os corpos queentes. $\rightarrow$ QuENTURA. sf. Calor. $\bullet$ queentura, S. $\mathrm{XV}_{;}$quententura [?]: $\left(\mathbf{b}^{\mathrm{v}}, 6\right)$ mas porque muyto aqueenta. \& a queentura traz podridom. I $\left(\mathbf{b}^{v}, 7\right)$ melhor me pareçe soo a cousa amargosa que queentura cheyro \& sabor. | (b2v, 4) \& ysto em andando. porque em ho somno ha queentura intrinseca. caladamente traz a peçonha ao coraçam $\mid$ (b3, 1) \& sente de bayxo de frio grande quententura $\rightarrow$ AQUEENTAR. v. Aquecer. aqueenta, S.XIV: $\left(\mathbf{b}^{v}, 6\right)$ mas porque muyto aqueenta. \& a queentura traz podridom - ESQUENTAR. $v$. esqueentam, S. XIV; squeenta. $\$$ Aquecer: $\left(\mathbf{b}^{v}, 11\right)$ \& nom consinta emtrar ho aar seco. empero contorua os olhos \& squeenta a cabeça de cada huũ que ho ameude come. Aquecer o sangue: $(\mathbf{a} 4,19)$ \& os homens que se muyto esqueentam com grande trabalho ou grande yra 
QUENTURA. vide QUENTE.

QUERER. [<lat. quaerere.] v.• quer; querem; quero; quiser. $\square$ Fazer tenção de; ensaiar: (a2v, 7) pareçe que quer chouuer \& nom choue $\mid\left(\mathbf{b} 4^{\mathbf{v}}, \mathbf{1 4}\right)$ \& pisa todo muyto bem atee que vejas que quer pareçer que say destas cousas assy pisadas augoa ou çumo. Ter o propósito de; desejar: $(\mathbf{a} 6,4)$ E por tanto diz auiçena em o quarto do canone. que aquelles que sempre quere $m$ encher seus ventres que abreuiam seus dias I $\left(\mathbf{b} 4^{v}, 5\right)$ \& despois poõe tudo na apostema. posto que alguũs çirogiaães querem que lhe ponham triaga I $(b 4 v, 7)$ mas eu queria antes que quando alguũ teuesse tal apostema que soruesse em si toda a triagal $(\mathbf{a} 2,13)$ Quero algũas cousas da pestenença que nos ameude fere: dos ditos dos mays autenticos medicos: screuer I (b2v $\left.{ }^{2}, \mathbf{1 6}\right)$ Empero diz auiçena que se homem quiser dormir ha de beber hũa bõa vez de vinho ou çerueja ante de dormir. I $(\mathbf{b 3}, \mathbf{1 3})$ mas se alguũ nom quiser creer: spere per huũ meo dia \& logo sentira apostema de bayxo dos braços. I (b3v , 1) \& se homem nom quiser cortar muytas veas juntamente: emtam leyxe yr a vea aberta ou ferida atee o retardamento do sangue

QUESTÃo. [<lat. quaestio, -onis.] sf. Pergunta. questam, S. XIV; questões: $(a 4,3)$ Segunda questam he esta.I $(\mathbf{a} 4,5)$ A primeyra questam: digo que esto pode aqueçer por duas causas | $(\mathbf{a} 4,22)$ A segunda questam digo que taaes infirmidades pestilençiaaes sam contagiosas $\mid(\mathbf{a} 3$ v, 24) Aqui se mouem duas questões

QUINTO. [<lat. quintus, -a,-um.] num. Que ocupa a posição do número cinco numa seqüência. • quinto: $(\mathbf{a} 2,21)$ Quinto \& derradeyro da sangria

QUITAR. [<lat. quitare.] v. Evitar; tirar. - quitar; quita: $(a 3,2)$ Quando ergo estes signaes apareçerem. he pera temer grande pestilencia.se ho senhor deus todo poderoso ho nom quitar \& estoruar. $\mid(\mathbf{b} 2,7)$ \& tal salsa he muyto boõa \& destruye \& quita ou tira toda podridom 


\section{$\mathrm{R}$}

RAIZ. [<lat. radix, -icis.] sf. Origem. - rayz: $(\mathbf{a} 3,6)$ TRes sam as causas da pestilencia. porque as vezes vee $m$ \& proçede ha pestilencia da rayz superior. \& as vezes proçede da rayz inferior. I (a3, 9) \& as vezes veem dambos de dous scilicet. da rayz superior \& da rayz jnferior juntamente. $\mid(\mathbf{3}, 10)$ Da rayz jnferior proçede segundo nos veemos que da priuada que esta açerca da camera ou de alguũ fedor particular de alguũ canno çujo se corrompe ho aar em substançia \& qualidade | (a3, 22) Da rayz superior veem \& aconteçe a pestilençia per virtude dos corpos de çima dos çeos. I ((a3v, 5) Da rayz superior \& jnferior juntamente proçede quando da jmpressam celestrial corrompente ho aar. \& podridam dos corpos mortos. ou lugares çujos se causa ho morbo ou ha chagua em ho homem

RAZÃO. vide POR.

RECEBER. [<lat. recipere.] $v$. Ser atingido por. - reçeber; reçebas: $(\mathbf{a} 4, \mathbf{2 1 )} \&$ os homens que se muyto esqueentam com grande trabalho ou grande yra. teem os corpos mais dispostos pera reçeber ha pestilencia $\mid\left(\mathbf{a} 6^{v}, 23\right)$ E por ysso te digo que em toda maneyra te guardes que nom reçebas do baffo de outrem

RECREAR. [<lat. recreare.] v. Restaurar. - recrea: $\left(\mathrm{a}^{\mathrm{v}}, \mathbf{9 - 1 0}\right)$ E assi como per ho boõ cheyro \& aromatico: se recrea o coraço $m \&$ o sprito do home $m$. assi emfraqueçe per o çujo fedor

REFORMAÇÃo. [<lat. reformatio, -onis.] sf. Restabelecimento. reformaçam: $(\mathrm{a} 2,12)$ \& a proueyto do pouoo: por conseruaçam dos saãos: \& reformaçam dos caydos

REGER. [<lat. regere.] v. Governar, guiar. - reger: $(\mathbf{b} 4 \mathbf{v}, \mathbf{2 2})$ \& qualquer que se per este modo reger escapara muytos perijgos da pestilencia $\rightarrow$ REgIMENTO. sm. Prescrição médica. • regimento: (a2, 1) Começa se huũ boô regimento muyto neçessario \& muyto proueitoso aos viuentes. $\rightarrow$ REINo. [<lat. regnum, $-i$.] $\mathrm{sm}$. Divisâa geo-politica regida por um rei. - regno, S. XIII: $(\mathbf{a 2}, 5)$ Feyto per ho reuerendissimo Senhor dom Raminto bispo arusiense: do regno de dacia. I (a2v, 19) A morte se ensanha ha çidade se filha \& toma dos jmigos. ho mar se faz cruel. \& ho sol se cobre scilicet. de nuueens. ho regno se muda. ho pouoo padeçe fame \& pestilencia

REGNO. vide REINO.

REGo. [or. obsc.] sm. Instalação para esgotamento sanitário. • regos: $\left(\mathbf{a}^{\mathrm{v}}\right.$, 2) em algũas casas estam as agoas çujas per dous \& tres dias \& as lançam per canos \& regos soterranhos: em os quaaes taes agoas çujas causam grandes fedores

RELÂMPAGO. [or. obsc.] Sf. Fulgor produzido no céu. • relampados: (a2v, 20-21) Quinto sinal. he quando se faze $m$ mujtas relampados \& trouoadas

REMEDIO. [<lat. remedium, -ii.] sm. • remedio; remedios. $\mathbb{G}$ Medicamento: $\left(\mathbf{b} 4^{\mathrm{v}}, \mathbf{1 0}\right)$ Item outro remedio | (a2, 18) Terçeyro. dos remedios della. I (a4v , 25) Dos remedios da pestilençia | $(\mathbf{a 6}, \mathbf{1 3})$ E quando assi for que companhia \& ajuntamento de pouoo se euite. emtam huse homem dos remedios abayxo scriptas I (a6v, 14) Eu çertamente todos estos remedios prouey Expediente, recurso: $(\mathbf{a} 5,12)$ Empero prometo te que muyto boõ remedio he fugir \& mudar o lugar apeçonhentado. ( $(\mathbf{b}, \mathbf{6}) \mathrm{E}$ tambem he grande remedio vazar o ventre $\mid(\mathbf{b} 2,9)$ E tambem a alegria do coraçom he gram remedio pera a saude do corpo. I $(\mathbf{b} 3, \mathbf{1 6})$ He ergo gramde remedio sy se alguem sentir apeçonhentado ou em tempo de pestilencia sentir estas cousas que escuse o somno

REPOUSAR. [<lat. repousare.] v. Descanso. • repousa: $(\mathbf{b} 3, \mathbf{2 0 )}$ que em o tempo do somno o sprito vital repousa:\& emtom a peçonha espalha se per os membros de toda parte 
RESOLUÇÃo. [<lat. resolutio, -onis.] sf. "Resolução de apostema, inchaçaõ, ou outra coisa semelhante, he quando dos póros do couro, o humor, que està na parte, sahe insensivelmente por um vapor, que transpira [....] (Nos apostemas venenosos, \& nos feitos por via de Crisis, he melhor a maturação, do que a Resolução [....] )" (Bluteau: $7,285)$ - resoluçam: $(\mathbf{a} 4, \mathbf{1 7})$ \& por tanto deues de notar que os corpos mays despostos a jnfirmidade \& a morte sam os corpos queentes \& que teem os poros mays largos: \& os corpos peçonhentos que tem os poros opilados: \& çarrados de mujtos humores. E portanto dos quaaes se faz ha grande resoluçam assy como sam os corpos desordenados em luxuria \& coyto. \& os que vaam ameude aos banhos.

RESPONDER. [<lat. respondere.] v. Dizer em resposta. •respondo: (b2v, 23) Mas diras tu. como sintira homem que está apeçonhentado \& ferido da pestilençia. A ysto te respondo que o homem que em tal dia he apeçonhentado nom come mujto

RETARDAMENTo. [de retardar.] sm. Desaceleração; impedimento. - retardamento: $\left(\mathbf{b}^{\mathrm{r}}{ }^{\mathrm{v}}, \mathbf{3}\right)$ \& se homem nom quiser cortar muytas veas juntamente: emtam leyxe yr a vea aberta ou ferida atee o retardamento do sangue

REVERENDO. [<lat. reverendus, $-a,-u m$, 'venerável'.] adj. Forma de referência a figuras eclesiásticas que não estejam nos escalóes mais altos da Igreja. - reuerendo, S. XV: $(\mathbf{a} 2,6) \mathrm{E}$ tralladado de latim em lingoagem per ho reuerendo padre frey Luys de ras $\rightarrow$ REVERENDíssimo. adj. Forma de referência a figuras eclesiásticas que estejam em escaloes mais altos da Igreja, como bispos, arcebispos, monsenhores ou padres mitrados. -reuerendíssimo: $(\mathbf{a} 2,4)$ Feyto per ho reuerendíssimo Senhor dom Raminto bispo arusiense: do regno de dacia

REVOGAR. [<lat. revocare.] v. Anular. - reuogar, s. XIII: $\left(\mathbf{b} 2^{v}, 7\right)$ escassamente pode nenhũa herua tal peçonha reuogar I $\left(\mathbf{b} 2^{v}, 13\right)$ A ysto digo breuemente que em tempo da pestilencia. logo despois de comer. se alguũ teuer desejo de dormir: que tal desejo se deue reuogar \& impedir per alguũ andar em jardijs ou em campos

RICO. [or. obsc.] sm. Que ganha muito além do necessário para que se sustente. • ricos: (b2, 1) estas cousas busquem se pera os ricos muyto bõas salsas ou salseamentos

ROGAR. [<lat. rogare.] v. Instar, insistir. - rogo: $\left(\mathbf{b}^{\mathrm{v}}{ }^{\mathrm{v}}, 6\right)$ posto que alguũs çirogiaães querem que lhe ponham triaga mas eu rogo mujto que se nom ponha

Rомі̃. [<lat. (mala) romana.] sf. Fruto da romãzeira, ou Punica granatum Linnaeus, familia das Punicáceas, planta arbustiva, originária da Pérsia, domesticada no Irã ao redor de 2.000 a. C., que possui tronco espinhento, acinzentado, folhas alternadas brilhantes, flores vermelhas, frutos globosos, coriáceos, amarelo-avermelhados com manchas escuras de polpa suculenta que contém numerosas sementes cor-de-rosa púrpura. A planta tem aplicação medicinal desde longa data, principalmente como antidiarréica e vermífuga. • romaãs: (bv , 22) Isso mesmo se euitem todos os fructos se nom forem azedos. assi como sam çirejas. romaãs. ou huũ pequeno de pero ou maçaã em lugar de meezinha, porque todo ho fructo traz podridom

ROMPIDO. [de romper.] adj. Drenado. - rompida: $\left(b 4^{v}, 2\right)$ E ysso mesmo por que a apostema mais çedo \& milhor seja madura \& seja rompida faça se meezinha em tal maneira

ROSA. vide ÁGUA. $\rightarrow$ ROSADO. [<lat. rosatus, $-a,-u m$.] adj. Levemente avermelhado. $\bullet$ rosado; rosada: $(\mathbf{a} 6,23)$ E tambem a casa seja aguada: \& em special em o alto veraão com vinagre rosado \& folhas de vinhas.

$\rightarrow$ ÁGUA RosAdA. vide ÁGUA.

RosTo. [<lat, rostrum, -i.] sm. Face. $\bullet$ rostro: $\left(\mathbf{a 4}^{\mathbf{v}}, \mathbf{7 )}\right.$ por razam do qual os medicos prudentes quando visita $m$ os enfermos deuem de star afastados delles: teendo o rostro pera genela ou fresta $\mid\left(\mathbf{a}^{\mathrm{v}}, 1\right)$ \& ysso meesmo he muyto boõ ameude lauar as maãos com augoa \& vinagre. \& alimpar o rostro \& despois cheyrar as maãos 
MARIA CARLOTA ET AL

RUA, [<lat. ruga, -ae.] sf. Caminho, - ruas: $(\mathbf{a} 5,23)$ \& per esta mesma causa euitaras \& esquiuaras todo ho fedor .scilicet. de estrebarias. de campos. de ruas. \& em special donde ha hi corpos mortos \& podres 


\section{S}

.s. [< latim scilicet, "a saber, isto é".] adv. Abreviatura do adv. latino scilicet. • s.: (a2v", 18) A morte se ensanha ha çidade se filha \& toma dos jmigos. ho mar se faz cruel. \& ho sol se cobre scilicet. de nuueens. I (a2v, 22) Quinto sinal. he quando se fazem mujtas relampados \& trouoadas. \& mayormente se veem da parte do meo dia .scilicet. do sul. I $(a 3,9)$ \& as vezes veem dambos de dous .scilicet. da rayz superior \& da rayz jnferior juntamente. I $(a 4,5)$ Segunda questam he esta. II Se taaes jnfirmidades pestilençiaes sam contagiosas .scilicet. se se apegam. I $(\mathrm{a} 4,6)$ A primeyra questam: digo que esto pode aqueçer por duas causas scilicet. por parte do agente \& por parte do paçiente | $(a 5,5)$ pollo qual deues de notar que segundo diz o grande medico .scilicet. dauid.l $(a 5,7)$ que primeiro se deue o homem de afastar do mal \& inclinar se ao bem scilicet. que homem primeiramente ha de confessar seus pecados humildosamente. I $(a 5,22)$ \& per esta mesma causa euitaras \& esquiuaras todo ho fedor .scilicet. de estrebarias. de campos. de ruas. \& em special donde ha hi corpos mortos \& podres $\mid\left(a 5^{v}, 18\right)$ \& faça se tambem com fumo de boõas heruas aqui scriptas .scilicet. baga de louro. junipero. vberiorgano I (a6, 14) emtam huse homem dos remedios abayxo scriptas .scilicet. de manhaã quando se alguũ aleuantar logo coma da aruda lauada em agoa limpa espargida com sal I (a6v, 17) AS cousas canfortatiuas sam estas scilicet. açafram. cassiafistola. chantagem. com todas as outras heruas que endereçam ho spirito interior I $(\mathrm{b} 2,20)$ se nom se a ydade ou outra cousa for em contrayro. assy como he em as molheres que som prenhes. ou em alguũ muyto fraco .scilicet. em alguũ que teem corrença ou fluxu do ventre I (b3", 16) sangre se em ha vea meaã daquelle meesmo braço. ou na vea epatica scilicet. em a vea que he açerca do dedo mais pequeno

SABOR. [<lat. sapor, -oris.] sm. Paladar; gosto. Entre os séculos XIV e XVI, os temperos, responsáveis pelo sabor final dos alimentos, foram considerados no âmbito das questões relativas à saúde, pois corrigiam problemas inerentes a alguns alimentos. Em geral, os sabores foram classificados em três tipos (Flandrin, 1996: 486-487; Bluteau: 7, 414): sabores quentes (o acre, o amargoso e o salgado); frios (o azedo, o austero e o acerbo); $e$ temperados (o gorduroso, o doce e o desenxabido ou insípido) [vide DIGESTÃo.] - sabor: $\left(\mathrm{b}^{v}, 7\right)$ mas porque muyto aqueenta. \& a queentura traz podridom. melhor me pareçe soo a cousa amargosa que queentura cheyro \& sabor

SABUGo. [<lat. sambucus, -i.] sm. Sabugueiro. Sambucus nigra Linnaeus da família das Caprifoliáceas. Planta arbustiva, originária da Europa. Possui tronco áspero acinzentado ou pardacento, folhas opostas verdes escuras, flores pequenas, brancas, reunidas em corimbos terminais com pedúnculo avermelhado, frutos drupas, globosos, ovais negro-violáceos ou branco-esverdeados. A planta tem aplicação medicinal desde longa data. A madeira é aproveitada para fins industriais, sendo empregada em curtumes para tingir peles (Cruz, 1979), Reza a lenda que a cruz de Cristo foi feita com madeira de sabugueiro, e por esse motivo, acreditava-se que dava azar cortar um tronco desta planta. Apresenta propriedades sudorifera, laxativa, diurética e refrescante (Balmé, 1978). No Brasil o chá de sabugueiro é utilizado, tradicionalmente, contra o sarampo, a catapora e a escarlatina (Cruz 1979). . sabugo: $\left(\mathrm{b} 4^{\mathrm{v}}, 3\right)$ Toma folhas de sabugo pisadas \& com mostar da pisada \& faze emprasto

SAIR. [<lat. salire.] $v$. • say; saya, s. XIII. $\mathbb{E}$ Ir para fora de casa: $\left(a 4^{v}, 22\right)$ \& se for neçessario que saya este em casa atee que saya o sol \& suba huũ boõ espaço sobre o nosso orizonte $\mathbb{1}$ Surgir: $\left(a 4^{v}, 23\right) \&$ se for neçessario que saya este em casa atee que saya o sol \& suba huũ boõ espaço sobre o nosso orizonte Desprender-se: $\left(\mathrm{b} 4^{\mathrm{v}}, 14\right)$ \& pisa todo muyto bem atee que vejas que quer pareçer que say destas cousas assy pisadas augoa ou çumo $\rightarrow$ SAÍDA. sf. Escoamento. - sayda, S. XIII: (b3 ${ }^{2}$, 4) porque pequena sangria: ou pequena sayda de sangue. mais fortemente esperta a peçonha segundo dicto he

SAL. [<lat. sal, -is.] sm. Condimento quente e seco, o mais comum dentre os temperos. Flandrin (1996: 484) refere uma obra de meados do século XIV que atribuía ao sal o papel de retirar a umidade de qualquer alimento, produzindo melhor diges tão [q.v.]. - sal, s.XIII: $(a 6,16)$ de manhaã quando se alguũ aleuantar logo coma da aruda lauada em agoa limpa espargida com sal \& noz nozcada hũa ou duas bem limpas

SALSA. [or. obsc.] sf. Molho. - salsa: $(\mathrm{b} 2,4)$ porque se forem pobres contentem se com arruda \& salua. noz nozcadas. pere $<x>$ il \& todo misturado com vinagre faz muy bõa salsa $\mid(b 2,6)$ E se nom forem 
muyto pobres: tomem cuminhos \& açafram \& misturem tudo com vinagre. \& tal salsa he muyto boõa \& destruye \& quita ou tira toda podridom. I (b2, 2) estas cousas busquem se pera os ricos muyto bõas salsas ou salseamentos $\rightarrow$ SALSEAMENTO. sm. Salsa. $\bullet$ salseamentos: $(\mathrm{b} 2,2)$ estas cousas busquem se pera os ricos muyto bõas salsas ou salseamentos

SÁlvia. [<lat. salvia, -ae.] sf. Salva, sálvia. Salvia officinalis Linnaues, família das Labiadas. Planta subarbustiva, originária da Europa, medindo, no máximo, $1 \mathrm{~m}$ de altura. Possui caule reto, folhas verdeacinzentadas ou cinza-prateadas, lanceoladas e largas, flores entre vermelhas e violáceas, agrupadas em espigas. A sálvia se apresenta como uma das ervas aromáticas mais populares desde a Antigüidade, por sua aplicação na cozinha, na terapêutica e também pelos princípios mágicos a ela atribuídos, contra malefícios e encantamentos (Balmé, 1978). A erva seca é usada em defumação. Apresenta propriedades diurética, adstringente, tônica, cicatrizante, antiinflamatória e anti-séptica. salua: (b2,3) porque se forem pobres contentem se com arruda \& salua. noz nozcadas. pere $<x>i l$

SANGUE. [<lat. sanguis, -inis.] sm. Líquiido vermelho que circula por veias e artérias. • sangue, 5.XV: (b3v, 3-4) emtam leyxe yr a vea aberta ou ferida atee o retardamento do sangue. I (b3v , 5) porque pequena sangria: ou pequena sayda de sangue. mais fortemente esperta a peçonha segundo dicto he.l (b3, 25) Estantes ergo assi estas cousas quando se homem sente ser tocado da peçonha pestilençial. logo naquelle meesmo dia mingue ho sangue: \& se sangre atee esmoreçer. I (b3v, 1) \& se sangre atee esmoreçer. porque pouco minguamento de sangue esperta a peçonha. I (b4,5) E se polla ventura for açerca das espadoas: minguaras o sangue com ventosas. I $(b 4,12)$ E se pella ventura sentir chagas despois de dormir: emtom ha de menuyr o sangue em a parte crucifixa I (b4, 19) sempre se mingue o sangue per modo contrayro I (b4, 20) E despois do sangue menuido se for muyto fraco emtom podera dormir despois do meo dia $\rightarrow$ SANGRAR. v. Aplicar s a $n$ g $r$ i a [q.v.]. • sangrar; sangra; sangre; sangrado, S. XV: (b2, 26) \& nom conuem dormir em aquelle dia que se sangrar \& abrir a vea. I (b3v, 10) \& sempre naquella meesma parte do corpo: em a qual ha doença ou chaga apareçer se deue de sangrar \& abrir a vea $\mid\left(b 3^{v}, 6\right)$ Item o homem que se sangra ou tenha pestenença ou nom. em nenhũa maneyra nom deue de dormir per todo o dia atee mea noyte $\mid(b 3 v, 12)$ E se pella ventura naçer a apostema de bayxo do braço direyto. sangre se em ho meo daquelle braço da vea meaã I ( b3ㄴ, 14) Se de bayxo do braço seestro ou esquerdo. sangre se em ha vea meaã daquelle meesmo braço I (b4, 14) porque se apareçer despois em o braço direyto:que se sangre em o braço esquerdo do figado: ou basilica: ou da meaã. I(b3, 25-26) Estantes ergo assi estas cousas quando se homem sente ser tocado da peçonha pestilençial. logo naquelle meesmo dia mingue ho sangue: \& se sangre atee esmoreçer. I (b3v, 20) E se a apostema for em ho pescoço. seja sangrado em a vea de çephalica açerca do dedo polegar em a maão daquelle meesmo lado. $\rightarrow$ SANGRIA. sf. Perda de sangue com finalidades terapêuticas, provocada ou pela secção de uma veia ou pela aplicação de sanguessugas. Cabe notar que o uso de sanguessugas viria a generalizarse apenas a partir do século XVII, não sendo comum na época de circulação do Regimento. • sangria: (a2, 21) Quinto \& derradeyro da sangria. I $(b 2,15)$ Da sangria. I $(b 2,16)$ SAngria huũa vez em huũ mes se pode bem fazer. se nom se a ydade ou outra cousa for em contrayro I (b2,21) Faça se ergo a sangria em a vea destra ou seestra ante de comer I $\left(b^{v}{ }^{v}, 4\right)$ porque pequena sangria: ou pequena sayda de sangue. mais fortemente esperta a peçonha segundo dicto he

SANTO. [<lat. sanctus, -a, - -um.] adj. Que tem carácter sagrado. - sancta, s. xIV: $(\mathrm{a} 2,7)$ mestre em sancta theologia da ordem de sam francisco I $(a 5,9)$ polla qual causa grande remedio he em tempo da pestilençia a sancta penitencia \& a confissam as quaaes preçedem \& sam muyto melhores que todas as mezinhas $\rightarrow$ SANTÍSSIMO. adj. Que tem carácter extremamente sagrado. • santissima, s. XV: (a2, 9)EM louuor da santissima trijndade $\rightarrow$ SÃO. $s m$. Santo. sam, S. XIII: $(\mathrm{a} 2,8)$ E tralladado de latim em lingoagem per ho reuerendo padre frey Luys de ras: mestre em sancta theologia da ordem de sam francisco

SAúde. [<lat, salus, -utis.] sf. Bem-estar físico. - saude; saudes, S. xIV; (b2, 9) E tambem a alegria do coraçom he gram remedio pera a saude do corpo I $\left(b 4^{v}, 25\right) \mathrm{com}$ virtude \& meezinha de nosso senhor jesu christo. sem o qual nom ha hy saude. I (a2,3) Começa se huũ boõ regimento muyto neçessario \& muyto proueitoso aos viuentes. \& per conseruaçam de suas saudes \& segurança das pestinençias 
$\mathrm{SE}^{1}$. [<lat. si.] $\mathbb{C}$ conj. $\bullet$ se: $\left(\mathrm{a} 2^{\mathrm{v}}, 21\right)$ \& mayormente se veem da parte do meo dia .scilicet. do sul, I (a2v, 7) \& emtam se isto mujto durar he pera temer de vijr grande pestilençia.l $(a 3,1)$ se ho senhor deus todo poderoso ho nom quitar \& estoruar I $\left(\mathrm{b} 2^{v}, 9\right)$ Mas dira alguũ. se o homem deue de euitar ho somno que fara homem se teuer o somno natural $\mid\left(a 4^{v}, 22\right) \&$ se for neçessario que saya este em casa atee que saya o sol I $\left(a 6^{v}, 25\right)$ Os olhos do aar empeçonhentado logo escureçem se estas cousas nom trouuer homem em ha maão $l(b, 3)$ \& se estas cousas nom poder auer faça se com vinagre $\mid(b, 7)$ \& se o ventre naturalmente se nom poder vazar. toma huũ cristel $\mathrm{I}\left(\mathrm{b}^{v}, 18\right) \&$ potagios se euitem: se nom forem azedos I ( $\mathrm{b}^{\mathrm{v}}$,21) Isso mesmo se euitem todos os fructos se nom fore $m$ azedos $\mid(\mathrm{b} 2,2)$ porque se forem pobres contentem se com arruda \& salua $\mid(b 2,5)$ E se nom forem muyto pobres: tomem cuminhos \& açafram \& misturem tudo com vinagre $\mid(b 2,26) \&$ se alguũ se agrauar de apostema ou sentir agrauado: ou se sentir apeçonhentado. em toda maneyra tal como este euite o somno I (b2v, 8) a qual cousa nom se faria se o homem andar em mouimento I (b2v, 12) A ysto digo breuemente que em tempo da pestilencia. logo despois de comer. se alguũ teuer desejo de dormir: que tal desejo se deue reuogar \& impedir per alguũ andar em jardijs ou em campos I (b2v, 16) Empero diz auiçena que se homem quiser dormir ha de beber hũa bõa vez de vinho ou çerueja ante de dormir | (b3, 13) Ergo per estes signaaes se sente homem apeçonhentado.mas se alguũ nom quiser creer: spere per huũ meo dia \& logo sentira apostema de bayxo dos braços I (b3, 16) He ergo gramde remedio sy se alguem sentir apeçonhentado ou em tempo de pestilencia sentir estas cousas que escuse o somno | (b3 $\left.{ }^{\mathrm{v}}, 1\right)$ \& se homem nom quiser cortar muytas veas juntamente: emtam leyxe yr a vea aberta ou ferida atee o retardamento do sangue I $\left(b 3^{v}, 11\right)$ E se pella ventura naçer a apostema de bayxo do braço direyto. sangre se em ho meo daquelle braço da vea meaã I (b3v', 13) Se de bayxo do braço seestro ou esquerdo. sangre se em ha vea meaã daquelle meesmo braço I (b3 ${ }^{\mathrm{v}}$, 17) E se açerca das partes vergonçosas. sangre se em o pee daquelle mesmo lado açerca do calcanhar I $\left(b 3^{v}, 19\right)$ E se a apostema for em ho pescoço. seja sangrado em a vea de çephalica açerca do dedo polegar em a maão daquelle meesmo lado.l (b3 ${ }^{v}$, 23) E se pela ventura apareçer açerca da orelha: faça se a sangria de çephaliça daquelle meesmo lado I (b4, 4) E se polla ventura for açerca das espadoas: minguaras o sangue com ventosas । (b4, 7) E se for em o espinhaço mingua sobre a vea que he chamada a pedica grande $\mid(b 4,9)$ E todas estas cousas se façam se homem nom dormir antes que conheça que tem a postema $\mid(\mathrm{b} 4,10)$ E se pella ventura sentir chagas despois de dormir: emtom ha de menuyr o sangue em a parte crucifixa I $(\mathrm{b} 4,13)$ porque se apareçer despois em o braço direyto: que se sangre em o braço esquerdo do figado: ou basilica: ou da meaã. I (b4, 15) E se apareçer a apostema de bayxo do braço direyto: emtom faça se como dito he do braço esquerdo I (b4, 24) E se despois creçer a postema:nom tema I (b2,17) SAngria huũa vez em huũ mes se pode bem fazer. se nom se a ydade ou outra cousa for em contrayro conj.: (a4, 4) Segunda questam he esta. II Se taaes jnfirmidades pestilençiaes sam contagiosas $\mid(a 4,5)$.scilicet. se se apegam

$\mathrm{SE}^{2}$. [<lat. sui, sibi,se.] pron. - se: $(\mathrm{b} 4,14)$ porque se apareçer despois em o braço direyto:que se sangre em o braço esquerdo do figado: ou basilica: ou da meaã. I $(b 4,16)$ E se apareçer a apostema de bayxo do braço direyto: emtom faça se como dito he do braço esquerdo I $\left(b 4^{v}, 22\right)$ \& qualquer que se per este modo reger escapara muytos perijgos da pestilencia $\left(\mathrm{b} 4^{\mathrm{v}}, 6\right)$ posto que alguũs çirogiaães querem que lhe ponham triaga mas eu rogo mujto que se nom ponha I $(\mathrm{b} 4,19)$ em maneira que sempre se mingue o sangue per modo contrayro I (b3 $\left.{ }^{v}, 18\right)$ E se açerca das partes vergonçosas. sangre se em o pee daquelle mesmo lado açerca do calcanhar I (b3v, 12) E se pella ventura naçer a apostema de bayxo do braço direyto. sangre se em ho meo daquelle braço da vea meaã. I $\left(b 3^{\vee}, 14\right)$ Se de bayxo do braço seestro ou esquerdo. sangre se em ha vea meaã daquelle meesmo braço I (b3v $\left.{ }^{v}, 10\right)$ \& sempre naquella meesma parte do corpo: em a qual ha doença ou chaga apareçer se deue de sangrar \& abrir a vea I (b3v, 6) Item o homem que se sangra ou tenha pestenença ou nom. em nenhũa maneyra nom deue de dormir per todo o dia atee mea noyte I (b3,23) Estantes ergo assi estas cousas quando se homem sente ser tocado da peçonha pestilençial. logo naquelle meesmo dia mingue ho sangue $\mid(b 3,25)$ \& se sangre atee esmoreçer I $(\mathrm{b} 3,21)$ \& emtom a peçonha espalha se per os membros de toda parte. I $(\mathrm{a} 2,1)$ Começa se huũ boõ regimento muyto neçessario \& muyto proueitoso aos viuentes | (a2, 25) Primeiro quando em huũ dia do estio \& do alto veraão se muda a manhaã muytas vezes l (a2v 16$)$ A morte se ensanha $\mathrm{I}\left(\mathrm{a} 2^{\mathrm{v}}, 17\right)$ ha çidade se filha \& toma dos jmigos I $\left(\mathrm{a} 2^{\mathrm{v}}, 18\right)$ ho mar se faz cruel. \& ho sol se cobre .scilicet. 
de nuueens I $\left(\mathrm{a} 2^{\mathrm{v}}, 19\right)$ ho regno se muda. I $\left(\mathrm{a} 2^{\mathrm{v}}, 20\right)$ Quinto sinal. he quando se fazem mujtas relampados \& trouoadas I $(\mathrm{a} 3,12)$ Da rayz jnferior proçede segundo nos veemos que da priuada que esta açerca da camera ou de alguũ fedor particular de alguũ canno çujo se corrompe ho aar em substançia \& qualidade I (a3,24) dos quaaes se corrompem os spiritos vitaes em ha creatura viuente I $\left(3^{*}, 1\right) \&$ de tal diz auicena no quarto liuro que muy ligeyramente se empeçonhentam os corpos da jndisposiçam ou da maa desposiçam dos çeos $\mid\left(a 3^{v}, 4\right)$ \& assy se geera ha pestilençia per esta causa $\mid$ $\left(a 3^{v}, 8\right)$ quando da jmpressam celestrial corrompente ho aar. \& podridam dos corpos mortos. ou lugares çujos se causa ho morbo ou ha chagua em ho homem I (a3 $\left.{ }^{v}, 14\right)$ mas ajnda tam sobejamente se agraua ha natureza que nom sinte sy ser ferida nem emferma I $(\mathrm{a} 3 \mathrm{v}, 21)$ Ergo he neçessario que todo enfermo se proueja de boõ fisico \& bem esperto I (a3v, 24) Aqui se mouem duas questões I $(a 4,5)$ Segunda questam he esta. If Se taaes jnfirmidades pestilençiaes sam contagiosas .scilicet. se se apegam I (a4, 16) E por tanto dos quaaes se faz ha grande resoluçam assy como sam os corpos desordenados em luxuria \& coyto I $(a 4,19)$ \& os homens que se muyto esqueentam com grande trabalho ou grande yra. teem os corpos mais dispostos pera reçeber ha pestilencia I $(\mathrm{a} 4,23)$ A segunda questam digo que taaes infirmidades pestilençiaaes sam contagiosas \& apegam se muy asinha I $\left(a 4^{v}, 17\right)$ A segunda que assi como se escreue em o terçeyro liuro dos amforismos I $(a 5,2)$ VIstas as causas da pestilencia. agora ajamos de veer per que modo \& como se deue home $m$ de guardar da pestilencia $\mid(\mathrm{a} 5,4)$ \& preseruar se della I $(a 5,5)$ primeiro se deue o homem de afastar do mal I $(a 5,6)$ \& inclinar se ao bem $\mid(a 5,18)$ Fechem se ergo as frestas ou genelas como dito he que vaam ou estam pera o sul atee hũa hora depois do meo dia $\mid(a 5,21)$ \& abram se as que stam pera o norte $\mid\left(a 5^{v}, 6\right)$ onde se lançam verças \& caldos podres que sobejam em taaes casas I $\left(\mathrm{a}^{\mathrm{v}}, 9\right)$ per ho boõ cheyro \& aromatico: se recrea o coraçom \& o sprito do homem $\mid(a 5 \mathrm{v}, 11)$ \& por tanto se deue bem de guardar a casa $\mid\left(a 5^{v}, 15\right)$ Apure se ergo \& asutileze se a casa per clara chama ou flama $\mid\left(a 5^{v}, 16\right)$ \& faça se fogo claro de lenha $\mid\left(a 5^{v}, 17\right)$ \& faça se tambem com fumo de boõas heruas aqui scriptas $1\left(a 5^{v}, 21\right)$ \& com lenho de aloes que he melhor de tudo posto que se nom pode comprar por pequeno preço I $\left(a 5^{\mathrm{v}}, 24\right)$ Item per esta meesma ca<u>sa se euite \& esquiue: todo ho inchamento do ventre que veem per muyto comer I $(a 6,6)$ Item per esta mesma causa se deue euitar ho banho de cada dia I $(\mathrm{a} 6,10)$ onde finalmente digo que toda multidom de pouoo \& comunidade em tal tempo se deue de euitar em quanto for possiuel $\mid(a 6,11)$ porque se nom apeçonhente homem do aar apeçonhentado I $(a 6,13)$ E quando assi for que companhia \& ajuntamento de pouoo se euite $\mid(a 6,14)$ de manhaã quando se alguũ aleuantar logo coma da aruda lauada em agoa limpa espargida com sal $\mid\left(26^{*}, 21\right)$ \& estas cousas prestam pera antre pouoo onde ligeyramente se aconteçe huũ seer empeçonhentado do outro | $(b, 1)$ Muyto saã cousa he que se laue a boca \& os olhos \& as maãos ameude cada dia com agoa rosada mesturada com vinagre | (b, 15) toma se ergo duas vezes no dia com boõ vinho claro \& auguado I $(b, 17)$ nem se tome mais da triaga que a quantidade de huũ piseo $\mid\left(\mathrm{b}^{v}, 14\right)$ a pestilençia que veem per causa queente ameude se acreçenta $\mid$ (bv", $18)$ \& potagios se euitem: se nom forem azedos I $\left(b^{v}, 20\right)$ Isso mesmo se euite $m$ todos os fructos se nom forem azedos $1(b 2,1)$ estas cousas busquem se pera os ricos $1(b 2,3)$ porque se forem pobres contentem se com arruda \& salua । (b2, 10) polla qual cousa deue se homem de guardar em tempo da pestilencia I (b2, 16) SAngria huũa vez em huũ mes se pode bem fazer I (b2, 21) Faça se ergo a sangria em a vea destra ou seestra ante de comer $\mid(b 2,25)$ empero sempre se tome temperadamente $\mid(b 2,26) \&$ nom conuem dormir em aquelle dia que se sangrar \& abrir a vea $\mid\left(b 2^{v}, 1\right)$ \& se alguũ se agrauar de apostema $\mid\left(b 2^{v}, 2\right)$ ou sentir agrauado: ou se sentir apeçonhentado. em toda maneyra tal como este euite o somno | (b2v, 7) a qual cousa nom se faria se o homem andar em mouimento I (b2v, 13) tal desejo se deue reuogar \& impedir per alguũ andar em jardijs ou em campos I (b2v 15$)$ em modo que o somno natural se possa tomar per hũa hora despois de comer 1 (b2v, 20) \& estes maaos humores se lançam fora per tomar hũa bõa vez de vinho boõ ou bõa çerueja. | (b3, 12) Ergo per estes signaaes se sente homem apeçonhentado.mas se alguũ nom quiser creer: spere per huũ meo dia \& logo sentira apostema de bayxo dos braços I $\left(b 4^{v}, 2\right)$ faça se meezinha em tal maneira I (b4, 9$)$ E todas estas cousas se façam se homem nom dormir antes que conheça que tem a postemal (b3 $\left.{ }^{v}, 24\right)$ E se pela ventura apareçer açerça da orelha; faça se a sangria de çephalica daquelle meesmo lado $\rightarrow$ sI, pron. • sy; si, s, XIII; $(a 5,15) \&$ por ysso quanto for possiuel taaes deuem de euitar \& de sy esquiuar as causas de tal podridom $\mid(b 3,3)$ mas todas estas cousas pode muyto bem euitar \& de sy lançar andando ou espaçando huũ pouco antre ho comer \& o dormir I $\left(a 4^{v}, 14\right)$ o vento do sul teem em si duas causas de 
de apodrentar $\mid\left(\mathrm{b} 2^{v}, 19\right)$ porque o homem estando em o somno traz em si muytos vapores $\mid\left(b 4^{v}, 9\right)$ mas eu queria antes que quando alguũ teuesse tal apostema que soruesse em si toda a triaga

SECO. [<lat. siccus, $-a,-$ um.] adj. Sem umidade. - seco, S. XV: (bv, 10) \& nom consinta emtrar ho aar seco. empero contorua os olhos \& squeenta a cabeça de cada huũ que ho ameude come

SEGUNDO'. [<lat. secundus, -a, um.] [DI num. Que ocupa o lugar equivalente a dois numa série. segunda; segunda: $(a 4,3)$ Segunda questam he esta $\mid(a 4,22)$ A segunda questam digo que taaes infirmidades pestilençiaaes sam contagiosas I $\left(a 4^{v}, 16\right)$ A segunda que assi como se escreue em o terçeyro liuro dos amforismos $\mathbb{a d v}$. Em segundo lugar. segundo: $(\mathrm{a} 2,17)$ Segundo das cousas della

SEGUNDO ${ }^{2}$. [<lat. secundum.] conj. • segundo, s. XIII. Conforme: (a2v, 13) \& segundo diz aristoteles em os metauros I (b3 $\left.{ }^{v}, 5-6\right)$ porque pequena sangria: ou pequena sayda de sangue. mais fortemente esperta a peçonha segundo dicto he Porque: (a3, 10) Da rayz jnferior proçede segundo nos veemos que da priuada que esta açerca da camera ou de alguũ fedor particular de alguũ canno çujo se corrompe ho aar em substançia \& qualidade I (b3, 19) \& assi segundo estas cousas he assaz manifesto: que em o tempo do somno o sprito vital repousa

SEGURANÇA. [de segurar.] sf. Situação na qual não há razão para temores. - segurança, S. XIV: (a2, 3) Começa se huũ boõ regimento muyto neçessario \& muyto proueitoso aos viuentes. \& per conseruaçam de suas saudes \& segurança das pestinençias $\rightarrow$ SEGURAMENTE. [de seguro.] adv. Com segurança. $\bullet$ seguramente, $s$. XV: $(b, 5) \&$ assi guardando estas cousas seguramente entraras em pouoo ou amtre gente

SEMPRE [<lat. semper.] adv. • sempre, S. XIII. Continuamente: $(\mathrm{a} 6,4)$ E por tanto diz auiçena em o quarto do canone. que aquelles que sempre querem encher seus ventres que abreuiam seus dias $\mid\left(a 6^{v}, 7\right)$ \& emtam leuaua commigo huũa sponja ou paão enssopado em vinagre: \& sempre no punha nos narizes \& na boca. I (b, 10) Em casa sempre este fogo açesol $(\mathrm{b} 3,11)$ porque o homem ja apeçonhentado em todas as horas teem grande desejo de dormir. porque a peçonha intrinseca pertorua o sprito vital. em modo que sempre deseja folgança. Todas as vezes: $\left(\mathrm{b3}^{*}{ }^{*}, 9\right)$ Item o homem que se sangra ou tenha pestenença ou nom. em nenhũa maneyra nom deue de dormir per todo o dia atee mea noyte: \& sempre naquella meesma parte do corpo: em a qual ha doença ou chaga apareçer se deue de sangrar \& abrir a vea I $(b 4,19) \&$ assi dos outros lugares em os quaaes apareçer a apostema: em maneira que sempre se mingue o sangue per modo contrayro I $(\mathrm{b} 4,22)$ E despois do sangue menuido se for muyto fraco emtom podera dormir despois do meo dia. \& sempre antes do meo dia sera em continuo mouimento $\mathbb{E} \equiv m$ todos os casos: $(\mathrm{b} 2,14)$ mas qualquer com muyto prazer \& alegria sempre espere de muyto viuer $\rightarrow$ PARA SEMPRE. Eternamente. - pera sempre: $\left(b 4^{v}, 26\right)$ sem o qual nom ha hy saude. \& da benta virgem maria sua madre seja gloria \& louuor pera sempre

SENHOR. [<lat. senior, -oris.] $5 m$. Amo, dono: $\left(b 4^{v}, 24\right)$ \& qualquer que se per este modo reger escapara muytos perijgos da pestilencia com virtude \& meezinha de nosso senhor jesu christo Forma de tratamento. - senhor, S. XIII: (a2, 4) Feyto per ho reuerendíssimo Senhor dom Raminto bispo arusiense: do regno de dacia I $(\mathrm{a} 3,1)$ Quando ergo estes signaes apareçerem. he pera temer grande pestilencia. se ho senhor deus todo poderoso ho nom quitar \& estoruar

SENSUAlmente. [de sensual.] adv. Por meio dos sentidos. • senssualmente: (a3,7) TRes sam as causas da pestilencia. porqueas vezes veem \& proçede ha pestilencia da rayz superior. \& as vezes proçede da rayz jnferior. em tanto que senssualmente pareçe aos homens mudança do aar

SENTIR. [<lat. sentire.] v. Experimentar a sensação de algo. • sentir; sente; sinte; sentira; sintira, S. XIV: (b2v, 1) \& se alguũ se agrauar de apostema ou sentir agrauado I $\left(\mathrm{b} 22^{*}, 2\right)$ ou se sentir apeçonhentado. em toda maneyra tal como este euite o somno I (b3, 17) He ergo gramde remedio sy se alguem sentir apeçonhentado ou em tempo de pestilencia sentir estas cousas que escuse o somno | (b4, 10) E se pella ventura sentir chagas despois de dormir: emtom ha de menuyr o sangue em a parte crucifixa I (b2v, 26) 
logo despois de comer tem desejo de dormir. \& sente de bayxo de frio grande quententura I (b3, 12) Ergo per estes signaaes se sente homem apeçonhentado I (b3, 24) Estantes ergo assi estas cousas quando se homem sente ser tocado da peçonha pestilençial. logo naquelle meesmo dia mingue ho sangue I $(\mathrm{a} 3 \mathrm{v}, 15)$ mas ajnda tam sobejamente se agraua ha natureza que nom sinte sy ser ferida nem emferma. I (b3, 14) mas se alguũ nom quiser creer: spere per huũ meo dia \& logo sentira apostema de bayxo dos braços $1(\mathrm{~b} 2 \mathrm{v}, 21)$ Mas diras tu. como sintira homem que está apeçonhentado \& ferido da pestilençia

SER. [<lat. sedere e esse.] v. lig; v. aux. - seer; ser; serem; he; som; som; sam; sam; sera; seja; sejam; for: $\left(a 6^{\vee}, 21\right)$ \& estas cousas prestam pera antre pouoo onde ligeyramente se aconteçe huũ seer empeçonhentado do outro I $\left(\mathrm{a}^{\vee}, 15\right)$ mas ajnda tam sobejamente se agraua ha natureza que nom sinte sy ser ferida nem emferma. I (a2v, 10) Tercio he quando ha hy muytas moscas em ha terra. porque emtam pareçe ho aar ser empeçonhentado I $\left(a 4^{v}, 4\right)$ mais ajnda digo que em o tempo pestilençial nenhuũ nom deue de star em ajuntamento do pouoo. porque podera ser que alguũ delles sera apeçonhentado ou feridol $(b 4,26)$ E se despois creçer a postema: nom tema. porque tal apostema lança o mal de fora \& faz o homem ser muyto saão I $(\mathrm{b} 3,24)$ Estantes ergo assi estas cousas quando se homem sente ser tocado da peçonha pestilençial I $\left(b^{v}, 12\right)$ [?] \& por ysso nom pareçe se neçessario mas antes jnpidoso I $(a 3,16)$ açerca das quaes muytos medicos sam emganados. porque nom conheçem taes febres serem pestilençiaes. nem ho creem $\mid\left(\mathrm{a}^{*}, 7\right)$ \& por serem assi podres causam tal fedor \& doença que muyto empeçe $\mid\left(\mathrm{a}^{\mathrm{v}}, 3\right)$ \& prinçipalmente quando he ho vento meridional. ou da parte de estrela do Sul $\mid\left(a 2^{v}, 5\right)$ Segundo sinal he quando e $m$ tal estio muytas vezes escureçem: ou pareçem escureçer os dias I (a2v, 8) \& emtam se isto mujto durar he pera temer de vijr grande pestilençia I (a2v, 9) Tercio he quando ha hy muytas moscas em ha terra. I (a2v, 12) Quarto sinal he quando ha cometa pareçe voar I $\left(a 2^{v}, 20\right)$ Quinto sinal. he quando se fazem mujtas relampados \& trouoadas I (a2v, 22) Sexto sinal he quando veem muytos ventos do meo dia I (a2v, 25) Quando ergo estes signaes apareçerem. he pera temer grande pestilencia I (a3, 21) \& tambem esta causa he as vezes particular I (a3 $\left.{ }^{v}, 10\right)$ \& tal morbo ou jnfirmidade as vezes he febre I $\left(\mathrm{a} 3^{\mathrm{v}}, 12\right)$ ho aar jnspirado as vezes he peçonhento $\mid\left(\mathrm{a} 3^{\mathrm{v}}, 13\right)$ em tanto que ha natureza he per muytas manejras agrauada $\mid\left(\mathrm{a}^{\mathrm{v}}{ }^{\mathrm{v}}, 21\right)$ Ergo he neçessario que todo enfermo se

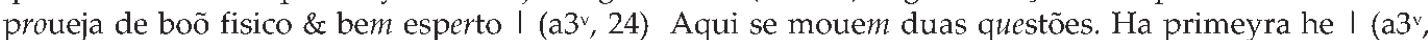
25) Porque he assy que huũ morre \& ho outro nom I (a4,3) Segunda questam he esta I (a4, 11)Da parte do paciente que aquelle he mays desposto aa morte que aquel outro I $(\mathrm{a} 4 \mathrm{v}, 10)$ a tal doente de pestilençia he boõ per alguũs dias mudar a camera $\mid\left(a 4^{v}, 18\right)$ Ho sul he vento inchado I $\left(a 4^{v}, 20\right)$ pola qual cousa boõ he ao saão em tempo da pestilençia quando venta vento sul estar em casa per todo o dia $\mid(a 5,9)$ polla qual causa grande remedio he em tempo da pestilençia a sancta penitencia \& a confissam I (a5, 12) Empero prometo te que muyto boõ remedio he fugir I (a5v, 13) porque nom entre em ella ho aar peçonhentado porque ho aar apeçonhentado he humido I $\left(\mathrm{a} 5^{\mathrm{v}}, 21\right)$ \& com lenho de aloes que he melhor de tudo I $(\mathrm{a} 6,20)$ Mas em tempo de pestilencia milhor he estar em casa que andar fora. I $(a 6,21)$ nem he saão andar per a villa ou çidade $\mid(a 6,24)$ \& ysso meesmo he muyto boõ ameude lauar as maãos com augoa \& vinagre $\mid\left(a 6^{v}, 2\right)$ \& tambem he boõ assi em ho inuerno como no veraão cheirar cousas azedas $\mid(b, 1)$ Muyto saã cousa he que se laue a boca $\mid(b, 6)$ E tambem he grande remedio vazar o ventre I (b, 13) Quanto he ao teu mantijmento digo te que a triaga te he muyto proueytosa: assi saãos como aos enfermos $\mid(b, 14)$ \& tal salsa he muyto boõa $\mid(b 2,6)$ E tambem a alegria do coraçom he gram remedio pera a saude do corpo $(\mathrm{b} 2,18)$ se nom se a ydade ou outra cousa for em contrayro. assy como he em as molheres que som prenhes. ou em alguũ muyto fraco I (b2v, 24) A ysto te respondo que o homem que em tal dia he apeçonhentado nom come mujto. porque he cheo de maos humores I (b3, 16) He ergo gramde remedio sy se alguem sentir apeçonhentado ou em tempo de pestilencia sentir estas cousas que escuse o somno I (b3,19) \& assi segundo estas cousas he assaz manifesto I (b3 $\left.{ }^{v}, 16\right)$ em a vea que he açerca do dedo mais pequeno I (b4, 2) ou da vea que he açerca do dedo menor I (b4, 3) ou açerca do articulo que he de muytos medicos chamada basilica I $(\mathrm{b} 4,8)$ E se for em o espinhaço mingua sobre a vea que he chamada a pedica grande I $(\mathrm{b} 4,12)$ emtom ha de menuyr o sangue em a parte crucifixa que he a parte contrayra I $(a 5 \mathrm{v}, 6) \mathrm{em}$ tal casa como esta morrem os homens mais azinha \& em outra nom como dito he I (b4, 17) emtom faça se como dito he do braço esquerdo. I $\left(b 33^{v}, 6\right)$ pequena sangria: ou pequena sayda de sangue. mais fortemente esperta a peçonha segundo dicto he I 
$(\mathrm{a} 5,19)$ Fechem se ergo as frestas ou genelas como dito he que vaam ou estam pera o sul I (bv , 2) E em os mantijmentos guarte das cousas queentes. assi como som pigmenta \& alhos $\mid\left(b^{v}, 15\right)$ \& por tanto todos os mantijmentos quanto som de mais leue digestam I $\left(\mathrm{b}^{\mathrm{v}}, 16\right)$ tanto som milhores I $(\mathrm{b} 2,19)$ assy como he em as molheres que som prenhes I (a2, 24) SIgnaes pronosticos da pestilencia quanto ao presente pertençe: sam sete I $\left(\mathrm{a} 2^{v}, 24\right)$ Sexto sinal he quando veem muytos ventos do meo dia. porque taes ventosidades sam muyto çujas \& muito velhacas | $(a 3,4)$ TRes sam as causas da pestilencia I (a3, 15) \& daly procedem febres pestilençiaes. açerca das quaes muytos medicos sam emganados I (a3v, 20) E por tanto muytos medicos que em os enfermos soomente esguardam as ourinas superficialmente falam. \& lygeyramente sam emganados $\mid\left(3^{\mathrm{v}}, 22\right)$ E estas cousas sam assy ditas das causas das pestilençia $\mid$ $(a 4,4)$ Se taaes jnfirmidades pestilençiaes sam contagiosas $\mid(a 4,13)$ \& por tanto deues de notar que os corpos mays despostos a jnfirmidade \& a morte sam os corpos queentes \& que teem os poros mays largos $\mid(\mathbf{a} 4,17)$ E por tanto dos quaaes se faz ha grande resoluçam assy como sam os corpos desordenados em luxuria \& coyto I (a4, 23) A segunda questam digo que taaes infirmidades pestilençiaaes sam contagiosas \& apegam se muy asinha $\mid(a 5,10)$ polla qual causa grande remedio he em tempo da pestilençia a sancta penitencia \& a confissam as quaaes preçedem \& sam muyto melhores que todas as mezinhas $\mid(a 6,2)$ porque os corpos cheos dos maaos humores sam mais asinha empeçonhentados I (a6 v , 17) AS cousas canfortatiuas sam estas I ( $\left.\mathrm{b}^{\mathrm{v}}, 22\right)$ Isso mesmo se euitem todos os fructos se nom forem azedos. assi como sam çirejas. romaãs I ( $\left.\mathrm{b}^{\mathrm{v}}, 25\right) \mathrm{E}$ as speçias que comuummente conuem a comer. sam gingiure. canela. cuminhos. froles de heruas cheyrosas. \& açafram | $(4,22) \&$ sempre antes do meo dia sera em continuo mouimentol $\left(a 4^{v}, 4\right)$ porque podera ser que alguũ delles sera apeçonhentado ou ferido I $(\mathrm{a} 6,19)$ \& ysto seja mayormente em tempo de neuoeiro \& chựoso I $(a 6,22)$ E tambem a casa seja aguada $\mid(b, 20)$ \& a triaga seja delida em ho vaso ou copo em que ha tomares I (b3 $\left.{ }^{v}, 19\right) \mathrm{E}$ se a apostema for em ho pescoço. seja sangrado em a vea de çephalica açerca do dedo polegar em a maão daquelle meesmo lado I (b4v, 1) E ysso mesmo por que a apostema mais çedo \& milhor seja madura $\mid\left(b 4^{v}, 2\right)$ \& seja rompida faça se meezinha em tal maneira $\mid\left(b^{v}, 17\right)$ pela manhaã sejam os manjares cozidos: \& de noyte assados $(b 2,18)$ se nom se a ydade ou outra cousa for em contrayro. I $\left(a 4^{v}, 22\right)$ \& se for neçessario que saya este em casa atee que saya o sol \& suba huũ boõ espaço sobre o nosso orizonte. $(a 5,14)$ \& por ysso quanto for possiuel taaes deuem de euitar \& de sy esquiuar as causas de tal podridom. $I(a 6,10)$ toda multidom de pouoo \& comunidade em tal tempo se deue de euitar em quanto for possiuel I $(26,12)$ E quando assi for que companhia \& ajuntamento de pouoo se euite $\mid(\mathrm{b} 2,22) \&$ despois que a vea for ferida ou aberta aproueyta muyto tomar muyto prazer I (b3v , 19) E se a apostema for em ho pescoço. seja sangrado em a vea de çephalica açerca do dedo polegar em a maão daquelle meesmo lado I $(b 4,5)$ E se polla ventura for açerca das espadoas: minguaras o sangue com ventosas I (b4,7) E se for em o espinhaço mingua sobre a vea que he chamada a pedica grande $\mid(\mathrm{b} 4,20) \mathrm{E}$ despois do sangue menuido se for muyto fraco emtom podera dormir despois do meo dia

SERPILHO. [<lat. serpyllum, $-i$ ou serpillum, -i.] sm. Thymus serpillum Linnaeus, familia das Labiadas. Erva originária da Europa, de cerca de $20 \mathrm{~cm}$ de altura. Possui haste ereta ou prostrada, lenhosa, folhas planas, verdes, pequenas e pubescentes, flores pequenas, avermelhadas agrupadas em capítulos terminais. O serpilho é conhecido por suas propriedades terapêuticas desde os tempos antigos, tendo também uso culinário (Balmé, 1978). serpillo, S. XV: $(\mathrm{b} 4 \mathrm{v}, 11)$ Tomaras hũa herua que chamam barba jouis. \& outro que chamam serpillo que acharas ao boticairo

SERVIDOR. [<lat. servitor, -oris.] sm. Servo. - seruidores, S. XV: $\left(a 4^{\vee}, 8\right)$ \& assi ho deuem de fazer os seruidores dos enfermos

SESTRo. [<lat. sinistrus, $-a_{f}-u m$.] adj. Que está do lado esquerdo. • seestro; seestra: $\left(\mathbf{b 3}{ }^{\mathrm{v}}, 14\right)$ Se de bayxo do braço seestro ou esquerdo. sangre se em ha vea meaã daquelle meesmo braço I (b2, 21-22) Faça se ergo a sangria em a vea destra ou seestra ante de comer

SETE. [<lat. septem.] num. - sete, S. XIV: $(\mathrm{a} 2,24)$ SIgnaes pronosticos da pestilencia quanto ao presente pertençe: sam sete 
SEU. [<lat. suus, sua, suum.] pron. poss. Que é próprio de algo ou alguém. • seus; sua; suas: (a5, 7) que homem primeiramente ha de confessar seus pecados humildosamente I $(a 6,4)$ que aquelles que sempre querem encher seus ventres $\mid(a 6,5)$ que abreuiam seus dias $\mid(a 6,5)$ \& tempos da sua fim \& minguam sua vida I (b, 22) \& nom jantaras atee ho meo dia porque possa a triaga em o corpo fazer sua operaçam I (b4" 25) \& da benta virgem maria sua madre I (a2, 3) Começa se huũ boõ regimento muyto neçessario \& muyto proueitoso aos viuentes. \& per conseruaçam de suas saudes \& segurança das pestinençias

SEXTO. [<lat. sextus, - $a_{r}-u m$.] num. O que ocupa a posição seis numa série. • Sexto, S. XV: (a2v, 22) Sexto sinal he quando veem muytos ventos do meo dia. porque taes ventosidades sam muyto çujas \& muito velhacas

$\mathrm{SI}^{1}$. vide ASSIM.

$\mathrm{SI}^{2}$, vide $\mathrm{SE}$

SILIGEM. [<lat. siligo, -inis.] sf. Trigo comum (Costa Roque, 1979: 339, n. 102, em que refere c.p. de Maria Helena Rocha Pereira, que remetera o A. ao Lexique des termes de Botanique en Latin, de J. André, Paris, 1956). - siligem, s. Xv: $(b 4 v, 13)$ \& ysso mesmo toma chantagem \& siligem (vay te ao boticayro)

SINAL. [<lat. signalis, -e.] Sm. Indício. • sinal, s. XII; signaaes; signaes, S XV: (a2v, 5) Segundo sinal he quando em tal estio muytas vezes escureçem: ou pareçem escureçer os dias I (a2v, 12) Quarto sinal he quando ha cometa pareçe voar I $\left(\mathrm{a} 2^{\mathrm{v}}, 20\right)$ Quinto sinal. he quando se fazem mujtas relampados \& trouoadas $1\left(\mathrm{a} 2^{\mathrm{v}}, 22\right)$ Sexto sinal he quando veem muytos ventos do meo dia $1(\mathrm{a} 2,16)$ Dos signaes pronosticos da pestilençia I $(a 2,23)$ SIgnaes pronosticos da pestilencia quanto ao presente pertençe: sam sete I (a2v, 25) Quando ergo estes signaes apareçerem. he pera temer grande pestilencia. I (a2, 22) Dos signaaes. Capitollo primeyro I $(b 3,12)$ Ergo per estes signaaes se sente homem apeçonhentado

só. $\left[<\right.$ lat. solus, $-a,-u m$.] adv. Apenas. - soo, s. Xv: $\left(b^{v}, 6\right)$ mas porque muyto aqueenta. \& a queentura traz podridom. melhor me pareçe soo a cousa amargosa que queentura cheyro \& sabor $\rightarrow$ SOMENTE. adv. Apenas. - soomente, S. XV: $\left(\mathrm{a}^{2}\right.$, 19) E por tanto muytos medicos que em os enfermos soomente esguardam as ourinas superficialmente falam. \& lygeyramente sam emganados

SOBEJAR. [ de sobejo, "o que sobra".] v. Sobrar, estar em excesso. - sobejam, s. XIV: (a5v, 7) \& daqui veem que em tal casa como esta morrem os homens mais azinha \& em outra nom como dito he mesmo onde se lançam verças \& caldos podres que sobejam em taaes casas. $\rightarrow$ SOBEJAMENTE adv. Fortemente. - sobejamente, s. Xv: $\left(\mathrm{a} 3^{\mathrm{v}}, 14\right)$ mas ajnda tam sobejamente se agraua ha natureza que nom sinte sy ser ferida nem emferma

SOBRe. [<lat. super.] prep. - sobre, s. XIII. II Por cima de: $\left(a 4^{v}, 24\right)$ \& se for neçessario que saya este em casa atee que saya o sol \& suba huũ boõ espaço sobre o nosso orizonte. em o espinhaço mingua sobre a vea que he chamada a pedica grande

sol. [<lat. sol, -is.] sm. Estrela cuja luz emitida, aliada ao movimento de rotação da Terra, divide cada periodo de 24 horas numa dada região da Terra em dias e noites. - sol, s. XV: $\left(\mathrm{a} 2^{\mathrm{v}}, 18\right)$ A morte se ensanha ha çidade se filha \& toma dos jmigos. ho mar se faz cruel. \& ho sol se cobre scilicet. de nuueens $\mid\left(a 4^{v}, 23\right) \&$ se for neçessario que saya este em casa atee que saya o sol \& suba huũ boõ espaço sobre o nosso orizonte

sono.[<lat. somnus, -i.] sm. Desejo de ou o próprio dormir. - somno, s. XV: (b2v, 3) em toda maneyra tal como este euite o somno I (b2v,4) porque em ho somno ha queentura intrinseca I (b2v,9) Mas dira algut̃. se o homem deue de euitar ho somno I $\left(\mathrm{b} 2^{\mathrm{v}}, 10\right)$ que fara homem se teuer o somno natural I (b2v, 14) em modo que o somno natural se possa tomar per hũa hora despois de comer $1\left(\mathrm{~b} 2^{v}\right.$, 18$)$ o homem estando em o somno traz em si muytos vapores I $(b 3,18)$ sy se alguem sentir apeçonhentado ou em 
tempo de pestilencia sentir estas cousas que escuse o somno \& ho euite quanto poder I (b3, 20) \& assi segundo estas cousas he assaz manifesto: que em o tempo do somno o sprito vital repousa

SOPA. [or. obsc.] sf. Pedaços de pão imersos em matéria lígiiida, como leite, caldo, vinho. $\bullet$ sopa, S. XV: (a6, 18) E ysto nom poder auer. emtam coma paão ou hũa sopa molhada em vinagre $\rightarrow$ ENSOPAR. $v$. Embeber. enssopado, s. XV: $\left(a 6^{v}, 7\right)$ \& emtam leuaua commigo huũa sponja ou paão enssopado em vinagre

SORVER. [<lat. sorbere.] v. Absorver, engolir. - soruesse, S. XIV: $\left(\mathbf{b 4}^{\mathrm{v}}{ }^{\mathrm{y}}, 8-9\right)$ mas eu queria antes que quando alguũ teuesse tal apostema que soruesse em si toda a triaga

SOTERRANHo. [<lat. subterraneus, -a, -um.] adj. Que está sob a terra. - soterranhos, s. XIV: (a5v, 2-3) em algũas casas estam as agoas çujas per dous \& tres dias \& as lançam per canos \& regos soterranhos: em os quaaes taes agoas çujas causam grandes fedores

SUbIR [<lat. subire.] v. Elevar-se. • suba: $\left(a 4^{\mathrm{v}}, 23\right)$ \& se for neçessario que saya este em casa atee que saya o sol \& suba huũ boõ espaço sobre o nosso orizonte

SUbSTÂNCIA. [<lat. substantia, -ae.] sf. Essência. • substançia, s. XV: (a3, 13) Da rayz jnferior proçede segundo nos veemos que da priuada que esta açerca da camera ou de alguũ fedor particular de alguũ canno çujo se corrompe ho aar em substançia \& qualidade

sujo. [<lat. sucidus,-a, um, 'úmido'.] adj. Sem limpeza. • çujo; çujos; çujas, s.xIV: $\left(a 5^{\vee}, 11\right)$ E assi como per ho boõ cheyro \& aromatico: se recrea o coraçom \& o sprito do homem. assi emfraqueçe per o çujo fedor I $(\mathrm{a} 3,19)$ As vezes jsso mesmo veem de corpos mortos. ou de corrupçom de pauees \& charcos ou chafarizes çujos podres \& federentos $\mid\left(a 3^{v}, 8\right)$ da jmpressam celestrial corrompente ho aar. \& podridam dos corpos mortos. ou lugares çujos se causa ho morbo ou ha chagua em ho homem I(a2v 24$)$ taes ventosidades sam muyto çujas \& muito velhacas $\mid\left(a 5^{v}, 1\right)$ em algũas casas estam as agoas çujas per dous \& tres dias $\mid\left(a 5^{\vee}, 3\right)$ em os quaaes taes agoas çujas causam grandes fedores $\rightarrow$ CANO SUJO. vide CANO.

sumo. [< lat. succu.] sm. Líquiido. $\bullet$ çumo, s. XIV: $\left(\mathrm{b} 4{ }^{v}, 15\right)$ \& pisa todo muy to bem atee que vejas que quer pareçer que say destas cousas assy pisadas augoa ou çumo I $\left(\mathrm{b} 4^{v}, 16\right)$ emtom toma aquelle çumo \& mistura ho com leyte de mulher

Sul. [<fr. sud.] • sul. sm. relampados \& trouoadas. \& mayormente se veem da parte do meo dia scilicet. do sul I (a4v, 13) E por tanto digo que a tal doente de pestilençia he boõ per alguũs dias mudar a camera: \& muytas vezes teer as frestas pera ho norte ou pera o leuante abertas. \& as genelas ou frestas pera ho meo dia ou pera ho sul estem çarradas I $(\mathrm{a} 4 \mathrm{v}, 14)$ porque o vento do sul teem em si duas causas de de apodrentar I (a5, 20) Fechem se ergo as frestas ou genelas como dito he que vaam ou estam pera o sul atee hũa hora depois do meo dia $\mid\left(a 2^{v}, 4\right)$ em modo que de manhaã pareçe chuuosa \& chea neuoa. \& depois ventosa. \& prinçipalmente quando he ho vento meridional. ou da parte de estrela do Sul 0 vento do sul: $\left(a 4^{v}, 18\right)$ Ho sul he vento inchado \& agraua o ouuido fere o coraçam $\rightarrow$ SUL. adj. Meridional: (a5, 18) E per conseguinte todo o coyto \& toda luxuria. \& tambem o vento meridional ou sul: o qual naturalmente apeçonhenta I $\left(\mathrm{a} 4^{\mathrm{v}}, 21\right)$ pola qual cousa boõ he ao saão em tempo da pestilençia quando venta vento sul estar em casa per todo o dia

SUPERFICIALMENTE, [de superficial.] adv. Com superficialidade. superficialmente: $\left(\mathrm{a} 3^{\mathrm{v}}, 19-20\right)$ E por tanto muytos medicos que em os enfermos soomente esguardam as ourinas superficialmente falam. \& lygeyramente sam emganados

SUPERIOR. [<lat. superior, -oris.] adj. Que está em posição mais alta. • superior, S. XV: $(\mathrm{a} 3,6)$ TRes sam as causas da pestilencia. porque as vezes veem \& proçede ha pestilencia da rayz superior $\mid(a 3,9)$ \& as 
MARIA CARLOTAET AL

vezes veem dambos de dous scilicet. da rayz superior \& da rayz jnferior juntamente | (a3, 22) Da rayz superior vee $m \&$ aconteçe a pestilençia per virtude dos corpos de çima dos çeos I (a3 $\left.{ }^{v}, 5-6\right)$ Da rayz superior \& jnferior juntamente proçede quando da jmpressam celestrial corrompente ho aar. \& podridam dos corpos mortos. ou lugares çujos se causa ho morbo ou ha chagua em ho homem 
TAL.[<lat. talis, -e.] pron. demonst. $\bullet$ tal; taes, S. XIII; taaes. Esse; semelhante: $(\mathrm{a} 5,16)$ \& por ysso quanto for possiuel taaes deuem de euitar \& de sy esquiuar as causas de tal podridom $\mid\left(\mathrm{a} 2^{v}, 5\right)$ Segundo sinal he quando e $m$ tal estio muytas vezes escureçem: ou pareçem escureçer os dias I (a3, 25) \& de tal diz auicena no quarto liuro I $\left(\mathrm{a} 3^{\mathrm{v}}, 9\right)$ \& tal morbo ou jnfirmidade as vezes he febre $\mid\left(\mathrm{a}^{\mathrm{v}}, 22\right) \mathrm{E}$ tal fumo entre per a boca \& per os narizes $\mid\left(a 6^{v}, 12\right)$ \& assi escapey de tal pestilencia. $\mid(b 2,6)$ \& tal salsa he muyto boõa \& destruye \& quita ou tira toda podridom $\mid\left(b 2^{v}, 7\right)$ em modo que escassamente pode nenhũa herua tal peçonha reuogar I (b2v, 12) em tempo da pestilencia. logo despois de comer. se alguũ teuer desejo de dormir: que tal desejo se deue reuogar I (b2v, 23) A ysto te respondo que o homem que em tal dia he apeçonhentado nom come mujto $\mathrm{I}(\mathrm{b} 4,25)$ E se despois creçer a postema: nom tema. porque tal apostema lança o mal de fora $\mid\left(b 4^{v}, 8\right)$ mas eu queria antes que quando alguũ teuesse tal apostema que soruesse em si toda a triaga $\mid\left(a 5^{v}, 4\right) \&$ daqui veem que em tal casa como esta morrem os homens mais azinha \& em outra nom como dito he I $\left(a 4^{v}, 9\right)$ E por tanto digo que a tal doente de pestilençia he boõ per alguũs dias mudar a camera $\mid\left(a 5^{v}, 4\right) \&$ daqui veem que em tal casa como esta morrem os homens mais azinha \& em outra nom $\mid(a 6,9)$ onde finalmente digo que toda multidom de pouoo \& comunidade em tal tempo se deue de euitar em quanto for possiuel $\mid\left(a 5^{v}, 8\right)$ \& por serem assi podres causam tal fedor \& doença que muyto empeçe I (a2v 23$)$ Sexto sinal he quando veem muytos ventos do meo dia. porque taes ventosidades sam muyto çujas \& muito velhacas $\mid(a 3,16) \&$ daly procedem febres pestilençiaes, açerca das quaes muytos medicos sam emganados. porque nom conheçe $m$ taes febres serem pestilençiaes $\mid\left(a 5^{v}, 3\right)$ em algũas casas estam as agoas çujas per dous \& tres dias \& as lançam per canos \& regos soterranhos: em os quaaes taes agoas çujas causam grandes fedores I (a4, 4) Segunda questam he esta. II Se taaes jnfirmidades pestilençiaes sam contagiosas .scilicet. se se apegam $\mid(a 4,22)$ A segunda questam digo que taaes infirmidades pestilençiaaes sam contagiosas \& apegam se muy asinha.l $\left(\mathrm{a}^{\mathrm{v}} \mathrm{v}, 7\right)$ mesmo onde se lançam verças \& caldos podres que sobejam em taaes casas $\mid\left(a 6^{v}, 9\right) \&$ sempre no punha nos narizes \& na boca. porque as cousas azedas \& os cheyros taaes opilam \& çarram os poros Essas pessoas: $(a 5,15)$ \& por ysso quanto for possiuel taaes deuem de euitar \& de sy esquiuar as causas de tal podridom $\rightarrow$ EM TAL MANEIRA. vide MANEIRA. TAL CoMo. Assim como. - tal como: $(b 3,5)$ Posto que tal como este nom pode andar em cauallo ou nem andar grande caminho por a grande pigriça do corpo \& muyto grande peso \& carrega corporal.besta I $\left(\mathrm{b} 2^{v}, 2-3\right)$ em toda maneyra tal como este euite o somno \& ysto em andando

TÃo. [de tanto.] adv. Em tal grau. - tam, s. XIV: $\left(\mathrm{a3}^{\mathrm{v}}, 14\right)$ mas ajnda tam sobejamente se agraua ha natureza que nom sinte sy ser ferida nem emferma. $\rightarrow$ TANTO. adv. Tão. $\bullet$ tanto, S. XIII: $\left(b^{v}, 16\right) \&$ por tanto todos os mantijmentos quanto som de mais leue digestam tanto som milhores $\rightarrow$ EM TANTO QUE. Em tal modo que. em tanto que: $\left(\mathrm{a}^{\mathrm{v}}{ }^{\mathrm{i}}, 12-13\right)$ porque ho aar jnspirado as vezes he peçonhento: \& assy corrupto feere ho coraçom. em tanto que ha natureza he per muytas manejras agrauada $\mid(a 3,7)$ \& as vezes proçede da rayz jnferior, em tanto que senssualmente pareçe aos homens mudança do aar. $\rightarrow$ POR TANTO. vide POR.

TANTO. vide TÃO.

TE. vide TU.

TEMER. [<lat. timere.] v. Recear. • tema: $(\mathrm{b} 2,12)$ em tempo da pestilencia que nenguem nom tema morte. sem teer infirmidade pestilencial. I (b4, 25) E se despois creçer a postema: nom tema. porque tal apostema lança o mal de fora \& faz o homem ser muyto saão

TEMPERADAMENTE. [de temperado, 'moderado'.] adv. Com moderação, moderadamente. - temperadamente; temperadamente, S. XV: (b2, 25) \& despois que a vea for ferida ou aberta aproueyta muyto tomar muyto prazer. beber muy boõ vinho ou bõa çerueja. empero sempre se tome temperadamente I (b4, 24) \& sempre antes do meo dia sera em continuo mouimento: ou caualgando: ou andando temperadamente 
TEMPO. [<lat. tempus, -oris.] sm. tempo; tempo; tempos. [] Época, periodo: $\left(\mathrm{a} 4^{\mathrm{v}}, 2\right)$ mais ajnda digo que em o tempo pestilençial nenhuũ nom deue de star em ajuntamento do pouoo I $\left(a 4^{v}\right.$, 21) pola qual cousa boõ he ao saão em tempo da pestilençia quando venta vento sul estar em casa per todo o dia $\mid(a 5,9)$ polla qual causa grande remedio he em tempo da pestilençia a sancta penitencia \& a confissam as quaaes preçedem \& sam muyto melhores que todas as mezinhas I (a6, 20) Mas em tempo de pestilencia milhor he estar em casa que andar fora. $\left(\mathrm{b}^{v}, 19\right) \mathrm{Em}$ tempo da pestilencia valem mais cousas azedas que todalas meezinhas $\mid(\mathrm{b} 2,10)$ polla qual cousa deue se homem de guardar em tempo da pestilencia que nenguem nom tema morte. sem teer infirmidade pestilencial $\mid$ ( $\left.b 2^{v}, 11\right)$ A ysto digo breuemente que em tempo da pestilencia. logo despois de comer. se alguũ teuer desejo de dormir: que tal desejo se deue reuogar I $(b 3,17)$ He ergo gramde remedio sy se alguem sentir apeçonhentado ou em tempo de pestilencia sentir estas cousas que escuse o somno I $(a 6,19)$ E ysto nom poder auer, emtam coma paão ou hũa sopa molhada em vinagre. \& ysto seja mayormente em tempo de neuoeiro \& chuuoso I $(\mathrm{a} 6,10)$ onde finalmente digo que toda multidom de pouoo \& comunidade em tal tempo se deue de euitar em quanto for possiuel. Duraçẫo: $(\mathbf{b 3}, 20)$ \& assi segundo estas cousas he assaz manifesto: que em o tempo do somno o sprito vital repousa:\& emtom a peçonha espalha se per os membros de toda parte. A vida: $(\mathrm{a} 6,5)$ E por tanto diz auiçena em o quarto do canone. que aquelles que sempre querem encher seus ventres que abreuiam seus dias \& tempos da sua fim \& minguam sua vida

TEOLOGIA. [<lat. theologia, ae.] sf. Estudo das coisas divinas. - theologia, s. XV: (a2, 7) E tralladado de latim em lingoage $m$ per ho reuerendo padre frey Luys de ras: mestre em sancta theologia da ordem de sam francisco

TER. [<lat. tenere.] $v$. teer; tem; teem; teuer; teuesse; tenha: $\left(\mathrm{a}^{\mathrm{v}}\right.$, 11) E por tanto digo que a tal doente de pestilençia he boõ per alguũs dias mudar a camera: \& muytas vezes teer as frestas pera ho norte ou pera o leuante abertas I $(\mathrm{b} 2,11)$ polla qual cousa deue se homem de guardar em tempo da pestilencia que nenguem nom tema morte. sem teer infirmidade pestilencial I (a4,15) \& os corpos peçonhentos que tem os poros opilados: \& çarrados de mujtos humores. I (b2v, 25) \& logo despois de comer tem desejo de dormir $\mid(b 3,1)$ \& ysso mesmo tem grande door em ha parte dianteira da cabeça $\mid$ (b4, 10) E todas estas cousas se façam se homem nom dormir antes que conheça que tem a postema.l (a4, 14) os corpos mays despostos a jnfirmidade \& a morte sam os corpos queentes \& que teem os poros mays largos $1(\mathrm{a} 4,20)$ \& os homens que se muyto esqueentam com grande trabalho ou grande yra. teem os corpos mais dispostos pera reçeber ha pestilencia I $\left(a 4^{v}, 14\right)$ porque o vento do sul teem em si duas causas de de apodrentar $\mid(b 2,20)$ se nom se a ydade ou outra cousa for em contrayro. assy como he em as molheres que som prenhes. ou em alguũ muyto fraco .scilicet. em alguũ que teem corrença ou fluxu do ventre I (b3,9) o homem ja apeçonhentado em todas as horas teem grande desejo de dormir I $(\mathrm{b} 2 \mathrm{v}, 10)$ Mas dira alguũ. se o homem deue de euitar ho somno que fara homem se teuer o somno natural | (b2v, 12) se alguũ teuer desejo de dormir: que tal desejo se deue reuogar I (b4v, 17) emtom toma aquelle çumo \& mistura ho com leyte de mulher \& da ho a beber aquelle que teuer a postema I $\left(b 4^{v}, 8\right)$ a triaga lança a peçonha fora, mas eu queria antes que quando alguũ teuesse tal apostema que soruesse em si toda a triaga I $\left(\mathrm{b}^{\mathrm{v}}{ }^{\mathrm{v}}, 7\right)$ Item o homem que se sangra ou tenha pestenença ou nom. em nenhũa maneyra nom deue de dormir per todo o dia atee mea noyte

TERCEIRO. [<lat. tertiarius, -a, -um.] num. O que ocupa o lugar três numa série. • terceyro, S. XIII; terçeyro: $\left(\mathrm{a} 4^{\mathrm{v},}, 26\right)$ Capitollo terceyro I $(\mathrm{a} 2,18)$ Terçeyro. dos remedios della I $\left(\mathrm{a} 4^{*}, 17\right)$ assi como se escreue em o terçeyro liuro dos amforismos $\rightarrow$ TÉRCIO. num. Terceiro. • tercio, S. XIV: (a2v, 9) Tercio he quando ha hy muytas moscas em ha terra

TERRA. $\left[<\right.$ lat. terra, -ae.] sf. Chão. - terra: $\left(a 2^{v}, 10\right)$ Tercio he quando ha hy muytas moscas em ha terra

TEU. [<lat. tuus, -a, um.] pron. possess. Que pertence à segunda pessoa do discurso. $\bullet$ teu, S. XV: (b, 13) Quanto he ao teu mantijmento digo te que a triaga te he muyto proueytosa 
TIRAR. [or. obsc.] v. Eliminar. - tira, S. XIII: (b2, 7) E se nom forem muyto pobres: tomem cuminhos \& açafram \& misturem tudo com vinagre. \& tal salsa he muyto boõa \& destruye \& quita ou tira toda podridom

TOCADO. [or. obsc.] adj. Atingido. - tocado, s. XV: $(\mathrm{b} 3,24)$ Estantes ergo assi estas cousas quando se homem sente ser tocado da peçonha pestilençial. logo naquelle meesmo dia mingue ho sangue

TODo. [<lat. totus, -a, -um.] pron. indef. todo; todos; toda; todas; todalas. $\mathbb{\square}$ Qualquer: $(\mathrm{a} 3 \mathrm{v}, 21)$ Ergo he neçessario que todo enfermo se proueja de boõ fisico \& bem esperto $\mid\left(\mathrm{b}^{\mathrm{v}}, 23\right)$ porque todo ho fructo traz podridom $\mid(a 5,22) \&$ per esta mesma causa euitaras \& esquiuaras todo ho fedor $\mid\left(a 5^{v}, 25\right)$ Item per esta meesma ca<u>sa se euite \& esquiue: todo ho inchamento do ventre que veem per muyto comer I (a5, 16-17) \& por ysso quanto for possiuel taaes deuem de euitar \& de sy esquiuar as causas de tal podridom. E per conseguinte todo o coytol $(a 5,17) \&$ toda luxuria $\mid$ onde finalmente digo que toda multidom de pouoo \& comunidade em tal tempo se deue de euitar em quanto for possiuel Inteiro: $\left(a 4^{v}, 22\right)$ pola qual cousa boõ he ao saão em tempo da pestilençia quando venta vento sul estar em casa per todo o dia | $\left(b 3^{v}, 8\right)$ Item o homem que se sangra ou tenha pestenença ou nom. em nenhũa maneyra nom deue de dormir per todo o dia atee mea noyte $\mid(b 2,7)$ \& tal salsa he muyto boõa \& destruye \& quita ou tira toda podridom I $(\mathrm{a} 6,8)$ porque pouco creçente apeçonhenta toda a massa. $\mid(\mathrm{b} 4 \mathrm{v}, 9)$ mas eu queria antes que quando alguũ teuesse tal apostema que soruesse em si toda a triaga $\mathbb{I}=$ Totalidade (de um conjunto): $\left(\mathrm{b}^{\mathrm{v}}, 15\right)$ \& por tanto todos os mantijmentos quanto som de mais leue digestam tanto som milhores I $\left(b^{v}, 21\right)$ Isso mesmo se euitem todos os fructos se nom forem azedos I $\left(a 6^{v}, 14\right)$ Eu çertamente todos estos remedios prouey I $\left(\mathrm{a}^{\mathrm{v}}, 18\right)$ AS cousas canfortatiuas sam estas scilicet. açafram. cassiafistola. chantagem. com todas as outras heruas que endereçam ho spirito interior I (b4, 8) E todas estas cousas se façam se homem nom dormir antes que conheça que tem a postema $\mid(b 3,2)$ mas todas estas cousas pode muyto bem euitar \& de sy lançar andando ou espaçando huũ pouco antre ho comer \& o dormir $\mid(\mathrm{b} 3,9)$ porque o homem ja apeçonhentado em todas as horas teem grande desejo de dormir I $(a 5,11)$ polla qual causa grande remedio he em tempo da pestilençia a sancta penitencia \& a confissam as quaaes preçedem \& sam muyto melhores que todas as mezinhas I (bv, 20) Em tempo da pestilencia valem mais cousas azedas que todalas meezinhas $T u d o:(b 2,4)$ porque se forem pobres contentem se com arruda \& salua. noz nozcadas. pere $<x>$ il \& todo misturado com vinagre faz muy bõa salsa | (b4v , 13) \& ysso mesmo toma chantagem \& siligem (vay te ao boticayro) \& pisa todo muyto $\rightarrow$ TODO-PODEROSO. vide PODEROSO. $\rightarrow$ EM TODA MANEIRA. vide MANEIRA. $\rightarrow$ TUDO. pron. indef.O conjunto, a totalidade. tudo: $\left(a 5^{*}, 21\right)$ \& com lenho de aloes que he melhor de tudo posto que se nom pode comprar por pequeno preço I $(\mathrm{b} 2,6)$ E se nom forem muyto pobres: tomem cuminhos \& açafram \& misture $m$ tudo com vinagre $\mid\left(b 4^{v}, 4\right)$ \& despois poõe tudo na apostema $\mid\left(b 4^{v}, 20\right)$ Item quando a postema primeyro apareçer. tome auelaãs. figos passados \& aruda \& tudo bem pisado: pom tho em çima da apostema

TOMAR. [or, obsc.] v. tomar; toma; tomaras; tomares; tomem; tome. Ingerir: (b2v, 20) \& estes maaos humores se lançam fora per tomar hũa bõa vez de vinho boõ ou bõa çerueja $\mid$ (b, 15) toma se ergo duas vezes no dia com boõ vinho claro \& auguado $\mid(b, 8)$ \& tambem tomaras pirolas pestilençiaaes $\mid(b$, 19) \& do vinho ou augoa ou çerueja tomaras quantidade de duas colhares I (b, 21) \& a triaga seja delida em ho vaso ou copo em que ha tomares $\mid(b, 18)$ nem se tome mais da triaga que a quantidade de huũ piseo I (b2, 25) beber muy boõ vinho ou bõa çerueja. empero sempre se tome temperadamente Empregar, utilizar: E se nom forem muyto pobres: tomem cuminhos \& açafram \& misturem tudo com vinagre $\left(\mathrm{b} 4^{\mathrm{r}}, 3\right)$ Toma folhas de sabugo pisadas \& com mostarda pisada \& faze emprasto $\mid(\mathrm{b}, 8)$ \& se o ventre naturalmente se nom poder vazar. toma huũ cristel $\mid\left(b 4^{v}, 10\right)$ Tomaras hũa herua que chamam barbajouis. \& outro que chamam serpillo que acharas ao boticairo I (b4v , 12-13) \& ysso mesmo toma chantagem \& siligem I (b4v, 16) emtom toma aquelle çumo \& mistura ho com leyte de mulher I Conquistar: $(\mathrm{a} 2 \mathrm{v}, 17)$ A morte se ensanha ha çidade se filha \& toma dos jmigos Experimentar: (b2, 23) \& despois que a vea for ferida ou aberta aproueyta muyto tomar muyto prazer $\mid\left(b 2^{v}, 15\right)$ em modo que o somno natural se possa tomar per hũa hora despois de comer 
TRABALHO. [de trabalhar.] sm. Afazeres. - trabalho: $(\mathrm{a} 4,20)$ \& os homens que se muyto esqueentam com grande trabalho ou grande yra. teem os corpos mais dispostos pera reçeber ha pestilencia

TRAladar. [or. obsc.] $v$. Traduzir. tralladado, s. xV: $(\mathrm{a} 2,5)$ E tralladado de latim em lingoagem per ho reuerendo padre frey Luys de ras

TRAzER. [or. obsc.] v. Causar. - tras; traz: (b, 26) a sobeja abastança \& grande inchamento tras apodrentamento dos humores $\mid\left(b^{v}, 6\right)$ mas porque muyto aqueenta. \& a queentura traz podridom. melhor me pareçe soo a cousa amargosa que queentura cheyro \& sabor I (bv, 24) todo ho fructo traz podridom $\mathrm{I}\left(\mathrm{b} 2^{\mathrm{v}}\right.$, 4) porque em ho somno ha queentura intrinseca. caladamente traz a peçonha ao coraçam \& aos outros membros speciaaes I (b2w,18) porque o homem estando em o somno traz em si muytos vapores $\rightarrow$ TRAZER NA MÃO. Ter consigo. - trouuer em ha maão: (a6v, 25-b,1) Os olhos do aar empeçonhentado logo escureçem se estas cousas nom trouuer homem em ha maão

TRÊs. [<lat. tres, tres, tria.] num. - tres, S. XIII: $(a 3,4)$ TRes sam as causas da pestilencia I (a5', 2) em algũas casas estam as agoas çujas per dous \& tres dias

TRIAGA. [<lat. theriaca, -ae.] sf. Medicamento à base de trociscos de víbora. $\bullet$ triaga, s. xv: (b,18) nem se tome mais da triaga que a quantidade de hữ piseo I $(b, 20)$ \& a triaga seja delida em ho vaso ou copo em que ha tomares $\mid(b, 22)$ \& nom jantaras atee ho meo dia porque possa a triaga em o corpo fazer sua operaçam | $\left(\mathrm{b} 4^{\mathrm{v}}, 6\right)$ posto que alguũs çirogiaães querem que lhe ponham triaga mas eu rogo mujto que se nom ponha $\mid\left(\mathrm{b} 4^{v}, 7\right)$ porque a triaga lança a peçonha fora I $\left(\mathrm{b} 4^{\mathrm{v}}, 9\right)$ mas eu queria antes que quando alguũ teuesse tal apostema que soruesse em si toda a triaga | (b, 13-14) Quanto he ao teu mantijmento digo te que a triaga te he muyto proueytosa

TRINDADE. [<lat. trinitas, -atis.] sf. O Pai, o Filho e o Espirito Santo. - trijndade, s. XIV: (a2, 9-10) EM louuor da santissima trijndade

TRovoada. [or. obsc.] sf. Sucessão de trovões. - trouoadas, S. XV: (a2, 20) Quinto sinal. he quando se fazem mujtas relampados \& trouoadas

TU. [<lat. tu.] pron. pessoal. Indica aquele que ouve. • tu, s. XIII: (b2v, 21) Mas diras tu. como sintira homem que está apeçonhentado \& ferido da pestilençia $\rightarrow$ TE. [<lat. te.] pron. pessoal. A ti. • te, S. XIII: (b, 13) Quanto he ao teu mantijmento digo te I (b, 14) que a triaga te he muyto proueytosa I (a5, 11) Empero prometo te que muyto boõ remedio he fugir \& mudar o lugar apeçonhentado I (a6\%, 22) E por ysso te digo que em toda maneyra te guardes que nom reçebas do baffo de outrem I (b2v, 23) A ysto te respondo que o home $m$ que em tal dia he apeçonhentado nom come mujto I (b4v, 13) \& ysso mesmo toma chantagem \& siligem (vay te ao boticayro) 


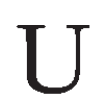

[No texto, a distinção entre $<u>$ e $<v>$ é posicional: em início de palavra há somente $<v>$; nas demais posições, apenas <u>.]

UBERIORGANO. O termo não consta de qualquer dicionário. Roque (1979: 325, n. 39) remete o leitor ao famoso médico português Pedro Hispano, posteriormente Papa João XXI (séc. XIII), que refere o médico grego Dioscórides (40-90 d.C.) como o criador de um emplastro de orégano. Uma das versōes francesas do Regimento consultadas por Roque parece confirmar a hipótese dos beneficios do orégano, ao apresentar a expressão uberi origani ('abundantes oréganos'). • vberiorgano: (a5v, 18-19) \& faça se fogo claro de lenha. \& faça se tambem com fumo de boõas heruas aqui scriptas scilicet. baga de louro. junipero. vberiorgano. as quaaes acharas aos apotecayros

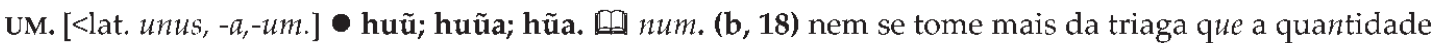
de huũ piseo I (b2, 16) SAngria huũa vez em huũ mes se pode bem fazer. I (a6, 16) de manhã̃ quando se alguũ aleuantar logo coma da aruda lauada em agoa limpa espargida com sal \& noz nozcada hũa ou duas bem limpas. I $(\mathbf{a} 5,20)$ Fechem se ergo as frestas ou genelas como dito he que vaam ou estam pera o sul atee hũa hora depois do meo dia $\mid\left(\mathbf{b} 2^{v}, \mathbf{1 5}\right)$ em modo que o somno natural se possa tomar per hũa hora despois de comer. neçessario \& muyto proueitoso aos viuentes. I (a2, 25) Primeiro quando em huũ dia do estio \& do alto veraão se muda a manhaã muytas vezes. $\mid\left(\mathbf{a} 4^{v}, 24\right) \&$ se for neçessario que saya este em casa atee que saya o sol \& suba huũ boõ espaço sobre o nosso orizonte. $\mid(\mathbf{b}, \mathbf{8 )} \&$ se o ventre naturalmente se nom poder vazar. toma huũ cristel. I ( $\mathbf{b}^{\mathbf{v}}, \mathbf{2 2 )}$ Isso mesmo se euite $m$ todos os fructos se nom forem azedos. assi como sam çirejas. romaãs. ou huñ pequeno de pero ou maçaã $\mid(\mathbf{b} 3, \mathbf{4})$ mas todas estas cousas pode muyto bem euitar \& de sy lançar andando ou espaçando huũ pouco antre ho comer \& o dormir I (b3, 13) Ergo per estes signaaes se sente homem apeçonhentado.mas se alguũ nom quiser creer: spere per huũ meo dia \& logo sentira apostema de bayxo dos braços. I $\left(2 \mathbf{6}^{\mathrm{v}}, \mathbf{6}\right)$ andaúa de casa em caşa curando enfermos por causa da minha pobreza. \& emtam leuaua commigo huũa sponja ou paão enssopado em vinagre: | (a6, 18) E ysto nom poder auer. emtam coma paão ou hũa sopa molhada em vinagre. | (b2v, 17) Empero diz auiçena que se homem quiser dormir ha de beber hũa bõa vez de vinho ou çerueja ante de dormir $\mid\left(\mathbf{b} 2^{v}, \mathbf{2 0}\right)$ \& estes maaos humores se lançam fora per tomar hũa bõa vez de vinho boõ ou

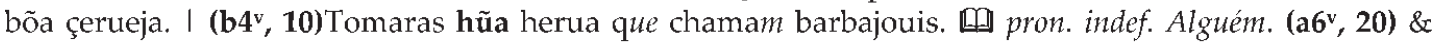
estas cousas prestam pera antre pouoo onde ligeyramente se aconteçe huũ seer empeçonhentado do outro. $\rightarrow$ UM .... E O OUTRO... • huũ... e o outro...: $\left(\mathrm{a}^{\mathrm{v}}{ }^{\mathrm{v}}, 25\right)$ Porque he assy que huñ morre \& ho outro nom. $\rightarrow$ CADA UM. vide CADA.

ÚMIDO. [<lat. humidus, -a, -um.] adj. Que tem umidade, uma das quatro qualidades (calor, frio, úmido e seco) que agiam sobre o equilíbrio humano.

URINA. [<lat. urina, -ae.] sf. Líqiiido excretado pelo aparelho urinário. Pela teoria dos humores [q.v. HUMOR], a urina era uma das bases do diagnóstico, não só pelo exame de sua densidade, coloração e odor, mas também pela observação das camadas que se formavam no frasco em que fora coletada: turvação na camada superior, por exemplo, indicava que a origem da doença era na cabeça; se na parte inferior, na bexiga ou nos órgãos genitais (Margotta, 1967: 66). Courinas, S. XIV: $\left(\mathbf{a}^{\mathrm{v}}{ }^{\mathrm{v}}, \mathbf{1 6}\right)$ tam sobejamente se agraua ha natureza que nom sinte sy ser ferida nem emferma. \& jsto porque apareçem bõas ourinas \& boõas augoas. \& bõas digestiões.l ( $\left(\mathbf{3}^{\mathrm{v}}\right.$, 19) E por tanto muytos medicos que em os enfermos soomente esguardam as ourinas superficialmente falam.\& lygeyramente sam emganados

USAR. [<lat. uso, -avi, -atum.] v. Lançar mão. @huse, s.XIV: $\left(a 6^{v}, 13\right)$ emtam huse homem dos remedios abayxo scriptas 


\section{$\mathrm{V}$}

[No texto, a distinção entre $<u>$ e $<v>$ é posicional: em início de palavra há somente $<v>$; nas demais posições, apenas <u>.]

valer. $\left[<\right.$ lat. valere.] v. Convir. - valem: $\left(\mathrm{b}^{v}, 19\right)$ Em tempo da pestilencia valem mais cousas azedas que todalas meezinhas

vapor. [<lat. vapor, -oris.] sm. -vapores. Gás que se desprende da terra úmida: Tercio he quando ha hy muytas moscas em ha terra. porque emtam pareçe ho aar ser empeçonhentado. \& que sobem muytos vapores peçonhentos ao aar. Exalaçôes que sobem do estômago e dos intestinos e ofendem o cérebro (Blueteau,VII; 361): (b2v , 19) Empero diz auiçena que se homem quiser dormir ha de beber hũa bõa vez de vinho ou çerueja ante de dormir. porque o homem estando em o somno traz em si muytos vapores

vaso. [<lat. vasum ou vasus, $-i$.] sm. Tipo de copo, maior e mais pesado que os atuais (Marques, 1964: 19). vaso: $(b, 20) \&$ a triaga seja delida em ho vaso ou copo em que ha tomares

vazar. [<lat. vacare.] v. Tornar vazio, esvaziar. vazar:(b,6) E tambem he grande remedio vazar o ventre I $(b, 8)$ \& se o ventre naturalmente se nom poder vazar. toma huũ cristel

veia. [<lat. vena, -ae.] sf. Vaso sangüíneo que transporta sangue venoso. Uma vez que, na época de circulação do Regimento, a nomenclatura anatômica não estava formalmente estabelecida e que não há indicação pictórica dos pontos referidos para a flebotomia, a localização das veias mencionadas no texto é imprecisa. Cabe notar que a mesma denominação poderia indicar veias diferentes em diferentes autores. De qualquer modo, as diferentes ilustrações para orientação quanto aos pontos de sangria conhecidas como homem flebotômico apresentavam os braços, as pernas e as extremidades como as áreas do corpo humano onde deveriam ser procuradas as veias a serem sangradas. vea; veas, s. xv: $(\mathrm{b} 2,22)$ \& despois que a vea for ferida ou aberta aproueyta muyto tomar muyto prazer $(b 2,26)$ \& nom conuem dormir em aquelle dia que se sangrar \& abrir a vea.I $\left(b 3^{v}, 11\right)$ sempre naquella meesma parte do corpo: em a qual ha doença ou chaga apareçer se deue de sangrar \& abrir a vea. I ( $\left.\mathrm{b}^{\mathrm{v}} \mathrm{v}, 16\right)$ ou na vea epatica scilicet. em a vea que he açerca do dedo mais pequeno. I (b3v, 25) ou da vea que esta antre o dedo demostrador \& ho dedo polegar. I (b3 $\left.3^{v}, 3\right)$ emtam leyxe yr a vea aberta ou ferida atee o retardamento do sangue. $I(b 4,2)$ ou da vea que he açerca do dedo menor: ou açerca do articulo que he de muytos medicos chamada basilica. I (b3v, 2) \& se homem nom quiser cortar muytas veas juntamente $\rightarrow$ veia basílica. A denominação dada a essa veia parece denotar sua importância na prática dos barbeiros: basílica vem do adj. latino basilicus, -a, -um, que significava 'importante, principal'. - basilica, s.xv: $(\mathrm{b} 4,4)$ ou da vea que he açerca do dedo menor: ou açerca do articulo que he de muytos medicos chamada basilica. I $\rightarrow$ veia de cefálica. - vea de çephalica; çephalica: (b3', 20) E se a apostema for em ho pescoço. seja sangrado em a vea de çephalica açerca do dedo polegar em a maão daquelle meesmo ladol $\left(\mathrm{b} 3^{\mathrm{v}}\right.$, 25) E se pela ventura apareçer açerca da orelha: faça se a sangria de çephalica daquelle meesmo lado $\rightarrow$ veia destra. $\bullet$ vea destra: $(\mathrm{b} 2,21)$ Faça se ergo a sangria em a vea destra. $\rightarrow$ veia hepática. - vea epatica: (b3v, 15-16) sangre se em ha vea meaã daquelle meesmo braço. ou na vea epatica. $\rightarrow$ veia meã. $\bullet$ vea meaã; meaã: $(b 3 v, 13)$ E se pella ventura naçer a apostema de bayxo do braço direyto. sangre se em ho meo daquelle braço da vea meaã. I (b3v, 15) Se de bayxo do braço seestro ou esquerdo. sangre se em ha vea meaã daquelle meesmo braço. I (b3v, 22) E se a apostema for em ho pescoço. seja sangrado em a vea de çephalica açerca do dedo polegar em a maão daquelle meesmo lado. ou na meaã daquelle meesmo braço. I (b4, 6) \& primeiramente minguaras a meaã. I (b4, 15) que se sangre em o braço esquerdo do figado: ou basilica: ou da meaã $\rightarrow$ veia pédica grande. $\bullet$ pedica grande: $(b 4,7)$ E se for em o espinhaço mingua sobre a vea que he chamada a pedica grande $\rightarrow$ veia sestra. $\bullet$ seestra: $(b 2,21-22)$ Faça se ergo a sangria em a vea destra ou seestra ante de comer

velhaco. [<esp. bellaco.] adj. Que engana com artimanhas. velhacas: $\left(\mathrm{a} 2^{\mathrm{v}}, 24\right)$ Sexto sinal he quando veem muytos ventos do meo dia. porque taes ventosidades sam muyto çujas \& muito velhacas 
vento. [<lat. ventus, -i.] sm. O ar em movimento. - vento; ventos: $\left(a 2^{v}, 3\right)$ \& prinçipalmente quando he ho vento meridional. ou da parte de estrela do Sul $I\left(a 2^{v}, 23\right)$ Sexto sinal he quando veem muytos ventos do meo dia. I $\left(a 4^{v}, 13\right) \&$ as genelas ou frestas pera ho meo dia ou pera ho sul estem çarradas, porque o vento do sul teem em si duas causas de de apodrentar $\mid\left(a 4^{v}, 18\right)$ Ho sul he vento inchado I $\left(a 4^{v}, 21\right)$ pola qual cousa boõ he ao saão em tempo da pestilençia quando venta vento sul estar em casa per todo o dia | $(\mathrm{a} 5,17)$ \& tambem o vento meridional ou sul: o qual naturalmente apeçonhenta. $\rightarrow$ ventar. $v$. Haver vento. - venta, s. xiv: $(\mathrm{a} 4 \mathrm{v}, 21)$ pola qual cousa boõ he ao saão em tempo da pestilençia quando venta vento sul estar em casa per todo o dia $\rightarrow$ ventosa. sf. Processo, com ou sem incisões na pele, que deveria eliminar o humor maligno pela expulsão de sangue, provocada pela aplicação à pele do paciente de vaso de metal, vidro ou chifre sob o qual se colocava um pedaço de linho ou estopa aceso. • ventosas: $(\mathrm{b} 4,6)$ E se polla ventura for açerca das espadoas: minguaras o sangue com ventosas. $\rightarrow$ ventoso. adj. Cheio de vento. - ventosa: $(\mathrm{a} 2$ v 3 3) Primeiro quando em huũ dia do estio \& do alto veraão se muda a manhaã muytas vezes. em modo que de manhaã pareçe chuuosa \& chea neuoa. \& depois ventosa $\rightarrow$ ventosidade. Vento. ventosidades: $(\mathrm{a} 2 \mathrm{v}, 23-24)$ Sexto sinal he quando veem muytos ventos do meo dia. porque taes ventosidades sam muyto çujas \& muito velhacas

ventre. [<lat. venter, -tris.] sm. Abdômen. ventre; ventres: $\left(\mathrm{a}^{\mathrm{v} v}, 25\right)$ Item per esta meesma ca<u>sa se euite \& esquiue: todo ho inchamento do ventre que veem per muyto comer I (a6, 4) E por tanto diz auiçena em o quarto do canone. que aquelles que sempre quere $m$ encher seus ventres que abreuiam seus dias I $(b, 8)$ E tambem he grande remedio vazar o ventre \& se o ventre naturalmente se nom poder vazar. toma huũ cristel. $\rightarrow$ encher o ventre. vide encher.

ventura. vide per.

ver. [<lat. videre.] v. •veemos; vejas; veer, s. xiv; vistas: 10 Perceber: (b4v, 14) \& ysso mesmo toma chantagem \& siligem (vay te ao boticayro) \& pisa todo muyto bem atee que vejas que quer pareçer que say destas cousas assy pisadas augoa ou çumo. Examinar; observar: (a5, 1) VIstas as causas da pestilencia. agora ajamos de veer per que modo \& como se deue homem de guardar da pestilencial $(a 3,10)$ Da rayz jnferior proçede segundo nos veemos que da priuada que esta açerca da camera ou de alguũ fedor particular de alguũ canno çujo se corrompe ho aar em substançia \& qualidade

verão. [<lat. veranum (tempus).] sm. Período do ano compreendido entre o final da primavera e o estio. • veraão: $(a 2,25)$ Primeiro quando em hũ dia do estio \& do alto veraão se muda a manhaã muytas vezes. I (a6, 23) E tambem a casa seja aguada: \& em special em o alto veraão com vinagre rosado \& folhas de vinhas. I $\left(a 6^{v}, 2\right)$ \& tambem he boõ assi em ho inuerno como no veraão cheirar cousas azedas

verças. [or. obsc.] sf.pl. Comida. Bluteau (VIII, 418) traduz o termo como "Herva", mas, dada a dieta da época, não parece provável que ervas ou hortaliças "sobejassem" nas casas. No interior de Portugal o termo ainda é empregado, sob a variante "berças", significando 'comida'. •verças: $\left(a 5^{y}, 6\right)$ \& daqui veem que em tal casa como esta morrem os homens mais azinha \& em outra nom como dito he mesmo onde se lançam verças \& caldos podres que sobejam em taaes casas. \& por serem assi podres causam tal fedor \& doença que muyto empeçe

vergonçoso. vide parte.

verso. [<lat. versus, -us.] sm. Unidade métrica da poesia. Costa Roque (1979:318n.13) encontrou o citado verso apenas na edição latina do Regimento impressa em Colonia por Iohann Guldenschaff, ca. 1490: "Mors furit, urbs rapitur, seuit mare, sol aperitur./ Regnum mutatur, plebs peste fame[que] cruciatur" ['Desencadeia-se a morte, a cidade é tomada,o mar torna-se violento, o sol se abre / O reino se modifica, o povo é torturado pela peste (e) pela fome $e^{\prime}$ conjunção pospositiva que acrescentada - trad. de H. Cairus]. Chama a atenção, porém, que o texto português diga que o sol se cobre de nuvens, levando a crer que traduzisse uma outra versão desse verso - verso, s. xiv: $\left(\mathrm{a} 2^{v}, 15\right)$ \& por isso diz ho verso poetico falando do 
apareçimento da cometa. A morte se ensanha ha çidade se filha \& toma dos jmigos. ho mar se faz cruel. $\&$ ho sol se cobre .scilicet. de nuueens. ho regno se muda. ho pouoo padeçe fame \& pestilencia

vez. [<lat. vix, -cis.] sf. vez; vezes. [D Ocasião: (a2v, 1) Primeiro quando em huu dia do estio \& do alto veraão se muda a manhaã muytas vezes. I $\left(a 2^{*}, 5\right)$ Segundo sinal he quando em tal estio muytas vezes escureçem: ou pareçem escureçer os dias $1(\mathrm{a} 3,20)$ \& esto aconteçe muytas vezes onde ha lugares podres \& corruptos. I $\left(\mathrm{a} 4^{\mathrm{v}}, 11\right)$ E por tanto digo que a tal doente de pestilençia he boõ per alguũs dias mudar a camera: \& muytas vezes teer as frestas pera ho norte ou pera o leuante abertas. I (b, 15) toma se ergo duas vezes no dia com boõ vinho claro \& auguado I $(\mathrm{b} 2,16)$ SAngria huũa vez em huũ mes se pode bem fazer. se nom se a ydade ou outra cousa for em contrayro. Dose. - vez: (b2v, 17) Empero diz auiçena que se homem quiser dormir ha de beber hũa bõa vez de vinho ou çerueja ante de dormir I $\left(\mathrm{b} 2^{v}, 20\right)$ porque o homem estando em o somno traz em si muytos vapores. \& estes maaos humores se lançam fora per tomar hũa bõa vez de vinho boõ ou bõa çerueja. $\rightarrow$ às vezes. Em certas ocasiões. $\bullet$ as vezes: $(a 3,5)$ TRes sam as causas da pestilencia, porque as vezes veem \& proçede ha pestilencia da rayz superior $\mid(a 3,6)$ \& as vezes proçede da rayz jnferior $\mid(a 3,8)$ \& as vezes veem dambos de dous .scilicet. da rayz superior \& da rayz jnferior juntamente. $1(\mathrm{a} 3,17)$ As vezes jsso mesmo veem de corpos mortos. I $(\mathrm{a} 3,21)$ \& tambem esta causa he as vezes particular $\mid\left(\mathrm{a}^{\mathrm{v}}, 10\right) \& \mathrm{tal}$ morbo ou jnfirmidade as vezes he febre. \& as vezes apostema \& jsto em os demais.l $\left(a 3^{v}, 11\right)$ porque ho aar jnspirado as vezes he peçonhento

vida. [<lat. vita, -ae.] sf. Período de existência. • vida, s. xiii: (a6, 5-6) E por tanto diz auiçena em o quarto do canone. que aquelles que sempre querem encher seus ventres que abreuiam seus dias \& tempos da sua fim \& minguam sua vida. $\rightarrow$ vital. vide espírito.

vila. [<lat. villa. -ae.] sf. Na Idade Média, organização populacional menor que a cidade, com produção agrícola e uma ou duas feiras por ano, que dinamizavam a produção e o comércio [cf. cidade]. • villa, s. xiii: $(\mathrm{a} 4,1)$ Porque he assy que huũ morre \& ho outro nom. \& daquella villa morrem homens \& daqueloutra nom. I $(a 6,21)$ Mas em tempo de pestilencia milhor he estar em casa que andar fora. nem he saão andar per a villa ou çidade

vinho. [<lat. vinum,-i.] sm. Bebida alcoólica feita do sumo fermentado de uvas. • vinho: $(b, 16)$ toma se ergo duas vezes no dia com boõ vinho claro \& auguado I $(b, 18)$ nem se tome mais da triaga que a quantidade de huũ piseo. \& do vinho ou augoa ou çerueja tomaras quantidade de duas colhares. I (b, 24) E ysso meesmo deues de comer boõ manjar \& bõa yguaria com boõ vinho puro \& a meude. I (b2, 24) \& despois que a vea for ferida ou aberta aproueyta muyto tomar muyto prazer. beber muy boõ vinho ou bõa çerueja. empero sempre se tome temperadamente. I(b2v, 17) Empero diz auiçena que se homem quiser dormir ha de beber hũa bõa vez de vinho ou çerueja ante de dormir. I(b2v, 20) \& estes maaos humores se lançam fora per tomar hũa bõa vez de vinho boõ ou bõa çerueja. $\rightarrow$ vinha. sf. Videira. - vinhas: $(\mathrm{a} 6,24) \mathrm{E}$ tambem a casa seja aguada: \& em special em o alto veraão com vinagre rosado \& folhas de vinhas. $\rightarrow$ vinagre. sm. Vinho azedo. Para Bluteau (VIII, 495), " he antidoto da peste, tão soberano, que seus effeitos saõ muito mais certos, que os da Triaga". Por ser ácido, o vinagre era considerado frio e seco (Flandrin, 1996: 491) e podia, assim, corrigir o calor de outros condimentos, em particular, das especiarias [q.v. espécia]. - vinagre: $(\mathrm{a} 6,18) \mathrm{E}$ ysto nom poder auer. emtam coma paão ou hũa sopa molhada em vinagre $\mid(a 6,23)$ E tambem a casa seja aguada: \& em special em o alto veraão com vinagre rosado \& folhas de vinhas $\mid(a 6,25)$ \& ysso meesmo he muyto boõ ameude lauar as maãos com augoa \& vinagre I (b, 3) Muyto saã cousa he que se laue a boca \& os olhos \& as maãos ameude cada dia com agoa rosada mesturada com vinagre. $\mid(b, 4) \&$ se estas cousas nom poder auer faça se com vinagre $\mid$ $(b 2,4)$ estas cousas busquem se pera os ricos muyto bõas salsas ou salseamentos. porque se forem pobres contente $m$ se com arruda \& salua. noz nozcadas, pere $<x>$ il \& todo misturado com vinagre faz muy bõa salsa $\mathrm{E}$ se nom forem muyto pobres: tomem cuminhos \& açafram \& misturem tudo com vinagre. I $\left(a 6^{v}, 7\right)$ \& emta $m$ leuaua commigo huũa sponja ou paão enssopado em vinagre: \& sempre no punha nos narizes \& na boca 
vir. [<lat. venire.] $v$. • vijr; veem. Chegar: $\left(\mathrm{a} 2^{\mathrm{v}}, 8\right)$ \& emtam se isto mujto durar he pera temer de vijr grande pestilençia. $₫$ Ter origem, proceder: $\left(a 2^{v}, 21\right)$ Quinto sinal. he quando se fazem mujtas relampados \& trouoadas. \& mayormente se veem da parte do meo dia I (a2v, 23) Sexto sinal he quando veem muytos ventos do meo dia $\mid(a 3,5)$ TRes sam as causas da pestilencia. porqueas vezes veem \& proçede ha pestilencia da rayz superior $\mid(a 3,8) \&$ as vezes veem dambos de dous .scilicet. da rayz superior \& da rayz jnferior juntamente. I (a3,17) As vezes jsso mesmo veem de corpos mortos. ou de corrupçom de pauees \& charcos ou chafarizes çujos podres \& federentos. I (a3, 22)Da rayz superior vee $m \&$ aconteçe a pestilençia per virtude dos corpos de çima dos çeos. Resultar: $\left(\mathrm{a} 5^{v}, 4\right)$ \& daqui vee $m$ que em tal casa como esta morrem os homens mais azinha \& em outra nom I (a5v, 25) Item per esta meesma $\mathrm{ca}<\mathrm{u}>\mathrm{sa}$ se euite \& esquiue: todo ho inchamento do ventre que veem per muyto comer 1 $\left(b^{v}, 13\right)$ a pestilençia que veem per causa queente ameude se acreçenta

virgem maria. A mãe de jesus. $\bullet$ virgem maria: (a2, 10) EM louuor da santissima trijndade. \& da gloriosa virge $m$ maria co $m$ virtude \& meezinha de nosso senhor jesu christo. sem o qual nom ha hy saude I (b4", 25) \& da benta virgem maria sua madre seja gloria \& louuor pera sempre

virtude. [<lat. virtus, -utis.] sf. Valor. • virtude: $\left(\mathrm{b} 4^{v}, 23\right)$ \& qualquer que se per este modo reger escapara muytos perijgos da pestilencia com virtude \& meezinha de nosso senhor jesu christo $\rightarrow$ per virtude de. vide per.

vis $<$ c $>$ oso. vide humor.

visitar. [<lat. visitare.] v. Ir à moradia ou ao lugar em que alguém está. • visitam: $\left(\mathrm{a}^{4}{ }^{\mathrm{v}}, 6\right)$ por razam do qual os medicos prudentes quando visitam os enfermos deuem de star afastados delles: teendo o rostro pera genela ou fresta

viver. [<lat. vizere.] v. Ficar vivo. • viuer, s. xiii: $\left(a 6^{v}, 13\right)$ \& assi escapey de tal pestilencia. que os meos companheiros nom podiam creer que eu podesse viuer \& escapar | $(b 2,14)$ porque ymaginaçam faz causa \& perijgo. mas qualquer com muyto prazer \& alegria sempre espere de muyto viuer $\rightarrow$ vivente. adj; sm. (Aquele) que está vivo. • viuentes, s. xiv: $(\mathrm{a} 3,25)$ Da rayz superior veem \& aconteçe a pestilençia per virtude dos corpos de çima dos çeos. dos quaaes se corrompem os spiritos vitaes em ha creatura viuente $\mid(\mathrm{a} 2,2)$ Começa se huũ boõ regimento muyto neçessario \& muyto proueitoso aos viuentes

voar. [<lat. volare.] v. Mover-se pelo ar. • voar: $(\mathrm{a} 2 \mathrm{v}, 12)$ Quarto sinal he quando ha cometa pareçe voar 